VALTER CLEBER GUEDES DA ROCHA LIMA

\title{
Análise Experimental e Numérica de Trincheiras de Infiltração em Meio Não Saturado
}

Dissertação apresentada ao Programa de PósGraduação em Hidráulica e Saneamento da Escola de Engenharia de São Carlos, Universidade de São Paulo, para obtenção do título de Mestre em Engenharia Hidráulica e Saneamento.

Área de Concentração: Drenagem Urbana

Orientador: Prof. Dr. Eduardo Mario Mendiondo

São Carlos 
AUTORIZO A REPRODUÇÃO E DIVULGAÇÃO TOTAL OU PARCIAL DESTE TRABALHO, POR QUALQUER MEIO CONVENCIONAL OU ELETRÔNICO, PARA FINS DE ESTUDO E PESQUISA, DESDE QUE CITADA A FONTE.

Ficha catalográfica preparada pela Seção de Tratamento da Informação do Serviço de Biblioteca - EESC/USP

L732a

Lima, Valter Cleber Guedes da Rocha Análise experimental e numérica de trincheiras de infiltração em meio não saturado / Valter Cleber Guedes da Rocha Lima ; orientador Eduardo Mario Mendiondo. -São Carlos, 2009.

Dissertação (Mestrado-Programa de Pós-Graduação e Área de Concentração em Hidráulica e Saneamento) -- Escola de Engenharia de São Carlos da Universidade de São Paulo, 2009 .

1. Drenagem urbana. 2. Trincheira de infiltração. 3. Meio não saturado. I. Título. 
FOLHA DE JULGAMENTO

Candidato: Engenheiro VALTER CLEBER GUEDES DA ROCHA LIMA

Dissertação defendida e julgada em 05/05/2009 perante a Comissão Julgadora:

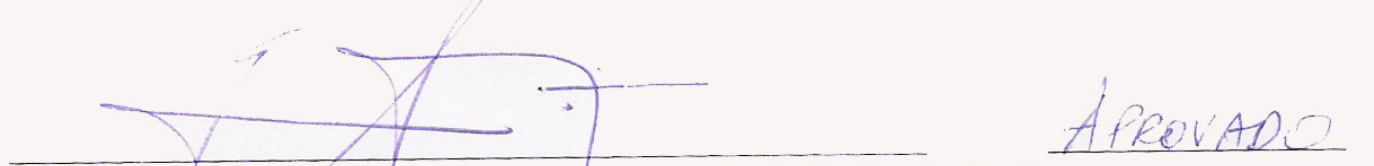

Prof. Dr. EDUARDO MARIO MENDIONDO (Orientador)

(Escola de Engenharia de São Carlos/USP)

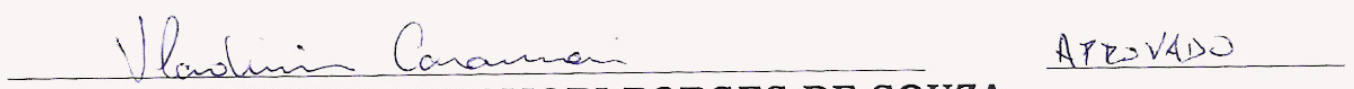

Prof. Dr. VLADIMIR CARAMORI BORGES DE SOUZA

(Universidade Federal de Alagoas/UFAL)

Dr. CARLOS MANOEL PEDRO VAZ

(Empresa Brasileira de Pesquisa Agropecuária/EMBRAPA)

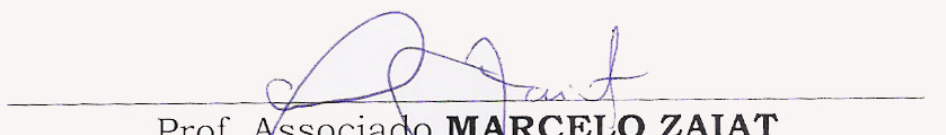

Prof. Associado MARCELO ZAIAT

Coordenador do Programa de Pós-Graduação em

Engenharia(Hidráulica e Saneamento).

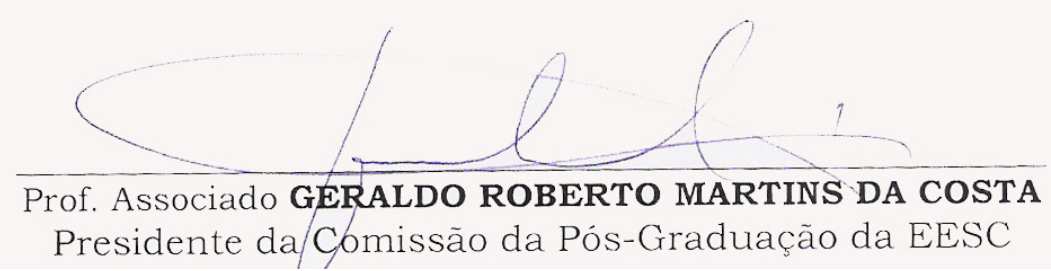


Dedico a minha Mãe, Gláucia Malta, pois tudo que sou devo a ela, e a minha tia, Gilda Guedes, pois sem ela esta etapa não seria possível. 


\section{AGRADECIMENTOS}

Uma dissertação de mestrado não corresponde simplesmente uma pesquisa científica, encontra-se uma história de mais de dois anos, história da qual participaram muitas pessoas e que cabem aqui alguns agradecimentos por todo o incentivo e ajuda dada no decorrer deste trabalho.

Agradeço primeiramente a Deus, fonte de toda sabedoria;

À Capes - Coordenação de Aperfeiçoamento de Pessoal de Nível Superior, pela concessão de bolsa;

À Embrapa - Empresa Brasileira de Pesquisa Agropecuária, onde pude realizar as imagens de tomografia computadorizada;

Ao professor Eduardo Mendiondo pela orientação e pela confiança depositada neste trabalho;

Aos professores, Edson Wendland e Rodrigo Porto, pela elucidação de dúvidas em diferentes ocasiões, pela leitura apurada do texto, bem como pelos questionamentos e pelas sugestões dadas;

À professora Luisa Fernanda, pelo carinho, incentivo e amizade;

Ao professor Orencio Vilar, chefe do Departamento de Geotecnia, por ter liberado as instalações do seu laboratório para realização dos ensaios de solo;

Ao Dr. Carlos Vaz, pelas sugestões dadas durante a primeira etapa de qualificação do projeto de mestrado e por ter viabilizado, junto a Embrapa, a realização das imagens de tomografia computadorizada;

Aos professores da Universidade Federal de Alagoas, principalmente Cleuda Freire e Vladimir Souza, pela iniciação à pesquisa científica.

Aos funcionários do Departamento de Hidráulica e Saneamento, em especial Rose, Sá e Flávia, por solucionarem todos os problemas surgidos no decorrer do mestrado.

Aos técnicos do Laboratório de Solos do Departamento de Geotecnia, Oscar Santos e José Luiz, pelo auxílio na realização dos ensaios de solo;

Ao técnico do Departamento de Hidráulica e Saneamento, Luiz Muzzeti, pelas informações concedidas durante a construção do vertedor; 
Ao Eduardo Lucena e Antônio Pedro, por me acolherem durante a seleção do mestrado;

A todos os colegas do NIBH - Núcleo Integrado de Bacias Hidrográficas, Anaí Vasconcelos, Diogo Almeida, Flávia Bottino, Tatiane Furlaneto, Fernando Simão, Micheli Gonçalves, Ignázio Giontelli, Melissa Graciosa, Ricardo Galavoti, Pedro Cabaleiro e Richard Pehovaz;

Aos colegas do mestrado, Alice Araújo, Camila Tolledo, Jaqueline Almeida, Juliana Lourenção, Julio Mesquita, Luiz Henrique, Thiago Galvão, Tiago Magalhães e Vitor Tosetto, que proporcionaram momentos de alegria e descontração;

Às amigas do mestrado, Micheli Gonçalves, Milena Gardai e Nayara Borges, por transformar este período de grande dificuldade em momentos divertidos e por estarem sempre presentes nos momentos de angústia;

Aos amigos de Maceió, que, embora distantes, sempre estiveram presentes;

À minha família, porque sem eles este trabalho não seria possível;

Por fim, a todos que direta ou indiretamente ajudaram na realização deste trabalho. 
"O homem não pode alterar as condições geológicas do terreno para tornar mais permeável; pode, porém,... restabelecer condições naturais acessórias para que as águas das chuvas se detenham na sua descida rápida pelas encostas e pelos talvegues torrenciais, e nas dilatações pelas várzeas alagadiças, de modo a retardar afluência do volume total que tenha de se escoar pelo curso principal”.

Eng. Sanitarista Saturnino de Brito 


\section{RESUMO}

LIMA, V. C. G. DA R. (2009). Análise experimental e numérica de trincheiras de infiltração em meio não saturado. Dissertação de Mestrado. Escola de Engenharia de São Carlos, Universidade de São Paulo, 170 p.

Este trabalho tem como objetivos avaliar, para eventos de chuvas simuladas, o comportamento hidráulico de uma trincheira de infiltração experimental instalada na EESC/USP e propor uma nova metodologia de dimensionamento para trincheiras de infiltração.

Para realizar a avaliação, foram conduzidos ensaios experimentais para determinar o volume infiltrado, sendo este calculado pela diferença entre o volume de entrada, medido através de vertedor triangular, e o volume armazenado na trincheira, medido a partir de medidor de nível. Em relação à nova metodologia de dimensionamento, esta foi proposta com base no modelo de Green-Ampt adaptado ao processo de infiltração horizontal. Os parâmetros de entrada do modelo: umidade, potencial matricial e condutividade hidráulica saturada, foram determinados, respectivamente, através de sondas que utilizam a Reflectometria no Domínio do Tempo (TDR), por curvas de retenção determinadas em laboratório pela técnica do papel filtro e câmara de Richards e por ensaio laboratorial com permeâmetro de carga constante.

As curvas de retenção além de serem determinadas por dois métodos laboratoriais também foram avaliadas em função da distribuição uni e bimodal do tamanho médio dos poros. Para isto, utilizou-se a tomografia computadorizada para analisar o comportamento dos poros no solo estudado.

O solo onde foi instalada a trincheira constitui-se de areia média a fina argilosa e apresenta a condutividade hidráulica saturada em torno de $9,06 \cdot 10^{-6} \mathrm{~m} \cdot \mathrm{s}^{-1}$. A câmara de Richards foi o método de determinação da curva de retenção que melhor caracterizou o solo quanto à sua porosidade. Os resultados demonstraram que a trincheira de infiltração é eficiente, controlando $100 \%$ do volume escoado, mesmo para chuvas com intensidades superiores aos projetos de microdrenagem. Verificou-se também que o modelo de GreenAmpt se ajusta bem ao processo de infiltração horizontal e que a metodologia de dimensionamento proposta contribui de forma eficiente e economicamente eficaz para o dimensionamento de dispositivos de infiltração.

Palavras-chave: drenagem urbana, trincheira de infiltração, meio não saturado. 


\begin{abstract}
LIMA, V. C. G. DA R. (2009). Experimental and numeric analysis of infiltration trenches in unsaturated zone. M.Sc. Dissertation. Engineering School of São Carlos, University of São Paulo, 170 p.
\end{abstract}

This work assessed the hydraulic behavior of a experimental infiltration trench built at the EESC/USP and proposed a new sizing methodology for infiltration trench, for simulated events.

In order to evaluate the hydraulic behavior experimental tests were taken to determine the infiltrated volume. The infiltrated volume was calculated through the difference between the entry volume, obtained by triangular weir, and the volume stored in the trench, determined by level meter. The sizing methodology proposed was based on Green-Ampt model adapted to horizontal infiltration process. The model parameters: water content, pressure head and saturated hydraulic conductivity were determined by Time Domain Reflectometer, retention curve and constant head permeameter, respectively.

Retention curves were determined applying two laboratorial methods: Richard's camara and filter-paper method, and were evaluate by the unimodal and bimodal distributions of the medium size of the pores. Tomography computerized was used to analyze the behavior of the soil pores.

Infiltration trench was installed in a sand soil which presents the saturated hydraulic conductivity around $9,06.10^{-6} \mathrm{~m} \cdot \mathrm{s}^{-1}$. The Richards's camera was the method that better represented the soil porosity. The results proved the efficiency of the infiltration trench, which controlled $100 \%$ of the runoff, even for events with intensities greater than drainage systems design storms. It was also verified that Green-Ampt model has good adjustments to horizontal infiltration process and the sizing methodology proposed is efficient for sizing of infiltration dispositive.

Key-words: urban drainage, infiltration trench, unsaturated zone. 


\section{LISTA DE FIGURAS}

Figura 1.1- Quadro síntese das atividades a serem realizadas.

Figura 2.1- Representação de inundações em áreas ribeirinhas: a) o rio ocupando o seu leito menor; e b) o rio ocupando o seu leito maior.

Figura 2.2 -Balanço hídico: a) antes da introdução de áreas impermeáveis; e b) depois da introdução de áreas impermeáveis.

Figura 2.3 - Trincheiras de infiltração implantadas em canteiros centrais, ao redor de áreas verdes e em jardins

Figura 3.1 - Curva de retenção determinada para um solo caracterizado como siltoso. 58

Figura 3.2 - Elemento de volume definido para determinar a taxa de variação da umidade com o tempo através da equação da continuidade.

Figura 3.3 - Taxa de infiltração e infiltração acumulada ao longo do tempo para um mesmo solo.

Figura 3.4 - Coluna Horizontal infinita de seção transversal constante preenchida com solo homogêneo..

Figura 4.1- Local de implantação da trincheira de infiltração 82

Figura 4.2 - Retirada dos blocos indeformados. 84

Figura 4.3 - Bloco indeformado envolto por parafina para conter a perda de umidade. 84

Figura 4.4 - Etapas da construção do permeâmetro: (a) Retirado do prisma do bloco; (b) Construção do cilindro; (c) Colocação de um camada de pedregulho para reduzir o impacto da água no cilindo; (d) Colocação da bentonita para impermeabilizacao das paredes da amostra; (e) Finalização do permeâmetro com colocação da parafina.

Figura 4.5 - Equipamento de aplicação e medição da carga hidráulica no permêmatro de carga constante. 88

Figura 4.6 - Etapas de moldagem dos corpos-de-prova. 89

Figura 4.7 - Processo de saturação das amostras do solo. 90

Figura 4.8 - Funil de placa porosa.

Figura 4.9 - Layout da área de contribuição para trincheira de infiltração. 95

Figura 4.10 - Instrumentos utilizados para determinar a porosidade do material de preenchimento da trincheira. 97

Figura 4.11 - Volumes acumulados de entrada e saída no dispositivo de infiltração. 97

Figura 4.12 - Escavação manual da trincheira. 
Figura 4.13 - Escavação da trincheira com retro-escavadeira. 99

Figura 4.14 - Aplicação da manta geotêxtil: a) no fundo; b) nas paredes da trincheira. 100

Figura 4.15 - Corte longitudinal da trincheira de infiltração.

Figura 4.16 - Lavagem do material de preenchimento da trincheira antes de sua utilização.101

Figura 4.17 - Preenchimento manual da trincheira de infiltração..................................... 101

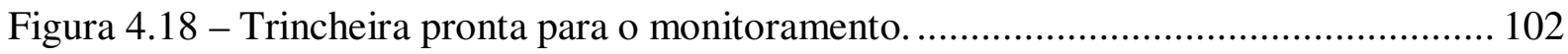

Figura 4.19 - Construção de paredes de alvenaria circundantes ao vertedor....................... 103

Figura 4.20 - Vertedor pronto para medição da vazão de entrada na trincheira................... 103

Figura 4.21 - Manômetro para medição da altura de água no vertedor triangular................. 104

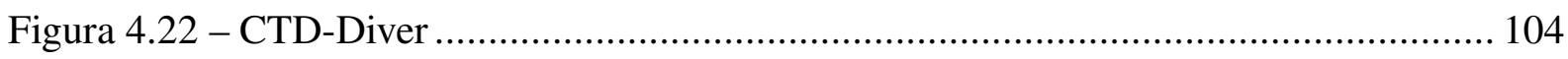

Figura 4.23 - Esquema de instalação das sondas no interior da trincheira de infiltração...... 105

Figura 4.24 - Instalação das sondas: (a) localização de cada sonda; (b) término da instalação;

(c) colocação da caixa gradeada para proteção das sondas............................................... 106

Figura 4.25 - Ilustração do ensaio experimental. ............................................................. 109

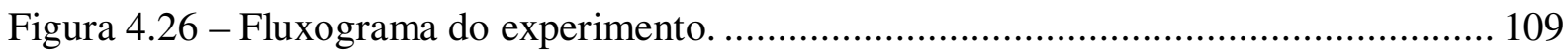

Figura 4.27 - Infiltração horizontal pelo modelo de Green-Ampt...................................... 111

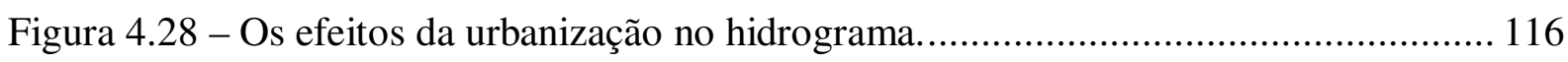

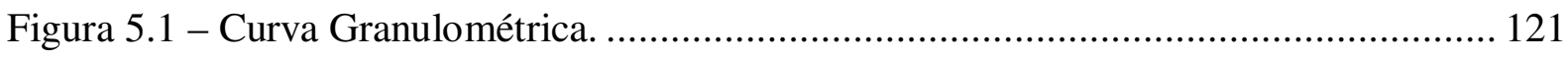

Figura 5.2 - Curvas de retenção determinada pela abordagem unimodal. .......................... 124

Figura 5.3 - Curvas de distribuição unimodal dos poros do solo. ....................................... 125

Figura 5.4 - Curvas de retenção determinada pela abordagem bimodal. ............................ 127

Figura 5.5 - Curvas de distribuição bimodal dos poros do solo........................................ 128

Figura 5.6 - Distribuição uni e bimodal obtida a partir da curva de retenção determinada através da técnica do papel filtro e da câmara de placa porosa.......................................... 129

Figura 5.7 - Corte transversal de uma amostra do solo em estudo. ................................. 130

Figura 5.8 - Curva de calibração do vertedor triangular. .............................................. 131

Figura 5.9 - Vazão de entrada e altura na trincheira durante a adução e recessão do

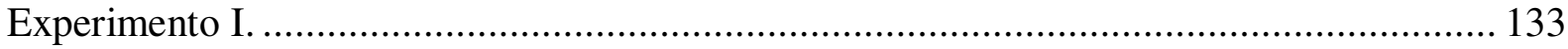

Figura 5.10 - Variação do volume durante a fase de adução e recessão do Experimento I. . 134 Figura 5.11 - Umidades do solo durante a adução e recessão do Experimento I. ................ 135

Figura 5.12 - Infiltração acumulada calculada e observada para o Experimento I............... 136

Figura 5.13 - Vazão de entrada e altura na trincheira durante a adução e recessão do

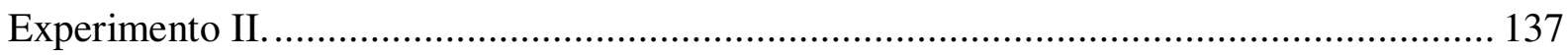

Figura 5.14 - Variação do volume durante a fase de adução e recessão do Experimento II. 138 
Figura 5.15 - Umidade do solo durante a adução e recessão do Experimento II.................. 139

Figura 5.16 - Infiltração acumulada e observada para o Experimento II. ........................... 140

Figura 5.17 - Vazão de entrada e altura na trincheira durante a adução e recessão do

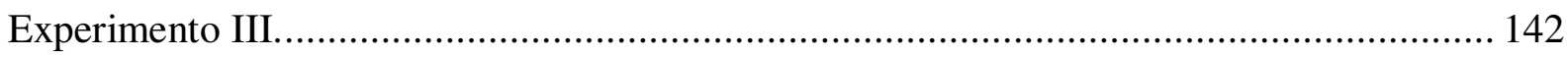

Figura 5.18 - Variaçaõ do volume durante a fase de adução e recessão do Experimento III.142

Figura 5.19 - Umidade do solo durante a adução e recessão do Experimento III. ............... 144

Figura 5.20 - Infiltração acumulada e observada para o Experimento III........................... 145

Figura 5.21 -Exempo ilustrativo da trincheira de infiltração adotada para dimensionamento. 148

Figura 5.22 - Planta baixa da trincheira adotada para dimensionamento.......................... 148 


\section{LISTA DE TABELAS}

Tabela 2.1- Vantagens e desvantagens apresentadas mediante a utilização de trincheiras de infiltração 36

Tabela 2.2 - Ordem de grandeza da condutividade hidráulica em diferentes solos. 38

Tabela 2.3 - Hipóteses para a consideração da área efetiva na concepção em diferentes países.

Tabela 3.1- Métodos de medida de sucção.

Tabela 3.2- Modelos matemáticos que expressam o processo de retenção de água no solo... 56

Tabela 3.3 - Propriedades hidráulicas do solos utilizados para o estudo de infiltração. 74

Tabela 3.4 - Parâmetros texturais e hidráulicos de diferente tipos de solos. 75

Tabela 3.5 - Modelos usados na determinação da infiltração horizontal. 76

Tabela 5.1 - Composição granulométrica e índices físicos.

Tabela 5.2 - Ensaio de condutividade hidráulica saturada. 122

Tabela 5.3 - Pontos experimentais das curvas de retenção

Tabela 5.4 - Parâmetros de ajuste para abordagem bimodal.

Tabela 5.5 - Calibração do vertedor triangular.

Tabela 5.6 - Umidade, potencial matricial e sortividade para abordagem unimodal e bimodal.

Tabela 5.7 - Umidade, potencial matricial e sortividade para abordagem unimodal e bimodal

Tabela 5.8 - Umidade, potencial matricial e sortividade para abordagem unimodal e bimodal.

Tabela 5.9 - Dados experimentais para avaliação da metodologia de dimensionamento..... 146

Tabela 5.10 - Orçamento para construção da trincheira.

Tabela 5.11 - Custos por metro cúbico mitigado $\left(\mathrm{R} \$ . \mathrm{m}^{-3}\right)$ para valores distintos de porosidade, período de retorno e coeficiente de escoamento.

Tabela A.1 - Dados físicos para determinação da massa específica dos sólidos................... 168

Tabela A.2 - Dados do ensaio de massa específica dos sólidos. ........................................ 168

Tabela A.3- Ensaio de peneiramento para determinação da composição granulométrica.... 169

Tabela A.4 - Ensaio de sedimentação para composição granulométrica. 170

Tabela A.5 - Índices físicos obtidos no ensaio com papel filtro. 171

Tabela A.6 - Parâmetros de secagem obtidos no ensaio com papel filtro. 
Tabela A.7 - Teor da umidade da amostra obtido no ensaio com papel filtro 173

Tabela A.8 - Sucção matricial obtido no ensaio com papel filtro. 174

Tabela A.9 - Índices físicos obtidos no ensaio de curva de retenção................................ 175

Tabela A.10 - Dados para a composição da curva de retenção. 


\section{LISTA DE SÍMBOLOS}

A - Área de contribuição à trincheira, $\mathrm{m}^{2}$.

$A_{\text {base }} \quad$ Área da base da trincheira, em $\mathrm{m}^{2}$.

$A_{c p} \quad$ - $\quad$ Área da seção transversal do corpo-de-prova, $\mathrm{m}^{2}$.

$A_{l} \quad$ - Área lateral da trincheira de infiltração, $\mathrm{m}^{2}$.

$A_{\text {inf }} \quad$ - Área efetiva de infiltração, $\mathrm{m}^{2}$.

$A_{\text {lote }} \quad$ - Área do lote, $\mathrm{m}^{2}$.

$A_{\text {molhada }}{ }^{-} \quad$ Área lateral da trincheira, $\mathrm{m}^{2}$.

$A_{T} \quad$ - $\quad$ Área transversal da tubulação, $\mathrm{m}^{2}$.

a - $\quad$ Parâmetro de ajuste da curva $i d f$, adimensional.

$B \quad$ - $\quad$ Largura da trincheira, $\mathrm{m}$.

$b \quad$ - $\quad$ Parâmetro de ajuste da curva $i d f$, adimensional.

C - $\quad$ Coeficiente de escoamento, adimensional.

$C_{a} \quad$ - Coeficiente de escoamento pré-ocupação, adimensional.

$C_{d} \quad$ - Coeficiente de escoamento pós-ocupação, adimensional.

c - $\quad$ - Parâmetro de ajuste da curva $i d f$, adimensional.

$c_{v} \quad$ - Velocidade no vácuo, $\mathrm{m} \cdot \mathrm{s}^{-1}$.

$D \quad$ - $\quad$ Declividade, $\mathrm{m} \cdot \mathrm{m}^{-1}$.

$D(\theta) \quad$ - Difusividade hidráulica não saturada, $\mathrm{em} \mathrm{m}^{2} \cdot \mathrm{s}^{-1}$.

$d \quad$ - Diâmetro equivalente da partícula, em $\mathrm{mm}$.

$e \quad-\quad$ Índice de vazios, $\%$.

$g \quad$ - Aceleração da gravidade, $\mathrm{m} \cdot \mathrm{s}^{-2}$.

$H \quad$ - $\quad$ Altura do corpo-de-prova, m.

$h \quad$ - $\quad$ Carga hidráulica aplicada, m.

$h_{\text {exp }} \quad$ - $\quad$ Altura da trincheira atingida no experimento, $\mathrm{m}$.

$h_{\text {mit }} \quad$ - $\quad$ Altura da trincheira considerando a mitigação do escoamento, m.

$h_{\text {exp }} \quad$ - $\quad$ Altura total da trincheira, m.

$I \quad$ - Infiltração acumulada, $\mathrm{m}^{3} \cdot \mathrm{m}^{-2}$.

$I_{c} \quad$ - Infiltração acumulada calculada, $\mathrm{m}^{3} \cdot \mathrm{m}^{-2}$.

$I b_{c} \quad$ - Infiltração acumulada calculada bimodal, $\mathrm{m}^{3} \cdot \mathrm{m}^{-2}$.

$I u_{c} \quad$ - Infiltração acumulada calculada unimodal, $\mathrm{m}^{3} \cdot \mathrm{m}^{-2}$.

$I_{o} \quad$ - Infiltração acumulada observada, $\mathrm{m}^{3} \cdot \mathrm{m}^{-2}$. 
$i_{o} \quad$ - Taxa de infiltração inicial, $\mathrm{m}^{3} \cdot \mathrm{s}^{-1} \cdot \mathrm{m}^{-2}$.

$i \quad$ - $\quad$ Taxa de infiltração, $\mathrm{m}^{3} \cdot \mathrm{s}^{-1} \cdot \mathrm{m}^{-2}$.

$i_{\text {chuva }} \quad$ - $\quad$ Intensidade de chuva, $\mathrm{m} . \mathrm{s}^{-1}$.

$i_{i} \quad$ - Taxa de infiltração em $\mathrm{t}=0, \mathrm{~m}^{3} \cdot \mathrm{m}^{-2} \cdot \mathrm{s}^{-1}$.

$i_{f} \quad$ - Taxa de infiltração constante em $\mathrm{t} \rightarrow \infty, \mathrm{m}^{3} \cdot \mathrm{m}^{-2} \cdot \mathrm{s}^{-1}$.

$i_{c} \quad$ - Taxa de infiltração calculada pelos ensaios experimentais, $\mathrm{m}^{3} \cdot \mathrm{s}^{-1} \cdot \mathrm{m}^{-2}$.

$K(\theta) \quad$ - $\quad$ Condutividade hidráulica do solo, $\mathrm{m}_{\mathrm{s}} \mathrm{s}^{-1}$.

$K_{I}(\theta)$ - Condutividade hidráulica dos microporos, em função da umidade, $\mathrm{m}_{\text {. }} \mathrm{s}^{-1}$.

$K_{I I}(\theta)$ - Condutividade hidráulica dos macroporos, em função da umidade, $\mathrm{m}_{\mathrm{s}} \mathrm{s}^{-1}$.

$K_{I}(\psi)$ - Condutividade hidráulica dos microporos, em função do potencial matricial, $\mathrm{m} \cdot \mathrm{s}^{-1}$.

$K_{I I}(\psi)$ - Condutividade hidráulica do macroporos, em função do potencial matricial, $\mathrm{m} \cdot \mathrm{s}^{-1}$.

$K_{o} \quad$ - $\quad$ Condutividade hidráulica saturada, $\mathrm{m} \cdot \mathrm{s}^{-1}$.

$K_{p s} \quad$ - $\quad$ Constante que indica condição do máximo comportamento hidráulico exercido pelos microporos, adimensional.

$k \quad-\quad$ Constante dielétrica relativa, adimensional.

$L_{F M} \quad$ - Distância entre a superfície e a frente de molhamento, em $\mathrm{m}$.

$L_{T D R} \quad$ - $\quad$ Comprimento da haste metálica, $\mathrm{m}$.

$l \quad$ - $\quad$ Comprimento da trincheira, $\mathrm{m}$.

$M_{1} \quad$ - $\quad$ Somatório das massas da água, do picnômetro e dos sólidos, $\mathrm{kg}$.

$M_{2} \quad$ - $\quad$ Somatório das massas da água e do picnômetro, em $\mathrm{kg}$.

$M_{s} \quad$ - $\quad$ Massa de sólidos do ensaio, em kg.

$m \quad$ - $\quad$ Coeficiente de ajuste da equação de van Genuchten, adimensional.

$m_{b} \quad$ - Coeficiente de ajuste da curva de retenção bimodal, adimensional.

$m_{c} \quad$ - $\quad$ Massa da cápsula, $\mathrm{kg}$.

$m_{s} \quad$ - $\quad$ Massa de solo, $\mathrm{kg}$.

n $\quad$ - $\quad$ Coeficiente de ajuste da equação de van Genuchten, adimensional.

$n_{b} \quad$ - $\quad$ Coeficiente de ajuste da curva de retenção bimodal, adimensional.

$Q \quad$ - Vazão circulante, $\mathrm{em} \mathrm{m}^{3} \cdot \mathrm{s}^{-1}$.

$Q_{\text {ent }} \quad$ - Vazão que entra na trincheira, $\mathrm{m}^{3} \cdot \mathrm{s}^{-1}$.

$Q_{\text {inf }} \quad$ - Vazão infiltrada, $\mathrm{m}^{3} \cdot \mathrm{s}^{-1}$.

$q \quad$ - Densidade de fluxo, $\mathrm{m}^{3} \cdot \mathrm{s}^{-1} \cdot \mathrm{m}^{-2}$. 
$q_{x} \quad$ - $\quad$ Densidade de fluxo na direção $\mathrm{x}, \mathrm{m}^{3} \cdot \mathrm{s}^{-1} \cdot \mathrm{m}^{-2}$.

$q_{y} \quad$ - $\quad$ Densidade de fluxo na direção $\mathrm{y}, \mathrm{m}^{3} \cdot \mathrm{s}^{-1} \cdot \mathrm{m}^{-2}$.

$q_{z} \quad$ - Densidade de fluxo na direção $\mathrm{z}, \mathrm{m}^{3} \cdot \mathrm{s}^{-1} \cdot \mathrm{m}^{-2}$.

$P_{a t m} \quad$ - Pressão atmosférica, $\mathrm{kg} \cdot \mathrm{m}^{-1} \cdot \mathrm{s}^{-2}$.

$\mathrm{P}(<\mathrm{D})$ - $\quad$ Porcentagem de solo em suspensão no momento da leitura.

$R \quad$ - $\quad$ Coeficiente de correlação de Pearson, adimensional.

$R^{2} \quad$ - Coeficiente de determinação, adimensional.

$R_{h} \quad$ - $\quad$ Raio hidráulico, m.

$r(H) \quad$ - Leitura do densímetro na proveta contendo suspensão de solo, adimensional.

$r_{w}(H)$ - Leitura do densímetro na proveta contendo água e defloculante, adimensional.

$S \quad$ - $\quad$ Sortividade, $\mathrm{m} \cdot \mathrm{s}^{-1 / 2}$.

$T \quad$ - Período de retorno, anos.

$t \quad$ - $\quad$ Duração da chuva, minutos.

$t_{d} \quad-\quad$ Tempo de drenagem interna no interior da trincheira, s.

$t_{e} \quad-\quad$ Tempo entre o início e o fim do ensaio, $\mathrm{s}$.

$t_{p} \quad$ - Tempo de propagação do pulso, s.

$t_{s} \quad$ - Tempo de sedimentação, s.

$V \quad$ - Volume total de água acumulado ou perdido no elemento de volume do

solo, $\mathrm{m}^{3}$.

$V_{\text {trin }} \quad$ - Volume da trincheira, $\mathrm{m}^{3}$.

$V_{a} \quad$ - Volume de água que percorre o $\mathrm{CP}, \mathrm{m}^{3}$.

$V_{\text {aflu }} \quad$ - Volume afluente no instante $t, \mathrm{~m}^{3}$.

$V_{c p} \quad$ - Volume de água que percorre o $\mathrm{CP}, \mathrm{m}^{3}$.

$V_{\text {ent }} \quad$ - Volume de água precipitado sobre a área de contribuição, no intervalo de tempo considerado, $\mathrm{m}^{3}$.

$V_{\text {inf }} \quad$ - Volume infiltrado no instante $t, \mathrm{~m}^{3}$.

$V_{x} \quad$ - Volume de água acumulado ou perdido na direção $\mathrm{x}, \mathrm{m}^{3}$.

$V_{y} \quad$ - Volume de água acumulado ou perdido na direção $\mathrm{y}, \mathrm{m}^{3}$.

$V_{z} \quad$ - Volume de água acumulado ou perdido na direção $\mathrm{z}, \mathrm{m}^{3}$.

$w \quad$ - $\quad$ Umidade gravimétrica, $\mathrm{kg} . \mathrm{kg}^{-1}$.

$z \quad$ - Distância entre o centro de volume do bulbo do densímetro e a superfície da suspensão calculada através da curva de calibração do densímetro, m.

$\alpha \quad$ - $\quad$ Parâmetro de ajuste da equação de van Genuchten, $\mathrm{m}^{-1}$.

$\alpha_{1} \quad$ - $\quad$ Parâmetro de ajuste dos microporos da curva de retenção bimodal, $\mathrm{m}^{-1}$. 
$\alpha_{2} \quad$ - Parâmetro de ajuste dos macroporos da curva de retenção bimodal, $\mathrm{m}^{-1}$.

$\Delta h \quad$ - $\quad$ Variação da altura de água no interior da trincheira durante 1 minuto, em m.s $\mathrm{s}^{-1}$.

$\Delta V e$ - Diferença entre o volume escoado pré e pós-ocupação, $\mathrm{m}^{3}$.

$\partial \theta / \partial t$ - Taxa de acumulação de água por unidade de tempo, $\mathrm{m}^{3} \cdot \mathrm{m}^{-3} \cdot \mathrm{s}^{-1}$.

$\phi \quad-\quad$ Potencial total da água no solo, $\mathrm{mH}_{2} \mathrm{O}$.

$\phi_{g} \quad$ - Potencial gravitacional da água no solo, $\mathrm{mH}_{2} \mathrm{O}$.

$\phi_{n} \quad$ - Potencial pneumático da água no solo, $\mathrm{mH}_{2} \mathrm{O}$.

$\phi_{o} \quad$ - Potencial osmótico da água no solo, $\mathrm{mH}_{2} \mathrm{O}$.

$\phi_{p} \quad$ - $\quad$ Potencial de pressão da água no solo, $\mathrm{mH}_{2} \mathrm{O}$.

$\phi_{T} \quad$ - Potencial de temperatura da água no solo, $\mathrm{mH}_{2} \mathrm{O}$.

$\gamma_{w} \quad$ - Peso específico da água, $\mathrm{kg} \cdot \mathrm{m}^{-3}$.

$\eta_{b} \quad$ - $\quad$ Porosidade da brita, $\%$.

$\eta_{s} \quad$ - $\quad$ Porosidade do solo, $\%$.

$\lambda(\theta) \quad$ - Variável de Boltzmann, $\mathrm{m} \cdot \mathrm{s}^{-1 / 2}$.

$\mu \quad$ - Viscosidade absoluta, Pa.s.

$\Theta \quad$ - $\quad$ Saturação efetiva, adimensional.

$\theta \quad$ - Umidade volumétrica, $\mathrm{m}^{3} \cdot \mathrm{m}^{-3}$.

$\hat{\theta} \quad$ - Umidade volumétrica estimada pelo modelo, $\mathrm{m}^{3} \cdot \mathrm{m}^{-3}$.

$\bar{\theta} \quad$ - $\quad$ Valor da umidade média, $\mathrm{m}^{3} \cdot \mathrm{m}^{-3}$.

$\theta_{f} \quad$ - Conteúdo de água ao final da alimentação ao dispositivo, $\mathrm{m}^{3} \cdot \mathrm{m}^{-3}$.

$\theta_{i} \quad$ - Conteúdo de água ao início da alimentação ao dispositivo, $\mathrm{em}^{3} \cdot \mathrm{m}^{-3}$.

$\theta_{0} \quad$ - Umidade volumétrica inicial, $\mathrm{m}^{3} \cdot \mathrm{m}^{-3}$.

$\theta_{p s} \quad$ - Umidade de pseudo-saturação, $\mathrm{m}^{3} \cdot \mathrm{m}^{-3}$.

$\theta_{r} \quad$ - Umidade volumétrica residual, $\mathrm{m}^{3} \cdot \mathrm{m}^{-3}$.

$\theta_{s} \quad$ - Umidade volumétrica de saturação, $\mathrm{m}^{3} \cdot \mathrm{m}^{-3}$.

$\theta(Z) \quad$ - $\quad$ Função representativa do perfil de conteúdo de água, $\mathrm{m}^{3} \cdot \mathrm{m}^{-3}$.

$\rho_{s} \quad$ - Massa específica dos sólidos, $\mathrm{kg} \cdot \mathrm{m}^{-3}$.

$\rho_{\mathrm{w}} \quad$ - $\quad$ Massa especifica da água, $\mathrm{kg} \cdot \mathrm{m}^{-3}$.

$\psi \quad$ - Potencial matricial da água no solo, $\mathrm{mH}_{2} \mathrm{O}$.

$\psi_{0} \quad$ - $\quad$ Potencial matricial da água no solo na superfície transversal ao fluxo, $\mathrm{mH}_{2} \mathrm{O}$.

$\psi_{f} \quad$ - $\quad$ Potencial matricial da água no solo na frente de molhamento, $\mathrm{mH}_{2} \mathrm{O}$. 


\section{LISTA DE SIGLAS}

$\begin{array}{lll}\text { ABNT } & - & \text { Associação Brasileira de Normas Técnicas } \\ \text { Asce } & - & \text { American Society of Civil Engineers } \\ \text { BMP } & - & \text { Best Management Practices } \\ \text { CETESB } & - & \text { Companhia de Esgoto do Estado de São Paulo } \\ \text { CP } & - & \text { Corpo de Prova } \\ \text { DAEE } & - & \text { Departamento de Águas e Energia Elétrica } \\ \text { EESC } & - & \text { Escola de Engenharia de São Carlos } \\ \text { Embrapa } & - & \text { Empresa Brasileira de Pesquisa Agropecuária } \\ \text { IPH } & - & \text { Instituto de Pesquisas Hidráulicas } \\ \text { IBGE } & - & \text { Instituto Brasileiro de Geografia e Estatística } \\ \text { LID } & - & \text { Low Impact Development } \\ \text { NBR } & - & \text { Norma Brasileira } \\ \text { NIBH } & - & \text { Núcleo Integrado de Bacias Hidrográficas } \\ \text { PET } & - & \text { Politereftalato de etila } \\ \text { PVC } & - & \text { Poly Vinyl Chloride (Policloreto de Vinila) } \\ \text { SCS } & - & \text { Soil Conservation Service } \\ \text { TDR } & - & \text { Time Domain Reflectometry } \\ \text { UFRGS } & - & \text { Universidade Federal do Rio Grande do Sul } \\ \text { USP } & - & \text { Universidade de São Paulo }\end{array}$




\section{SUMÁRIO}

1 - INTRODUÇÃ

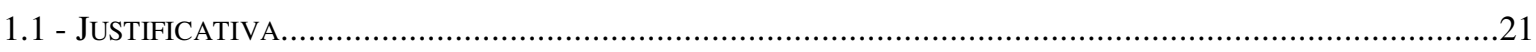

1.2 - OBJETIVOS

2 - TRINCHEIRAS DE INFILTRAÇÃO NA DRENAGEM URBANA …..............................................25

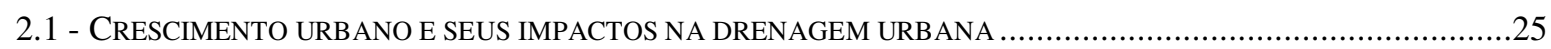

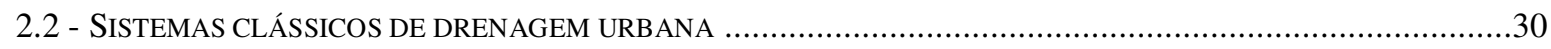

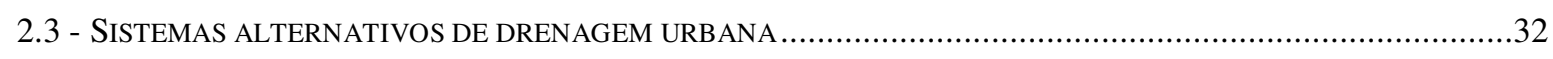

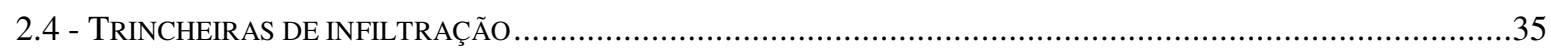

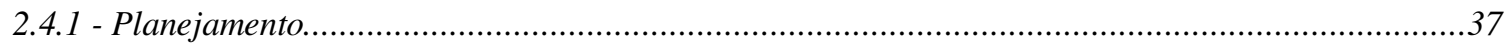

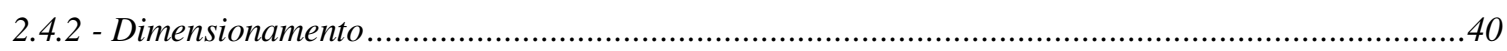

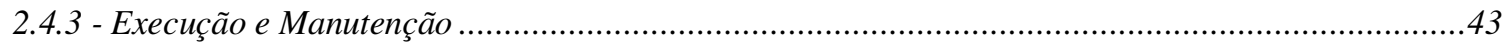

2.4.4 - Trabalhos realizados sobre trincheiras de infiltração...................................................................4

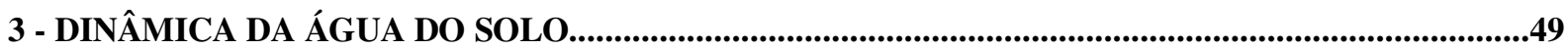

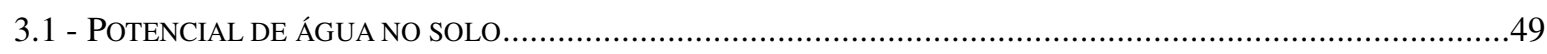

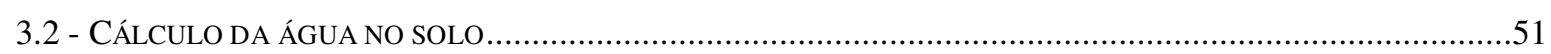

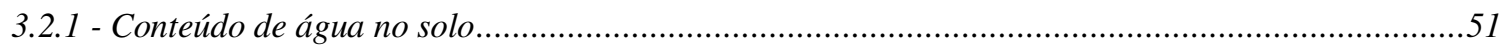

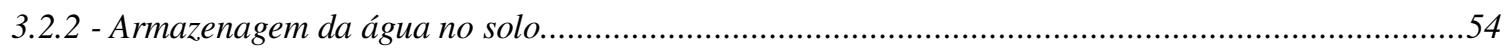

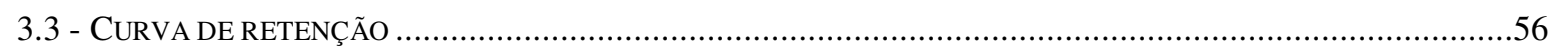

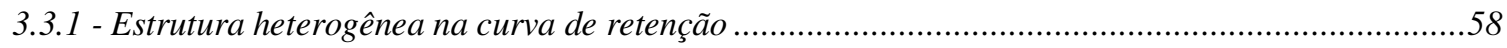

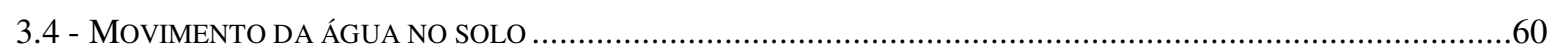

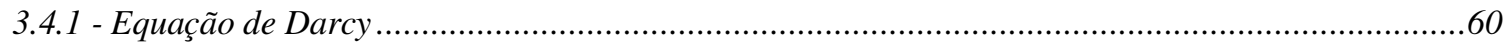

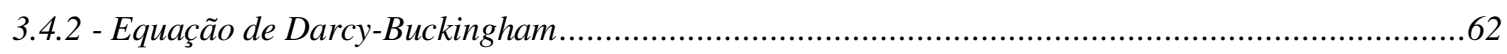

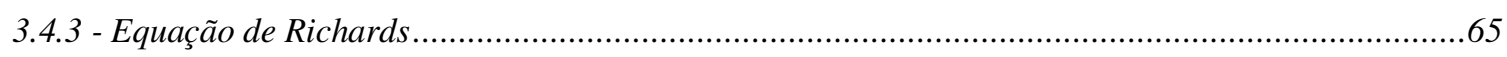

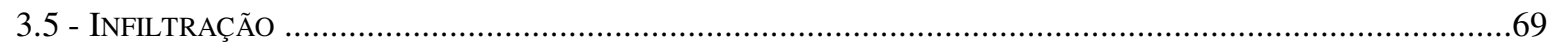

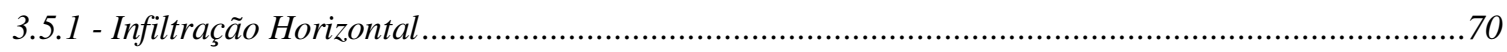

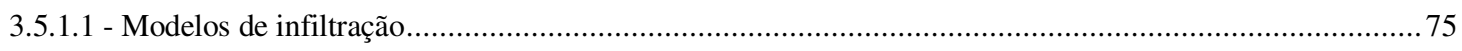

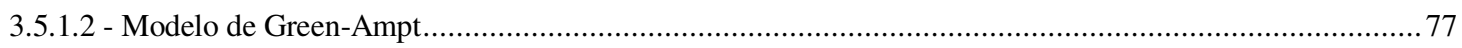

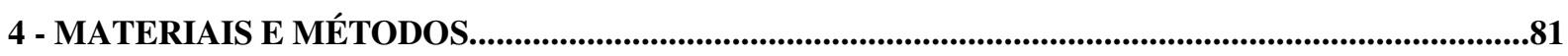

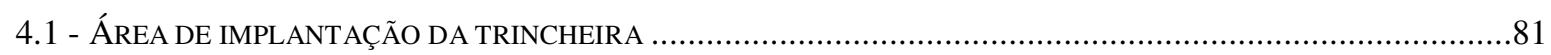

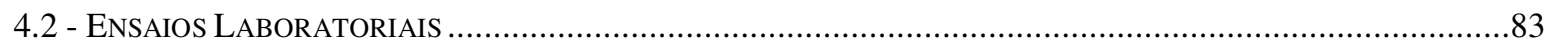

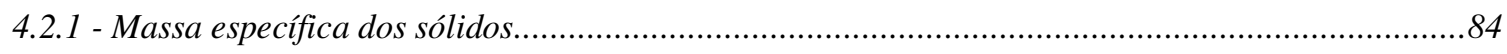

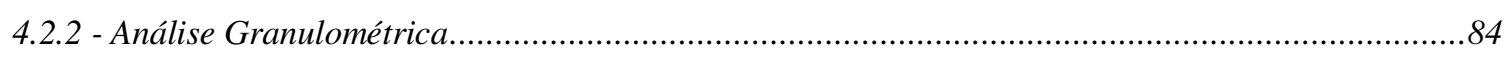

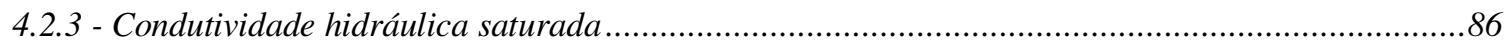

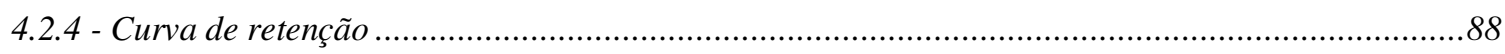

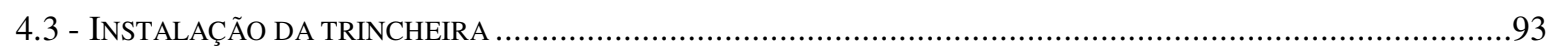




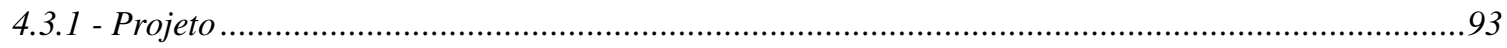

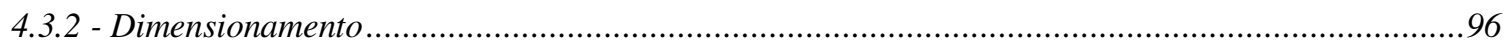

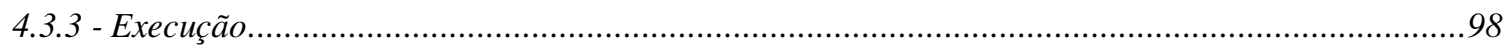

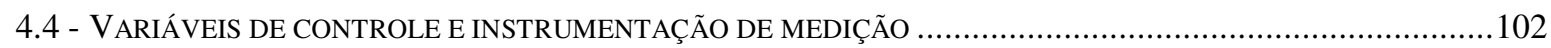

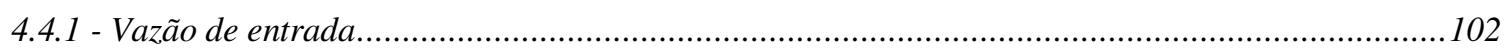

4.4 .2 - Nível de água no interior da trincheira .................................................................... 104

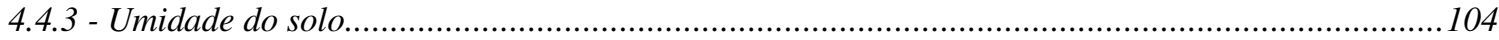

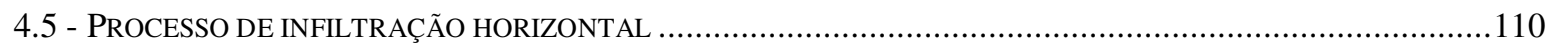

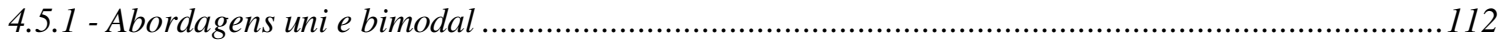

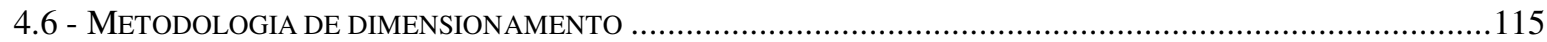

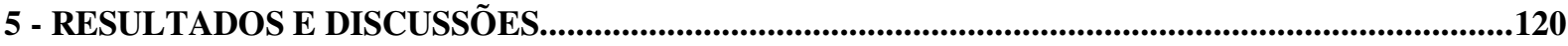

5.1 - ANÁLISE GRANULOMÉTRICA .................................................................................... 120

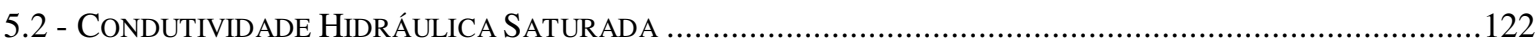

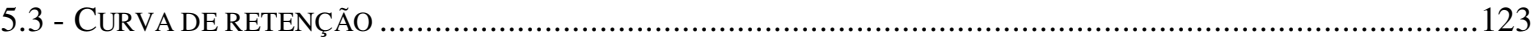

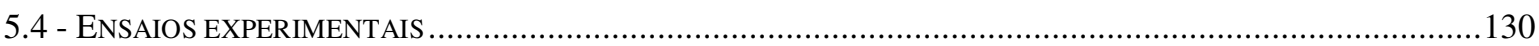

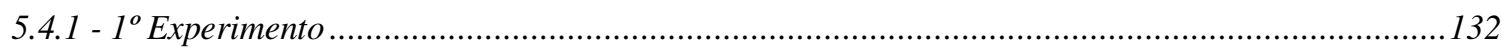

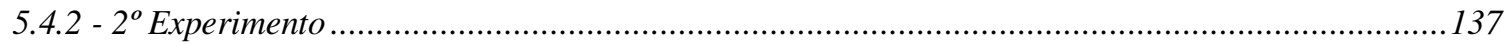

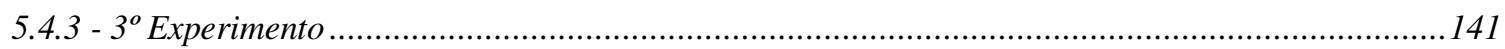

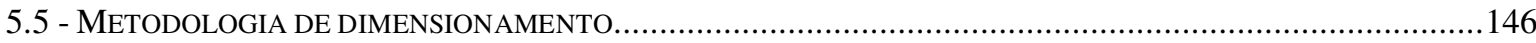

6 - CONCLUSÃO E RECOMENDAÇÕES ......................................................................................151

6.1 - ENSAIOS DE CARACTERIZAÇÃO GEOTÉCNICA E HIDRÁULICA DO SOLO .........................................151

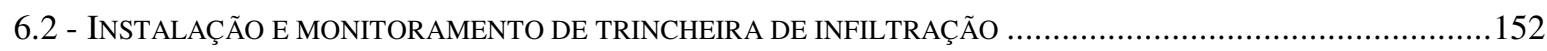

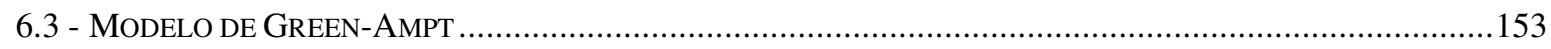

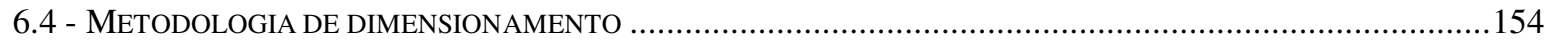

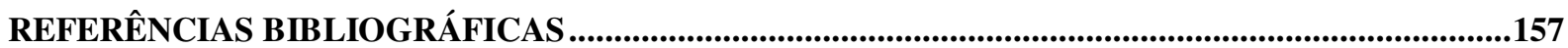

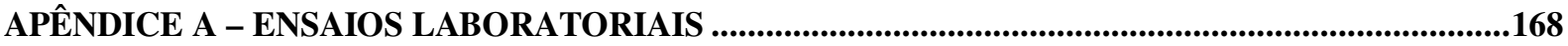




\section{Capítulo 1}

"Viver sem buscar o conhecimento é o mesmo que jogar sem saber as regras."

André $\mathcal{N}$ eves

\section{1 - INTRODUÇÃO}

\section{1 - Justificativa}

No Brasil, em virtude do crescimento urbano ocorrer, em sua maioria, de forma mal planejada, observa-se um aumento no volume escoado devido ao acréscimo de áreas impermeáveis e, consequentemente, redução da infiltração. Estas alterações causam sobrecargas nos sistemas clássicos de drenagem urbana, os quais muitas vezes se tornam incapazes de veicular a vazão adicional, provocando aumento na frequência e na magnitude das inundações.

Os sistemas clássicos de drenagem urbana têm por objetivo conduzir o escoamento o mais rápido possível para os cursos de água próximos. Desta forma, tendem, na medida em que contribuem para o aumento da velocidade de escoamento, ampliar os impactos da urbanização sobre os processos hidrológicos ocasionando danos à jusante da área de aplicação dessas estruturas.

No atual contexto de insuficiência dos sistemas de drenagem urbana, surgem os sistemas alternativos ou tecnologias alternativas de infiltração, detenção ou retenção que buscam neutralizar os efeitos da urbanização através do controle dos excedentes de água gerados na origem do escoamento (fonte).

Os sistemas alternativos permitem a manutenção do desenvolvimento urbano sem gerar custos excessivos, ao contrário do remodelamento do sistema com tecnologias 
convencionais que traduz-se em custos elevados, por vezes proibitivos, para as finanças públicas.

O uso das tecnologias alternativas ainda é relativamente incipiente no Brasil. Todo um potencial de benefícios advindos do uso dessas tecnologias está ainda para ser adequadamente utilizado. Por isso, existem muitas lacunas a serem preenchidas nos aspectos de dimensionamento e funcionamento, principalmente em solos com características heterogêneas.

Outro ponto importante, é que a atual realidade da drenagem urbana requer a utilização de diferentes tipos de modelos adaptados ou desenvolvidos para a nossa realidade. Um dos exemplos que podem ser utilizados são modelos que simulem mais realisticamente o processo de infiltração e que forneçam informações necessárias para a sua implantação como dispositivos na atenuação da cheia urbana.

Considerando o contexto atual simplificado acima, este trabalho estuda uma tecnologia alternativa voltada para o controle do escoamento através da infiltração. O comportamento hidráulico desta tecnologia foi monitorado em resposta a eventos de chuvas simuladas, e seus dados serviram de base para analisar o processo de infiltração unidimensional que foi calculado através do modelo de Green-Ampt adaptado ao processo de infiltração horizontal.

\section{2 - Objetivos}

O objetivo deste trabalho é estudar o comportamento hidráulico de trincheira de infiltração em meio não saturado através de modelagem numérica e experimental.

Considerando-se as especificidades no que se refere ao comportamento hidráulico de dispositivos de infiltração em meio não saturado, os objetivos específicos deste estudo são os seguintes: 
- caracterizar geotecnicamente e hidraulicamente o solo estudado;

- instalar e monitorar experimentalmente uma trincheira de infiltração conectada a um lote urbano experimental e com controle de fluxo;

- avaliar o modelo de Green-Ampt na modelagem do processo de infiltração horizontal e adaptá-lo a porosidade heterogênea do solo; e

- propor uma metodologia de dimensionamento de trincheira de infiltração.

Para uma melhor visualização dos objetivos, assim como dos resultados esperados, segue o fluxograma do trabalho na Figura 1.1. 


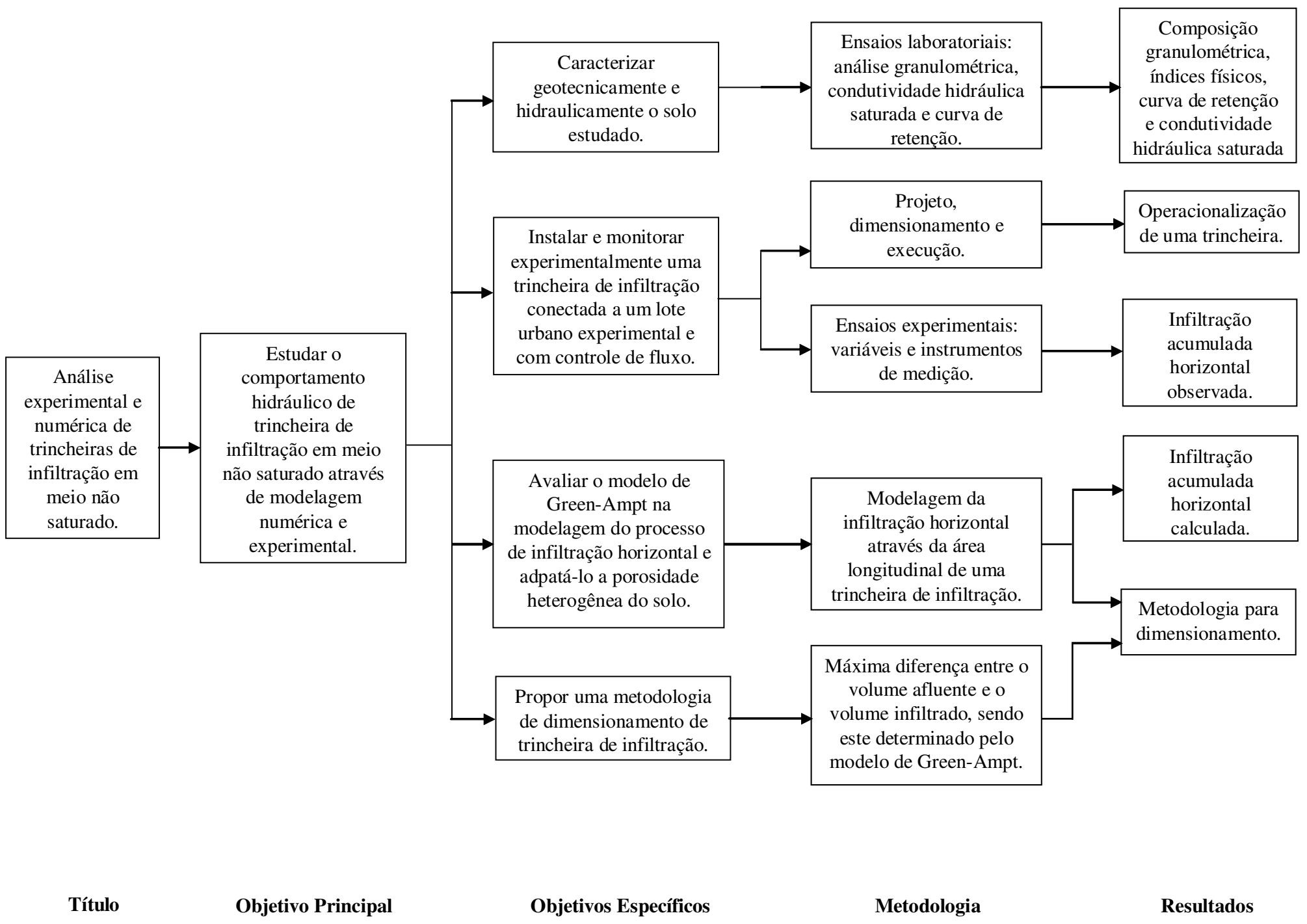

Figura 1.1- Quadro síntese das atividades a serem realizadas. 


\section{Capítulo 2}

"Torna-se indispensável que a humanidade formule um novo modo de pensar se ela quer sobreviver e atingir um plano mais elevado."

Albert Einstein

\section{2 - TRINCHEIRAS DE INFILTRAÇÃO NA DRENAGEM URBANA}

No item 2.1 deste capítulo, serão abordadas as consequências do crescimento urbano sobre as características hidrológicas locais. Nos itens 2.2 e 2.3, serão tratados os sistemas de drenagem urbanos utilizados para minimizar os problemas decorrentes do crescimento mal planejado em áreas urbanas. Por fim, no item 2.4, serão apresentadas as principais características construtivas (planejamento, dimensionamento e execução) relacionadas às trincheiras de infiltração.

\section{1 - Crescimento urbano e seus impactos na drenagem urbana}

O crescimento urbano resulta em inúmeros impactos no ambiente e em suas comunidades. Os impactos são positivos quando o crescimento é devidamente planejado, pois resulta no avanço tecnológico e proporciona benefícios na infra-estrutura do local, e são negativos, especialmente no que diz respeito ao destino das águas pluviais, quando é realizado de forma acelerada e desordenada porque podem causar, através do aumento das áreas impermeáveis e da ocupação irregular, o agravamento de inundações em centros urbanos.

Em se tratando do Brasil, o crescimento urbano aliado com a intensa migração da população rural se deu de forma desenfreada e caótica, contribuindo com inúmeros impactos negativos sobre todo aparelhamento urbano relativo a recursos hídricos. Como forma de exemplificar o processo de crescimento, segundo dados do IBGE (2008), a população urbana 
passou 12.880.182 para 137.925.238 habitantes em menos de sessenta anos. Em termos de população total isto representa um aumento de $31,24 \%$ para $81,19 \%$.

Um dos motivos desse crescimento mal planejado está diretamente associado à ineficiência da política de desenvolvimento urbano no planejamento e na implantação de ações que conduzam de forma adequada a ocupação do solo. No contexto de ocupação mal planejada ocorre a ocupação em áreas ribeirinhas e o aumento desordenado de áreas impermeáveis.

Segundo Tucci (2002) a ocupação em áreas ribeirinhas se deve, em geral, às seguintes ações:

- inexistência de restrição no Plano Diretor Urbano da maioria das cidades brasileiras quanto ao loteamento de áreas de risco de inundação, com isso a sequência de anos sem enchentes é razão suficiente para que empresários loteiem áreas inadequadas; e

- a população que migra para as cidades geralmente é de baixa renda e, por não ter condições de adquirir imóvel em área segura, ocupa as áreas de risco de inundação pertencentes ao poder público.

De acordo com Lima (2003) a ocupação em áreas ribeirinhas decorre dos diversos benefícios que as planícies de inundação apresentam à ocupação humana, tais como facilidade de acesso, topografia favorável, entre outras.

Desta forma, por quaisquer que sejam os motivos que levem a população a ocupar áreas ribeirinhas, esta ação gera inúmeros problemas a população e a administração pública, pois as inundações em áreas ribeirinhas não podem ser controladas visto que elas ocorrem por um processo natural do ciclo hidrológico, no qual o rio, que geralmente escoa no seu leito menor, passa a escoar no seu leito maior que está ocupado pela população (Figura 2.1). Segundo Tucci (2002) o risco com esse tipo de inundação ocorre geralmente entre 1,5 a 2 anos. 


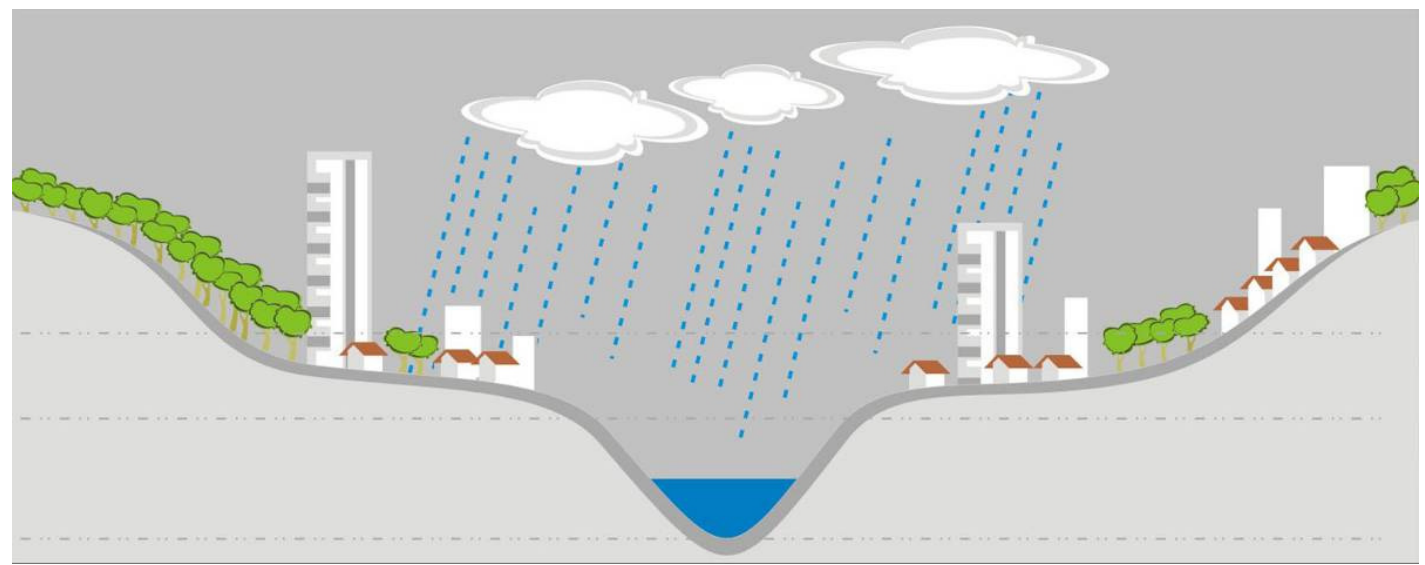

(a)

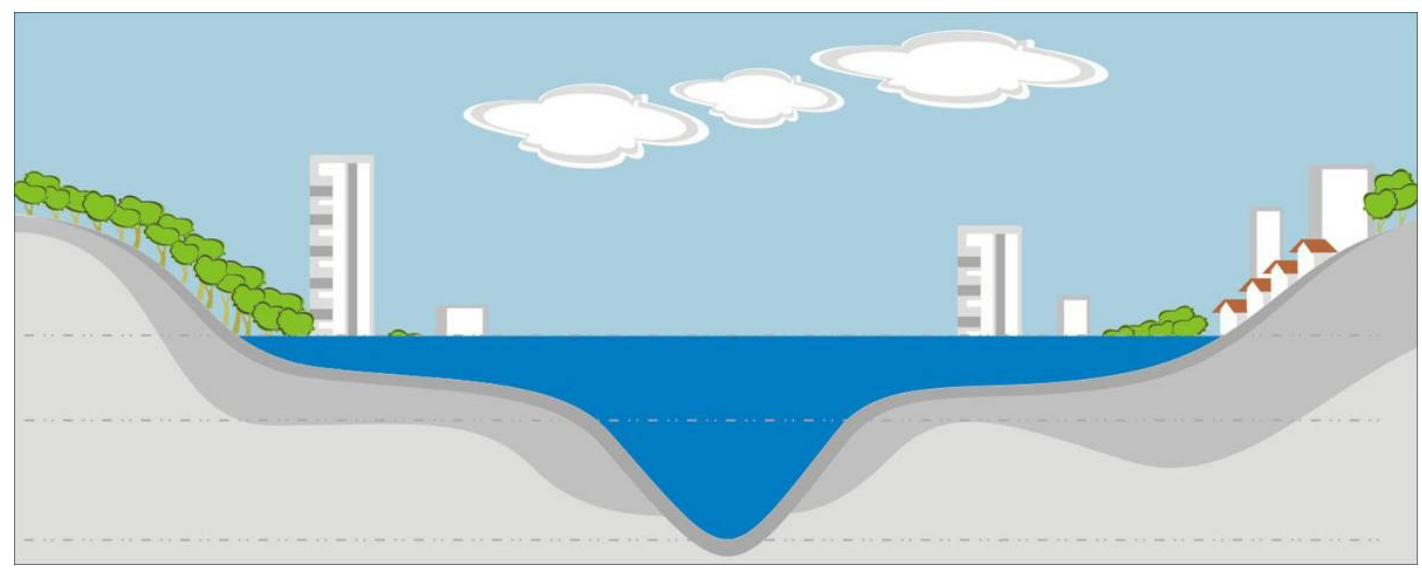

(b)

Figura 2.1- Representação de inundações em áreas ribeirinhas: a) o rio ocupando o seu leito menor; e b) o rio ocupando o seu leito maior. Fonte: Goerl e Kobiyama (2005), modificado por Andrade (2006).

No que se refere aos problemas relacionados à drenagem de águas pluviais decorrentes do aumento de áreas impermeáveis, estes estão fortemente ligados à questão da mudança da cobertura natural do solo pelo processo de ocupação urbana (Figura 2.2). 


\section{Evapotranspiração}

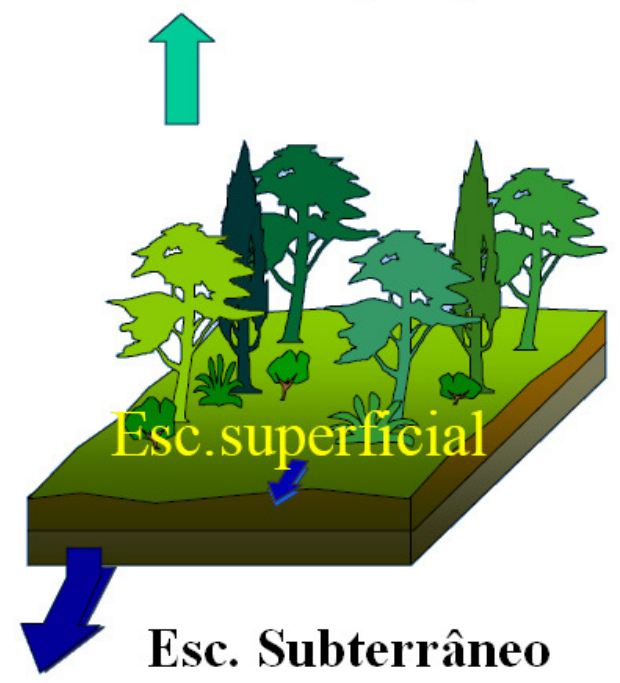

(a)

\section{Evapotranspiração}

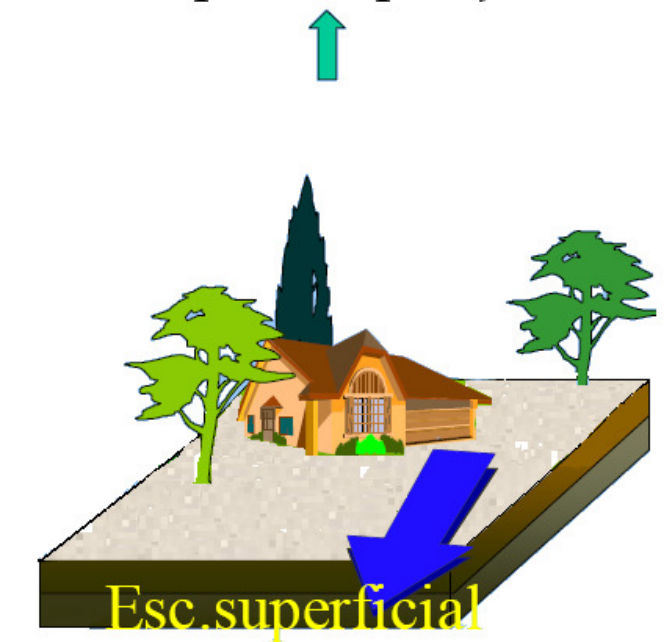

Figura 2.2 -Balanço hídico: a) antes da introdução de áreas impermeáveis; e b) depois da introdução de áreas impermeáveis. Fonte: Adaptado de Goldenfum (2008).

A expansão de áreas urbanas, em detrimento a cobertura vegetal, modifica a ocorrência natural do ciclo hidrológico. Com o ambiente impermeabilizado, parte da água que infiltrava, evaporava ou era retida na cobertura vegetal passa a compor o escoamento superficial. Nestas condições ocorre aumento da velocidade do escoamento, redução do tempo de concentração na bacia e aumento na vazão de pico.

Na área metropolitana de Denver, Estados Unidos, Roesner et al. (2001) ressaltam que as vazões de pico posteriores ao processo de ocupação aumentaram de duas ou mais vezes em relação à vazão na situação de não urbanização. Braune e Wood (1999), em estudos realizados na África do Sul, demonstraram que a vazão de pico causada pela urbanização pode ser de três a quatro vezes maiores que em uma área natural (sem urbanização).

No Brasil, Silveira (1999) estudando a cidade metropolitana de Porto Alegre encontrou que a impermeabilização causada pela urbanização provocou aumento na ordem de 4 a 5 vezes na vazão de escoamento e aumento na ordem de 6 vezes na vazão de pico em relação à vazão natural. 
Desta forma, o aumento da velocidade do escoamento superficial, causado pela urbanização, exige maior capacidade de escoamento pelos sistemas de drenagem. Entretanto, muitas vezes os sistemas de drenagem não são capazes de receber este aumento, ocasionando, com isso, as inundações urbanas, responsáveis por prejuízos sociais, econômicos e políticos.

$\mathrm{Na}$ ausência de dados brasileiros que quantifiquem os prejuízos econômicos devidos às inundações, Baptista e Nascimento (1996), tomando com base a média dos valores anuais de despesas e prejuízos com inundações na Austrália e nos Estados Unidos, estimaram prejuízo na ordem de dois bilhões de dólares causados por eventos de inundações no Brasil. Destaca-se que apesar da incerteza desta estimativa, devido ao critério simplificado adotado, a mesma pode ser muito útil, visto que fornece uma ordem da magnitude do problema e da importância de se minimizar os impactos das cheias no país.

Além dos problemas quantitativos causados pela impermeabilização, existem também problemas qualitativos no ambiente e nas suas comunidades. Um destes problemas acontecem em função do aumento da deposição atmosférica de poluentes sobre as superfícies urbanas, os quais durante a lavagem das ruas nos primeiros minutos do escoamento serão carreados até um corpo de água receptor.

Porto (1995) cita como exemplos de impactos no corpo de água receptor estão as alterações estéticas (cor e turbidez), os depósitos de sedimentos causando a destruição de habitats, a depleção da concentração de oxigênio dissolvido, a contaminação por organismos patogênicos e a eutrofização.

Outro problema qualitativo na drenagem urbana relacionado à urbanização acontece em função do aumento da produção de sedimentos e resíduos sólidos. Estes, além de contribuírem com carga de poluição devido aos constituintes adsorvidos, provocam assoreamento dos cursos de águas na macrodrenagem (SILVA, 2006). 
Como pode ser observado, a ocupação de áreas ribeirinhas e, principalmente, a introdução de superfícies impermeáveis de maneira acelerada, desordenada e inadequada, tem ocasionado problemas notáveis de desequilíbrio na drenagem urbana, sendo uma de suas principais consequências a ocorrência de inundações. Deste modo, como forma de conter estes problemas, são adotados sistemas de drenagem que buscam reduzir os impactos do crescimento populacional. Os sistemas adotados são classificados como clássicos e alternativos.

\section{2 - Sistemas clássicos de drenagem urbana}

Durante muito tempo as estruturas de drenagem urbana eram concebidas levando em consideração os pensamentos higienistas do século XIX, os quais preconizavam a rápida evacuação das águas dos locais onde haviam sido originadas, buscando com isso a diminuição da ocorrência de doenças de veiculação hídrica decorrentes da água parada ou empoçada, sujeita a contaminação. Este tipo de pensamento deu origem aos sistemas clássicos de drenagem.

Os sistemas clássicos são constituídos, basicamente, pelas sarjetas que transportam as águas superficiais nas ruas, pelas bocas de lobo que captam o escoamento quando a vazão é superada e pelos condutos que transportam as águas até o deságue ou até os sistemas de macro-drenagem. No contexto da macro-drenagem, os sistemas clássicos são constituídos de galerias e canais abertos (BAPTISTA et al., 2005).

Por muito tempo os sistemas clássicos foram desenvolvidos com o objetivo de remover de forma eficiente e economicamente eficaz as águas pluviais em excesso. Desta forma, os sistemas eram dimensionados para determinadas contribuições de águas, porém com a contínua introdução de superfícies impermeáveis através da urbanização há necessidade de ampliação das canalizações, aumento da declividade de fundo e retificações dos trechos dos rios. Tais soluções funcionam bem nos primeiros estágios da urbanização, 
pois o aumento do hidrograma a jusante é compensado pelas áreas a montante ainda não urbanizadas.

Entretanto, com ampliação da urbanização para áreas a montante, há acréscimos significativos na vazão máxima, causando aumento da enchente na região a jusante. Neste estágio, em geral, os leitos dos rios, muitas vezes canalizados, tornam-se incapazes de veicular a vazão adicional, recaindo em alternativas (aprofundamento da calha, alteração da geometria da seção transversal ou redução da rugosidade do canal) com custos, muitas vezes, incompatíveis com a disponibilidade do poder público (GRACIOSA, 2005).

Nascimento et al. (1997) afirmam que os sistemas clássicos tendem a amplificar os impactos da urbanização sobre os processos hidrológicos, gerando como consequência a obsolescência das redes de drenagem, o aumento da frequência de inundações e a poluição dos corpos de água. Souza (2002) ressalta que os sistemas clássicos atuam de forma concentrada sobre trechos críticos e transfere para a jusante todo o excesso de água gerado por superfícies impermeáveis construídas na parte montante do rio. Além disso, de acordo com Baptista et al. (2005), os sistemas clássicos não contemplam os problemas de qualidade de água, pois os problemas não são geralmente percebidos em virtude de grandes cargas de poluentes, geradas pelos esgotos sanitários lançados in natura, disfarçarem a real dimensão do problema.

Desta forma, levando em consideração as limitações dos sistemas clássicos na resolução dos problemas de enchentes urbanas e o aumento da consciência ecológica advinda de conceitos ambientalistas, vêm sendo estudados e desenvolvidos sistemas alternativos que em conjunto com os sistemas clássicos buscam limitar as mudanças impostas pela urbanização a patamares hidrologicamente sustentáveis, ou minimizar os impactos destas mudanças, caso elas já estejam estabelecidas (GRACIOSA, 2005). 


\section{3 - Sistemas alternativos de drenagem urbana}

Nas últimas três décadas, os impactos provocados pela infraestrutura tradicional de drenagem em grandes centros do mundo e a preocupação gradativa com as questões de preservação ambiental evidenciaram a necessidade de mudanças substanciais na forma de planejamento da drenagem urbana (SILVA, 2006). Com isso, a partir da década de 70, surgiu especialmente na América do Norte e na Europa uma abordagem ambientalista como consequência da maior conscientização ecológica. Nessa nova abordagem os sistemas alternativos de drenagem surgem para tratar o problema das enchentes urbanas.

O uso de soluções alternativas para a disposição de águas pluviais em áreas urbanas tem sido relatado na literatura internacional, frequentemente, no contexto das BMPs (Best Management Practices). Mais recentemente, aplicações de soluções alternativas têm sido reportadas no contexto de urbanização de baixo impacto (LID - Low Impact Development), que fazem parte de uma linha de estudos urbanísticos.

Os sistemas alternativos buscam compensar e neutralizar os efeitos da urbanização sobre os processos hidrológicos através do controle dos excedentes hídricos e da minimização da transferência rápida para jusante. Possuem uma estrutura bastante simples e aproveitam os processos naturais para promover a drenagem e disposição das águas pluviais. Desta forma, se mostram bem mais vantajosos que os sistemas clássicos, além disso, de acordo com Souza (2002), baseado em trabalhos como Azzout et al. (1994), Nascimento et al. (1997) e Urbonas e Stahre ${ }^{1}$ (1993), permitem:

- considerar os impactos da urbanização não apenas em novas áreas em urbanização, mas no contexto global;

- compensar sistematicamente os efeitos da urbanização;

\footnotetext{
${ }^{1}$ URBONAS, B.; e STAHRE, P. (1993) Stormwater: best management practices and detention for water quality, drainage and CSO management. Englewood Cliffs: Prentice Hall. 447p.
} 
- controlar o escoamento superficial sem restringir o processo de urbanização, já que os sistemas alternativos podem ser implantados à medida que a urbanização progride;

- diminuir o risco de inundação;

- reduzir ou mesmo eliminar a rede de microdrenagem local;

- a modulação do sistema de drenagem em função do crescimento urbano sem gerar custos excessivos;

- boa integração com o espaço e possibilidade de valorização da água no meio urbano, adicionando valor estético à cidade;

- melhorar a recarga de água subterrânea, normalmente reduzida em razão da impermeabilização de superfícies;

- melhorar a qualidade da água de escoamento superficial; e

- baixos custo de implantação.

Os mesmos autores também citam desvantagens na aplicação destes sistemas, podendo ser citadas:

- preocupação com manutenção frequente, a fim de se evitar a perda de desempenho da vida útil;

- utilização de sistemas condicionados a características de solo;

- risco de contaminação do solo e aquífero; e

- falta de padrão de projetos e escassez de informações a respeito do seu funcionamento a longo prazo.

Os sistemas alternativos podem ser diferenciados a partir de distintos critérios. Um deles é baseado na escala de atuação. Desta forma, podem ser divididos em sistemas distribuídos, ou de controle na fonte, e sistemas concentrados. Os sistemas de controle na fonte atuam sobre pequenas áreas e são aplicados de forma difusa na bacia. Já os sistemas 
concentrados promovem o controle sobre todo o escoamento proveniente de uma área de contribuição, atuando no hidrograma resultante de um ou mais loteamentos (SILVA, 2006).

Outra forma de diferenciar os sistemas alternativos centra-se no princípio básico de funcionamento das técnicas. Assim, podem ser distinguidos entre sistemas alternativos de retenção ou infiltração.

Os sistemas de infiltração são atualmente os mais requeridos por ocuparem menor área e por favorecerem a recarga de aquíferos possibilitando o restabelecimento do balanço hídrico pré-existente (SILVA, 2007). Além disso, segundo Araújo et al. (2000), outras vantagens são inerentes aos sistemas de infiltração, tais como:

- preservação do equilibro da água no local;

- controle das descargas de pico;

- baixo custo de implantação; e

- suprimento de água para a vegetação no meio urbano.

Em contrapartida, o sistema possui desvantagens que, de acordo com as circunstâncias, podem inviabilizar sua implantação, como por exemplo, o risco de contaminação do solo e do lençol freático, a necessidade de inspeções regulares e a redução da eficiência pelo processo de colmatação. Em relação à última desvantagem, esta pode ser minimizada através da disposição de uma estrutura a montante para remoção de sedimentos.

Diversos são os sistemas alternativos disponíveis para promover a infiltração das águas pluviais. Um deles é o pavimento permeável que tem se revelado eficiente em estacionamentos, calçadas e vias de tráfego pouco intenso (MIKKELSEN et al., 1996). Ele armazena a água em reservatórios sob os pavimentos pelo tempo necessário para sua infiltração no solo ou, de forma alternativa, funcionam como reservatórios de amortecimento, mediante drenos auxiliares para o excesso de água (SOUZA, 2002). 
Outra alternativa é a trincheira de infiltração como elemento isolado em lotes residenciais ou, como componentes de um sistema integrado de estruturas de infiltração em grandes áreas (GRACIOSA, 2005). Este tipo de sistema armazena a água precipitada por tempo suficiente para sua infiltração no solo. De acordo com Souza (2002), apresenta um melhor desempenho em relação ao reservatório, pois favorecem a infiltração da água no solo. Além disso, apresenta um custo bem menor se comparado para a mesma redução de vazão.

\section{4 - Trincheiras de infiltração}

Trincheiras de infiltração são dispositivos de controle de escoamento na fonte que têm o objetivo de captar, armazenar e infiltrar uma parcela do escoamento superficial gerado dentro do lote, reduzindo o volume de água pluvial que chega até as galerias e retardando os picos do hidrograma de cheias. Segundo Duchene et al. (1994) também funcionam para estabilizar ou atenuar os contaminantes contidos no escoamento urbano. Contudo, há risco da contaminação da água subterrânea se o volume de contaminantes infiltrados for maior que a capacidade de atenuação natural do solo. Butler e Davis² (2000 Baptista, 2005, p. 76) mencionam eficiência de $65 \%$ em termos de remoção de carga anual média de sólidos em suspensão, de metais, de hidrocarbonetos e outros poluentes.

As trincheiras de infiltração são dispositivos lineares que apresentam largura e profundidade reduzidas em contraposição às dimensões longitudinais. São constituídos por valetas preenchidas ou não por material granular graúdo (seixo rolado, brita, etc.) com porosidade em torno de 30 a $40 \%$. No fundo, nos lados e na superfície acima do material de preenchimento são dispostos manta de geotêxtil com o objetivo de impedir a entrada de material fino na estrutura, diminuindo o risco de colmatação (obstrução por material fino) precoce e podendo ainda trabalhar como filtro anticontaminante. Sua alimentação pode ser

\footnotetext{
${ }^{2}$ BUTLER, D.; e DAVIES, J. W. (2000) Urbain Drainage. Londres: St Edmundsbury Press, p. 489.
} 
efetuada diretamente ou através de tubulação perfurada implantada ao longo do seu comprimento.

As trincheiras funcionam como reservatórios de amortecimento de cheias, proporcionando a redução dos volumes e das vazões máximas (SOUZA, 2002). Além disso, outras vantagens inerentes à trincheira de infiltração podem ser observadas na Tabela 2.1.

Tabela 2.1- Vantagens e desvantagens apresentadas mediante a utilização de trincheiras de infiltração.

- Redução das vazões de pico de escoamento a jusante;

- Ganho financeiro pela redução das dimensões das tubulações a jusante;

\section{Vantagens}

- Baixo custo;

- Redução dos riscos de inundação;

- Fácil construção;

- Boa integração no meio urbano; e

- Recarga do aquífero subterrâneo.

- Possibilidade de colmatação;

- Limitações no caso de declividade longitudinal superior a 5\%;

- Manutenção regular; e

- Risco de poluição do lençol subterrâneo.

Fonte: Azzout et al. ${ }^{3}$ (1994 apud Souza, 2002, p. 15).

As trincheiras de infiltração, segundo Baptista et al. (2005), são bastante versáteis, podendo ser implantadas em canteiros centrais e passeios, estacionamentos, jardins, terrenos esportivos, áreas verdes, ou ainda ao longo do sistema viário (Figura 2.3). Outra possibilidade interessante de implantação em grandes áreas consiste na combinação de diferentes tipos de soluções técnicas em um mesmo empreendimento. Um exemplo é o sistema de retenção e infiltração de águas de chuva monitorado por Coombes et al. (1999) e implantado em Figtree Place, subúrbio de New Castle, Austrália.

\footnotetext{
${ }^{3}$ AZZOUT, Y.; BARRAUD, S.; CRES, F. N.; ALFAKIH, E. (1994). Techniques alternatives en assainissement pluvial: choix, conception, réalisation et entretien. Paris: Lavoisier. 372p.
} 

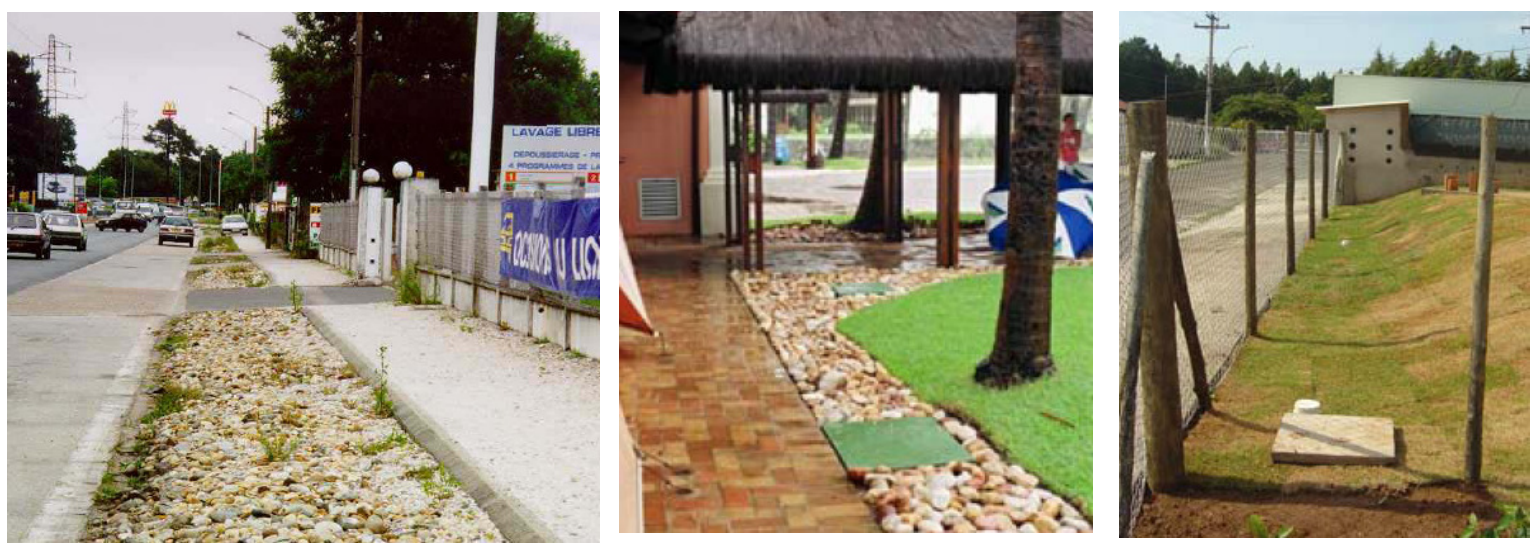

Figura 2.3 - Trincheiras de infiltração implantadas em canteiros centrais, ao redor de áreas verdes e em jardins.

\subsection{1 - Planejamento}

Anteriormente a implantação da trincheira, durante a fase de planejamento, alguns aspectos devem ser analisados, os quais, segundo Baptista et al.(2005), Urbonas e Stahre (1993 apud Souza, 2002, p. 23), e Landphair et al. (2000), são:

- a permeabilidade do solo, pois em solos com valores de permeabilidade inferiores a $10^{-7}$ $\mathrm{m} . \mathrm{s}^{-1}$ a infiltração não deve ser o único meio de evacuação das águas pluviais;

- a localização do nível máximo do lençol freático, pois se ele situar a menos de 1 metro de distância da base da trincheira, existe a possibilidade de contaminação do lençol freático;

- se o local apresenta uma excessiva movimentação de terra, pois pode gerar um aporte significativo de sedimentos para o interior da estrutura;

- a origem do solo que compõe a superfície de infiltração, pois não deve ser implantada em solos de aterro;

- a taxa de infiltração saturada do solo, pois em solos contendo argilas expansivas e pouco profundo não se recomendam a implantação com valores menores que $2.10^{-6} \mathrm{~m} \cdot \mathrm{s}^{-1}$;

- a declividade no sentido longitudinal da trincheira, pois a sua utilização fica limitada em virtude da redução do volume útil de armazenamento;

- a topografia do terreno, pois a inclinação do terreno intervém na determinação do sentido preponderante do escoamento da água sobre as superfícies drenadas para as trincheiras; e 
- a capacidade de absorção do solo.

Analisado os aspectos acima e concluído que a implantação da trincheira é viável, parte-se para caracterização das propriedades dos solos através de ensaios in situ, os quais fornecem informações necessárias ao dimensionamento, devendo ser efetuados nas profundidades em que a trincheira será implantada. Dentre os ensaios necessários, o de infiltração deve ser realizado primeiramente, uma vez que a escolha desses sistemas é realizada com base nas condições de infiltração do solo. Segundo Mikkelsen et al. (1996) uma baixa capacidade de infiltração do solo não consiste numa restrição técnica, porém pode inviabilizar economicamente o projeto, visto que as dimensões da estrutura deverão ser maiores para suportar maiores volumes armazenados.

Outro ensaio a ser realizado é o da condutividade hidráulica saturada, uma vez que este parâmetro traduz a facilidade com que o líquido se movimenta ao longo do perfil do solo. Valores baixos deste parâmetro podem comprometer a viabilidade do projeto, já valores altos podem acarretar na contaminação do aquífero, pois a rápida movimentação do líquido no solo não oferece tempo suficiente de filtrar e remover os poluentes.

Segundo Souza (2002), os limites para os valores mínimos e máximos são discutidos por vários autores, não havendo consenso. As ordens de grandeza da condutividade hidráulica saturada em diferentes solos são dadas na Tabela 2.2.

Tabela 2.2 - Ordem de grandeza da condutividade hidráulica em diferentes solos.

\begin{tabular}{|c|c|c|c|c|c|c|c|}
\hline$K(\mathbf{m} / \mathbf{s})$ & $10^{-2}$ & $10^{-4}$ & $10^{-5}$ & $10^{-7}$ & $10^{-9}$ & $10^{-10}$ & $10^{-11}$ \\
\hline Tipos de solos & $\begin{array}{c}\text { Seixos sem areia } \\
\text { nem elementos finitos }\end{array}$ & $\begin{array}{l}\text { Areia com seixos, } \\
\text { areia grossa a fina }\end{array}$ & $\begin{array}{r}\text { Areia } 1 \\
\text { Silte grosso }\end{array}$ & $\begin{array}{l}\text { uito fina } \\
\text { silte argiloso }\end{array}$ & \multicolumn{3}{|c|}{$\begin{array}{c}\text { Argila siltosa a } \\
\text { argila homogênea }\end{array}$} \\
\hline $\begin{array}{l}\text { Possibilidade } \\
\text { de infiltracão }\end{array}$ & Excelente & Boa & \multicolumn{2}{|c|}{ Média a baixa } & \multicolumn{3}{|c|}{ Baixa a nula } \\
\hline
\end{tabular}

Fonte: Musy e Soutter ${ }^{4}$ (1991 apud Baptista et al., 2005, p. 86).

\footnotetext{
${ }^{4}$ MUSY, A., e SOUTIER, M. (1991) Physique du sol. Lausanne: Presses Polytechniques et Universitaires Romandes, 335p.
} 
$\mathrm{Na}$ fase de planejamento, além dos ensaios de caracterização, também se faz necessário o conhecimento de parâmetros hidrológicos, sendo o mais importante os dados de precipitação do local, uma vez que a característica aleatória das chuvas constitui um dos maiores problemas no dimensionamento de estruturas de drenagem.

Para a utilização dos dados de precipitação, é necessário o estabelecimento de uma relação analítica entre intensidade, duração e frequência das chuvas intensas, a qual se denomina de curva $i d f$. Para a cidade de São Carlos, onde a trincheira foi construída, a curva idf foi proposta por Barbassa (1991) e é dada pela Equação 2.1.

$$
i_{\text {chuva }}=0,278 \cdot 10^{-6} \cdot\left[\frac{1519 \cdot T^{0,236}}{(t \cdot 60+16)^{0,935}}\right]
$$

em que $T$ é o período de retorno, em anos; $t$ é a duração da chuva, em s; e $i_{\text {chuva }}$ é a intensidade da chuva, em m.s ${ }^{-1}$.

O período de retorno $T$ presente na Equação 2.1 corresponde ao intervalo médio de tempo decorrido entre duas ocorrências sucessivas de um dado evento ou sua superação.

O período de retorno deve ser adotado em função de um custo total mínimo que forneça um valor otimizado nos aspectos de segurança, de operação e custo de implantação. Contudo estes aspectos apresentam uma difícil quantificação. Por isso, órgãos públicos, como o DAEE/CETESB, fixam o tempo de retorno para diversos tipos de obra como critério de projeto (PORTO, 1995). Para o caso de obras de microdrenagem, o tempo de retorno varia de 2 a 10 anos, sendo dois para áreas pouco densas e residenciais e dez para áreas comerciais.

De acordo com Baptista et al. (2005), a adoção de valores tabelados conduz, geralmente, ao dimensionamento de estruturas hidráulicas que atendem a um único risco admissível de falha de projeto, tendo em vista apenas o controle de cheias. Risco admissível é definido como a probabilidade de ocorrência ou superação de um dado evento tomado como crítico. 


\subsection{2 - Dimensionamento}

No que diz respeito ao dimensionamento, a prática de projeto de obras pluviais, como trincheiras de infiltração, exige métodos simples e confiáveis de dimensionamento para não tornar complexo um estudo de alternativas que, muitas vezes, pode envolver um arranjo com diversos dispositivos ou medidas de controle na fonte.

O método normalmente usado é o método Rain-envelope-method ou método de envelopamento da chuva apresentado por Mikkelsen e Jacobsen (1993) e Mikkelsen et al. (1996). O método baseia-se na determinação da máxima diferença entre o volume afluente, parcela do volume precipitado que foi drenado para a trincheira, e o volume infiltrado.

Contudo, o método apresenta algumas desvantagens. Uma delas é que o volume infiltrado é estimado com base na formulação de Darcy para solo saturado, o que de acordo com Graciosa et al. (2008) pode subestimar a capacidade de infiltração da trincheira, uma vez que considera que a taxa de infiltração do solo é constante e igual à taxa de infiltração na condição de saturação (situação limite). Outra desvantagem é que o volume afluente é calculado com base no método racional e, segundo Mikkelsen et al. (1996), o método negligencia o efeito de chuvas sucessivas.

Diante dessas desvantagens, Graciosa et al. (2008) propôs um modelo de dimensionamento baseado no balanço de massa. Sendo o volume afluente calculado pela mesma hipótese do método Rain-envelope-method, com algumas alterações nas unidades dos parâmetros aplicados, e o volume infiltrado determinado pelo modelo de infiltração horizontal proposto por Philip que considera a equação do perfil de umidade. As equações do volume afluente e do volume infiltrado estão apresentadas na Equação 2.2 e na Equação 2.3, respectivamente.

$$
\begin{gathered}
V_{a f l u}(t)=C \cdot i_{\text {chuva }} \cdot A_{\text {lote }} \cdot t \\
V_{\mathrm{inf}}(t)=S \sqrt{t} \cdot A_{\mathrm{inf}}
\end{gathered}
$$$$
\text { Equação } 2.2
$$ 
em que $V_{a f l u}$ e $V_{\text {inf }}$ são os volumes afluente e infiltrado, respectivamente, até o instante $t$, em $\mathrm{m}^{3} ; C$ é o coeficiente de escoamento, adimensional; $i_{\text {chuva }}$ é a intensidade da chuva, em $\mathrm{m} . \mathrm{s}^{-1}$; $A_{\text {lote }}$ é a área do lote, em $\mathrm{m}^{2} ; t$ é a duração da chuva, em s; $S$ é a sortividade, grandeza relacionada com a capacidade do solo homogêneo em absorver água na ausência dos efeitos gravitacionais, em m.s ${ }^{-1 / 2}$; e $A_{i n f}$ é a área efetiva de infiltração, em $\mathrm{m}^{2}$.

O coeficiente de escoamento $(C)$ presente na Equação 2.2 é função do tipo e ocupação do solo, da intensidade, da distribuição temporal e espacial da precipitação e da umidade antecedente. Deste modo, a adoção de um valor constante para o coeficiente é uma hipótese pouco realista, devendo ser realizada com cuidado. Geralmente ele é estimado com base em tabelas que expressam o seu valor por meio da superfície ou da ocupação do solo.

A área efetiva de infiltração $\left(A_{\text {inf }}\right)$ presente na Equação 2.3 é estimada considerando que a área superficial da base é totalmente colmatada após certo tempo, que a superfície transversal ao eixo longitudinal é desprezível e que a infiltração ocorre somente na metade inferior da superfície lateral. Baptista et al. (2005) mostram em seu trabalho diferentes hipóteses para a consideração da área efetiva de infiltração feitas em diferentes países (Tabela 2.3).

Tabela 2.3 - Hipóteses para a consideração da área efetiva na concepção em diferentes países.

\begin{tabular}{cllcl}
\hline País & $\begin{array}{c}\text { Tipo de } \\
\text { estrutura }\end{array}$ & \multicolumn{1}{c}{ Hipóteses } & Vazão & Parâmetros do solo \\
\hline \multirow{2}{*}{$\begin{array}{c}\text { Dinamarca } \\
\text { poços, } \\
\text { trincheiras, } \\
\text { bacias }\end{array}$} & $\begin{array}{l}\text { Sem infiltração no fundo. } \\
\text { Infiltração na metade da altura } \\
\text { das paredes. }\end{array}$ & $A_{i n f} * K s$ & $\begin{array}{l}\text { Observações hidrogeológicas ou } \\
\text { medidas } i n \text { situ. }\end{array}$ \\
\hline \multirow{2}{*}{ Alemanha } & $\begin{array}{l}\text { trincheiras, } \\
\text { bacias, } \\
\text { valas }\end{array}$ & $\begin{array}{l}\text { Infiltração no fundo e na } \\
\text { metade da altura das paredes. } \\
\text { Todas as superfícies infiltram. }\end{array}$ & $A_{i n f} * K$ & $\begin{array}{l}\text { Solo saturado } K=K_{o} . \\
\text { Solo não saturado } K=K_{o}^{*} 0,5 . \\
\text { K medido } \text { in situ. }\end{array}$ \\
\hline
\end{tabular}


Tabela 2.3 - Hipóteses para a consideração da área efetiva na concepção em diferentes países.

\begin{tabular}{|c|c|c|c|c|}
\hline Holanda & $\begin{array}{l}\text { poços, } \\
\text { trincheiras, } \\
\text { bacias }\end{array}$ & $\begin{array}{l}\text { Sem pré-tratamento, o fundo } \\
\text { é suposto colmatado. } \\
\text { Infiltração na metade da altura } \\
\text { das paredes quando o fundo é } \\
\text { colmatado; se não, em toda a } \\
\text { altura. }\end{array}$ & $A_{i n f} * K$ & $\begin{array}{l}K=K_{o}^{*} c \\
c=0,5 \text { se } K_{o} \text { for medido in situ. } \\
c=0,3 \text { se } K_{o} \text { for estimado. }\end{array}$ \\
\hline Suíça & $\begin{array}{l}\text { poços, } \\
\text { trincheiras, } \\
\text { bacias }\end{array}$ & $\begin{array}{l}\text { Infiltração na metade da altura da } \\
\text { parede e pelo fundo. }\end{array}$ & $A_{i n f} * K$ & $K$ estimado ou medido. \\
\hline $\begin{array}{l}\text { Reino } \\
\text { Unido }\end{array}$ & poços & $\begin{array}{l}\text { Fundo colmatado. } \\
\text { Infiltração na metade da altura } \\
\text { das paredes. }\end{array}$ & $A_{i n f} * q_{a s}$ & $\begin{array}{l}q_{a s} \text { medido por um ensaio in situ } \\
\text { normalizado. }\end{array}$ \\
\hline $\begin{array}{l}\text { EUA e } \\
\text { Suécia }\end{array}$ & $\begin{array}{l}\text { poços, } \\
\text { trincheiras, } \\
\text { bacias }\end{array}$ & $\begin{array}{l}\text { Fundo colmatado. } \\
\text { Infiltração na metade da altura } \\
\text { das paredes. }\end{array}$ & $A_{i n f}{ }^{*} K^{*} c$ & $\begin{array}{l}K \text { medido por um ensaio in situ } \\
\text { normalizado e } 0,3<c<0,5 \text {. }\end{array}$ \\
\hline Japão & trincheiras & $\begin{array}{l}\text { Toda a superfície participa da } \\
\text { infiltração. }\end{array}$ & $A_{i n f} * q_{a s} * c$ & $\begin{array}{l}q_{a s} \text { medido por um ensaio in situ e } \\
\text { reduzido por um fator de segurança } \\
\text { c relativo à colmatação e ao lençol. }\end{array}$ \\
\hline França & $\begin{array}{l}\text { Poços, } \\
\text { trincheiras }\end{array}$ & Fundo colmatado. & $A_{i n f}{ }^{*} K^{*} c$ & $\begin{array}{l}K \text { medido por um ensaio in situ } \\
\text { normalizado. } \\
\text { medida de } K \text { in situ. } \\
c \text { função da configuração da obra. }\end{array}$ \\
\hline
\end{tabular}

Fonte: Baptista et al. (2005).

O volume dimensionado para trincheira é calculado com base na maior diferença entre o volume afluente e o volume infiltrado, sendo o cálculo efetuado por um processo iterativo em que:

1) calcula-se o volume afluente com base na Equação 2.2;

2) estima-se as dimensões iniciais da trincheira, lembrando que a vazão de saída depende da superfície de infiltração, ou seja, da área lateral da trincheira;

3) calcula-se o volume infiltrado pela Equação 2.3;

4) constrói-se a curva acumulada com os volumes afluente e infiltrado;

5) identifica-se o ponto de máxima diferença entre as curvas de volumes acumulados;

6) determina-se o volume necessário de armazenamento, levando em consideração a porosidade do material de preenchimento; e 
7) compara-se o volume da trincheira com o volume de dimensionamento, se o volume da trincheira for maior ou menor que o volume dimensionado, recomeça o processo a partir do passo 2.

No que diz respeito às dimensões iniciais da trincheira, o comprimento é frequentemente imposto pela área disponível para implantação, a largura é variável, porém não pode ser muito larga porque contribui para o processo de colmatação na base, e a profundidade deve ser compatível com os ensaios e restrita ao posicionamento do lençol freático.

\subsection{3 - Execução e Manutenção}

Terminada a fase de dimensionamento, parte-se para a execução propriamente dita. Entretanto, alguns cuidados devem ser tomados para evitar um mau funcionamento do dispositivo. A seguir são apresentados alguns procedimentos, sugeridos por Souza (2002), que visam minimizar esta possibilidade.

1. Na área planejada para a infiltração deve-se evitar a utilização de equipamentos pesados, pois podem compactar o solo.

2. Após a escavação da trincheira, deve-se colocar manta geotêxtil no fundo e nos lados do dispositivo para prevenir ou minimizar o processo de colmatação no solo.

3. O material de preenchimento deve ser adicionado limpo, porque pode provocar a colmatação precoce da estrutura.

4. Um poço de observação deve ser instalado na trincheira, pois é necessário o monitoramento do seu desempenho, além de servir para medir o nível de água no interior da estrutura.

Posteriormente a execução, algumas medidas precisam ser realizadas para aumentar a vida útil da estrutura. A principal medida consiste na construção de estruturas de remoção de sedimentos, como tanques de decantação ou faixas gramadas, que têm a finalidade de 
minimizar o processo de colmatação que ocorre principalmente na base da trincheira. Este processo consiste na redução da condutividade hidráulica em função da obstrução dos poros do solo pela deposição de partículas finas que estão suspensas no líquido presente no interior da estrutura.

Outra possibilidade de colmatação se dá por meio do crescimento de algas ou pela atividade microbiológica provocada pelo aporte de nutrientes e de matéria orgânica. Contudo, em dispositivos de infiltração esta origem de colmatação, em geral, não chega a acontecer, visto que o comportamento da água no interior da estrutura é intermitente, permitindo eliminar a vida bacteriana no período seco.

Outras medidas que devem ser tomadas visando à durabilidade da estrutura são: rotina de limpeza, inspeções regulares e controle dos sedimentos durante a construção.

\subsection{4 - Trabalhos realizados sobre trincheiras de infiltração}

No Brasil, a pesquisa científica sobre trincheira de infiltração como uma medida alternativa na drenagem urbana ainda é muito restrita. A literatura nacional relata casos isolados, mas cada vez em maior número (GRACIOSA, 2005; SILVA, 2007; e SOUZA, 2002).

Souza (2002) realizou um estudo com duas trincheiras de infiltração a fim de verificar se elas podem ser utilizadas de forma efetiva no controle da geração do escoamento superficial. As trincheiras foram instaladas no interior do IPH/UFRGS em áreas diferentes.

A primeira, projetada para drenar uma rua pavimentada de $200 \mathrm{~m}^{2}$, foi construída com 0,8 $\mathrm{m}$ de largura, $1 \mathrm{~m}$ de profundidade e $10 \mathrm{~m}$ de comprimento. A segunda, projetada para receber a contribuição do volume escoado no estacionamento de $450 \mathrm{~m}^{2}$, foi construída em três módulos, onde cada módulo apresentava 0,8 $\mathrm{m}$ de largura, $1 \mathrm{~m}$ de profundidade e $3 \mathrm{~m}$ de comprimento. Ambas as trincheiras foram dimensionadas pelo método de envelopamento da chuva, adotando o tempo de retorno igual a 5 anos. 
Durante o período de monitoramento (33 meses para a trincheira I e 6 meses para a trincheira II) não ocorreu vazões excedentes, embora tenha sido observado um evento de tempo de retorno superior ao de projeto. Os resultados mostraram eficiência total dos dispositivos de infiltração, permitindo concluir que a trincheira de infiltração é um eficiente elemento de controle do escoamento na fonte.

Graciosa (2005) estudou numericamente e experimentalmente o comportamento quantitativo de duas trincheiras de infiltração, sendo uma instalada na cidade de São Carlos SP e outra na cidade de Itirapina - SP. As duas trincheiras foram construídas com 0,5 m de largura, 0,7 $\mathrm{m}$ de profundidade e $4 \mathrm{~m}$ de comprimento.

O estudo experimental feito por Graciosa (2005) serviu para avaliar a simulação computacional do processo de redistribuição em torno de trincheiras de infiltração. A simulação foi realizada através de um modelo, com o nome de BidiSul, adaptado pela autora e desenvolvido pelo Departamento de Engenharia Rural do Instituto Superior de Agronomia da Universidade Técnica de Lisboa.

Os resultados obtidos com a simulação do modelo BidiSul subestimaram a capacidade de infiltração. Uma das causas desse resultado é a desconsideração da distribuição heterogênea do tamanho dos poros do solo. Considerando que a curva de van Genuchten é, juntamente com a equação de Richards, a base do modelo computacional, divergências no ajuste dos dados observados conduziram a estimativas divergentes dos volumes infiltrados.

Outro exemplo de estudo brasileiro foi recentemente realizado na Universidade de Brasília por Silva (2007). A autora avaliou a viabilidade técnica e econômica do uso de garrafas PET em substituição aos agregados granulares usados em trincheiras de infiltração.

Para o estudo, construíram-se quatro trincheiras com condições diferentes de enchimento com garrafa PET. As trincheiras foram dimensionadas pelo mesmo método utilizado no trabalho de Souza (2002) e apresentaram dimensões iguais a 0,8 m de largura, 2 
m de comprimento e 1,8 $\mathrm{m}$ de profundidade. A viabilidade técnica foi avaliada através de ensaios oedométricos, índices físicos, sucção e pinhole test, permitindo concluir que a utilização das garrafas em sistemas de infiltração pode ser vantajosa tanto tecnicamente como sócio-economicamente, permitindo a menor custo assegurar melhores condições de infiltração.

Em relação à literatura internacional, o desenvolvimento de trabalho sobre trincheira de infiltração é bem mais significativo quando comparado ao Brasil. Como exemplo, podem ser citados os trabalhos realizados por Kuo et al. (1989), Ducheme et al. (1994), Warnaars et al. (1999) e Kronaveter et al. (2001).

Kuo et al. (1989) desenvolveram um modelo bidimensional de elemento finito para simular o fluxo transiente da água e determinar a taxa de infiltração, a profundidade da água e o armazenamento na trincheira de infiltração.

Ducheme et al. (1994) usaram um modelo de elemento finito para examinar a taxa de infiltração na trincheira, e concluiu que:

- com o nível constante de água na trincheira, a taxa de infiltração no solo diminui assintoticamente com o tempo;

- o processo de colmatação no fundo da trincheira teve um efeito limitado na taxa de infiltração; e

- a condição de umidade inicial gerou influência na taxa de infiltração.

Warnaars et al. (1999) estudaram por 33 meses o funcionamento de duas trincheiras de infiltração subterrâneas construídas na região central de Copenhagen. As trincheiras foram projetadas para receber a contribuição do escoamento proveniente de um total de $600 \mathrm{~m}^{2}$ de área pavimentada e telhado, e ambas apresentavam $16 \mathrm{~m}$ de comprimento e $0,8 \mathrm{~m}$ de altura e de largura. Durante o período de monitoramento, ocorreram 89 eventos de chuva, dos quais 7 
causaram sobrecarga na estrutura, correspondendo a uma frequência de falha de 2,6 eventos/ano ou a um período de retorno de 0,38 anos.

Kronaveter et al. (2001) desenvolveram um micro-modelo para simular o processo hidrológico em um lote urbano localizado nas planícies costeiras de Israel. Os resultados da aplicação do modelo permitiram concluir que com a instalação da trincheira de infiltração para coletar o escoamento, a infiltração total da chuva sobre a residência foi aumentada em aproximadamente $18 \%$. 


\section{Capítulo 3}

"Águas que movem moinhos são as mesmas águas que encharcam o chão e sempre voltam humildes pro fundo da terra."

Guilherme Arantes

\section{3 - DINÂMICA DA ÁGUA DO SOLO}

A elaboração de uma metodologia padrão de dimensionamento de trincheiras de infiltração é a primeira etapa para viabilizar sua utilização em grande escala. No entanto, para que isso aconteça, ainda há muitos aspectos a serem estudados, como por exemplo, o comportamento hidráulico da trincheira de infiltração em meio não saturado.

Por isso, como forma de ampliar os conhecimentos acerca das propriedades hidráulicas que tratam da dinâmica da água em meio não saturado e transiente, serão abordadas, nos itens 3.1 a 3.3 deste capítulo, as propriedades relacionadas com a retenção de água no solo. Os itens 3.4 e 3.5 tratarão, respectivamente, do movimento e da infiltração da água no solo, dando ênfase a infiltração horizontal.

\section{1 - Potencial de água no solo}

Define-se o conceito de potencial total de água no solo, como sendo "a somatória dos trabalhos realizados quando a unidade de massa de água em estado padrão é levada isotérmica, isobárica e reversivelmente para o estado considerado no solo" (REICHARDT, 1985).

O potencial total de água no solo, em condições não saturadas, é resultante da soma da energia causada por um conjunto de fenômenos (Equação 3.1). 


$$
\phi=\phi_{p}+\phi_{n}+\psi+\phi_{g}+\phi_{T}+\phi_{o}
$$

Equação 3.1

em que $\phi$ é o potencial total de água no solo, em $\mathrm{mH}_{2} \mathrm{O} ; \phi_{p}$ é o potencial de pressão, em $\mathrm{mH}_{2} \mathrm{O} ; \phi_{n}$ é o potencial pneumático, em $\mathrm{mH}_{2} \mathrm{O} ; \psi$ é o potencial matricial, em $\mathrm{mH}_{2} \mathrm{O} ; \phi_{g}$ é o potencial gravitacional, em $\mathrm{mH}_{2} \mathrm{O} ; \phi_{T}$ é o potencial de temperatura, em $\mathrm{mH}_{2} \mathrm{O}$; e $\phi_{o}$ é o potencial osmótico, em $\mathrm{mH}_{2} \mathrm{O}$.

Como os processos que ocorrem no solo são aproximadamente isotérmicos, a componente térmica não tem importância. Além disso, na maioria dos problemas práticos em que se estuda a infiltração, considerações são feitas em relação ao solo, as quais são: solo não expansivo, pressão atmosférica atuante nos vazios do solo e água em circunstâncias ideais (pura). Nestas condições, o potencial total é dado pelo somatório entre o potencial gravitacional e matricial, já que os outros componentes não intervêm no comportamento do solo.

Libardi (2005) define o potencial gravitacional como a diferença do produto da aceleração da gravidade pela distância vertical. Portanto, em estudos de infiltração horizontal, onde não há variação da profundidade, o potencial gravitacional é constante.

Segundo Reichardt (1985) o potencial matricial decorre de forças capilares e de adsorção que ocorrem devido à influência mútua entre a água e as partículas sólidas. As forças atraem e fixam a água para estados de energia menores do que o estado livre (sob a pressão atmosférica). Portanto, o potencial matricial ( $\psi$ ) é sempre negativo. Este potencial foi também denominado potencial capilar, tensão da água no solo, sucção ou pressão negativa.

Experimentalmente, há inúmeras maneiras de medir a influência do conteúdo de água no solo sobre o potencial da água. Por isso, como forma de ilustrar cada método e suas características principais, seguem, na Tabela 3.1, os métodos de medição de potencial de água no solo. 
Tabela 3.1- Métodos de medida de sucção.

\begin{tabular}{|c|c|c|}
\hline Método de Sucção & $\begin{array}{c}\text { Faixa de Medida e } \\
\text { tempo aproximado de } \\
\text { equilíbrio }\end{array}$ & Observações \\
\hline $\begin{array}{l}\text { Funil de pedra porosa } \\
\qquad \text { (matricial) }\end{array}$ & $\begin{array}{c}0 \text { a } 70 \mathrm{kPa} \\
\text { (horas) }\end{array}$ & $\begin{array}{l}\text { - sucção é aplicada diretamente a amostra; e } \\
\text { - bom para baixas sucções onde a precisão da } \\
\text { câmara é limitada. }\end{array}$ \\
\hline $\begin{array}{c}\text { Câmara de pressão } \\
\text { (matricial) }\end{array}$ & $\begin{array}{l}0 \text { a } 1.500 \mathrm{kPa} \\
\text { (dias) }\end{array}$ & $\begin{array}{l}\text { - emprega a técnica de translação de eixos; } \\
\text { - depende da capacidade da pedra porosa } \\
\text { (pressão de entrada de ar); e } \\
\text { - continuidade da fase de ar. }\end{array}$ \\
\hline Tensiômetro & $\begin{array}{c}0 \text { a } 70 \mathrm{kPa} \\
\text { (minutos) }\end{array}$ & $\begin{array}{l}\text { - tempo de resposta: depende da condutância } \\
\text { da pedra porosa; e } \\
\text { - existem tensiômetros baseados em princípio } \\
\text { osmóticos. }\end{array}$ \\
\hline Papel filtro & $\begin{array}{c}30 \text { a } 30.000 \mathrm{kPa} \\
\text { (7 dias) }\end{array}$ & $\begin{array}{l}\text { - depende do contato entre o solo; } \\
\text { - necessita calibração do papel filtro; } \\
\text { - evitar formação de fungos; e } \\
\text { - pesagem (precisão de } 0,0001 \mathrm{~g} \text { ) }\end{array}$ \\
\hline Princípios osmóticos & $\begin{array}{c}200 \text { a } 1.600 \mathrm{kPa} \\
\text { (horas) }\end{array}$ & $\begin{array}{c}\text { - solo em contato com solução com } \\
\text { concentração conhecida através de membrana } \\
\text { seletiva; } \\
\text { - solução de PoliEtilenoGlicol (PEG); e } \\
\text { - útil para instalar e controlar sucção em } \\
\text { ensaios. }\end{array}$ \\
\hline
\end{tabular}

Fonte: Vilar (2002) adaptado por Silva (2005).

\section{2 - Cálculo da água no solo}

Dois pontos estão intimamente ligados ao cálculo da água no solo: o conteúdo e a armazenagem de água no solo. Por isso, ambos os assuntos serão tratados, respectivamente, nos subitens 3.2.1 e 3.2.2.

\subsection{1 - Conteúdo de água no solo}

O conhecimento do conteúdo de água no solo, comumente chamado de umidade, é imprescindível a qualquer estudo que envolva as propriedades do sistema solo-água. Sua determinação pode ser feita por métodos diretos que estimam a umidade a partir da remoção da água da matriz do solo e por métodos indiretos que utilizam propriedades físicas do solo que sejam proporcionais ao conteúdo de água presente nele. 
Entre as propriedades físicas utilizadas têm-se: resistência ou capacitância do solo, condutividade térmica, número de nêutrons termalizados, potencial matricial, constante dielétrica relativa, entre outras. Segundo Medeiros et al. (2007), a técnica que utiliza a constante dielétrica relativa, chamada de TDR (Time Domain Reflectometry), vem despertando grande interesse nos últimos anos. Para Coelho (2006) o interesse na aplicação da TDR é decorrente desta ser um método não-destrutivo, exato na medição da umidade e devido à possibilidade de automação da coleta de dados.

O princípio de funcionamento da TDR é baseado na medição do tempo de emissão e recepção de um pulso eletromagnético que se propaga em uma haste metálica inserida no solo, sendo o tempo de propagação bastante sensível ao conteúdo de água no solo, dada a grande diferença entre as constantes dielétricas da água e dos outros constituintes do solo. Numericamente, o funcionamento da TDR é expresso pela Equação 3.2.

$$
k=\left(\frac{c_{v} \cdot t_{p}}{2 \cdot L_{T D R}}\right)^{2}
$$

em que $c_{v}$ é a velocidade da luz no vácuo, em $\mathrm{m} \cdot \mathrm{s}^{-1} ; t_{p}$ é o tempo de propagação do pulso, em $\mathrm{s} ; L_{T D R}$ é o comprimento da haste metálica, em m; e $k$ é a constante dielétrica relativa, adimensional.

O equipamento de TDR é constituído de um emissor de pulsos, cabos, sondas e um interpretador de sinal que contabiliza o tempo de emissão e recepção do pulso eletromagnético (CICHOTA, 2003). Em relação às sondas, diversos tipos são estudados e desenvolvidos, tais como as sondas coaxiais de duas ou três hastes, as segmentadas e as espirais (MANIERI et al., 2007). Contudo, quando se deseja medir simultaneamente a umidade em várias camadas, sem precisar cavar uma vala, é recomendável utilizar as sondas segmentadas ou espirais. 
Assim como qualquer outro método de medição indireta da umidade, a TDR para ser usada necessita de uma curva de calibração específica para cada solo, o que para este método é a sua principal desvantagem em virtude da composição atípica de alguns solos. Entretanto, Topp et al. (1980), estudando cinco tipos de solos, propuseram uma relação empírica entre o umidade volumétrica e a constante dielétrica relativa, a qual para alguns autores (GRANTZ et al., 1990 e SOUZA e MATSURA, 2002) é considerada como "Equação Universal" de calibração de equipamentos de TDR (Equação 3.3 ou Equação 3.4).

$$
k=3,03+9,3 \cdot \theta+146 \cdot \theta^{2}+76,7 \cdot \theta^{3} \quad \text { Equação } 3.3
$$

ou

$$
\theta=0,053+0,0292 \cdot k-5,5 \cdot 10^{-4} \cdot k^{2}+4,3 \cdot 10^{-6} \cdot k^{3} \quad \text { Equação } 3.4
$$

em que $k$ é a constante dielétrica relativa, adimensional; e $\theta$ é a umidade volumétrica, em $\mathrm{m}^{3} \cdot \mathrm{m}^{-3}$

Ao mesmo tempo em que alguns trabalhos aceitam o universalismo da equação proposta por Topp et al. (1980), diversos trabalhos relatam discordâncias entre esta equação e a curva calibrada. Um dos motivos da falta de concordância é a variação nos atributos físicoquímicos do solo, tais como granulometria (teor de argila), densidade e constituição físicoquímica (CICHOTA, 2003). Desta forma, Pereira et al. (2006) afirmam que atualmente não há curva definida como padrão para calibração, porém existem pesquisas que buscam sistematizá-la (MEDEIROS et al., 2007; SOUZA et al., 2006; e VILLWOCK et al., 2004).

A calibração do TDR é feita por uma relação entre a umidade e a permissividade dielétrica expressa através de modelos empíricos, semi-empíricos ou físicos. Segundo Tommaselli (1997) os ajustes empíricos são os mais utilizados e, quase sempre, se utilizam de uma equação polinomial cúbica sem nenhuma análise estatística. Por isso, a depender do nível de acurácia do trabalho, é necessário realizar uma calibração para cada situação de uso. 
De acordo com a literatura nacional, nenhum trabalho foi ou está sendo realizado considerando a utilização da TDR no monitoramento da umidade em trincheiras de infiltração ou em estruturas com o mesmo comportamento hidráulico (sulcos de irrigação). Em relação à literatura internacional, alguns trabalhos utilizam a TDR para a estimativa da umidade em uma única profundidade (DAMODHARA et al., 2008; GVITRTZMAN et al., 2008), entretanto, não se tem conhecimento de algum estudo que aborde a mensuração da umidade no perfil do solo pela TDR em trincheiras de infiltração ou sulcos de irrigação.

\subsection{2 - Armazenagem da água no solo}

O valor de armazenamento de água no solo, expresso em termos de altura de água, representa a quantidade de água existente em qualquer camada do solo. Numericamente, este valor é dado pelo produto entre a umidade e a profundidade do solo. Porém em condições reais, onde o conteúdo de água do solo não é o mesmo para as várias camadas constituintes do solo, ele é dado pelo somatório entre o produto dos incrementos do perfil de solo e seus respectivos conteúdos de água. Matematicamente este valor é expresso pela Equação 3.5.

$$
h=\int_{z_{i}}^{z_{k}} \theta(z) \cdot d z
$$

em que $\theta(z)$ é a função representativa do perfil de conteúdo de água, $\mathrm{em}^{3} \cdot \mathrm{m}^{-3} ; d z$ é a diferencial da variável independente $z$, em m; e $z_{i}$ e $z_{k}$ são duas profundidades arbitrárias quaisquer, sendo $z_{k}$ maior que $z_{i}$.

Conforme se observa na Equação 3.5, para definir o valor da armazenagem de água num perfil de solo é necessário conhecer, analiticamente, a função $\theta(z)$. Entretanto, segundo Libardi (2005), na maioria das situações não se consegue qualquer forma analítica integrável de $\theta(z)$. Desta forma, estimativas da armazenagem de água no solo só podem ser obtidas por regras de integração numéricas. Dentre estas, utiliza-se normalmente a Regra do Trapézio e a 
Regra de Simpson. De acordo com Libardi (2005), para caso de perfis de conteúdo de água em solos heterogêneos, a regra de Simpson é a mais adequada.

A regra de Simpson assume que ao longo de três pontos consecutivos, igualmente espaçados, o conteúdo de água varia quadraticamente $\operatorname{com} z$ de acordo com a Equação 3.6.

$$
\theta=a+b \cdot z+c \cdot z^{2} \quad \text { Equação } 3.6
$$

em que $a, b$ e $c$ são parâmetros da equação.

Aplicando a Equação 3.6 na Equação 3.5, a armazenagem do solo é dada pelo cálculo integral demonstrado na Equação 3.7

$$
h=\int_{Z_{i}}^{Z_{k}} \theta(Z) \cdot d Z=\int_{Z_{i}}^{Z_{i+2}}\left(a+b z+c z^{2}\right) \cdot d z=\frac{\Delta z}{3}\left[\theta\left(z_{i}\right)+4 \theta\left(z_{i+1}\right)+\theta\left(z_{i+2}\right)\right] \quad \text { Equação } 3.7
$$

Considerando a situação que se deseja medir a armazenagem de água entre a superfície do solo e uma profundidade $L$, isto é, $z_{i}$ igual a zero e $z_{k}$ igual a $L$, o valor do conteúdo de água na superfície $\left(z_{i}=0\right)$ é considerado igual ao valor do conteúdo de água mais próximo a superfície.

No que se refere aos dispositivos de infiltração, um cálculo que pode ser obtido através da armazenagem de água no solo é a infiltração acumulada. Desta forma, levando-se em consideração a variação do conteúdo de água em relação à profundidade do solo, a infiltração acumulada é dada pela Equação 3.8. Cabe ressaltar que a Regra de Simpson também é válida para a Equação 3.8.

$$
I=\int_{Z_{i}}^{Z_{k}}\left(\theta_{f}-\theta_{i}\right) \cdot d z
$$

em que $I$ é a infiltração acumulada, em $\mathrm{m}^{3} \cdot \mathrm{m}^{-2}$; e $\theta_{f}$ e $\theta_{i}$ são os conteúdo de água ao final e ao início, respectivamente, da alimentação ao dispositivo, $\mathrm{em}^{3} \cdot \mathrm{m}^{-3}$. 


\section{3 - Curva de retenção}

A relação entre o teor de água no solo ou umidade $(\theta)$ e o potencial matricial do solo $(\psi)$ é chamada de curva de retenção ou curva característica de água no solo. Sua determinação é de suma importância não somente para agricultura, mas também para hidrologia, pois, de acordo com Schmugge et al. (1980), a partição da água da chuva nos componentes de escoamento superficial e de infiltração está relacionada com o teor de água no solo.

A curva de retenção, por refletir a retenção da água nos inúmeros poros do solo com diâmetros e formatos muitos variados, é, do ponto de vista prático, uma função contínua com formato geral conhecido, sendo comumente expressa em termos de um modelo matemático (CICHOTA e LIER, 2004).

Segundo Leong e Rahardjo (1997), vários modelos matemáticos têm sido propostos e quase todos são derivados da seguinte equação generalizada (Equação 3.9).

$$
a_{1} \cdot \Theta^{b 1}+a_{2} \cdot e^{a_{3} \cdot \Theta^{b_{1}}}=a_{4} \cdot \psi^{b_{1}}+a_{5} e^{a_{6} \psi^{b_{2}}}+a_{7} \quad \text { Equação } 3.9
$$

em que $a_{1}, a_{2}, a_{3}, a_{4}, a_{5}, a_{6}, a_{7}, b_{1}$ e $b_{2}$ são constantes; e $\Theta$ é a saturação efetiva, adimensional.

Na Tabela 3.2, estão apresentadas as relações propostas e as simplificações adotadas por Leong e Rahardjo (1997). Merece destaque a equação proposta por van Genuchten, pois, segundo Costa et al. (2008), vários trabalhos estudaram diferentes modelos para descrever a relação entre teor de água no solo e potencial matricial em solos não saturados e o que proporcionou maior valor de $\mathrm{R}^{2}$ foi o proposto por van Genuchten (1980).

Tabela 3.2- Modelos matemáticos que expressam o processo de retenção de água no solo.

\begin{tabular}{ccccc}
\hline Autor & Equação & Simplificações & $\begin{array}{c}\text { Termos } \\
\text { auxiliares }\end{array}$ & Legenda \\
\hline $\begin{array}{c}\text { Brooks e Corey } \\
(1964)\end{array}$ & $\Theta=\left(\frac{\psi_{b}}{\psi}\right)^{\lambda}$ & $a_{2}=a_{5}=a_{7}=0$ & $b_{2}=-\lambda$ & $\begin{array}{c}\psi_{b}=\text { sucção de } \\
\text { entrada de ar. } \\
\end{array}$ \\
$\begin{array}{c}\text { Van Genuchten } \\
(1980)\end{array}$ & $\Theta=\left[\frac{1}{1+(\alpha \cdot \psi)^{n}}\right]^{m}$ & $a_{1}=a_{7}$ & $a_{4} / a_{1}=\alpha^{n}$ & $\lambda=$ constante. \\
\hline & $a_{2}=a_{5}=0$ & $b_{1}=m$ & $\begin{array}{c}a_{i}, m \text { e } n \text { são } \\
\text { constantes. }\end{array}$ \\
\end{tabular}


Tabela 3.2 - Modelos matemáticos que expressam o processo de retenção de água no solo.

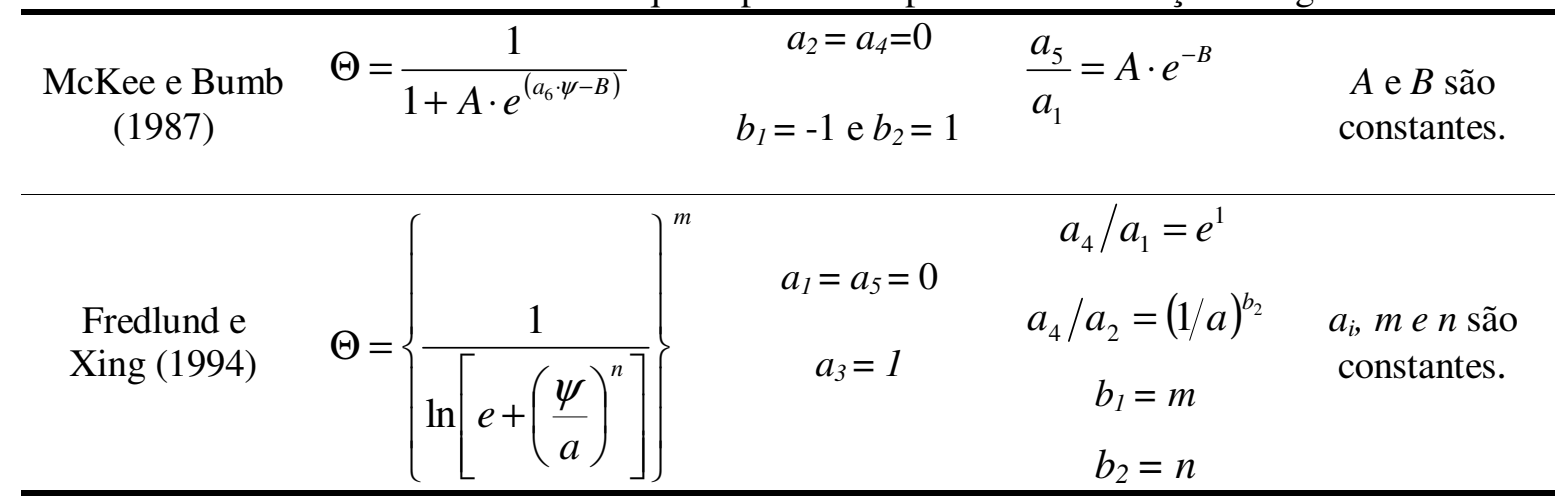

Fonte: Leong e Rahardjo (1997).

A relação expressa pela curva de retenção pode ser obtida por dois processos: secagem da amostra previamente saturada ou umedecimento gradual da amostra, inicialmente seca ao ar. Cada processo fornece uma curva contínua, as quais são diferentes em virtude do fenômeno de histerese.

Dentre outros aspectos, a histerese decorre, segundo Reichardt (1985), da nãouniformidade dos poros individuais com relação a fenômenos capilares, de bolhas de ar que permanecem fixas dentro dos macroporos e causam decréscimos do teor de umidade e da contração e expansão de argilas durante secamento e molhamento.

Segundo o mesmo autor, a histerese pode causar problemas na descrição matemática do fluxo de água no solo. Por isso é aconselhável utilizar uma curva específica para descrever o fenômeno estudado, isto é, para infiltração e redistribuição, utilizar a curva obtida pelo processo de umedecimento, e para evaporação, a curva determinada pelo processo de drenagem. Entretanto, conforme citam Costa et al. (2008), vários aspectos ligados ao teor de água no solo são negligenciados na obtenção da curva de retenção, e um deles é a histerese.

Como forma de exemplificar a histerese, é ilustrada na Figura 3.1 a curva de retenção de um solo siltoso. Nesta figura também são identificados as suas principais características, tais como: valor de entrada de ar (correspondente à sucção na qual a água presente nos maiores poros começa a sair), umidade volumétrica residual (umidade em que um grande 
valor de sucção é necessário para remover uma quantidade de água do solo - $\theta_{r}$ ) e a umidade volumétrica para o estado saturado $\left(\theta_{s}\right)$.

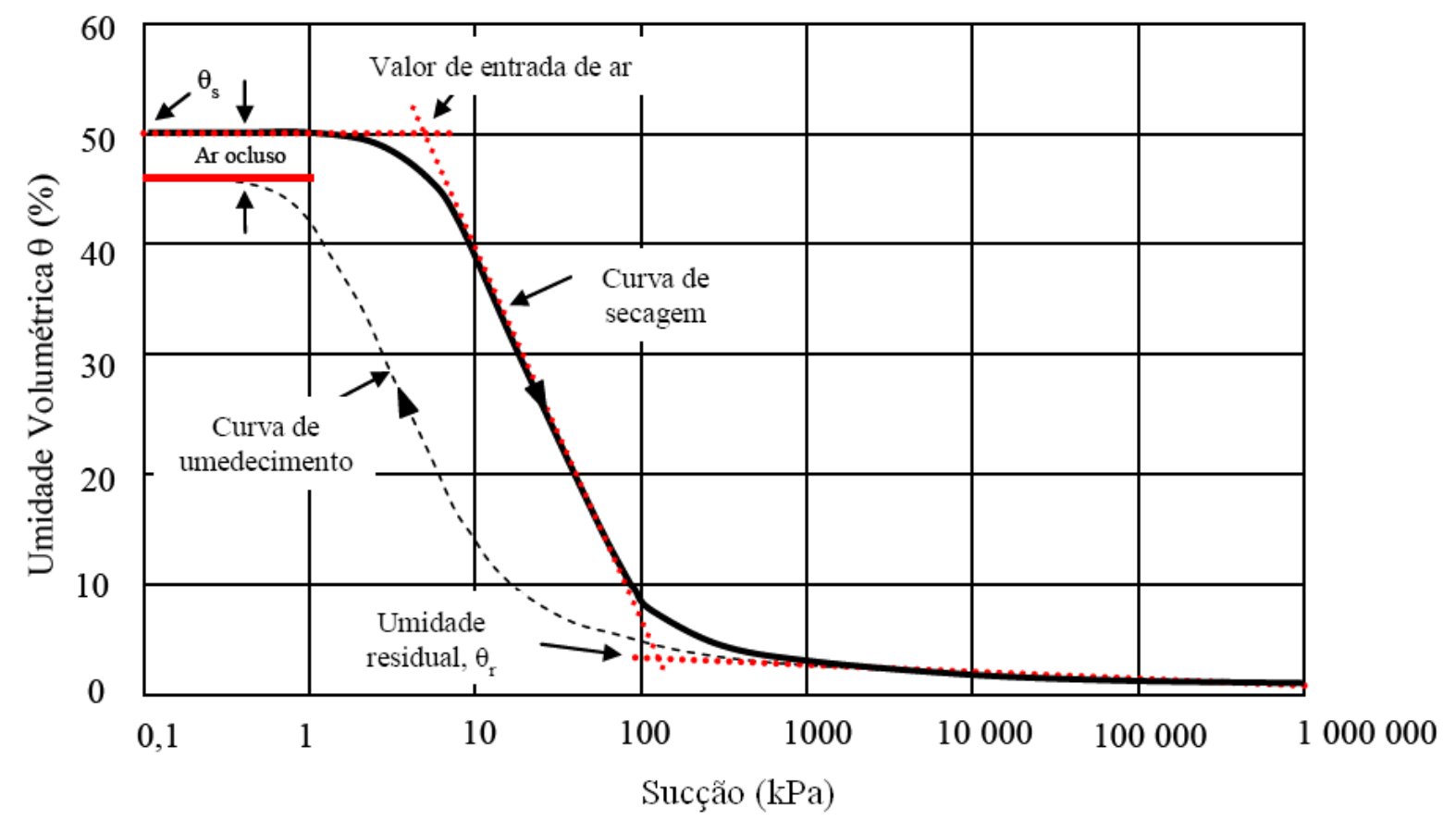

Figura 3.1 - Curva de retenção determinada para um solo caracterizado como siltoso. Fonte: Fredlund e Xing (1994).

\subsection{1 - Estrutura heterogênea na curva de retenção}

As curvas de retenção são frequentemente avaliadas sem incluir a estrutura heterogênea dos poros do solo que representam. Dessa forma, as expressões que representam as curvas de retenção são geralmente derivadas de modelos matemáticos (Tabela 3.2) que assumem a distribuição unimodal do tamanho dos poros do solo, ou seja, com o máximo da distribuição dos poros correspondendo a um único diâmetro característico.

Entretanto, de acordo Zurmuhl e Durner (1998), a utilização destes modelos pode ser insatisfatória, pois na maioria dos solos naturais a curva de retenção próxima a saturação apresenta uma declividade acentuada, onde o modelo unimodal não consegue reproduzir adequadamente o processo de retenção. 
Outro problema no uso de modelos com distribuição unimodal foi verificado por Mallants et al. (1997), os quais investigaram a aplicabilidade de curvas de retenção em solos areno-argilosos localizados no leste de Lovaina, Bélgica, e concluíram que curvas de retenção unimodal subestimam a umidade observada no solo tanto perto da saturação como na variedade de mesoporos (poros de tamanho intermediário que são responsáveis pela distribuição da água no espaço poroso).

Deste modo, com o objetivo de ganhar mais flexibilidade e superar as limitações da descrição unimodal da curva de retenção, alguns estudos (DURNER, 1994; e MENDIONDO, 2001) foram realizados para descrevê-la com distribuição bimodal. Nestes estudos, a bimodalidade é representada pela sobreposição de duas equações unimodais, descritas pelo modelo de van Genuchten, onde cada equação descreve uma distribuição máxima do tamanho das partículas do solo. Desta forma, os poros do solo são considerados como um sistema dual, onde uma distribuição de poros se ajusta perto da saturação, representando os macro e mesoporos ou inter-agregados, e outra distribuição em uma variedade de sucção, representando os microporos ou intra-agregados (OTHMER et al., 1991).

A respeito dos dois estudos realizados sobre bimodalidade, acredita-se que o modelo alternativo proposto por Mendiondo (2001) é mais apropriado para o trabalho em questão por dois motivos: 1) por ser uma metodologia aplicada e avaliada em solos brasileiros, o que de certa forma aproxima mais as características entre os solos; e 2) pela possibilidade da metodologia proposta por Durner sobreparametrizar o ajuste.

Mendiondo (2001) utilizando a conceituação hidráulica do meio não saturado, sob a idéia de "pseudo-saturação", e introduzindo formulações da natureza heterogênea do solo no modelo de van Genuchten (1980), desenvolveu a curva de retenção apresentada na Equação 3.10 . 


$$
\theta=\theta_{r}+\frac{\left(\theta_{p s}-\theta_{r}\right)}{\sqrt{\left.1+\left(\alpha_{1} \cdot|\psi|\right)^{n_{b}}\right]^{m_{b}}}}+\frac{\left(\theta_{s}-\theta_{p s}\right)}{\sqrt{\left.1+\left(\alpha_{2} \cdot|\psi|\right)^{n_{b}}\right]^{m_{b}}}}
$$

em que $\theta_{r}, \theta_{p s}$ e $\theta_{s}$ são, respectivamente, a umidade residual, a umidade de pseudo-saturação e a umidade de saturação, em $\mathrm{m}^{3} \cdot \mathrm{m}^{-3} ; \alpha_{1}$ e $\alpha_{2}$ são parâmetros de ajuste dos microporos e dos macroporos da curva de retenção bimodal, em $\mathrm{m}^{-1}$; e $n_{b}$ e $m_{b}$ são coeficientes de ajuste da curva de retenção bimodal, adimensionais, para os quais é válido a relação $m_{b}=1-1 . n_{b}{ }^{-1}$.

\section{4 - Movimento da água no solo}

Sob condições isotérmicas e estacionárias o movimento da água no solo é quantificado por duas equações: equação de Darcy, para solos saturados, e equação de Darcy-Buckingham, para solos saturados e não saturados. Já sob condição não estacionária, a qual ocorre na maioria das situações da natureza, o movimento é quantificado através da combinação entre a equação de Darcy-Buckingham e a equação da continuidade, a qual se denomina equação de Richards.

Deste modo, como forma de descrever as equações que regem o movimento da água no solo, sob condição estacionária ou não estacionária, este item apresenta nos subitens 3.4.1 a 3.4.3 uma breve descrição das equações de Darcy, de Darcy-Buckingham e de Richards, respectivamente.

\subsection{1 - Equação de Darcy}

O movimento da água no estado líquido ocorre sempre que existirem diferenças de potencial nos diferentes pontos dentro do sistema. Este movimento dá-se no sentido de decréscimo de potencial, isto é, a água sempre se move de pontos de maior potencial para pontos de menor potencial (REICHARDT, 1985). 
$\operatorname{Darcy}^{5}$ (1856 apud Prevedello, 1996), estudando a infiltração vertical da água em colunas de areia saturadas para fins de abastecimento, verificou que a densidade de fluxo, isto é, o volume de água que passa por unidade de área em função do tempo, é proporcional ao gradiente do potencial total do solo (Equação 3.11).

$$
\vec{q}=-K_{s} \cdot\left(\frac{\partial \phi}{\partial x}+\frac{\partial \phi}{\partial y}+\frac{\partial \phi}{\partial z}\right)
$$

em que $q$ é o vetor densidade de fluxo de água, $\mathrm{em} \mathrm{m}^{3} \cdot \mathrm{m}^{-2} \cdot \mathrm{s}^{-1} ; K_{s}$ é a condutividade hidráulica saturada do solo, em m.s ${ }^{-1} ; \phi$ é o potencial total da água, em $\mathrm{mH}_{2} \mathrm{O}$; e $x, y$ e $z$ são direções ortogonais, em m.

O sinal negativo na Equação 3.11 é devido ao sentido do fluxo ser inverso ao do gradiente, sendo a coordenada $z$ positiva no sentido de baixo para cima.

A condutividade hidráulica saturada $\left(K_{s}\right)$ é uma propriedade do meio poroso que traduz a rapidez com que determinado líquido atravessa o meio. Em virtude de ter sido admitido que o meio é isotrópico em relação a $K_{s}$, esta não depende da direção dentro do meio, sendo, portanto, escalar.

Segundo Prevedello (1996) não é fácil relacionar o valor de $K_{s}$ com as características do meio poroso. Um solo muito poroso pode ser condutivo se seus poros forem grandes e bem interconectados, ou quase impermeáveis se seus poros são muito pequenos, como ocorre em solos argilosos.

A determinação da condutividade hidráulica saturada do solo pode ser feita por métodos de laboratório e de campo. No laboratório é possível atingir um grau de precisão e refinamento muito superior ao campo, devido ao elevado grau de controle das condições experimentais. Por outro lado, nas condições de campo, apesar do grau de complexidade, as medidas são feitas em condições naturais e com perturbação mínima do solo.

\footnotetext{
${ }^{5}$ DARCY, H. (1856) Les fontaines publiques de La ville de Dijon. Peis, Dalmont, 647p.
} 
De forma geral, pode-se citar os seguintes métodos para determinação de $K_{s}$ : permeâmetro de carga constante e de carga variável, infiltrômetro de tensão e método do perfil instantâneo. A escolha do método depende de fatores como disponibilidade de equipamentos, natureza do solo, objetivo da determinação, entre outros.

Cabe ressaltar, que geralmente a permeabilidade é aplicada como sinônimo de condutividade hidráulica saturada. Porém, mesmo sendo uma propriedade relacionada com a capacidade de um material transmitir fluxo, ela é dada por um dimensional de comprimento ao quadrado, diferente da condutividade hidráulica saturada que representa velocidade (Equação 3.12).

$$
K_{s}=K_{e} \cdot \frac{\rho \cdot g}{v}
$$

em que $K_{s}$ é a condutividade hidráulica saturada, em $\mathrm{m} \cdot \mathrm{s}^{-1} ; K_{e}$ é a permeabilidade específica, em $\mathrm{m}^{2} ; \rho$ é a massa específica do fluido, em $\mathrm{kg} . \mathrm{m}^{-3} ; \nu$ é a viscosidade dinâmica do fluido, em $\mathrm{kg} \cdot \mathrm{m}^{-1} \cdot \mathrm{s}^{-1}$; e $g$ é a aceleração da gravidade, em $\mathrm{m} \cdot \mathrm{s}^{-2}$.

\subsection{2 - Equação de Darcy-Buckingham}

A equação de Darcy, Equação 3.11, foi desenvolvida para quantificar o movimento de um líquido que satura em meio poroso. Embora o estudo dinâmico da água em solo saturado seja importante, a maioria dos processos que envolvem o movimento de água no solo ocorre com o solo em condições não saturadas.

De acordo com Reichardt (1985), os processos de fluxo não saturado são, de maneira geral, complicados e de difícil descrição quantitativa. Variações da umidade do solo durante o movimento envolvem funções complexas entre as variáveis $\psi$ e $K$. 
Atento a esta realidade Buckinghan ${ }^{6}$ (1907 apud Libardi, 2005), propôs uma equação com base na analogia de fluxos de calor, chamada de equação de Buckinghan, que quantifica o movimento da água em condição de solo não saturado (Equação 3.13).

$$
\vec{q}=-K(\theta) \cdot\left(\frac{\partial \psi(\theta)}{\partial x}+\frac{\partial \psi(\theta)}{\partial y}+\frac{\partial \psi(\theta)}{\partial z}\right)
$$

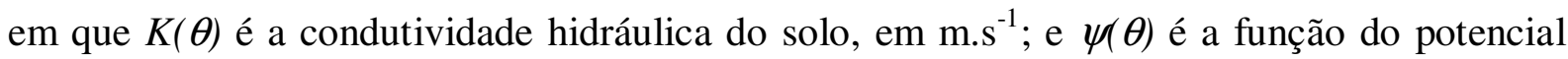
matricial em função da umidade volumétrica, que na ocasião da proposição da equação foi chamado de potencial capilar, em $\mathrm{mH}_{2} \mathrm{O}$.

A Equação 3.13 apresenta a limitação de ser válida apenas para o movimento da água no solo na direção horizontal ou para o caso no qual o efeito da gravidade é desprezível. Desta forma, Richards ${ }^{7}$ (1928 apud Libardi, 2005), redefiniu a Equação 3.13 introduzindo o potencial gravitacional. Assim, a Equação 3.13 foi reescrita na Equação 3.14, a qual se denomina de equação de Darcy-Buckingham.

$$
\vec{q}=-K(\theta) \cdot\left[\frac{\partial\left(\phi_{g}+\psi(\theta)\right)}{\partial x}+\frac{\partial\left(\phi_{g}+\psi(\theta)\right)}{\partial y}+\frac{\partial\left(\phi_{g}+\psi(\theta)\right)}{\partial z}\right] \quad \text { Equação } 3.14
$$

em que $\phi_{g}$ é o potencial gravitacional do solo, em $\mathrm{mH}_{2} \mathrm{O}$.

A condutividade hidráulica não saturada $K(\theta)$, presente na Equação 3.14, é altamente dependente do teor de água no solo e do potencial matricial, por isso também pode ser escrita como $K(\psi)$. Apresenta seu valor máximo no solo saturado $\left(K_{o}\right)$ e decresce acentuadamente com a diminuição da umidade.

Segundo Prevedello (1996), vários modelos (CHILDS e COLLIS-GEORGE, 1950; BURDINE, 1953; WYLLIE e GARDENER, 1958; FARRELL e LARSON, 1972; MUALEN, 1976; e VAN GENUCHTEN, 1980) foram apresentados para predizer a condutividade

\footnotetext{
${ }^{6}$ BUCKINGHAN, E. (1907) Studies on the movement of soil moisture. Bull. 38. USDA, Bureau of Soils, Washington D.C.

${ }^{7}$ RICHARDS, O. W. (1928). Potentially unlimited multiplication of yeast with constant environment, and the limiting of growth by changing environment. Bot Gaz, p. $86-93$.
} 
hidráulica não saturada do solo. Dentre esses, o modelo desenvolvido por van Genuchten (1980), a partir do modelo de Mualem (1976), vem sendo bastante utilizado (Equação 3.15).

$$
K(\theta)=K_{o}\left(\frac{\theta-\theta_{r}}{\theta_{s}-\theta_{r}}\right)^{1 / 2} \cdot\left[1-\left(1-\left(\frac{\theta-\theta_{r}}{\theta_{s}-\theta_{r}}\right)^{1 / m}\right)^{m}\right]^{2}
$$

em que $m=1-1 . n^{-1}$ e $0<m<1$.

Como dito acima, a condutividade hidráulica também pode ser expressa em termos do potencial matricial (Equação 3.16).

$$
K(\psi)=K_{o} \frac{\left[1-(\alpha \cdot|\psi|)^{n-1}\left[1+(\alpha \cdot|\psi|)^{n}\right]^{-m}\right]^{2}}{\left.11+(\alpha \cdot|\psi|)^{n}\right]^{n / 2}}
$$

Segundo Alonso (2005), a condutividade hidráulica estimada pelos modelos apresenta bastante variabilidade, o que segundo o mesmo autor e Carvalho (2006) pode ser, entre outros fatores, em virtude da heterogeneidade das amostras no que diz respeito à distribuição das partículas. Assim, como forma de minimizar esta variabilidade e considerando que dado um sistema heterogêneo quanto à textura um comportamento heterogêneo também é esperado quanto à hidráulica que rege o movimento de água no solo, Mendiondo (2001) estabeleceu a Equação 3.17 e a Equação 3.18 para determinarem, respectivamente, a condutividade hidráulica nos micro e macroporos (bimodalidade).

$$
K_{I}(\theta)=K_{s} \cdot K_{p s}\left(\frac{\theta-\theta_{r}}{\theta_{p s}-\theta_{r}}\right)^{1 / 2} \cdot\left[1-\left(1-\left(\frac{\theta-\theta_{r}}{\theta_{p s}-\theta_{r}}\right)^{1 / m_{b}}\right)^{m_{b}}\right]^{2} \quad \text { Equação } 3.17
$$

em que $K_{I}(\theta)$ é a condutividade hidráulica do microporos, em função da umidade, em m.s ${ }^{-1}$; $K_{p s}$ é uma constante que indica condição do máximo comportamento hidráulico exercido pelos microporos, adimensional. 


$$
K_{I I}(\theta)=K_{s}\left(\frac{\theta-\theta_{p s}}{\theta_{s}-\theta_{p s}}\right)^{1 / 2} \cdot\left[1-\left(1-\left(\frac{\theta-\theta_{r}}{\theta_{s}-\theta_{r}}\right)^{1 / m_{b}}\right)^{m_{b}}\right]^{2}
$$

em que $K_{I I}(\theta)$ é a condutividade hidráulica do macroporos, em função da umidade, em $\mathrm{m} . \mathrm{s}^{-1}$.

Assim, como para o modelo de van Genuchten, onde a condutividade hidráulica pode ser expressa em função do potencial matricial, Mendiondo (2001) estabeleceu a Equação 3.19 e a Equação 3.20 que determinam, respectivamente, a condutividade hidráulica nos micro e macroporos.

$$
K_{I}(\psi)=K_{p s} \cdot K_{o} \frac{\left[1-\left(\alpha_{1} \cdot|\psi|\right)^{n_{b}-1}\left[1+\left(\alpha_{1} \cdot|\psi|\right)^{n_{b}}\right]^{-m_{b}}\right]^{2}}{\left[1+\left(\alpha_{1} \cdot|\psi|\right)^{n_{b}}\right]^{n_{b} / 2}}
$$

em que $K_{I}(\psi)$ é a condutividade hidráulica dos microporos, em função do potencial matricial, em m.s. ${ }^{-1}$.

$$
K_{I I}(\psi)=K_{o} \frac{\left[1-\left(\alpha_{2} \cdot|\psi|\right)^{n_{b}-1}\left[1+\left(\alpha_{2} \cdot|\psi|\right)^{n_{b}}\right]^{-m_{b}}\right]^{2}}{\left[1+\left(\alpha_{2} \cdot|\psi|\right)^{n_{b}}\right]^{n_{b} / 2}}
$$

em que $K_{I I}(\psi)$ é a condutividade hidráulica dos macroporos em função do potencial matricial, em m.s. ${ }^{-1}$.

$\mathrm{O}$ valor de $K_{p s}$ presente na Equação 3.17 e na Equação 3.19 é estimado com base no $\theta_{p s}$ e em dois conteúdos volumétricos observados $\theta_{a}$ e $\theta_{b}$, para os quais é válido a relação $\theta_{a}<$ $\theta_{p s}<\theta_{b}$ (Equação 3.21).

$$
\operatorname{Ln}[K p s]=\operatorname{Ln}\left[\frac{K r_{I I}\left(\psi_{b}\right)}{K r_{I I}\left(\psi_{a}\right)}\right] \cdot \frac{\left(\theta_{p s}-\theta_{a}\right)}{\left(\theta_{b}-\theta_{a}\right)}+\operatorname{Ln}\left[K r_{I I}\left(\theta_{a}\right)\right]
$$

\subsection{3 - Equação de Richards}

Segundo Reichardt (1985), em estudos dinâmicos da água no solo apenas o conhecimento do fluxo pela aplicação de Darcy não é suficiente. Na realidade, o que mais 
interessa conhecer é a variabilidade espacial e temporal da umidade em um dado ponto dentro do perfil do solo. Assim, a equação da continuidade propicia meios para estabelecer uma equação diferencial de $\theta$ em função de $x$ e $t$, cuja solução descreve o seu comportamento em relação ao espaço e ao tempo.

Seja um elemento de volume $d V$ com dimensões $d x$, $d y$ e $d z$, tal como esquematizado na Figura 3.2, onde se considera que todas as componentes do fluxo sofrem variações ao longo de suas direções. Nestas condições, tem-se que o fluxo que entra no elemento de volume de solo é $q_{x} d y d z$ e o que sai pela face oposta é $\left(q_{x}+\partial q_{x} / \partial x \cdot d x\right) d y d z$. Desta forma, a taxa de acumulação ou perda de água no elemento de volume de solo, na direção $x$, é igual à diferença entre o fluxo que entra no elemento e o fluxo que sai durante o intervalo de tempo infinitesimal $d t$ (Equação 3.22).

$$
\frac{\partial V_{x}}{\partial t}=-\frac{\partial q_{x}}{\partial x} d V
$$

em que $V_{x}$ é o volume de água acumulado ou perdido na direção $x$, em $\mathrm{m}^{3} ; q_{x}$ é a densidade de fluxo na direção $x, \mathrm{em} \mathrm{m}^{3} \cdot \mathrm{m}^{-2} \cdot \mathrm{s}^{-1}$; e $d V$ é o volume do elemento de solo, em $\mathrm{m}^{3}$.

Analogamente, a Equação 3.22 pode ser estendida para calcular a taxa de acumulação nas direções $y$ e $z$. Somando-se essas componentes, obtém-se a taxa total de acumulação ou perda de água no elemento de volume de solo (Equação 3.23).

$$
\frac{\partial V}{\partial t}=-\left(\frac{\partial q_{x}}{\partial x}+\frac{\partial q_{y}}{\partial y}+\frac{\partial q_{z}}{\partial z}\right) \cdot d V
$$

em que $V$ é o volume total de água acumulado ou perdido no elemento de volume do solo, em $\mathrm{m}^{3} ; q_{y}$ é a densidade de fluxo na direção $y$, em $\mathrm{m}^{3} \cdot \mathrm{m}^{-2} \cdot \mathrm{s}^{-1}$; e $q_{z}$ é a densidade de fluxo na direção $z, \mathrm{em} \mathrm{m}^{3} \cdot \mathrm{m}^{-2} \cdot \mathrm{s}^{-1}$. 


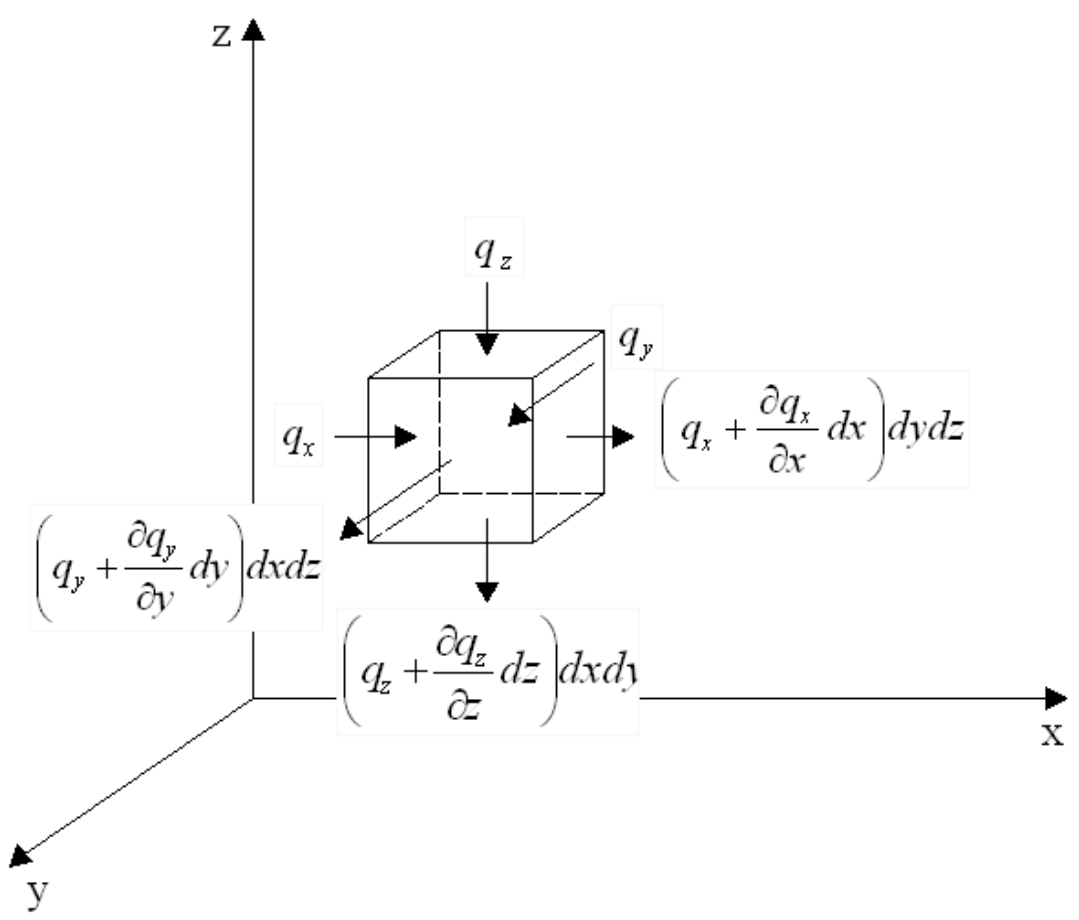

Figura 3.2 - Elemento de volume definido para determinar a taxa de variação da umidade com o tempo através da equação da continuidade.

Como o volume de água no solo $(V)$ pode ser dado por $\theta . d V$, então dividindo a Equação 3.23 por $d V$, obtém-se a Equação 3.24, que representa a equação da continuidade para fluxo de água em meios porosos.

$$
\frac{\partial \theta}{\partial t}=-\left(\frac{\partial q_{x}}{\partial x}+\frac{\partial q_{y}}{\partial y}+\frac{\partial q_{z}}{\partial z}\right)
$$

em que $\partial \theta / \partial t$ é a taxa de acumulação de água por unidade de tempo ou a taxa de variação temporal da umidade volumétrica, em $\mathrm{m}^{3} \cdot \mathrm{m}^{-3} \cdot \mathrm{s}^{-1}$.

A Equação 3.14 substituída na Equação 3.24 fornece a equação diferencial que rege o movimento da água em solos não saturados e isotrópicos com relação a $K(\theta)$, sendo conhecida pelo nome da equação de Richards (Equação 3.25).

$$
\frac{\partial \theta}{\partial t}=\frac{\partial}{\partial x}\left[K(\theta) \frac{\partial \psi}{\partial x}\right]+\frac{\partial}{\partial y}\left[K(\theta) \frac{\partial \psi}{\partial y}\right]+\frac{\partial}{\partial z}\left\{K(\theta)\left(\frac{\partial \psi}{\partial z}+1\right)\right\}
$$


É importante lembrar que o potencial total é, levando em consideração às simplificações presentes no item 3.1, a soma entre o potencial matricial e o potencial gravitacional; e que nas direções horizontais ( $x$ e $y$ ) o potencial gravitacional é constante, tornando-se nulo nos dois primeiros termos da Equação 3.25.

Se $\psi(\theta)$, presente na Equação 3.25, for única e $\theta$ variar em função das coordenadas de posição $(x, y$ e $z)$, então $\psi(\theta)$ pode ser estendida pela regra da cadeia. Assim, reescreve-se a Equação 3.25 na Equação 3.26 .

$$
\frac{\partial \theta}{\partial t}=\frac{\partial}{\partial x}\left[K(\theta) \frac{\partial \psi}{\partial \theta} \frac{\partial \theta}{\partial x}\right]+\frac{\partial}{\partial y}\left[K(\theta) \frac{\partial \psi}{\partial \theta} \frac{\partial \theta}{\partial y}\right]+\frac{\partial}{\partial z}\left[K(\theta) \frac{\partial \psi}{\partial \theta} \frac{\partial \theta}{\partial z}+K(\theta)\right] \quad \text { Equação } 3.26
$$

Admitindo meio isotrópico em relação a $K(\theta)$, distingue-se o produto $K(\theta)$ por $d \psi / d \theta$ como difusividade hidráulica. Portanto, a Equação 3.26 é reescrita na Equação 3.27.

$$
\frac{\partial \theta}{\partial t}=\frac{\partial}{\partial x}\left[D(\theta) \frac{\partial \theta}{\partial x}\right]+\frac{\partial}{\partial y}\left[D(\theta) \frac{\partial \theta}{\partial y}\right]+\frac{\partial}{\partial z}\left[D(\theta) \frac{\partial \theta}{\partial z}+K(\theta)\right]
$$

em que $D(\theta)$ é a difusividade hidráulica do solo, $\mathrm{em} \mathrm{m}^{2} \cdot \mathrm{s}^{-1}$.

Cabe ressaltar que a difusividade hidráulica, $D(\theta)$, só é válida para solo caracterizado por uma única função $\psi(\theta)$ e isotrópico em relação a $K(\theta)$. Além disso, como mencionado no item 3.2, as curvas de retenção obtidas por secagem e molhamento não são coincidentes, fenômeno que se dá o nome de histerese. Portanto, havendo histerese, a Equação 3.27 deve ser aplicada isoladamente para um processo de secagem ou para um processo de umedecimento, pois para cada um destes processos tem-se uma difusividade diferente devido à diferença das curvas de retenção (LIBARDI, 2005). 


\section{5 - Infiltração}

Denomina-se infiltração o processo dinâmico pelo qual a água no estado líquido atravessa a superfície do solo. A modelagem deste processo é de grande importância prática, pois a taxa de infiltração é um dos fatores que mais influencia o escoamento superficial. Além disso, segundo Reichardt (1985), a infiltração determina o balanço de água na zona radicular, assim, o conhecimento do processo de infiltração fornece importantes subsídios para o dimensionamento de reservatórios, estruturas de controle de erosão e de inundação, canais e sistemas de irrigação e drenagem.

A infiltração é um processo desacelerado. Começa com uma velocidade alta e, em função do decréscimo do gradiente do potencial total da água no solo, vai diminuindo gradativamente com o tempo até atingir um determinado nível constante, o que para Reichardt (1990) é igual à condutividade hidráulica saturada.

A infiltração é representada por duas variáveis: taxa de infiltração e infiltração acumulada. A taxa de infiltração é igual à densidade de fluxo, correspondendo ao volume de água que infiltra na unidade de área e de tempo. A infiltração acumulada corresponde ao volume (por unidade de área) de água infiltrada ao longo do tempo. De forma generalizada, o comportamento de ambas segue o esquema da Figura 3.3.

As equações utilizadas para descrever a taxa de infiltração e a infiltração acumulada são normalmente definidas para um fluxo unidimensional na direção vertical ou horizontal. Por isso, no item 3.5.1 deste trabalho será apenas abordado o processo analítico da infiltração horizontal, no qual o potencial gravitacional é constante. Em seguida, no item 3.5.2, serão descritos os modelos utilizados para quantificar o processo de infiltração da água no solo. 


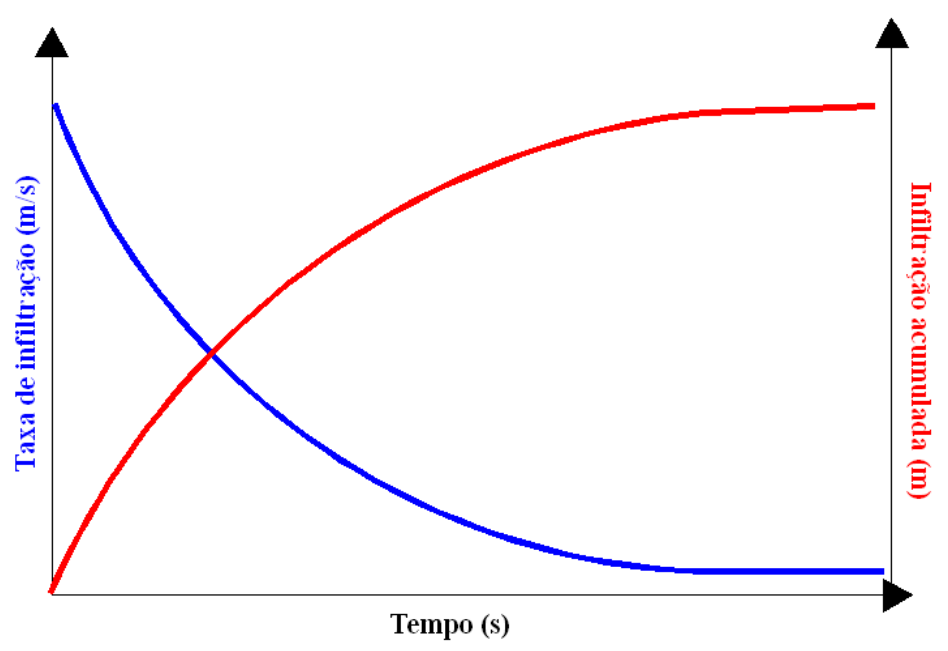

Figura 3.3 - Taxa de infiltração e infiltração acumulada ao longo do tempo para um mesmo solo.

\subsection{1 - Infiltração Horizontal}

A descrição matemática da infiltração horizontal é realizada considerando uma coluna horizontal com comprimento infinito e preenchida por solo homogêneo com massa específica global e umidade inicial $\theta_{o}$ constantes (Figura 3.4).

No instante $t=0$, inicia-se o processo de infiltração da água através da placa porosa com resistência desprezível. Durante todo o tempo de infiltração, a extremidade $(x=0)$ é mantida saturada e a umidade $\theta$ é dada em função da posição de $x$ na coluna e do tempo $t$, isto é, $\theta=\theta(x, t)$. 


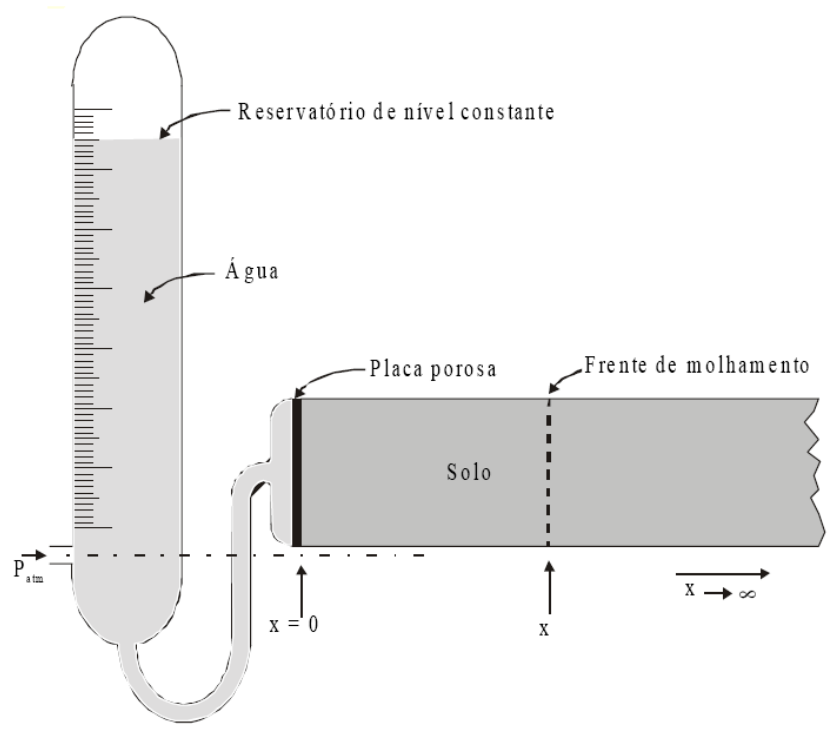

Figura 3.4 - Coluna Horizontal infinita de seção transversal constante preenchida com solo homogêneo. Fonte: Naime (2001).

O fluxo horizontal na coluna é provocado pela diferença de potencial entre dois pontos. Assim, a equação geral que governa o movimento é a Equação 3.27, que escrita somente para a direção $x$ e considerando a contribuição nula do potencial gravitacional, é reescrita na Equação 3.28 .

$$
\frac{\partial \theta}{\partial t}=\frac{\partial}{\partial x}\left[D(\theta) \frac{\partial \theta}{\partial x}\right]
$$

sujeita às condições expressa pela Equação 3.29.

$$
\begin{aligned}
& t=0, x>0, \theta=\theta_{o} \\
& t>0, x=0, \theta=\theta_{s} \\
& t>0, x=\infty, \theta=\theta_{o}
\end{aligned}
$$

A solução do problema de infiltração horizontal é dada pela função $\theta=\theta(x, t)$, que permite calcular a umidade em qualquer ponto $x$ a qualquer instante $t$. Esta solução não é fácil de ser encontrada a menos que a difusividade hidráulica, $D(\theta)$, seja conhecida. 
Swartzerndruber $^{8}$ (1969 apud Prevedello, 1996) propôs uma solução com $x$ sendo a variável dependente $x=x(\theta, t)$, através da Transformação de Boltzmann (Equação 3.30).

$$
\lambda(\theta)=x \cdot t^{-\frac{1}{2}}
$$

sendo suas derivadas expressas pela Equação 3.31.

$$
\begin{aligned}
& \frac{\partial \lambda(\theta)}{\partial t}=-\frac{\lambda}{2 t} \\
& \frac{\partial \theta}{\partial t}=\frac{d \theta}{d \lambda} \frac{\partial \lambda}{\partial t}=-\frac{\lambda}{2 t} \frac{d \theta}{d \lambda} \\
& \frac{\partial \lambda}{\partial x}=t^{-\frac{1}{2}}
\end{aligned}
$$

em que $\lambda(\theta)$ é a variável de Boltzmann, em $\mathrm{m} . \mathrm{s}^{-1 / 2}$

Segundo Prevedello (1996), a Equação 3.30 só pode ser aplicada se a representação gráfica da distância da frente de molhamento $x$ em função da raiz quadrada do tempo for uma reta com inclinação $\lambda$. Caso contrário, toda análise teórica que se desenvolve adiante será inválida.

Considerando que a linearidade seja respeitada, a Equação 3.31 aplicada na Equação 3.30 resulta na Equação 3.32.

$$
-\frac{\lambda}{2} \frac{d \theta}{d \lambda}=\frac{\partial}{\partial \lambda}\left[D(\theta) \frac{d \theta}{d \lambda}\right]
$$

com as seguintes condições de contorno (Equação 3.33).

$$
\begin{aligned}
& \lambda=0 \Rightarrow \theta=\theta_{s} \\
& \lambda \rightarrow \infty \Rightarrow \theta=\theta_{o}
\end{aligned}
$$

Integrando-se a Equação 3.32 entre os limites $\theta_{o}$ e um $\theta$ qualquer, resulta na Equação 3.34

\footnotetext{
${ }^{8}$ SWARTZENDRUBER, D. (1969) The flow of water in unsaturated soils in flow through Porous Media. Academic Press, New York.
} 


$$
\int_{\theta_{o}}^{\theta} \lambda d \theta=-2 D(\theta) \frac{d \theta}{d \lambda}
$$

Equação 3.34

Substituindo na Equação 3.34 a Equação 3.30, e considerando um instante fixo $\left(t_{0}\right)$, a Equação 3.34 é simplificada na Equação 3.35.

$$
D(\theta)=-\frac{1}{2 t_{0}}\left(\frac{d x}{d \theta}\right) \int_{\theta_{o}}^{\theta} x d \theta
$$

Assim, conhecida experimentalmente a curva $\theta(x)$ em um dado instante $t_{o}$ é possível determinar $D(\theta)$ em $t_{o}$ para qualquer $\theta$ entre $\theta_{o}$ e $\theta_{s}$ através da Equação 3.35.

A solução que se busca para o problema da infiltração horizontal é $\theta(\lambda)$. Os valores de umidade medidos no perfil, dados por $\theta\left[x\left(t_{1}\right)\right], \theta\left[x\left(t_{2}\right)\right], \theta\left[x\left(t_{3}\right)\right]$, etc, são transformados em um único $\theta(\lambda)$ dividindo por $t_{1}^{1 / 2}$ para o primeiro perfil, $t_{2}^{1 / 2}$ para o segundo e, assim sucessivamente. Quando $t=1, x=\lambda$; deste modo, fisicamente, $\theta(\lambda)$ é o perfil de água $\theta(x)$ no solo quando o tempo de infiltração é unitário.

A infiltração acumulada ( $I$ ) é obtida através do cálculo da área abaixo da curva limitada por $\theta_{o}$ e $\theta_{s}$ (Equação 3.36).

$$
I=\int_{\theta_{o}}^{\theta_{s}} \lambda(\theta) \cdot t^{1 / 2} d \theta
$$

Sendo $\lambda(\theta)$ único para cada solo, Philip ${ }^{9}$ (1957 apud Prevedello, 1996) e Minasny e McBratney (2000), apresentou o termo sortividade (capacidade de absorver líquido por capilaridade), conforme dado pela Equação 3.37.

$$
S=\int_{\theta_{o}}^{\theta_{s}} \lambda(\theta) \cdot d \theta
$$

\footnotetext{
${ }^{9}$ PHILIP, J. R. (1957) Numerical solution of equation of the diffusion type with diffusivity concentration dependent . Trans. Faraday Soc. n. 391, v. 51, p. 885-892.
} 
em que $S$ é a sortividade, grandeza relacionada com a capacidade do solo homogêneo absorver água na ausência dos efeitos gravitacionais, em $\mathrm{m} \cdot \mathrm{s}^{-1 / 2}$.

A infiltração acumulada horizontal e a taxa de infiltração horizontal podem, então, serem escritas, respectivamente, através da Equação 3.38 e da Equação 3.39.

$$
\begin{aligned}
& I=S \cdot t^{1 / 2} \\
& i=\frac{S}{2 \cdot t^{1 / 2}}
\end{aligned}
$$

A sortividade pode ser calculada a partir das equações teóricas obtidas por meio de métodos numéricos ou por intermédio de análise de regressão a partir de dados de infiltração medidos através de infiltrômetros de cilindros concêntricos. Trabalhos como: Minasny e McBratney (2000) e Maheshwari (1997) foram realizados buscando determinar esta grandeza.

Minasny e McBratney (2000) avaliaram o comportamento da infiltração em ensaios de campo a partir de disco de permeâmetro. Para o estudo, os autores mediram a sortividade de três tipos de solo através do disco de permeâmetro e chegaram ao resultado demonstrado na Tabela 3.3.

Tabela 3.3 - Propriedades hidráulicas do solos utilizados para o estudo de infiltração.

\begin{tabular}{lcccccc}
\hline \multicolumn{1}{c}{ Solo } & $\begin{array}{c}\boldsymbol{\theta}_{\mathbf{r}} \\
\mathrm{m}^{3} \cdot \mathrm{m}^{-3}\end{array}$ & $\begin{array}{c}\boldsymbol{\theta}_{\mathrm{s}} \\
\mathrm{m}^{3} \cdot \mathrm{m}^{-3}\end{array}$ & $\begin{array}{c}\boldsymbol{\alpha} \\
\mathrm{m}^{-1}\end{array}$ & $\mathbf{n}$ & $\begin{array}{c}\mathbf{K}_{\mathbf{s}} \\
\mathrm{m} \cdot \mathrm{s}^{-1}\end{array}$ & $\begin{array}{c}\mathbf{S} \\
\mathrm{m} \cdot \mathrm{s}^{-1 / 2}\end{array}$ \\
\hline Arenoso & 0,000 & 0,300 & 2,0 & 3,00 & $1,00 \mathrm{E}-04$ & $2,88 \mathrm{E}-04$ \\
Areno-argiloso & 0,078 & 0,430 & 3,6 & 1,56 & $2,90 \mathrm{E}-06$ & $1,37 \mathrm{E}-04$ \\
Argiloso & 0,124 & 0,495 & 1,5 & 2,00 & $1,23 \mathrm{E}-07$ & $3,64 \mathrm{E}-04$ \\
\hline
\end{tabular}

Fonte: Minasny e McBratney (2000).

Maheshwari (1997) avaliou a correlação entre a textura do solo, a massa específica, a condutividade hidráulica saturada e a sortividade. Para avaliação, foram realizados ensaios de campo com infiltrômetro de duplo anel, para determinar a infiltração, e com disco de 
permeâmetro, para medir a sortividade, a condutividade hidráulica saturada e o valor da taxa de infiltração estabilizada. Na Tabela 3.4, segue os valores dos parâmetros obtidos pelo autor.

Tabela 3.4 - Parâmetros texturais e hidráulicos de diferente tipos de solos.

\begin{tabular}{|c|c|c|c|c|c|c|c|}
\hline \multirow[b]{2}{*}{ Solo } & \multicolumn{3}{|c|}{ Composição granulométrica } & \multirow{2}{*}{$\begin{array}{l}\text { Umidade volumétrica } \\
\text { inicial } \\
\mathrm{m}^{3} \cdot \mathrm{m}^{-3}\end{array}$} & \multirow{2}{*}{$\begin{array}{c}\text { Umidade volumétrica } \\
\text { saturada } \\
\mathrm{m}^{3} \cdot \mathrm{m}^{-3}\end{array}$} & \multirow[b]{2}{*}{$\begin{array}{c}\text { Condutividade } \\
\mathrm{m} \cdot \mathrm{s}^{-1}\end{array}$} & \multirow[b]{2}{*}{$\begin{array}{c}\text { Sortividade } \\
\mathrm{m} \cdot \mathrm{s}^{-1 / 2}\end{array}$} \\
\hline & $\begin{array}{c}\text { Areia } \\
\%\end{array}$ & $\begin{array}{l}\text { Silte } \\
\%\end{array}$ & $\begin{array}{c}\text { Argila } \\
\%\end{array}$ & & & & \\
\hline 1 & $88,0 \%$ & $4,0 \%$ & $8,0 \%$ & 0,072 & 0,28 & $7,77 \mathrm{E}-05$ & $6,10 \mathrm{E}-02$ \\
\hline 2 & $42,0 \%$ & $28,0 \%$ & $30,0 \%$ & 0,072 & 0,33 & $5,80 \mathrm{E}-05$ & $4,38 \mathrm{E}-02$ \\
\hline 3 & $78,0 \%$ & $6,0 \%$ & $16,0 \%$ & 0,093 & 0,27 & $1,02 \mathrm{E}-04$ & $3,42 \mathrm{E}-02$ \\
\hline 4 & $38,0 \%$ & $44,0 \%$ & $18,0 \%$ & 0,130 & 0,50 & $7,48 \mathrm{E}-05$ & $5,08 \mathrm{E}-02$ \\
\hline 5 & $73,0 \%$ & $6,0 \%$ & $16,0 \%$ & 0,070 & 0,54 & $2,07 \mathrm{E}-04$ & $1,08 \mathrm{E}-01$ \\
\hline 6 & $76,0 \%$ & $8,0 \%$ & $16,0 \%$ & 0,120 & 0,57 & $3,63 \mathrm{E}-04$ & $8,29 \mathrm{E}-02$ \\
\hline 7 & $74,0 \%$ & $8,0 \%$ & $18,0 \%$ & 0,160 & 0,25 & $7,27 \mathrm{E}-05$ & $3,58 \mathrm{E}-02$ \\
\hline 8 & $86,0 \%$ & $4,0 \%$ & $10,0 \%$ & 0,230 & 0,36 & $1,88 \mathrm{E}-04$ & $1,06 \mathrm{E}-01$ \\
\hline
\end{tabular}

Fonte: Maheshwari (1997).

Com base nos valores de sortividade demonstrados na Tabela 3.3 e na Tabela 3.4, percebe-se que não há uma relação entre sortividade e tipo de solo, visto que para solos com composições granulométricas similares os valores de sortividade não são próximos. Além disso, percebe-se que não há uma ordem de grandeza comum aos dois trabalhos.

\subsubsection{1 - Modelos de infiltração}

Segundo Prevedello (1996), se a distribuição da umidade no perfil do solo for conhecida, a taxa de infiltração pode ser medida em condições de campo. Contudo, normalmente, não se dispõe de informações sobre a distribuição da umidade ao longo da distância e nem da distância da frente de molhamento alcançada. Assim, para se obter o perfil de umidade, é necessário utilizar modelos matemáticos desenvolvidos por equações empíricas ou a partir de considerações físicas, que se aplicam somente a solos homogêneos e que permanecem homogêneos durante o processo.

Conforme Brandão et al. (2003) os modelos empíricos têm a vantagem de relacionar os parâmetros do modelo a características de solo, permitindo englobar na determinação de suas constantes alguns fatores que são difíceis de serem considerados nos modelos teóricos. Já 
os modelos teóricos têm a vantagem de poderem ser utilizados para diferentes condições de solo, visto que são baseados na teoria física do escoamento em meios porosos.

Na Tabela 3.3 segue uma descrição dos modelos mais usuais na determinação da infiltração horizontal.

Tabela 3.5 - Modelos usados na determinação da infiltração horizontal.

\begin{tabular}{|c|c|c|c|}
\hline & Modelos & Taxa de infiltração & Hipóteses \\
\hline \multirow{3}{*}{ Empíricos } & $\begin{array}{l}\text { Kostiakov } \\
\text { (1932) }\end{array}$ & $i=k \cdot \alpha \cdot t^{a-1}$ & \begin{tabular}{llr}
\multicolumn{1}{c}{ Equação } & inteiramente & \multicolumn{2}{r}{ empírica, } \\
onde os parâmetros não & têm \\
significado físico próprio & e são \\
avaliados a partir de & dados \\
experimentais, podendo & ser \\
determinados estaticamente. & \\
\end{tabular} \\
\hline & $\begin{array}{c}\text { Kostiakov e Lewis } \\
\text { (1945) }\end{array}$ & $i=k \cdot \alpha \cdot t^{a-1}+i_{f}$ & $\begin{array}{l}\text { Equação empírica que foi concebida } \\
\text { introduzindo-se um termo de } \\
\text { infiltração constante na equação de } \\
\text { Kostiakov para descrever, de forma } \\
\text { adequada, a infiltração quando os } \\
\text { tempos forem longos. }\end{array}$ \\
\hline & $\begin{array}{l}\text { Horton } \\
(1940)\end{array}$ & $i=i_{f}+\left(i_{i}-i_{f}\right) \cdot e^{-\beta \cdot t}$ & $\begin{array}{l}\text { Relação empírica desenvolvida para } \\
\text { representar o decaimento da } \\
\text { infiltração com o tempo. A equação } \\
\text { foi estabelecida considerando que a } \\
\text { redução da taxa de infiltração com o } \\
\text { tempo é fortemente controlada por } \\
\text { fatores que ocorrem na superfície do } \\
\text { solo e que na redução a taxa de } \\
\text { infiltração se aproxima de um valor } \\
\text { constante, mas frequentemente menor } \\
\text { que a condutividade hidráulica } \\
\text { saturada. }\end{array}$ \\
\hline \multirow[t]{2}{*}{ Teórico } & $\begin{array}{l}\text { Green e Ampt } \\
\text { (1911) }\end{array}$ & $i=K_{o}\left[\frac{\left(\psi_{o}-\psi_{f}\right)}{L}\right]$ & $\begin{array}{l}\text { Equação derivada da equação de } \\
\text { Darcy através de simplificações no } \\
\text { fenômeno de propagação da frente de } \\
\text { molhamento. As simplificações são a } \\
\text { consideração que o solo é totalmente } \\
\text { saturado da superfície à profundidade } \\
\text { da frente de molhamento e que o } \\
\text { potencial matricial permanece sempre } \\
\text { constante na frente de molhamento, } \\
\text { independente do tempo e posição, e } \\
\text { igual ao valor do potencial matricial } \\
\text { do solo antes da infiltração. }\end{array}$ \\
\hline & $\begin{array}{l}\text { Philip } \\
\text { (1957) }\end{array}$ & $i=\frac{S}{2 \sqrt{t}}$ & $\begin{array}{l}\text { Equação teórica derivada da } \\
\text { equação de Richards e solucionada a } \\
\text { partir da consideração da condição de } \\
\text { contorno de saturação permanente na } \\
\text { superfície do solo. }\end{array}$ \\
\hline
\end{tabular}

Como um dos objetivos deste trabalho é propor uma metodologia de dimensionamento de trincheiras de infiltração, e considerando que quanto mais simplificada for a metodologia 
mais facilmente ela será aplicada, optou-se em determinar a infiltração a partir do modelo de Green-Ampt, visto que dentre os modelos teóricos é o que apresenta maior simplicidade.

\subsubsection{2 - Modelo de Green-Ampt}

O modelo de infiltração desenvolvido por Green-Ampt baseia-se nas seguintes hipóteses: a) o solo na zona úmida (superfície até a frente de umedecimento) apresenta-se saturado, com condutividade hidráulica $\left(K_{s}\right)$ e com densidade de fluxo $(q)$ constantes; b) o potencial da água na frente de molhamento $\left(\psi_{f}\right)$ é constante, independente do tempo e da posição, e igual ao potencial matricial do solo antes da infiltração; c) a mudança da umidade $\theta_{s}$ para $\theta_{f}$ ocorre na frente de molhamento numa camada de espessura desprezível; e d) a umidade na frente de molhamento $\left(\theta_{f}\right)$ é igual a umidade inicial $\left(\theta_{o}\right)$

Segundo Prevedello (1996) essas hipóteses são bastante reais para solos de textura grossa com baixa umidade inicial, visto que a frente de molhamento é, normalmente, muito brusca nessas condições.

Considerando as hipóteses supracitadas, a igualdade entre densidade de fluxo e taxa de infiltração e utilizando a Equação 3.14, Green e Ampt deduziram a Equação 3.40.

$$
i=K_{s} \frac{\psi_{s}-\left(\psi_{f}-L_{F M}\right)}{L_{F M}}
$$

em que $\psi_{s}$ é o potencial matricial da água no solo na superfície transversal ao fluxo, em $\mathrm{mH}_{2} \mathrm{O} ; \psi_{f}$ é o potencial matricial na água no solo na frente de molhamento, em $\mathrm{mH}_{2} \mathrm{O} ; L_{F M}$ é a distância entre a superfície e a frente de molhamento, em m; e $K_{s}$ é a condutividade hidráulica saturada, em $\mathrm{m} \cdot \mathrm{s}^{-1}$.

De acordo com Libardi (2005), a Equação 3.40 satisfaz plenamente os seguintes requisitos: alta taxa de infiltração quando $L_{F M}$ é pequeno (início da infiltração); e, após algum tempo, quando $L_{F M}$ alcança maiores distâncias, atinge um valor constante $K_{s}$. 
O modelo de Green-Ampt pode ser adotado para o caso de infiltração horizontal, sendo, neste caso, a gravidade desprezada (Prevedello, 1996). Portanto, a variável $L_{F M}$ presente no numerador do termo da direita é nula e a Equação 3.40 é reescrita na Equação 3.41 .

$$
i=K_{s} \frac{\left(\psi_{s}-\psi_{f}\right)}{L_{F M}}
$$

A infiltração acumulada é obtida considerando que a frente de molhamento localiza-se em $L_{F M}$ para o instante $t$ e que depois de um intervalo infinitesimal $d t$ estará em $L_{F M}+d L_{F M}$, e que durante este intervalo uma quantidade infinitesimal de água $d I$ infiltra (Equação 3.42).

$$
\frac{d I}{d t}=\left(\theta_{s}-\theta_{f}\right) \frac{d L_{F M}}{d t}
$$

Comparando-se a Equação 3.41 e a Equação 3.42, obtém-se a Equação 3.43.

$$
\frac{K_{s}}{\theta_{s}-\theta_{f}} d t=\frac{L_{F M} \cdot d L_{F M}}{\psi_{s}-\psi_{f}}
$$

Rearranjado a Equação 3.43 e integrando-a em relação a $t$ e $L_{F M}$, obtém-se a Equação 3.44 .

$$
L_{F M}=\left[2 K_{s} \frac{\psi_{s}-\psi_{f}}{\theta_{s}-\theta_{f}}\right]^{1 / 2} t^{1 / 2}
$$

Considerando que pelas hipóteses assumidas os valores de umidade, potencial e condutividade se mantêm constantes, então a frente de molhamento é proporcional à raiz quadrada do tempo.

Integrando a Equação 3.42 e reescrevendo em função da Equação 3.44, chega-se a Equação 3.45 . 


$$
I=\left(\theta_{s}-\theta_{f}\right) \cdot\left[2 K_{s} \frac{\psi_{s}-\psi_{f}}{\theta_{s}-\theta_{f}}\right]^{1 / 2} \cdot t^{1 / 2}
$$

Com base na Equação 3.38, que descreve o processo de infiltração horizontal, determina-se a sortividade para o modelo de Green-Ampt (Equação 3.46).

$$
S=\left(\theta_{s}-\theta_{f}\right) \cdot\left[2 K_{s} \frac{\psi_{s}-\psi_{f}}{\theta_{s}-\theta_{f}}\right]^{1 / 2}
$$

A partir da sortividade (Equação 3.46), o modelo de Green-Ampt determina a infiltração acumulada e a taxa de infiltração através, respectivamente, da Equação 3.45 e da Equação 3.47.

$$
i=\left(\theta_{s}-\theta_{f}\right) \cdot\left[2 K_{s} \frac{\psi_{s}-\psi_{f}}{\theta_{s}-\theta_{f}}\right]^{1 / 2} \cdot 0,5 \cdot t^{-1 / 2}
$$

Apesar de ser um modelo bastante conveniente, uma vez que os parâmetros exigidos por ele são, aparentemente, de obtenção razoavelmente fácil, as suas principais desvantagens estão relacionadas com as suas pressuposições (solo homogêneo e saturado até a frente de molhamento).

Deste modo, como forma de melhorar a acurácia do modelo em relação à determinação da taxa de infiltração de água no solo, pode-se adotar equações que descrevam a porosidade heterogênea do solo (Equação 3.10) no modelo de Green-Ampt, visto que na maioria das situações os solos são heterogêneos. 


\section{Capítulo 4}

"Não existem métodos fáceis para resolver problemas dificeis."

René Descartes

\section{4 - MATERIAIS E MÉTODOS}

Como o objetivo principal e secundário deste trabalho é, respectivamente, avaliar o comportamento quantitativo de uma trincheira de infiltração e propor uma nova metodologia de dimensionamento, então a metodologia utilizada neste trabalho foi elaborada buscando-se estudar a maneira mais realística de calcular a infiltração nas paredes da trincheira durante a adução e recessão de chuvas simuladas (alimentação exclusiva à trincheira).

Desta forma, este capítulo foi dividido em três partes. A primeira, itens 4.1 a 4.4 , aborda a instalação de uma trincheira para determinar experimentalmente a infiltração que ocorre em sua área longitudinal. A segunda, item 4.5, trata da modelagem numérica da infiltração através de um modelo teórico. Por fim, a terceira, item 4.6, apresenta uma nova metodologia de dimensionamento de trincheiras, sendo esta proposta com base na infiltração estudada nos itens anteriores.

\section{1 - Área de implantação da trincheira}

Conforme descrito no item 2.4.1, a escolha do local de implantação do dispositivo deve ser efetuada respeitando vários aspectos, tais como: taxa de infiltração, permeabilidade, origem do solo, etc. Com base nestes aspectos, algumas regiões no interior do campus da Escola de Engenharia de São Carlos (EESC) foram pré-selecionadas como possíveis locais de implantação da trincheira. 
Dentre estas opções, uma área em especial mostrou-se mais favorável visto que possuía informações referentes às propriedades do solo, disponibilizadas por Graciosa (2005), as quais permitiam caracterizar a área como viável para implantação de um dispositivo de infiltração; e, neste local, estava implantado um projeto de gerenciamento de águas pluviais com toda estrutura de captação de água de chuva já em funcionamento (calhas, condutores, reservatórios e separador), reduzindo assim os custos de implantação.

A área escolhida localiza-se nas imediações do Departamento de Hidráulica e Saneamento da EESC/USP e encontra-se ilustrada na Figura 4.1.

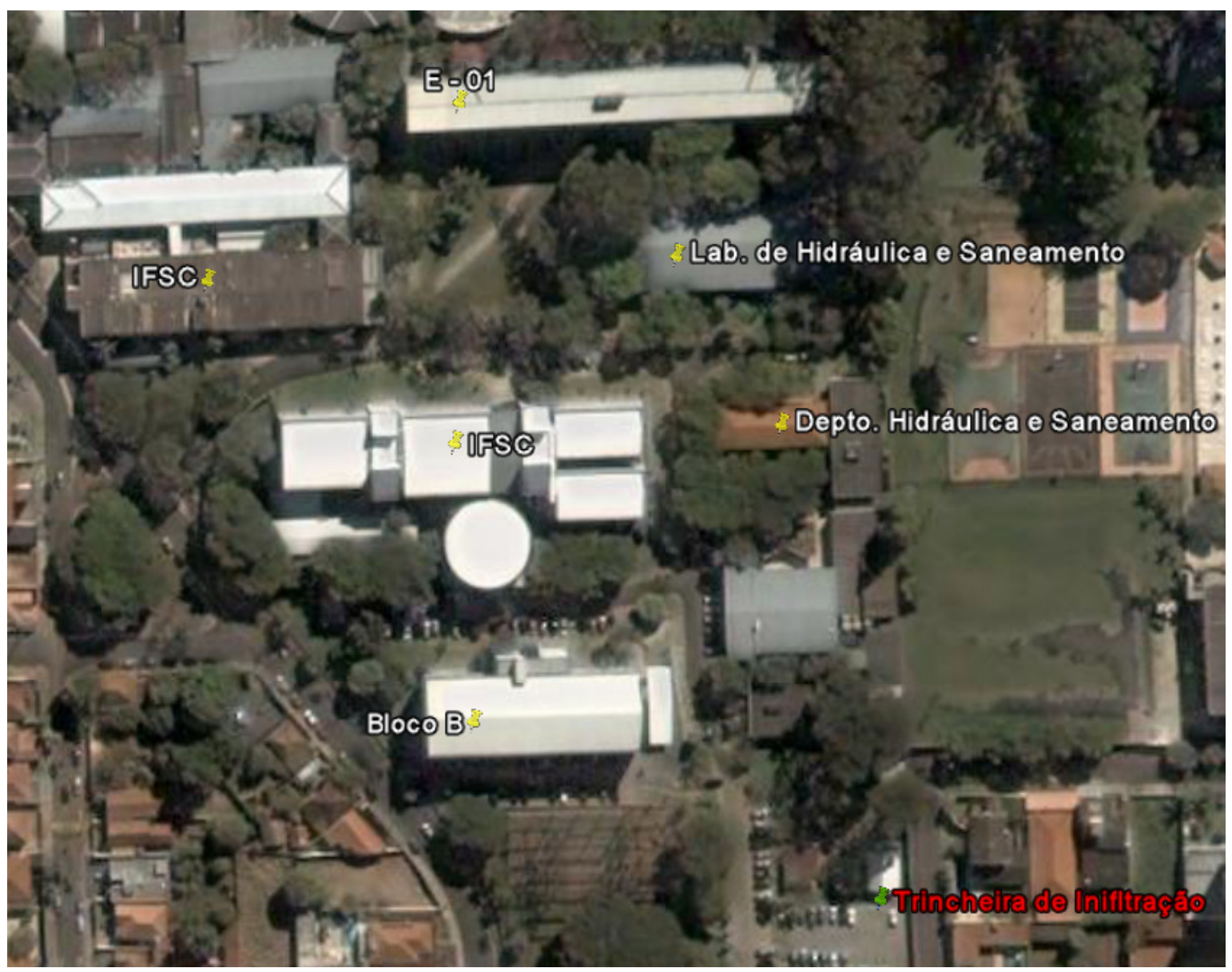

Figura 4.1- Local de implantação da trincheira de infiltração.

Definido o local de implantação da trincheira, procedeu-se a realização dos ensaios laboratoriais. 


\section{2 - Ensaios Laboratoriais}

Para determinação numérica do processo de infiltração horizontal no solo pelo modelo, alguns parâmetros de entrada que expressam as características físicas, mecânicas e hidráulicas do solo precisam ser estimados por meio de ensaios de campo ou laboratório. Neste trabalho, por haver limitações do laboratório e/ou de equipamentos em realizar ensaios de campo, optou-se por determinar estes parâmetros através de ensaios laboratoriais.

Os ensaios laboratoriais realizados foram: massa específica dos sólidos, análise granulométrica, permeabilidade e curva de retenção. Todos estes foram realizados no Laboratório de Solos do Departamento de Geotecnia da Escola de Engenharia de São Carlos e foram conduzidos conforme as especificações da Associação Brasileira de Normas Técnicas $(\mathrm{ABNT})$.

Realizou-se também, com o objetivo de verificar a textura do solo, o ensaio de tomografia computadorizada na Embrapa Instrumentação Agropecuária, obtendo-se as imagens de seções transversais de amostra do solo.

Para realização dos ensaios, as amostras foram obtidas através de blocos indeformados coletados na vertical a $0,6 \mathrm{~m}$ da superfície.

No momento da retirada dos blocos, estes foram envoltos com parafina para proteção contra perda de umidade conforme a NBR 9604/86 "Abertura de poço e trincheira de inspeção do solo, com retirada de amostras deformadas e indeformadas”.

Na Figura 4.2 e na Figura 4.3 apresentam-se ilustrados, respectivamente, a retirada dos blocos e recobrimento destes com parafina. 


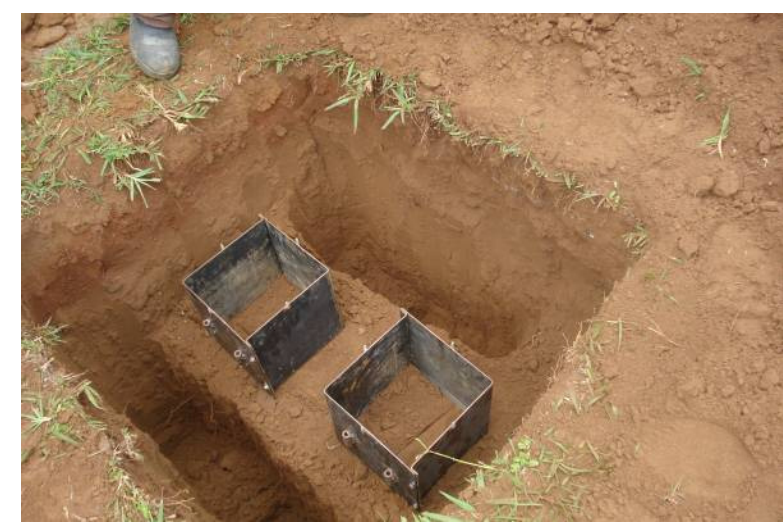

Figura 4.2 - Retirada dos blocos indeformados.

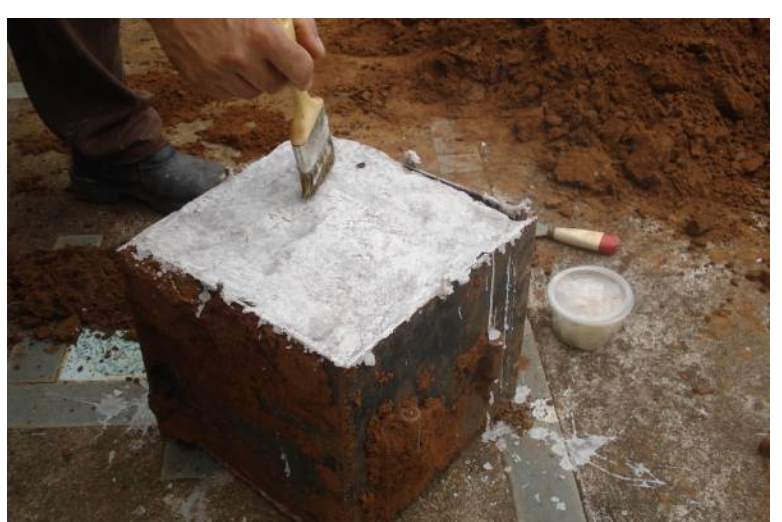

Figura 4.3 - Bloco indeformado envolto por parafina para conter a perda de umidade.

\subsection{1 - Massa específica dos sólidos}

O ensaio da massa específica dos sólidos consiste em obter, a partir de uma suspensão contendo $0,06 \mathrm{~kg}$ de solo e água destilada, cinco determinações da massa do conjunto (picnômetro + sólidos + água), para cinco diferentes temperaturas. Determinados estes valores, a massa específica do sólido foi estimada através da Equação 4.1.

$$
\rho_{s}=\frac{M_{s}}{M_{s}-M_{1}+M_{2}} \cdot \rho_{w}
$$

Equação 4.1

em que $\rho_{s}$ é a massa específica dos sólidos; g. $\mathrm{cm}^{-3} ; M_{s}$ é a massa de sólidos do ensaio, em g; $M_{1}$ é o somatório das massas da água, do picnômetro e dos sólidos para uma temperatura $\mathrm{T}^{\circ} \mathrm{C}$, em g; $M_{2}$ é o somatório das massas da água e do picnômetro obtida través da curva de calibração do picnômetro, em g; e $\rho_{\mathrm{w}}$ a massa específica da água, em g.cm ${ }^{-3}$.

\subsection{2 - Análise Granulométrica}

A partir da identificação tátil-visual, observou-se que o solo em estudo apresentava quantidade de partículas finas maiores que 5\%. Por isso, conforme sugerido por Nogueira (2001), a análise granulométrica do solo foi realizada por meio da combinação de peneiramento e sedimentação estabelecida pela norma NBR 7181/84 "Solo - Análise Granulométrica". 
Para a parcela mais grossa, efetuou-se o ensaio de peneiramento. Este foi iniciado com lavagem de $0,15 \mathrm{~kg}$ de solo na peneira de abertura 0,0075 $\mathrm{mm}$ (\#200), utilizando 0,125 L de defloculante (hexametafosfato de sódio) a fim de facilitar a lavagem. As partículas retidas na peneira foram recolhidas, levadas para estufa a $105^{\circ} \mathrm{C}$ durante 24 horas e, posteriormente, peneiradas através de uma sequência de peneiras de aberturas conhecidas (\#4, \#10, \#16, \#30, \#50, \#100, \#200).

As partículas do solo que passaram na peneira de $0,0075 \mathrm{~mm}$ (parcela fina) foram transferidas para o copo de um dispersor, com auxílio de água destilada, e deixada dispersar por 10 minutos. Após a dispersão, a suspensão foi colocada em uma proveta e homogeneizada. Em seguida, leituras de densidade e temperatura foram feitas com auxílio de densímetros e termômetros, respectivamente. As leituras foram realizadas após decorridos 1, $2,4,8,15,30,60,120,240$ e 480 minutos da homogeneização. Com os dados obtidos e usando a Equação 4.2 e a Equação 4.3 determinaram-se, respectivamente, os diâmetros equivalentes e as porcentagens de material.

$$
d=0,005530 \cdot\left[\frac{\mu}{\left(\rho_{s}-\rho_{w}\right)} \cdot \frac{z}{t_{s}}\right]^{1 / 2}
$$

em que $d$ é o diâmetro equivalente da partícula, em mm; $\mu$ é a viscosidade absoluta, em Pa.s; $\rho_{s}$ é a massa específica dos sólidos, em g.cm ${ }^{-3} ; \rho_{w}$ é a massa específica da água, em g.cm ${ }^{-3} ; z$ é a distância entre o centro de volume do bulbo do densímetro e a superfície da suspensão calculada através da curva de calibração do densímetro, em $\mathrm{cm}$; e $t_{s}$ é o tempo de sedimentação, em s.

$$
P(<d)=\frac{100}{M_{s}} \cdot \frac{\rho_{s}}{\rho_{s}-1} \cdot\left[r(H)-r_{w}(H)\right]
$$

em que $\mathrm{P}(<d)$ é a porcentagem de solo em suspensão no momento da leitura; $M_{s}$ é a massa dos sólidos, em $\mathrm{g} ; \rho_{s}$ é a massa específica dos sólidos, em $\mathrm{g} \cdot \mathrm{cm}^{-3}, r(H)$ é a leitura do 
densímetro na proveta contendo suspensão de solo, adimensional; e $r_{w}(H)$ é a leitura do densímetro na proveta contendo água e defloculante, adimensional.

Com os pares de valores: diâmetro da peneira e percentagem acumulada retida, determinados no peneiramento; e diâmetro equivalente e proporção de partículas com diâmetros equivalentes menores, calculados na sedimentação, procedeu-se à plotagem em gráficos de granulometria, obtendo-se, assim, a composição granulométrica das amostras.

\subsection{3 - Condutividade hidráulica saturada}

A escolha do método laboratorial para determinação da condutividade hidráulica saturada do solo é realizada em função da estrutura (deformada e indeformada) da amostra. Neste trabalho, a fim de garantir uma maior representatividade das condições de campo, optou-se pelo método que utiliza amostra indeformada do solo, sendo, neste caso, o permeâmetro de carga constante.

O ensaio com permeâmetro de carga constante iniciou-se com a moldagem do corpode-prova (CP) cilíndrico de solo indeformado. Após efetuar as medidas geométricas e a pesagem, inseriu-se o CP no permeâmetro para montagem do aparato do ensaio. As medidas foram $12,27 \mathrm{~cm}$ de altura, 4,85 cm de diâmetro e 346,1 g.

Com o objetivo de impermeabilizar as paredes e, com isso, evitar o fluxo lateral, a altura do CP foi dividida em três partes iguais e para cada uma dessas intercalou-se a aplicação de parafina e bentonita na parede do permeâmetro. A Figura 4.4 ilustra os passos realizados na confecção do permeâmetro. 


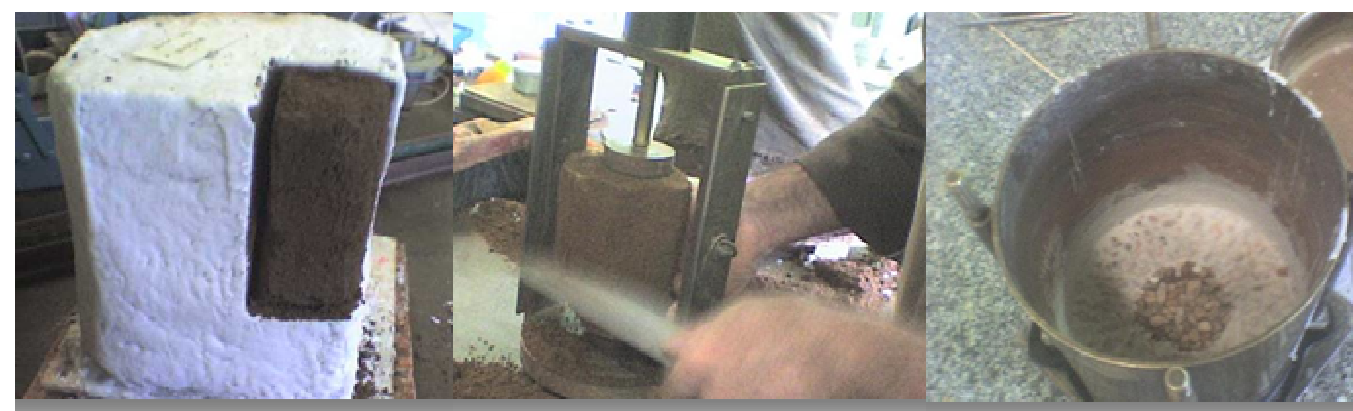

(a)

(b)

(c)

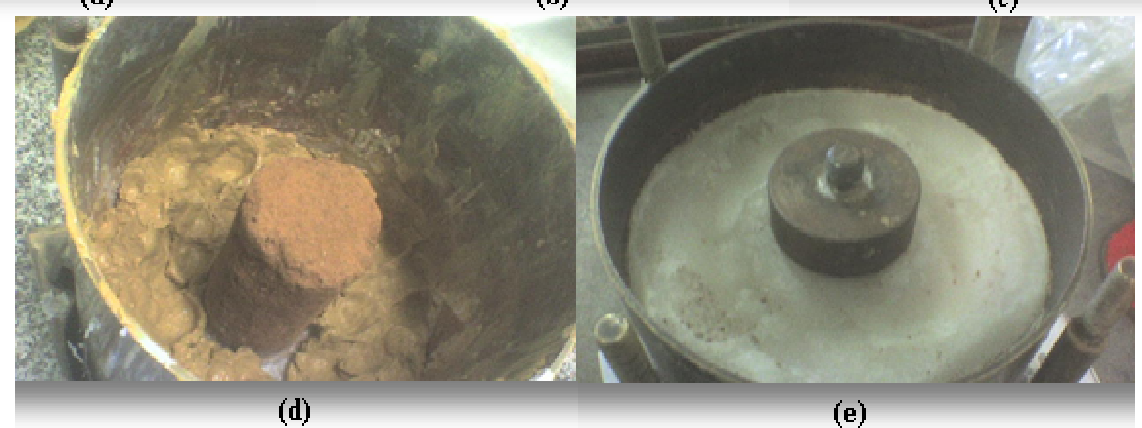

Figura 4.4 - Etapas da construção do permeâmetro: (a) Retirado do prisma do bloco; (b) Construção do cilindro; (c) Colocação de um camada de pedregulho para reduzir o impacto da água no cilindo; (d)

Colocação da bentonita para impermeabilizacao das paredes da amostra; (e) Finalização do permeâmetro com colocação da parafina.

Construído e instalado o permeâmetro (Figura 4.5), realizou-se o processo de saturação durante 48 horas e, posteriormente, a medição da vazão pelo método de carga constante.

$\mathrm{O}$ método da carga constante consiste em obter o fluxo de água que percorre o $\mathrm{CP}$ a partir da relação entre o volume de água percolada e o tempo do ensaio, mantendo constante a carga hidráulica aplicada na amostra.

Conhecendo a vazão e as dimensões do CP, calculou-se, pela Equação 4.4 e a partir de valores distintos de carga hidráulica, o valor médio da condutividade hidráulica saturada $\left(K_{s}\right)$. Para cada valor de carga hidráulica, foram determinados três valores de condutividade.

$$
K_{s}=\frac{V_{c p} \cdot H_{c p}}{A_{c p} \cdot h \cdot t_{e}}
$$

em que $V_{c p}$ é o volume de água que percorre o $\mathrm{CP}$, em $\mathrm{cm}^{3} ; H_{c p}$ é a altura do corpo-de-prova, em centímetros; $A_{c p}$ é a área da seção transversal do corpo-de-prova, em $\mathrm{cm}^{2} ; h$ é a carga 
hidráulica aplicada, em centímetros; e $t_{e}$ é tempo entre o início e o fim do ensaio, em segundos.

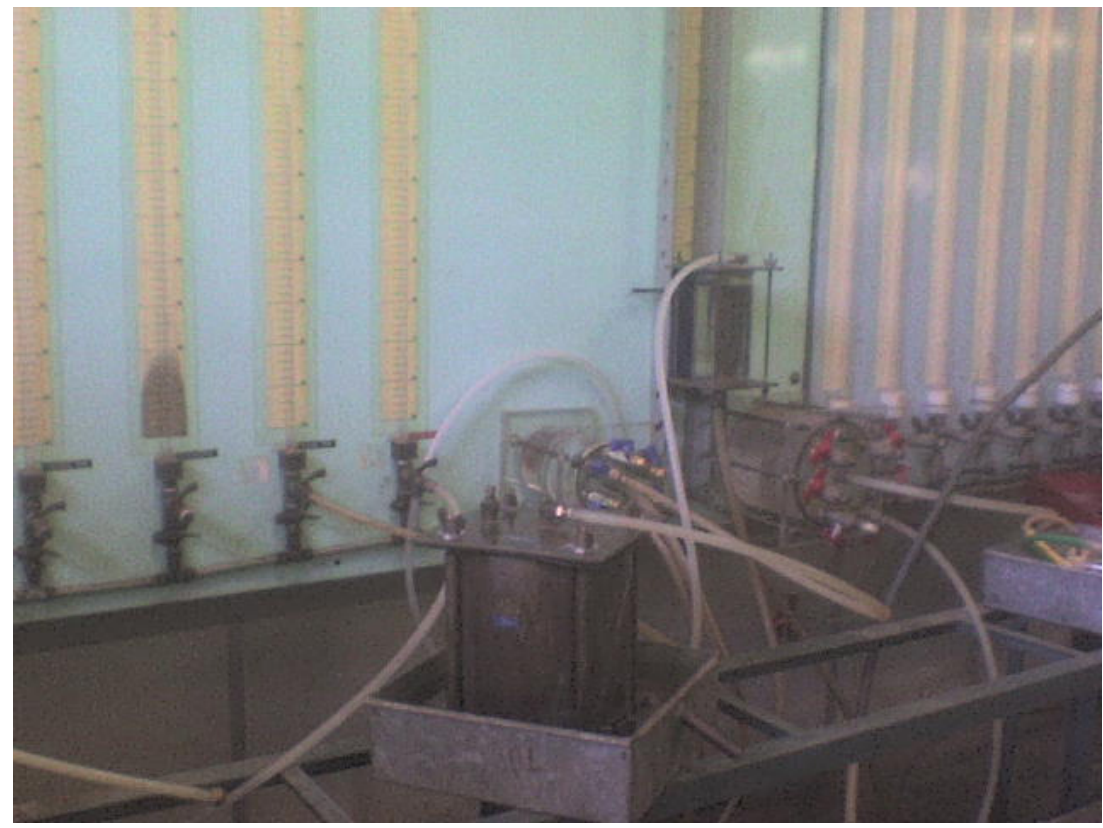

Figura 4.5 - Equipamento de aplicação e medição da carga hidráulica no permêmatro de carga constante.

\subsection{4 - Curva de retenção}

A curva de retenção ou curva característica do solo é expressa pela relação entre a umidade do solo e o potencial matricial (sucção) correspondente. Experimentalmente há inúmeras maneiras de medir esta relação (Tabela 3.1- Métodos de medida de sucção.Tabela 3.1). Neste trabalho optou-se por três métodos: funil de placa porosa, também chamado de funil de Haines, câmara de pressão de placa porosa, também chamada de câmara de Richards, e a técnica do papel-filtro. Os dois primeiros métodos foram utilizados, respectivamente, para obtenção dos pontos entre 0 e -1 m.c.a. e entre -1 e -70 m.c.a (metros de coluna de água) de uma única curva de retenção e o terceiro método foi utilizado para determinar uma segunda curva de retenção.

Considerando que a relação entre a umidade e o potencial matricial apresenta-se bastante variável para um mesmo solo, torna-se interessante comparar os pontos 
experimentais obtidos por cada ensaio e optar pela curva mais apropriada para o solo em questão.

Todos os ensaios foram iniciados com a moldagem de corpos-de-prova (CP) de 5,3 cm de diâmetro e $1 \mathrm{~cm}$ de altura, utilizando-se como gabarito um anel de PVC. Foram moldados $25 \mathrm{CP}$, sendo 15 para a técnica de papel filtro, 3 para a câmara de Richards, 6 para o funil de Haines e 1 para determinação da umidade de saturação. A Figura 4.6 ilustra os passos utilizados para retirada dos CP.

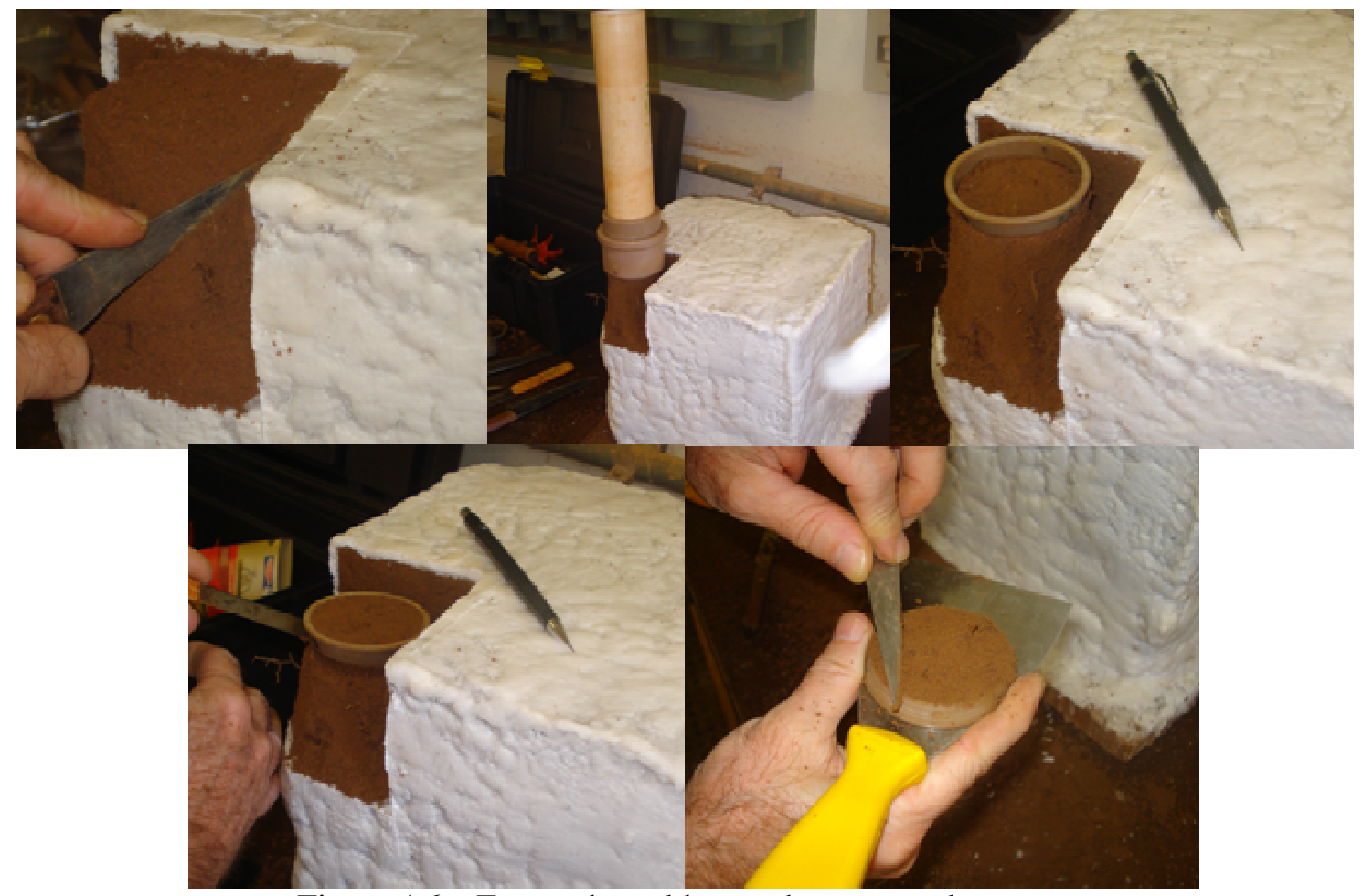

Figura 4.6 - Etapas de moldagem dos corpos-de-prova.

Posteriormente a confecção dos anéis, os índices físicos do solo foram calculados. Os índices necessários para o trabalho são: porosidade, índice de vazios e grau de saturação. Estes valores foram determinados, respectivamente, pela Equação 4.5, Equação 4.6 e Equação 4.7 .

$$
\eta=1-\frac{\rho_{d}}{\rho_{s}}
$$




$$
\begin{aligned}
& e=\frac{\rho_{s}}{\rho_{d}}-1 \\
& S r=\frac{\rho_{s} \cdot w}{e}
\end{aligned}
$$

em que $\eta$ é a porosidade do solo, adimensional; $\rho_{s}$ é a massa específica dos sólidos, g. $\mathrm{cm}^{-3} ; \rho_{d}$ é a massa específica do solo seco, g. $\mathrm{cm}^{-3} ; w$ é a umidade do solo, adimensional; $e$ é o índice de vazios, adimensional; e $S r$ é o grau de saturação, adimensional.

Em virtude de limitações do laboratório, para o ensaio utilizando câmara de Richards, ou de limitações do método, para a técnica de papel filtro, determinou-se a curva de retenção pelo processo de secagem da amostra previamente saturada, desconsiderando o efeito da histerese. Assim, saturaram-se as amostras lentamente pelo processo de ascensão capilar. Este consiste em colocar as amostras do solo sobre uma placa porosa, com quantidade de água (destilada e deaerada) suficiente para atingir 2/3 da altura das amostras (Figura 4.7).

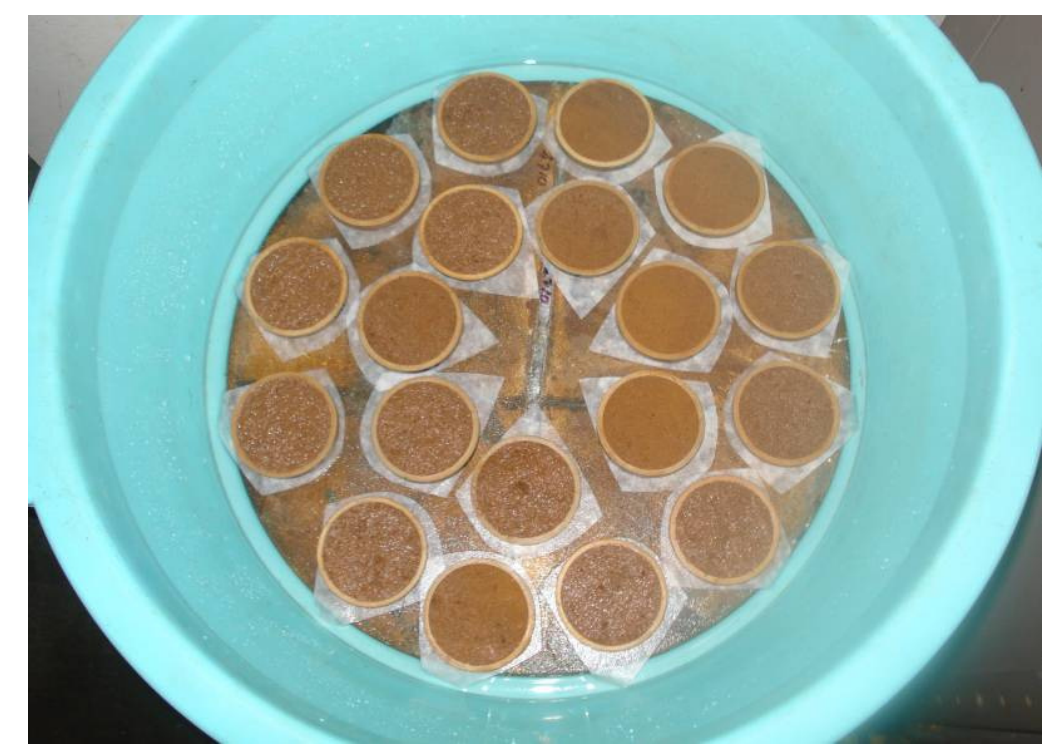

Figura 4.7 - Processo de saturação das amostras do solo.

As amostras permaneceram em contato com a água até que não houvesse variação representativa no peso de três $\mathrm{CP}$. Concluído o processo de saturação, os CP foram pesados e, posteriormente, deu-se sequência as etapas específicas de cada método. 
- Câmara de Richards

Três amostras foram dispostas no interior da câmara e submetidas a valores de sucção variáveis. Desta forma, para um mesmo valor de sucção, fez-se o acompanhamento do peso de cada $\mathrm{CP}$. Ao atingir o equilíbrio em todos os $\mathrm{CP}$, determinou-se o peso e aumentou-se o valor de sucção. Neste trabalho, os valores de sucção utilizados foram iguais a: 1, 2, 3, 4, 5, 10, 20, 40 e 70 m de coluna de água (m.c.a.).

- Funil de Haines

O funil de placa porosa é constituído de um cilindro de acrílico conectado pelo fundo a uma coluna pendente de água terminando num frasco de 0,2 L (Figura 4.8).
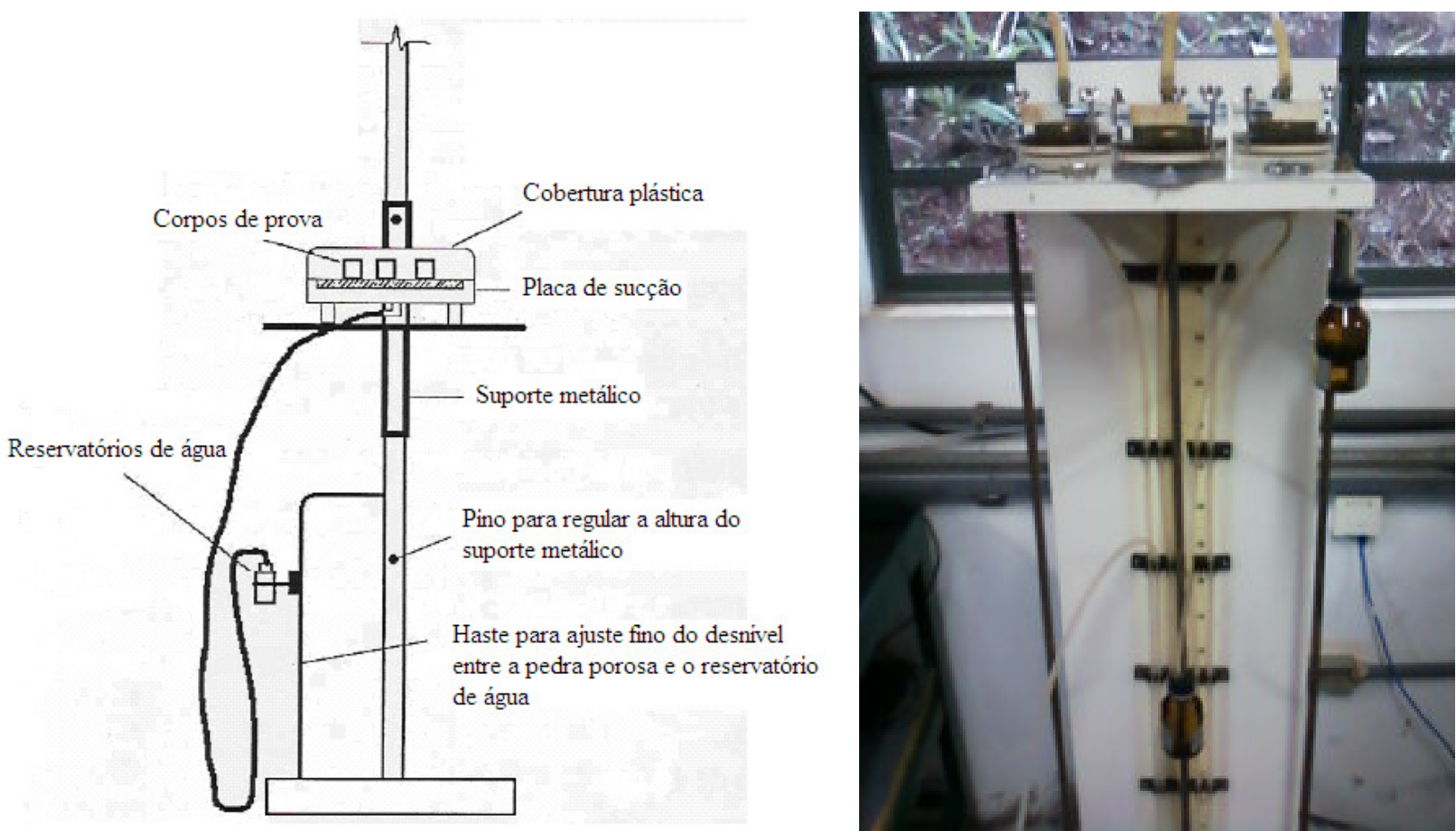

Figura 4.8 - Funil de placa porosa.

Cada CP foi colocado individualmente no interior do funil e assentado sobre uma placa porosa previamente saturada. Para cada $\mathrm{CP}$, ajustou-se o frasco a uma altura da coluna de água $(0,1,0,2$ 0,3, 0,4, 0,5 e 1 m.c.a.). Após cessar a drenagem de água pelo frasco, as amostras contidas nos CP foram pesadas e transferidas para estufa. Ao término da secagem, 
determinou-se a umidade volumétrica presente na amostra no momento em que foi atingido o equilíbrio.

- Papel-filtro

Após a saturação, os quinze CP foram colocados para secar até o teor de umidade gravimétrica desejado. O intervalo de umidade foi definido buscando uma boa representação ao longo dos intervalos que representam os micro e macroporos. Atingindo o valor de umidade requerido, colocou-se o topo e a base do $\mathrm{CP}$ em contato com um papel filtro calibrado (Whatman $\mathrm{N}^{\mathrm{o}}$ 42). Posteriormente, envolveu-se com o filme plástico o CP para evitar a perda ou ganho de umidade. Prontas todas as amostras, estas foram colocadas devidamente identificadas em um saco plástico selado dentro de uma caixa de Isopor para o equilíbrio da sucção. Após 10 dias, os papéis filtro foram retirados, pesados e levados a secar na estufa $\left(105^{\circ} \mathrm{C}\right)$ por um período de quatro horas. Em seguida, a umidade gravimétrica do papel filtro foi determinada e o valor de sucção foi obtido a partir da curva de calibração do papel (Equação 4.8). No mesmo momento, também foi determinado o teor de umidade das amostras de cada anel. Estes valores relacionados com os valores de sucção formam a curva de retenção do solo.

$$
\begin{aligned}
& w>47 \% \Rightarrow \psi=10^{(6.05-2.48 \cdot \log w)-2} \\
& w \leq 47 \% \Rightarrow \psi=10^{(4.84-0.0622 \cdot w)-2}
\end{aligned}
$$

em que $w$ é a umidade gravimétrica do papel, em kg. $\mathrm{kg}^{-1}$; e $\psi$ é potencial matricial, em $\mathrm{mH}_{2} \mathrm{O}$.

Realizados os ensaios, o modelo de van Genuchten (1980) e o modelo alternativo proposto por Mendiondo (2001) foram ajustados aos pontos experimentais. Para o primeiro ajuste, utilizou-se o software SWRC desenvolvido por Dourado Neto et al. (2000), que estima os valores dos parâmetros empíricos da curva de retenção usando o método dos mínimos quadrados e o método iterativo de Newton-Raphson. Para o segundo ajuste, utilizou-se o software Labfit, desenvolvido pelo departamento de Física da Universidade Federal de 
Campina Grande, usando também o método dos mínimos quadrados e o método iterativo de Newton-Raphson.

No ajuste à curva de retenção os valores de $\theta_{r}$ e $\theta_{s}$ foram escolhidos como constantes a partir dos valores observados, sendo estes iguais para o ajuste unimodal e bimodal, e a relação $m=1-1 . n^{-1}$ foi considerada.

Para cada conjunto de dados, foram testadas várias configurações dos vetores de valores iniciais $[\alpha, n]$, no caso do ajuste unimodal, e $\left[\alpha_{1}, \alpha_{2}, n_{b}\right.$ e $\left.\theta_{p s}\right]$, no caso de ajuste bimodal. O número de iterações necessárias para assegurar convergência para a solução ótima não ultrapassou, na maioria dos casos, 57 iterações. O máximo erro relativo permitido na solução foi de $0,001 \%$ do valor absoluto do respectivo parâmetro.

\section{3 - Instalação da trincheira}

A instalação da trincheira foi realizada em três etapas: projeto, dimensionamento e execução.

\subsection{1 - Projeto}

A trincheira de infiltração foi projetada para receber o volume precipitado sobre área de $50 \mathrm{~m}^{2}$, conforme layout ilustrado na Figura 4.9. No projeto não foi considerado o volume precipitado sobre a trincheira, visto que este é desprezível quando comparado ao volume gerado sobre toda área.

Conforme foi mencionado e é apresentado na Figura 4.9, o sistema de captação de água pluvial instalado na área de implantação da trincheira consta de um separador, responsável pela retirada de materiais de grandes tamanhos (folhas, resíduos desprendidos das telhas de Tetra Pak, etc) o que reduz a possibilidade de colmatação, e um reservatório de $6 \mathrm{~m}^{3}$ para acumulação da água proveniente do telhado. 
Como os ensaios experimentais foram realizados com chuvas simuladas (alimentação exclusiva à trincheira), o reservatório tinha o objetivo de acumular a parcela precipitante que escoava sobre o telhado para que, no momento do ensaio, alimenta-se a trincheira. Desta forma, para que todo o reservatório pudesse ser utilizado, implantou-se um sistema hidráulico na parte inferior do reservatório.

Como a trincheira após o trabalho continuará sendo utilizada e monitorada, instalou-se no reservatório de acumulação um sistema de escape a fim de possibilitar que a alimentação à trincheira, quando não esteja em experimento, seja realizada através do volume de água que precipita sobre o telhado e extrapola a capacidade de acumulação do reservatório. 


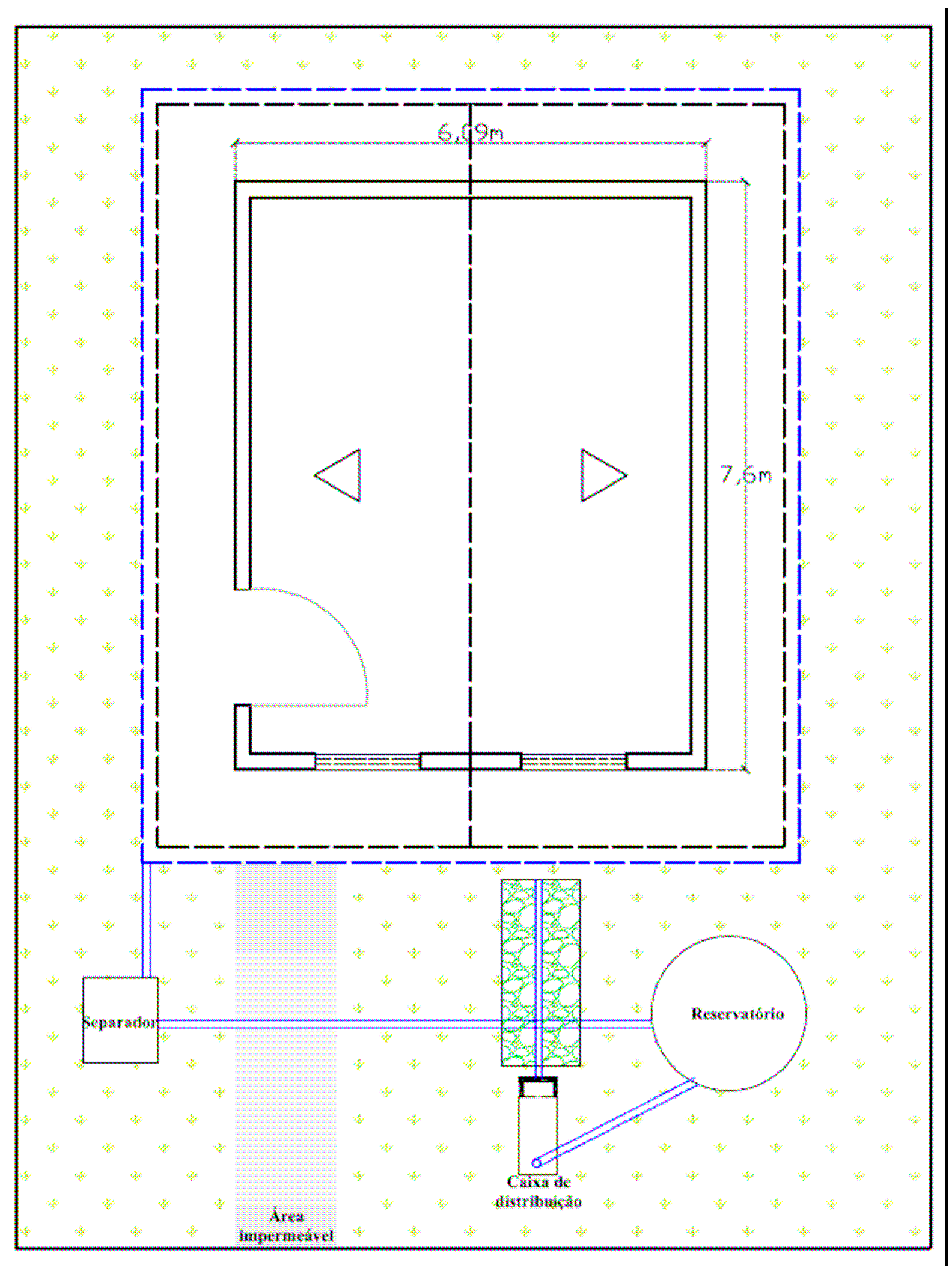

Figura 4.9 - Layout da área de contribuição para trincheira de infiltração. 


\subsection{2 - Dimensionamento}

A trincheira foi dimensionada com base na metodologia apresentada por Graciosa (2005) e descrita no item 2.4. Nesta metodologia, o volume da trincheira é obtido a partir da diferença máxima entre o volume de entrada, determinado pelo método racional, e o volume de saída, determinado pelo modelo de Philip.

O volume de entrada foi determinado utilizando-se tempo de retorno de 5 anos para a curva idf ajustada para São Carlos (Equação 2.1). O coeficiente de escoamento adotado foi igual a 0,95 , pois mesmo se tratando de um telhado totalmente impermeável (coeficiente de escoamento igual a 1,00), considerou-se perdas iniciais no telhado, bem como retardo no escoamento.

O volume de saída foi determinado considerando a sortividade igual a $7.10^{-5} \mathrm{~m} \cdot \mathrm{s}^{-1 / 2}$. Em virtude do laboratório de Geotecnia da EESC/USP não realizar ensaios com cilindros concêntricos (um dos ensaios mais usados na determinação da infiltração), o valor de sortividade utilizado foi obtido através do trabalho de Graciosa (2005).

Como descrito no item 2.4.2, para o dimensionamento da trincheira é necessário definir inicialmente suas dimensões. Desta forma, fixaram-se a largura e a profundidade em $0,8 \mathrm{~m}$ e $1,3 \mathrm{~m}$, respectivamente. A largura foi definida igual a $0,8 \mathrm{~m}$ por corresponder ao valor mínimo requerido por um poceiro para extrair um bloco indeformado. Contudo, por problemas durante a escavação, a largura da trincheira foi aumentada para 1 metro e, como a área lateral da trincheira não poderia ser modificada, a profundidade foi reduzida para 1 metro.

Em relação à porosidade do material de preenchimento, esta foi determinada através da relação entre o volume da água presente nos vazios do material granular, contido no interior de um recipiente, e o volume do recipiente, sendo encontrado o valor de 0,37 . A Figura 4.10 ilustra os materiais utilizados para determinação da porosidade. 


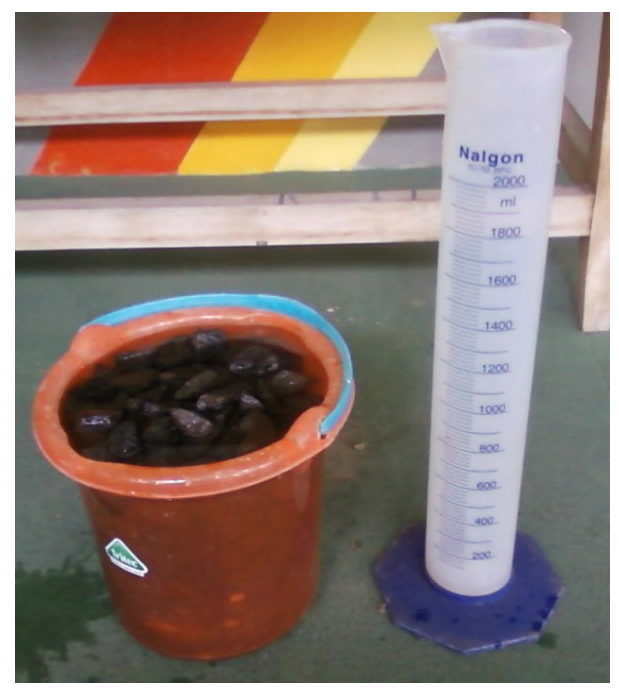

Figura 4.10 - Instrumentos utilizados para determinar a porosidade do material de preenchimento da trincheira.

Com base nestes dados, procedeu-se ao dimensionamento tal como descrito no item 2.4.2, o que resultou num gráfico de volumes acumulados de entrada e saída do dispositivo, conforme a Figura 4.11. Nesta figura também é apresentado o ponto de máximo volume (ponto de dimensionamento).

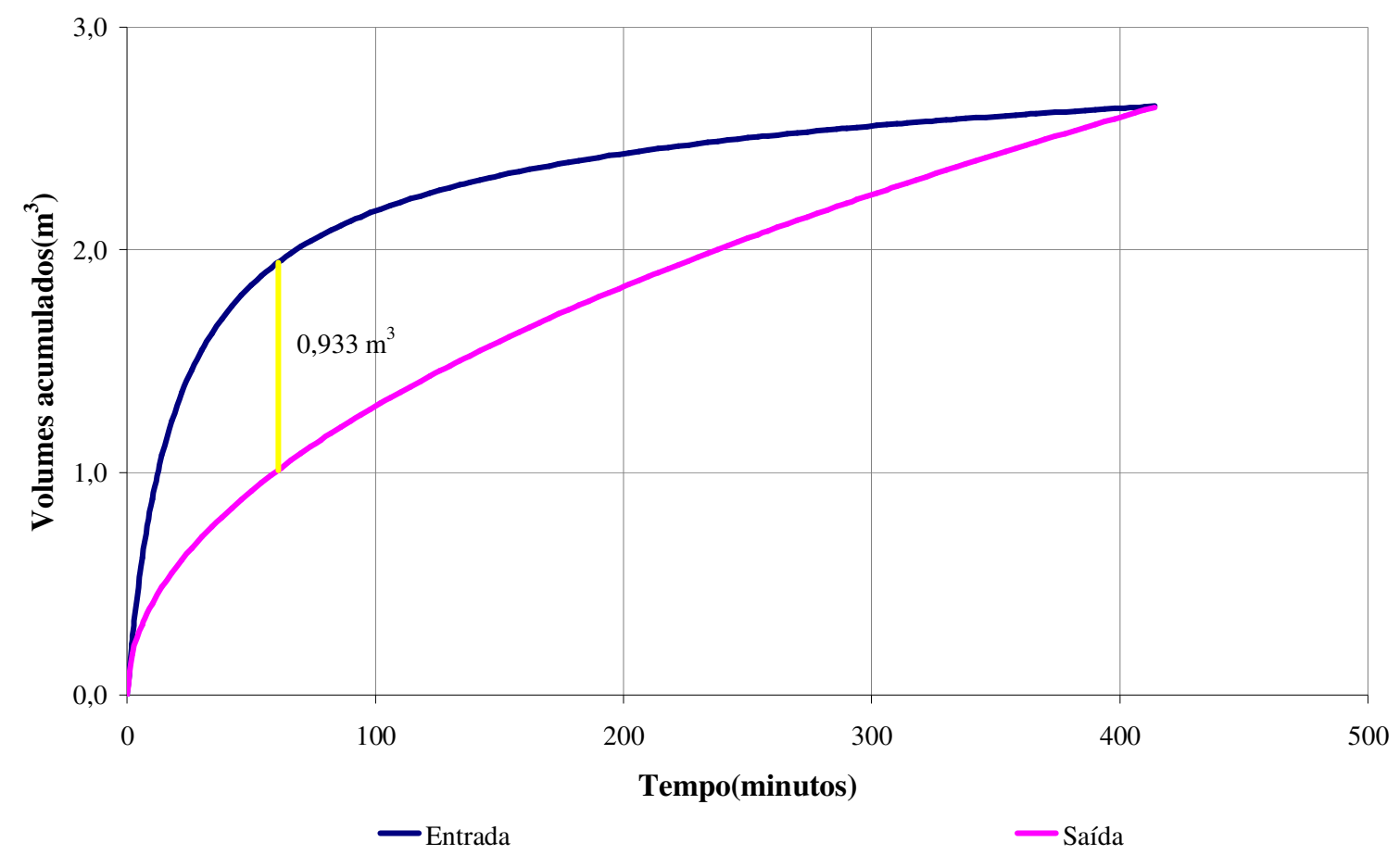

Figura 4.11 - Volumes acumulados de entrada e saída no dispositivo de infiltração. 
O processo de dimensionamento é iterativo, tendo sido iniciado para o comprimento de $2 \mathrm{~m}$ e chegando ao comprimento final de 2,4 $\mathrm{m}$, o que resulta em um volume da trincheira igual a $2,4 \mathrm{~m}^{3}$.

Além do dimensionamento da trincheira, também foi dimensionada a tubulação presente no seu interior e responsável por sua alimentação. Para isto, foram considerados os seguintes requisitos da NBR 10844 - "Instalações Prediais de Águas Pluviais":

- os condutores horizontais devem ser projetados com declividade mínima de 0,5\%;

- o coeficiente de Manning para tubo de PVC corresponde a 0,011; e

- a altura da lâmina de água é igual a $2 / 3$ do diâmetro da tubulação.

A vazão circulante na tubulação foi determinada pelo mesmo método utilizado para determinar o volume de entrada na trincheira. Desta forma, com o valor da vazão e com base nas recomendações da NBR 10844, determinou-se o diâmetro da tubulação a partir da equação de Manning (Equação 4.9).

$$
Q=\frac{1}{c_{M}} \cdot R_{h}^{2 / 3} \cdot A_{T} \cdot \sqrt{D}
$$

em que $Q$ é a vazão circulante, em $\mathrm{m}^{3} . \mathrm{s}^{-1} ; c_{M}$ é o coeficiente de Manning, adimensional; $R_{h}$ é o raio hidráulico, em m; $A_{T}$ é a área transversal da tubulação, em $\mathrm{m}^{2}$; e $D$ é a declividade, em $\mathrm{m} \cdot \mathrm{m}^{-1}$.

\subsection{3 - Execução}

A execução da trincheira foi realizada em três etapas: escavação, preenchimento e acabamento.

A escavação foi feita inicialmente de forma manual, pois havia a necessidade de retirar dois blocos de amostras indeformadas para realização dos ensaios laboratoriais, assim como foi ilustrado na Figura 4.2. Retirados os blocos, procedeu-se a escavação por uma retro- 
escavadeira com pá de $0,8 \mathrm{~m}$. Estes procedimentos são demonstrados na Figura 4.12 e na Figura 4.13.

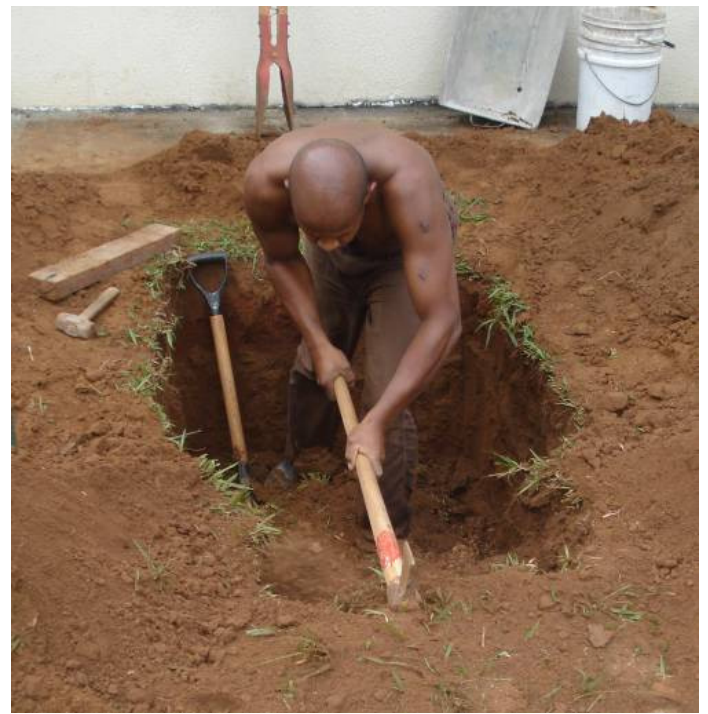

Figura 4.12 - Escavação manual da trincheira.

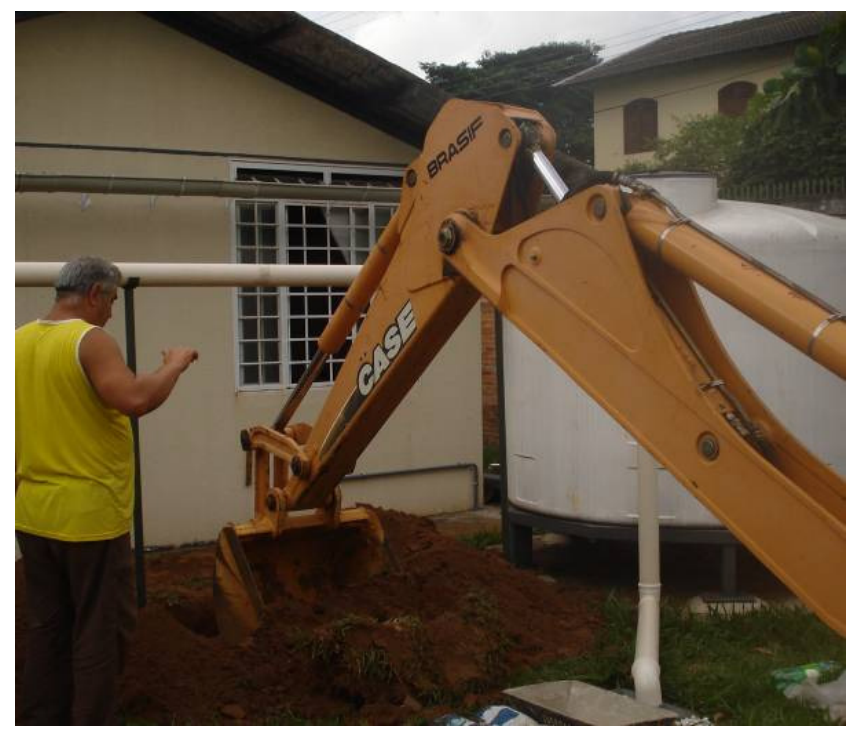

Figura 4.13 - Escavação da trincheira com retroescavadeira.

Posteriormente à escavação pela retro-escavadeira, houve o aparecimento de buracos nas paredes laterais decorrentes da presença de raízes. Por isso, a largura da trincheira precisou ser aumentada. Desta forma, foi necessário proceder novamente à escavação manual buscando tornar planas as paredes da trincheira.

É importante lembrar que em virtude das raízes podem ter sido formados macroporos ou caminho preferencial, porém esta possibilidade foi desconsiderada no estudo quantitativo da trincheira.

Após a escavação, recobriu-se com manta geotêxtil do tipo bidim ${ }^{\circledR}$ todas as faces e o fundo da estrutura (Figura 4.14), resguardando-se para evitar rasgos na manta quando em contato com a brita. Como o fundo é mais susceptível à colmatação, foram colocadas duas camadas de manta. 


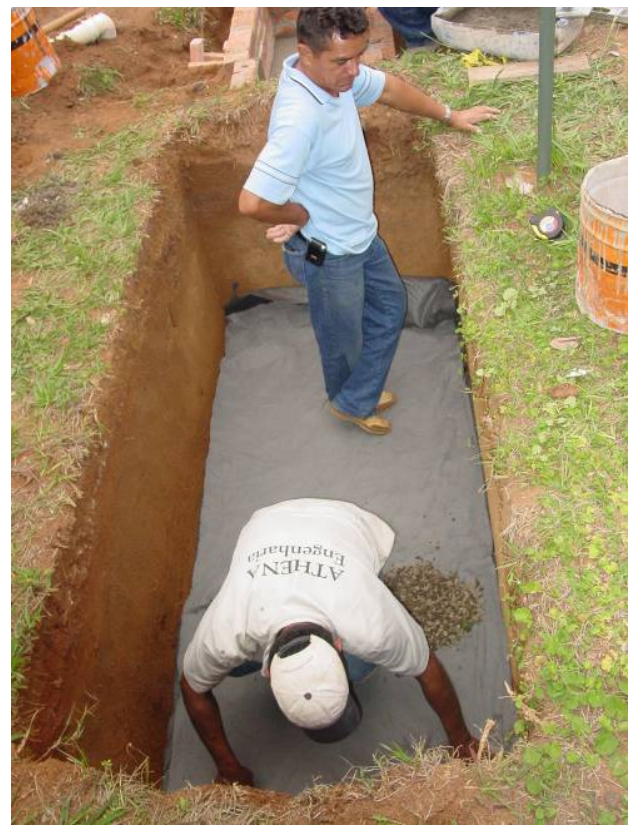

(a)

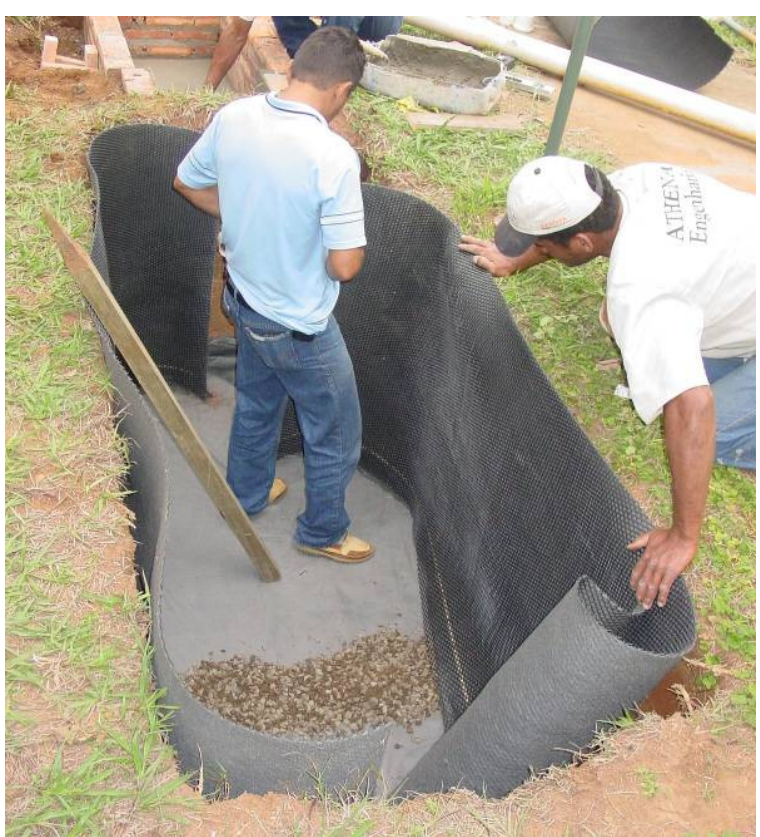

(b)

Figura 4.14 - Aplicação da manta geotêxtil: a) no fundo; b) nas paredes da trincheira.

No fundo da trincheira, o preenchimento foi iniciado utilizando brita $n^{\circ} 1$ até uma altura de $10 \mathrm{~cm}$. Este procedimento objetivou-se evitar que a alimentação concentrada, quando em contato com o fundo, provocasse erosão local.

A tubulação de alimentação construída de PVC de diâmetro de 3" foi perfurada e recoberta com manta geotêxtil para impedir a entrada de material fino em seu interior. Posterior a instalação da tubulação, finalizou-se o preenchimento com brita $n^{\circ} 3$.

O corte longitudinal da trincheira com as camadas de preenchimento encontra-se ilustrado na Figura 4.15. 


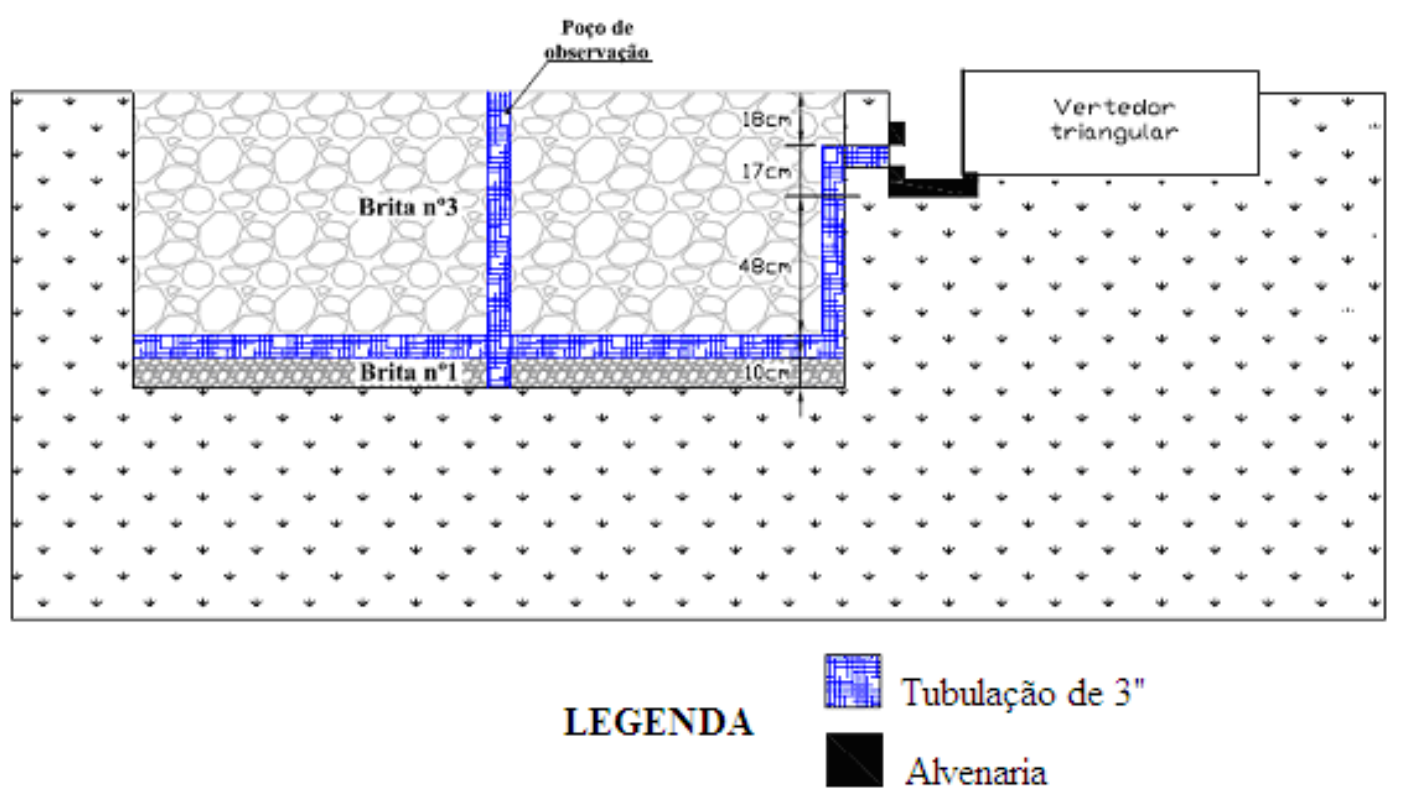

Figura 4.15 - Corte longitudinal da trincheira de infiltração.

O poço de observação ilustrado na Figura 4.15 foi executado em tubo PVC de 3" perfurado em pontos equidistantes. Este poço foi construído para permitir a medição do nível da trincheira a partir de sensores de nível.

Durante o preenchimento da trincheira, cuidou-se para que todo o material fosse colocado limpo como forma de evitar colmatação inicial decorrente das partículas finas (pó) presentes no material granular. A Figura 4.16 e a Figura 4.17 ilustram, respectivamente, a lavagem e o preenchimento da trincheira.

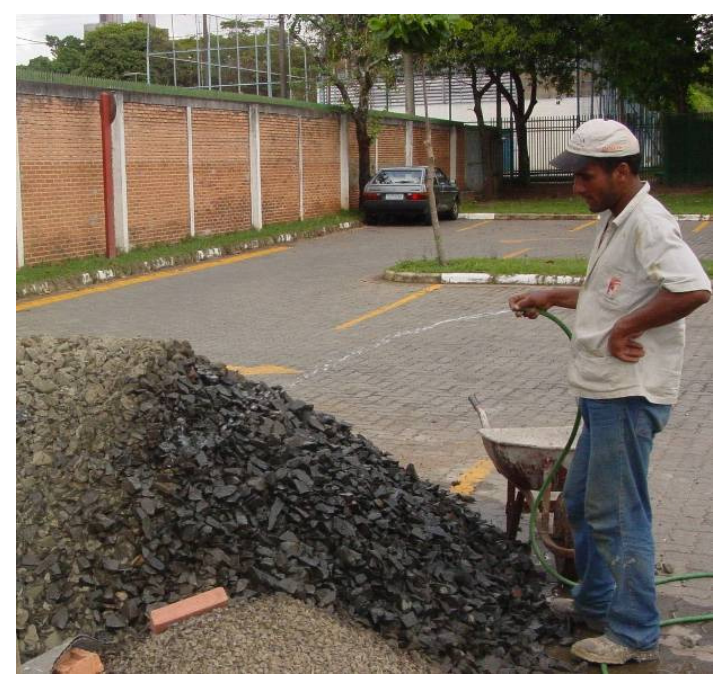

Figura 4.16 - Lavagem do material de preenchimento da trincheira antes de sua utilização.

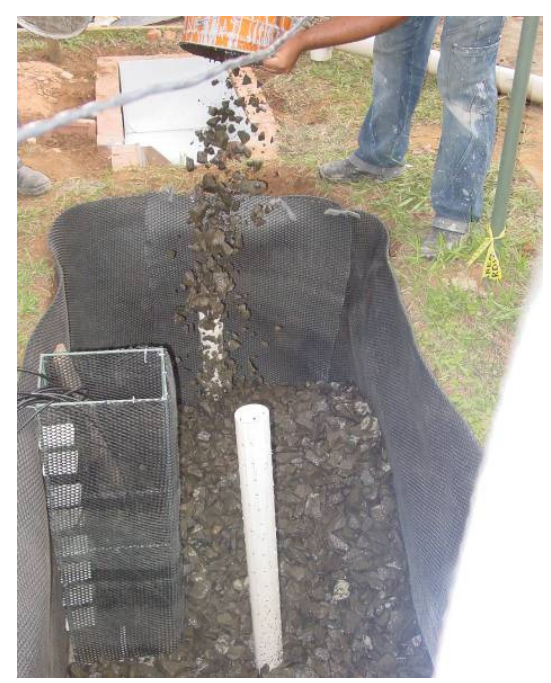

Figura 4.17 - Preenchimento manual da trincheira de infiltração. 
Finalizada a disposição do material de preenchimento, promoveu-se o envelopamento da trincheira com manta geotêxtil e, por fim, realizou-se o acabamento com pedra branca (Figura 4.18).

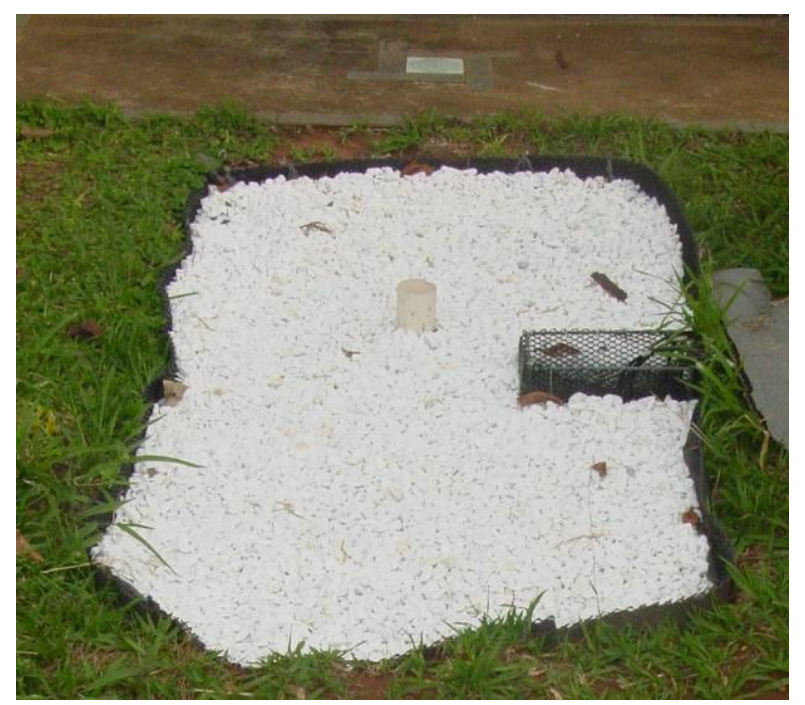

Figura 4.18 - Trincheira pronta para o monitoramento.

\section{4 - Variáveis de controle e instrumentação de medição}

A avaliação do comportamento quantitativo da trincheira perante chuvas simuladas (alimentação exclusiva à trincheira) e a determinação de valores de infiltração para comparação com os dados modelados foram efetuadas através de ensaios experimentais realizados durante a adução e recessão de água no interior da trincheira. Para realização dos ensaios, foram monitorados a vazão de entrada, o nível de água na trincheira e a umidade do solo.

\subsection{1 - Vazão de entrada}

Considerando a vazão de entrada na trincheira (inferior a $30^{10} 1 . \mathrm{s}^{-1}$ ) e os fatores econômicos e funcionais da instalação de um medidor de vazão, optou-se em determinar a vazão de entrada a partir da leitura de nível de um vertedor triangular de ângulo de abertura igual à $90^{\circ}$.

\footnotetext{
${ }^{10}$ Valor máximo recomendável para utilização do vertedor triangular com boa precisão.
} 
O vertedor foi construído de chapa de alumínio com $4 \mathrm{~mm}$ de espessura e acoplado a uma caixa de calha galvanizada com $1 \mathrm{~m}$ de comprimento. As dimensões do vertedor, $0,50 \mathrm{~m}$ de largura e 0,35 m de altura, foram determinadas a partir da equação proposta por Kindsvater e Carter $^{11}$ (1957 apud Lencastre, 1961, p. 210). A carga hidráulica máxima medida no vertedor é de 0,15 metros.

Para evitar o tombamento das paredes da caixa de distribuição, devido à pressão da água, foram construídas paredes de alvenaria circundante a caixa (Figura 4.19). Em virtude da instabilidade da linha de água no interior da caixa, foram instalados tranquilizadores de fluxo formado por tijolos de 8 furos (Figura 4.20).

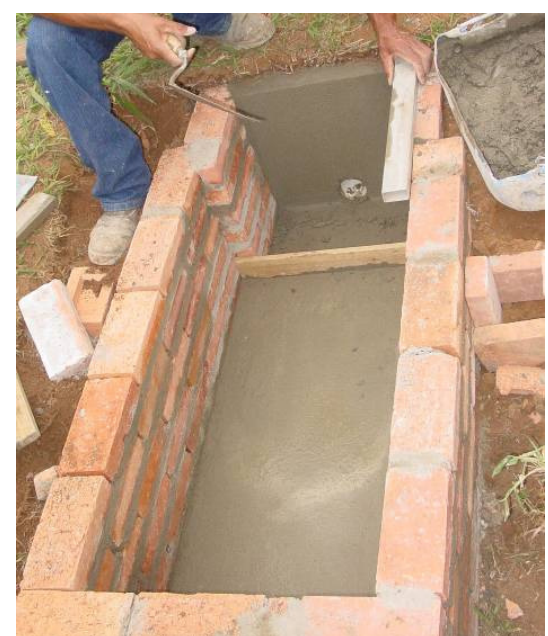

Figura 4.19 - Construção de paredes de alvenaria circundantes ao vertedor.

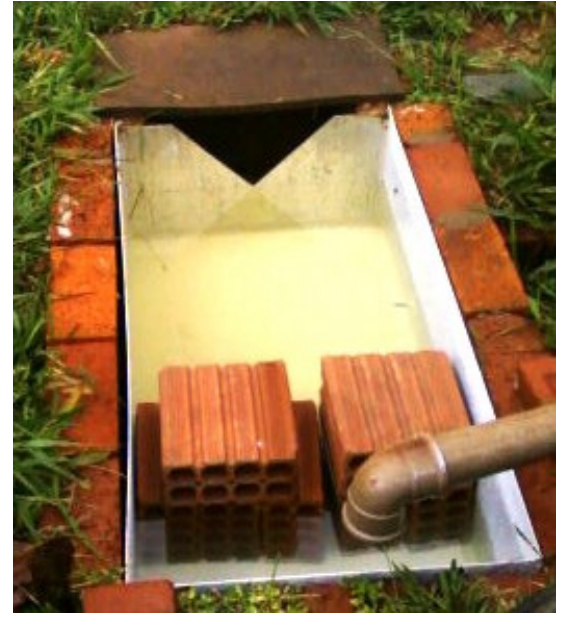

Figura 4.20 - Vertedor pronto para medição da vazão de entrada na trincheira.

A leitura de nível no vertedor foi estimada a partir de um manômetro diferencial digital acoplado ao fundo do vertedor e desenvolvido pela T\&S Equipamentos Eletrônicos. O manômetro (Figura 4.21) apresenta memória de armazenamento para 600 leituras e pressão máxima de $0,7 \mathrm{mH}_{2} \mathrm{O}$.

Anterior à determinação indireta da vazão a partir do vertedor, foi efetuada a calibração de sua equação. Para isto, foram utilizados dados de nível de água no vertedor e de

\footnotetext{
11 KINDSVATER, C. E.; e CARTER, R. W. (1959). "Discharge characteristics of rectangular thin-plate
} weirs." American Society of Civil Engineering. Journal of Hydraulic Engineering, v. 124, p. 772 - 822. 
vazão necessária para encher uma caixa de volume conhecido em um determinado intervalo de tempo.

\subsection{2 - Nível de água no interior da trincheira}

A medição de nível de água foi feita no poço de observação colocado no interior da trincheira através do linígrafo CTD-Diver® desenvolvido por Eijkelkamp Agrisearch Equipment. O CTD-Diver (Figura 4.22) consiste de um equipamento portátil, de fácil manipulação e representativo na solução de monitoramento de variáveis como: nível de água, temperatura e condutividade elétrica.

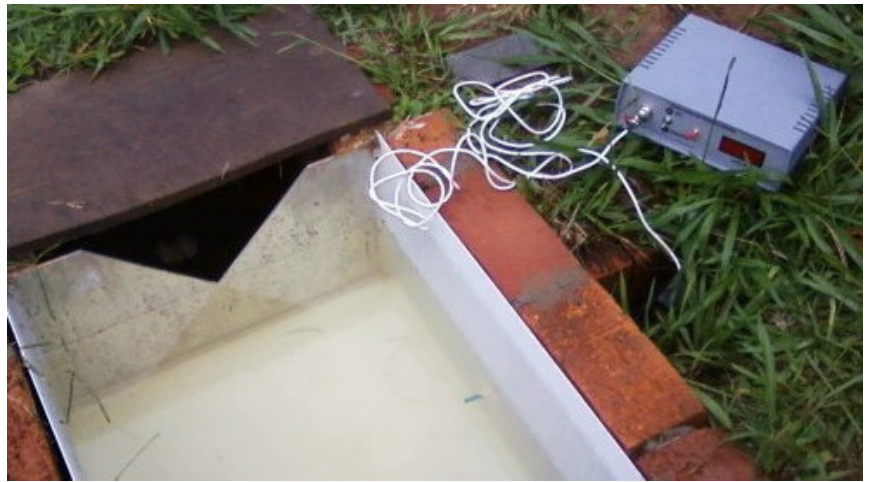

Figura 4.21 - Manômetro para medição da altura de água no vertedor triangular.

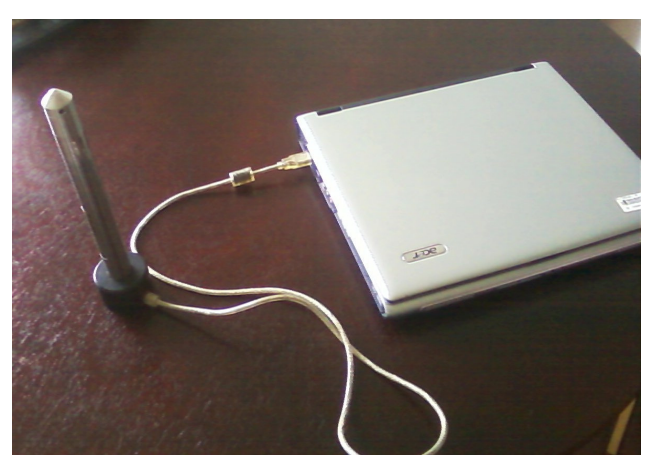

Figura 4.22 - CTD-Diver

A transmissão dos dados ocorre por infravermelho através de unidade de leitura conectada a um computador ou palm-top. O coletor de dados do equipamento possui memória de armazenamento para até 16.000 leituras. Os dados obtidos pelo equipamento foram processados pelo programa LoggerDataManager.

\subsection{3 - Umidade do solo}

A medição de umidade do solo foi determinada a partir da técnica Time Domain Reflectometry (TDR), por meio de sondas CS616 conectadas ao coletor de dados CR1000 da 
Campbell Scientific. As sondas são constituídas de 2 hastes de aço inoxidável de 0,3 m de comprimento conectadas a um circuito eletrônico protegido por epóxi.

A sonda CS616 utiliza o mesmo princípio da medida de tempo do trânsito do pulso eletromagnético, assim como realizado por equipamentos de TDR, e obtém a constante dielétrica do meio onde se encontra inserida através da Equação 3.2

Os dados de constante dielétrica determinados pelas sondas são automaticamente convertidos em valores de umidade do solo. Esta conversão, gerada no coletor de dados (datalogger), é realizada através de uma rotina computacional criada através do software (LoggerNet) fornecido pela Campbel Scientific. Nesta rotina, a equação utilizada para conversão dos dados de constante dielétrica em umidade do solo foi disponibilizada pelo fabricante e é representada pela Equação 4.10.

$$
\theta=-0,0663-0,0063 \cdot k+0,0007 \cdot k^{2} \quad \text { Equação } 4.10
$$

em que $\theta$ é a umidade volumétrica, $\mathrm{em}^{3} \cdot \mathrm{m}^{-3}$; e $k$ é a constante dielétrica, adimensional.

Os dados de umidade do solo foram determinados em uma única vertical localizada no centro da face leste da trincheira. Nesta vertical, foram inseridas horizontalmente oito sondas espaçadas em $10 \mathrm{~cm}$, com início da instalação a $10 \mathrm{~cm}$ da superfície (Figura 4.23).

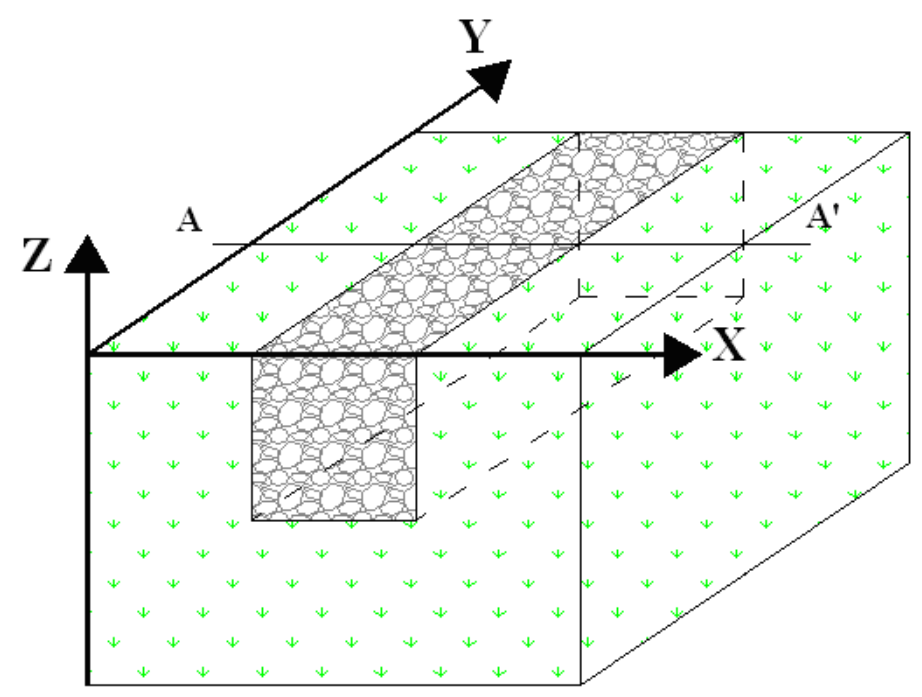

CORTE AA'

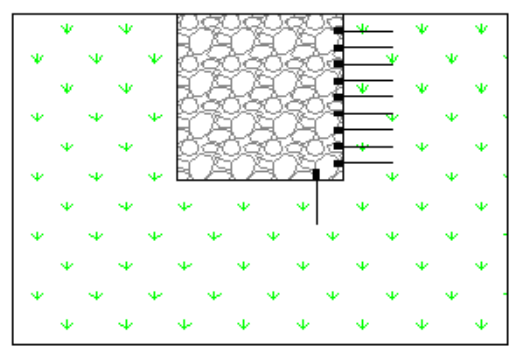

Figura 4.23 - Esquema de instalação das sondas no interior da trincheira de infiltração. 
Uma sonda inserida verticalmente foi colocada na base da trincheira a fim de avaliar a infiltração que se processa no fundo, entretanto, esta não fez parte da modelagem, uma vez que foi considerado fundo completamente colmatado.

Durante a instalação teve-se o cuidado para que as hastes não sofressem alteração em sua configuração, pois isto acarretaria alterações na direção do pulso, gerando problemas nos valores obtidos. Por isso, utilizou-se a ferramenta 14383, disponibilizada pela Campbell Scientific, para realizar o furo e, posteriormente, realizou-se a inserção de cada sonda.

Outro procedimento adotado para evitar alterações na configuração da sonda foi a instalação de uma caixa gradeada para separação das sondas em relação à brita. Com a utilização desta caixa, a porosidade média do material que compõe a trincheira foi alterada de 0,37 para 0,4 .

Todos os procedimentos adotados durante a instalação das sondas encontram-se ilustrados na Figura 4.24.

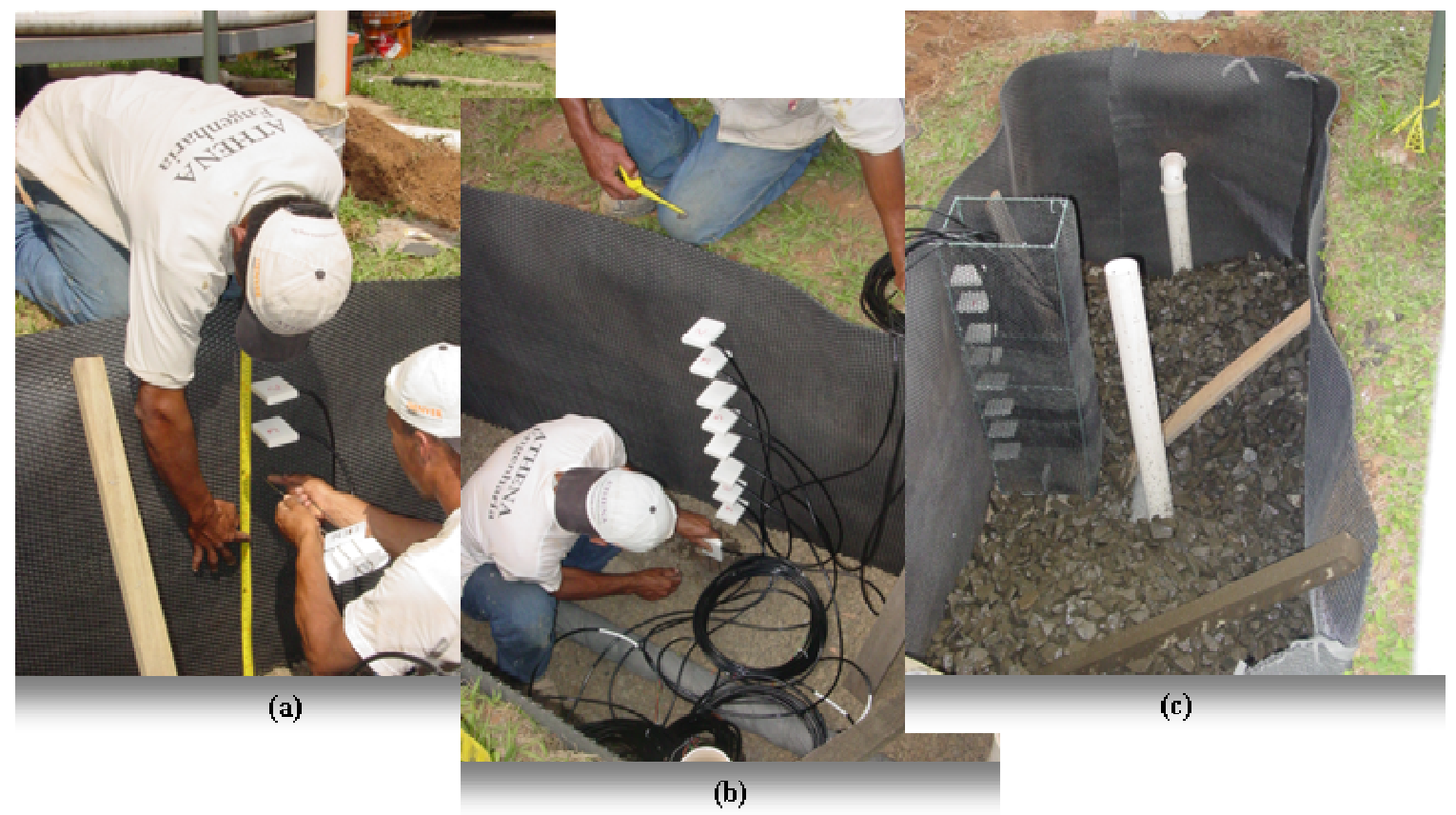

Figura 4.24 - Instalação das sondas: (a) localização de cada sonda; (b) término da instalação; (c) colocação da caixa gradeada para proteção das sondas. 
Instalados os equipamentos, procederam-se os ensaios experimentais. Estes foram realizados em duas fases: adução e recessão. $\mathrm{Na}$ adução foram medidos os valores de vazão de entrada, nível da trincheira e umidade. Com base nestes valores e utilizando a Equação 4.11, foi calculada a infiltração acumulada.

$$
I_{o}=\frac{V_{\mathrm{inf}}}{A_{\mathrm{inf}}}=\frac{\left(\sum_{j=1}^{n}\left(Q_{e n t}^{j} \cdot \Delta t\right)-h^{j} \cdot \eta_{t} \cdot A_{\text {base }}\right)}{A_{\mathrm{inf}}}
$$

em que $I_{o}$ é a infiltração acumulada observada nos ensaios experimentais, $\mathrm{em} \mathrm{m}^{3} \cdot \mathrm{m}^{-2} ; V_{\text {inf }}$ é o volume infiltrado, em $\mathrm{m}^{3} ; A_{\text {inf }}$ é a área efetiva de infiltração, em $\mathrm{m}^{2} ; Q_{e n t}$ é a vazão que entra na trincheira, em $\mathrm{m}^{3} \cdot \mathrm{s}^{-1} ; h$ é a altura no interior da trincheira, em $\mathrm{m} ; A_{b a s e}$ é a área da base da trincheira, em $\mathrm{m}^{2} ; \Delta t$ é o tempo de discretização do ensaio, em s; e $\eta_{b}$ é a porosidade do material de preenchimento da trincheira, adimensional.

$\mathrm{Na}$ fase de recessão, que se inicia ao fim da alimentação à trincheira (vazão de entrada nula), foram medidos o nível de água na trincheira e a umidade. A partir destes valores, determinou-se a infiltração acumulada através da Equação 4.12

$$
I_{o}=\frac{V_{\mathrm{inf}}}{A_{\mathrm{inf}}}=\frac{V_{e n t}-\left(\Delta h \cdot \eta_{t} \cdot A_{\text {base }}\right)}{A_{\mathrm{inf}}}
$$

em que $V_{\text {ent }}$ é o volume total aduzido para a trincheira durante a fase de adução, em $\mathrm{m}^{3}$; e $\Delta h$ é a variação da altura durante intervalos de tempo sucessivos, em $\mathrm{m}$.

Como descrito através da Tabela 2.3, a definição do parâmetro $A_{\text {inf }}$ é bastante variável em diferentes países. Por isso, como forma de encontrar o valor mais adequado para calcular a infiltração acumulada, mediu-se a variação da área infiltrante durante o processo de adução e recessão e utilizou-se o valor médio desta variação. Devido à possibilidade de colmatação na base da trincheira ao longo do tempo, foi admitido fundo colmatado para o cálculo da área. 
Todos os equipamentos supracitados utilizados para o monitoramento constam de registradores automáticos. Os dados são registrados continuamente, com intervalos de tempo conhecidos.

Foram realizados três experimentos, os quais ocorreram nos dia 7, 17 e 24 do mês de fevereiro do corrente ano. Em todos os experimentos, cuidou-se para que os valores de umidades iniciais (antes do experimento) estivessem próximos. Os dois primeiros ensaios foram realizados com intervalo igual a 1 minuto. Já o terceiro experimento foi feito com intervalo de 10 segundos. A utilização deste intervalo deve-se ao fato que a variação de nível na trincheira, no decorrer de intervalos sucessivos, ocorreu de maneira rápida nos experimentos anteriores. Por isso, buscou-se avaliar os dados de infiltração para um intervalo mais curto.

Para realização dos ensaios, primeiramente os equipamentos eram sincronizados temporalmente. Em seguida, as sondas eram ligadas para monitorar o valor de umidade antes do experimento. Depois de decorrido alguns minutos, iniciava-se a adução. Esta permanecia até que o nível na trincheira chegasse a uma altura máxima adotada. Ao atingir esta altura, a adução era interrompida e começava a recessão. Esta, por sua vez, durava enquanto houvesse água no interior da trincheira. A Figura 4.25 e a Figura 4.25 ilustram, respectivamente, o andamento e o fluxograma do experimento. 


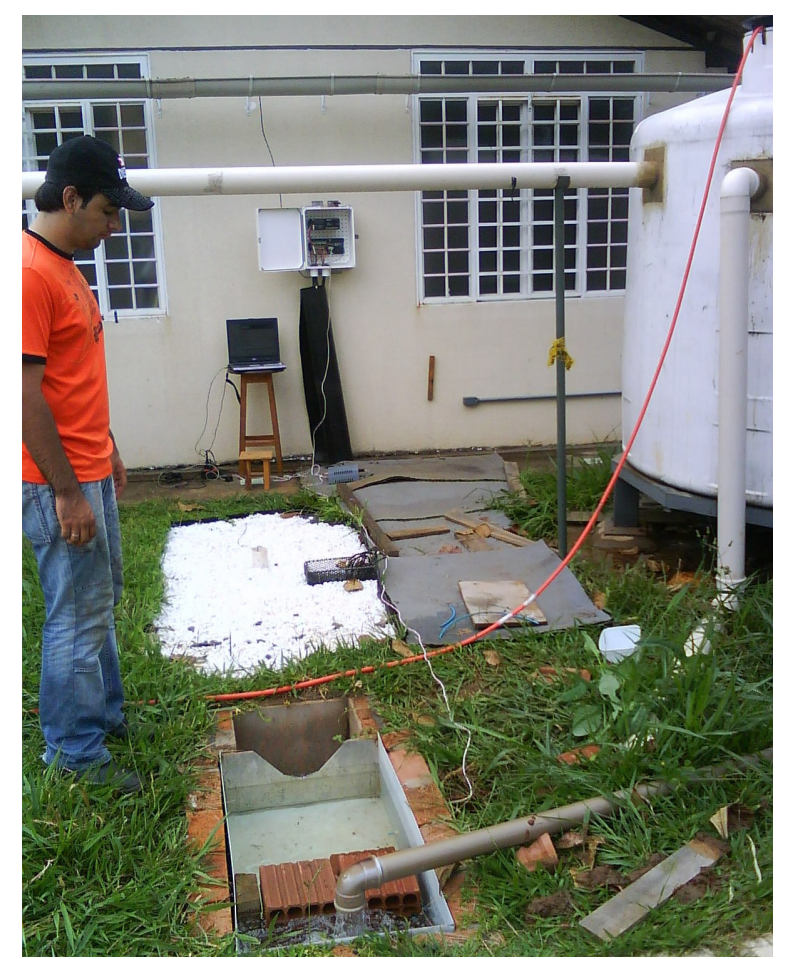

Figura 4.25 - Ilustração do ensaio experimental.

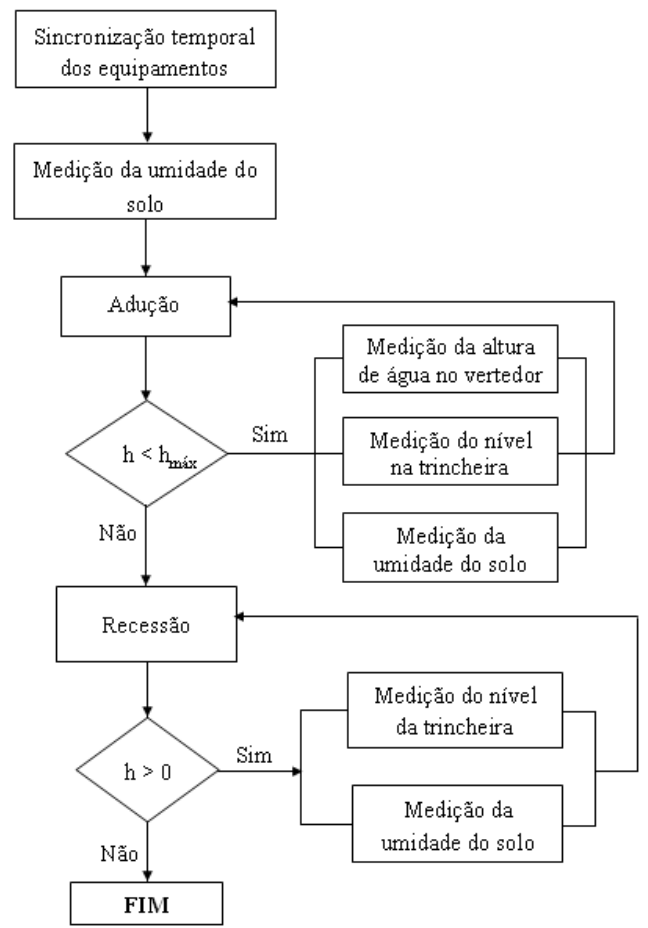

Figura 4.26 - Fluxograma do experimento. 


\section{5 - Processo de infiltração horizontal}

A determinação numérica da infiltração, calculada a partir de um modelo, foi realizada a fim de estudar uma nova forma de medir a vazão de saída em trincheiras de infiltração.

Para determinar a infiltração, algumas hipóteses tiveram que ser assumidas para simplificar o processo, pois sabe-se que a infiltração no interior da trincheira se dá nas três dimensões com quantitativos diferentes. Desta forma, assumiram-se as seguintes hipóteses:

1) A infiltração não varia ao longo do eixo longitudinal da trincheira e apresenta simetria de comportamento espacial para o lado esquerdo (LE) e lado direito (LD), $\theta^{L E}(t)=$ $\theta^{L D}(t)$ e $K\left(\theta^{L E}(t)\right)=K\left(\theta^{L D}(t)\right)$ para todos os tempos.

2) A infiltração é nula para todos os pontos do fundo.

3) A infiltração varia espacialmente ao longo da vertical, $z=1,2, \ldots, j$, sendo $z$ uma camada de $10 \mathrm{~cm}$ de espessura: $\theta_{z=1}(t) \neq \theta_{z=2}(t) \ldots \neq \theta_{z=j}(t)$

4) O solo é isotrópico em relação à condutividade hidráulica saturada e aos parâmetros que formam a curva de retenção uni e bimodal:

$$
\begin{aligned}
& K_{s(z=1)}=K_{s(z=2) \ldots=K_{s(z=j)}=K_{s}}
\end{aligned}
$$

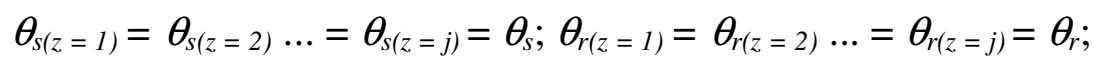

$$
\begin{aligned}
& \alpha_{(z=1)}=\alpha_{(z=2)} \ldots=\alpha_{(z=j)}=\alpha \\
& n_{(z=1)}=n_{(z=2)} \ldots=n_{(z=\mathrm{j})}=n \rightarrow m_{(z=1)}=m_{(z=2)} \ldots=m_{(z=\mathrm{j})}=m ; \\
& \alpha_{l(z=1)}=\alpha_{l(z=2) \ldots}=\alpha_{l(z=j)}=\alpha_{1} \\
& \alpha_{2(z=1)}=\alpha_{2(z=2) \ldots}=\alpha_{2(z=j)}=\alpha_{2}
\end{aligned}
$$

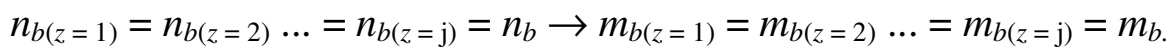

Com base nestas hipóteses, escolheu-se o modelo de Green-Ampt para simulação da infiltração, pois dentre os modelos descritos na Tabela 3.2 é o que mais se adequou às hipóteses assumidas. 
Para aplicação do modelo, foi assumido que, ocorrendo o processo de infiltração, a frente de molhamento é bem definida e o solo anterior a ela encontra-se uniformemente saturado $\left(\theta_{s}\right)$, com condutividade hidráulica saturada $\left(K_{s}\right)$. Além disso, assumiu-se que o potencial matricial nesta frente é constante, independente do tempo e da posição, e igual ao valor do potencial antes da infiltração.

A Figura 4.27 ilustra as hipóteses supracitadas para uma camada do solo durante o processo de infiltração horizontal.
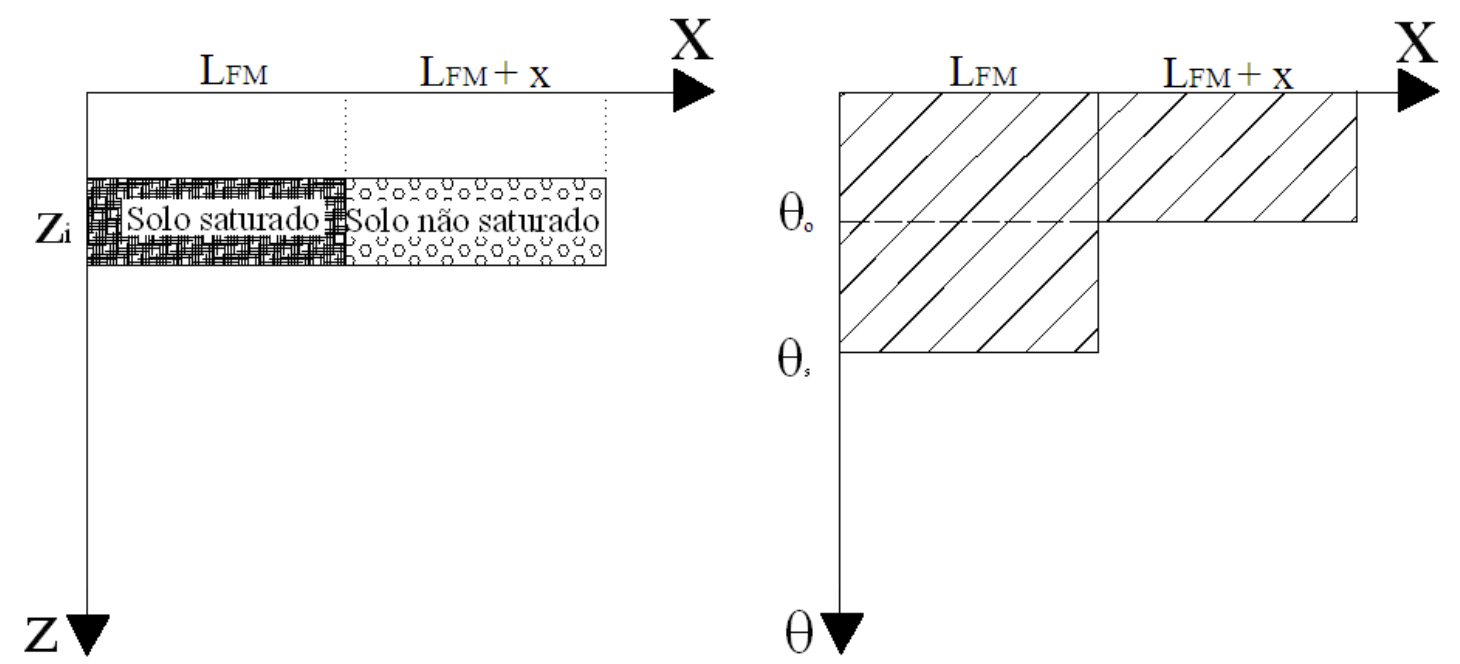

Figura 4.27 - Infiltração horizontal pelo modelo de Green-Ampt.

É sabido que as hipóteses adotadas resumem muito o processo de infiltração, visto que as propriedades do solo se comportam anisotropicamente e que o processo ocorre nas três dimensões. Porém é muito complicado realizar a modelagem tridimensional já que seria necessária além de uma caracterização detalhada de todos os lados da trincheira, uma quantidade maior de equipamentos. Por isso, como forma de minimizar as condições adotadas, buscou-se, através dos ensaios experimentais e da instalação dos equipamentos, uma boa representação das condições reais do processo de infiltração.

Como descrito no item 3.5.1.2, o modelo de Green-Ampt tem como dados de entrada a condutividade hidráulica saturada, o potencial matricial e a umidade presente no solo. A determinação destes valores foi descrita, respectivamente, nos itens 4.2.3, 4.2.4 e 4.4.3. 
Os valores de umidade utilizados para aplicação no modelo foram determinados durante ensaios experimentais por oito sondas CS616 inseridas horizontalmente na seção transversal do centro da trincheira, conforme foi descrito no item 4.4.3.

As sondas determinam a umidade através da integração de todo o conteúdo de água no solo que está em contato com os condutores da sonda. Em função deste tipo de medição, a umidade de saturação foi determinada quando a diferença entre os valores medidos em dois intervalos sucessivos satisfez a Equação 4.13.

$$
\theta_{i+1}-\theta_{i} \leq 0,01 \mathrm{~m}^{3} \cdot \mathrm{m}^{-3}
$$

Equação 4.13

Obtidos os valores de umidade e determinados os parâmetros da curva de retenção (item 4.2.4), calcularam-se os valores do potencial matricial antes e depois da infiltração a partir das abordagens uni e bimodal. Para realização do cálculo, utilizou-se a ferramenta solver do software Microsoft Excel (C).

\subsection{1 - Abordagens uni e bimodal}

Conforme foi descrito no item 3.3.1, determinar a curva de retenção através de modelo matemático que assume a distribuição unimodal do tamanho dos poros do solo pode fornecer informações limitadas para o processo de infiltração. Por isso, como forma de melhorar os dados modelados, os parâmetros do modelo de Green-Ampt foram determinados também através da curva de retenção com distribuição bimodal proposta por Mendiondo (2001).

Entretanto, anteriormente, avaliou-se, simplificadamente, se a curva de retenção com distribuição bimodal é precisamente mais realística que a unimodal. As curvas de retenção foram descritas no item 4.2.4.

A avaliação das duas distribuições foi feita através do coeficiente de determinação

$\left(\mathrm{R}^{2}\right)$ e do índice de confiança proposto por Camargo e Sentelhas (1997). O coeficiente de 
determinação e o índice de confiança estão representados, respectivamente, na Equação 4.14 e na Equação 4.15.

Assim como adotado por Camargo e Sentelhas (1997), o desempenho do ajuste foi obtido com o enquadramento do valor do índice de confiança " $c$ " nas faixas: $>0,90$, ótimo; entre 0,81 e 0,90 , muito bom; entre 0,71 e 0,80 , bom; entre 0,51 e 0,70 , mediano; entre 0,41 e 0,50, sofrível; entre 0,31 e 0,40, mau; e $\leq 0,30$, péssimo.

$$
\begin{aligned}
& R^{2}=\frac{\sum_{i=1}^{n}\left(\hat{\theta}_{i}-\bar{\theta}\right)^{2}}{\sum\left(\theta_{i}-\bar{\theta}\right)^{2}} \\
& c=\left[1-\frac{\sum_{i=1}^{n}\left(\hat{\theta}_{i}-\theta_{i}\right)^{2}}{\sum_{i=1}^{n}\left(\left(\hat{\theta}_{i}-\bar{\theta}\right)+\left(\theta_{i}-\bar{\theta}\right)\right)^{2}}\right] \cdot R
\end{aligned}
$$

em que $\theta$ é a umidade observada no solo, $\mathrm{em}^{3} \cdot \mathrm{m}^{-3} ; \hat{\theta}$ é a umidade volumétrica estimado pelo modelo, em $\mathrm{m}^{3} \cdot \mathrm{m}^{-3} ; \bar{\theta}$ é o valor da umidade média, $\mathrm{m}^{3} \cdot \mathrm{m}^{-3} ; R$ é a raiz quadrada do coeficiente de determinação, também chamado de coeficiente de correlação de Pearson, adimensional; e $c$ é o índice de confiança, adimensional.

$\mathrm{Na}$ análise das diversas possibilidades paramétricas da abordagem bimodal foi também avaliado o tamanho médio dos poros ${ }^{12}$ (Equação 4.16). Para isso, utilizou-se a classificação proposta por Klein e Libardi (2002), os quais classificaram como macroporos, os poros com diâmetro maior que $0,05 \mathrm{~mm}$ (que perdem a água em tensões menores que $0,6 \mathrm{mH}_{2} \mathrm{O}$ ), e como microporos, aqueles com diâmetro entre 0,05 e 0,0002 mm (que são esvaziados a tensões

\footnotetext{
${ }^{12} \mathrm{O}$ tamanho médio dos poros é o diâmetro do poro para o qual o módulo da capacidade específica $|c=d \theta / d \psi|$ é máximo.
} 
entre 0,6 e 1,50 mH $\mathrm{mH}_{2} \mathrm{O}$ ). A configuração paramétrica da curva de retenção com distribuição bimodal que apresentou um diâmetro médio fora deste intervalo foi desconsiderada.

$$
d=\frac{4 \tau \cdot \alpha \cdot \cos \phi}{\rho \cdot g}\left(\frac{n-1}{n}\right)^{-1 / n}
$$

em que $d$ é a diâmetro, em m; $\tau$ é a tensão superficial do líquido, em N.m ${ }^{-1} ; \phi$ é o ângulo de contato entre as paredes do tubo e o líquido que o preenche, em radianos, $\alpha$ é o coeficiente de ajuste da curva de retenção, $\mathrm{m}^{-1} ; n$ é parâmetro de ajuste da curva de retenção, adimensional; $\rho$ é a massa específica do líquido, em kg. $\mathrm{m}^{-3}$; e $g$ é a aceleração da gravidade, em m.s ${ }^{-2}$.

Cabe ressaltar que a avaliação supracitada é extremamente necessária, pois uma metodologia, que neste caso é a bimodalidade, que se mostrou eficiente em um tipo de solo pode não apresentar o mesmo comportamento em outro, já que os processos que o envolvem são complexos.

Determinados os parâmetros de entrada do modelo de Green-Ampt e analisado se a abordagem bimodal é, realmente, mais precisa que a abordagem unimodal. Calculou-se a infiltração acumulada através da Equação 3.45. Como forma de verificar a incerteza do modelo de Green-Ampt na determinação do processo de infiltração horizontal, determinou-se o coeficiente de eficiência de Nash e Sutcliffe (Equação 4.17).

$$
\operatorname{Coef}_{N-S}=1-\frac{\sum_{i=1}^{N}\left(I_{o}{ }^{i}-I_{c}{ }^{i}\right)^{2}}{\sum_{i=1}^{N}\left(I_{o}{ }^{i}-\bar{I}\right)^{2}}
$$

Segundo Andreolli (2003), para um ajuste perfeito entre os dados simulados e observados o coeficiente de Nash e Sutcliffe deve ser igual a 1, porém valores acima de 0,70 já mostram um ajuste razoável e valores acima de 0,80 podem ser considerados bons. 


\section{6 - Metodologia de dimensionamento}

O uso recente e a escassez de estudos sobre os dispositivos de infiltração no Brasil resultam no desconhecimento do seu funcionamento e, por conseguinte, geram dificuldades na escolha da metodologia mais adequada para o seu dimensionamento.

Por isso, como forma de preencher as lacunas existentes em relação ao dimensionamento de dispositivos de infiltração no Brasil, é proposta e testada neste trabalho uma metodologia de dimensionamento que busca mitigar a mudança de escoamento. Assim, a metodologia considera que apenas parte do volume que escoa no lote, a qual corresponde o volume que excede a condição anterior de pré-ocupação, deve ser absorvido através da detenção e da retenção em dispositivos de infiltração (Equação 4.18).

$$
\Delta V e=V_{\text {trin }} \cdot \eta_{b}+\frac{I}{\text { coefseg }} \cdot A_{\text {molhada }} \quad \text { Equação } 4.18
$$

em que $\Delta V e$ é a diferença entre o volume escoado pré e pós-ocupação, em $\mathrm{m}^{3} ; V_{\text {trin }}$ é o volume da trincheira, em $\mathrm{m}^{3} ; \eta_{b}$ é a porosidade do material de preenchimento da trincheira, adimensional; coefseg é o coeficiente de segurança, adimensional; I é a infiltração acumulada, $\mathrm{em} \mathrm{m}^{3} \cdot \mathrm{m}^{-2} ; \mathrm{e} A_{\text {molhada }}$ é a área lateral da trincheira (largura x altura), em $\mathrm{m}^{2}$.

Buscando um melhor esclarecimento em relação à metodologia proposta, segue na Figura 4.28 o hidrograma resultante da condição pré e pós-ocupação e o valor correspondente ao $\Delta V e$. 


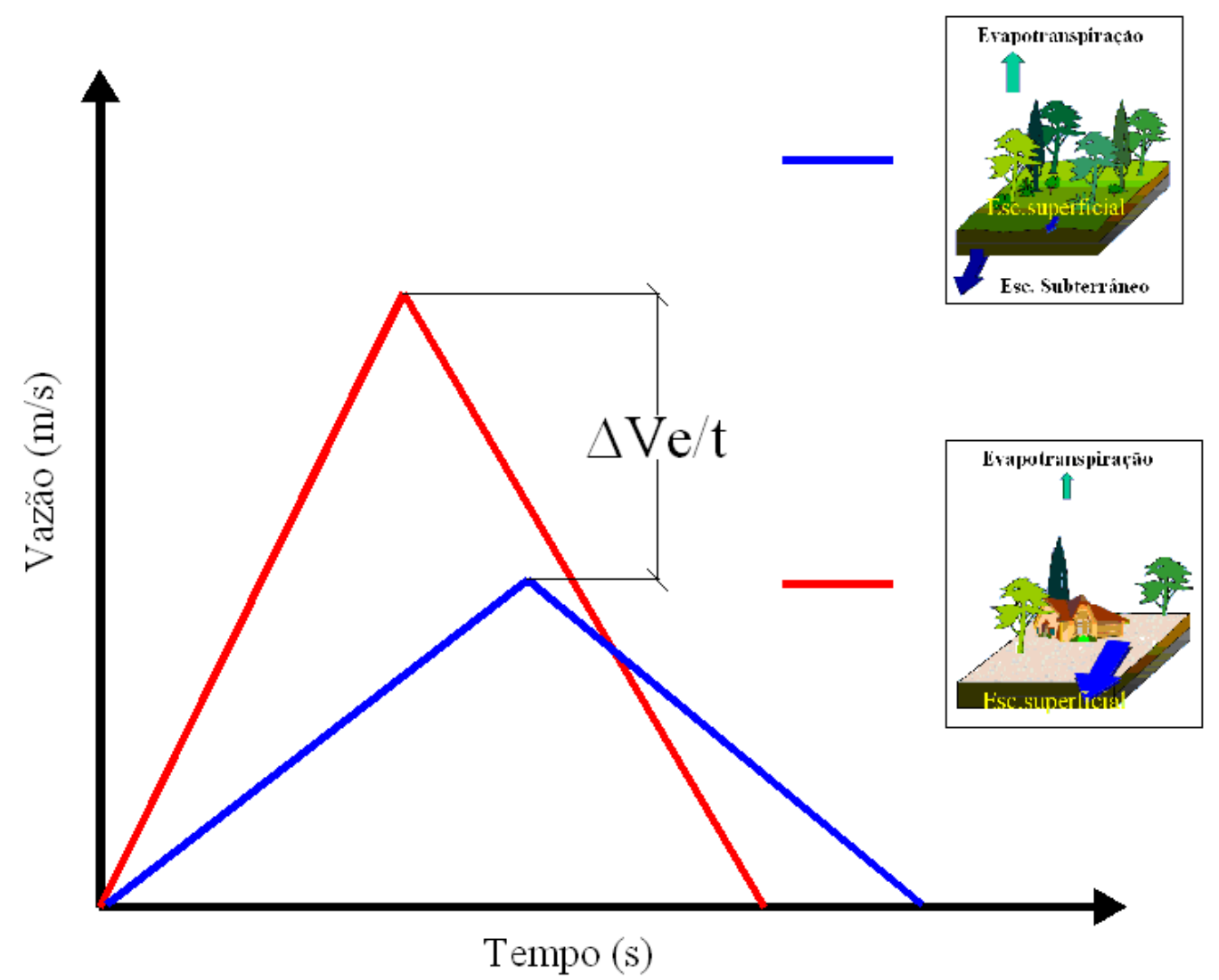

Figura 4.28 - Os efeitos da urbanização no hidrograma.

O $\Delta V e$ é calculado através do Método Racional (Equação 4.19), sendo o coeficiente de escoamento estimado com base no comportamento atual e natural do solo que constitui o lote estudado.

$$
\Delta V e=i_{\text {chuva }} \cdot A_{\text {lote }} \cdot\left(C_{d}-C_{a}\right) \cdot t
$$

em que $i_{\text {chuva }}$ é a intensidade da chuva, em $\mathrm{m}^{-1}{ }^{-1} ; A_{\text {lote }}$ é a área do lote ou terreno onde será implantada a trincheira, em $\mathrm{m}^{2} ; C_{a}$ e $C_{d}$ são respectivamente o coeficiente de escoamento pré e pós-ocupação, adimensionais; e $t$ é a duração da chuva, em s.

A falta de conhecimento preciso do funcionamento da trincheira e dos parâmetros do solo e a grande variabilidade das propriedades do solo levam à adoção de coeficientes de segurança (Souza, 2002). Por isso, o coefseg foi adotado na Equação 4.18 como forma de compensar eventuais diferenças. Inicialmente, utilizou-se o coeficiente de segurança igual a 2, pois é um valor sugerido por Urbonas e Stahre (1993 apud Souza, 2002, p. 29). 
A infiltração acumulada presente na Equação 4.18 é determinada através do modelo de Green-Ampt (Equação 3.45). Como já foi dito, a escolha deste modelo se deu em função dele, dentre os modelos apresentados neste trabalho, ser o mais adequado para modelagem do processo de infiltração com as hipóteses adotadas.

Além disso, outro ponto também foi levado em consideração na escolha do modelo. Considerando que para os órgãos gestores quanto maior for a complexidade da metodologia, maior será a dificuldade de sua aplicação, este modelo se mostra adequado por apresentar relativa simplicidade e por seus parâmetros (condutividade hidráulica saturada e curva de retenção) terem a possibilidade de serem determinados em laboratório.

A metodologia além de ser proposta também foi avaliada para os dados obtidos nos ensaios experimentais. Para isso, considerou-se que anteriormente a ocupação a superfície, onde foi construído o lote experimental, era constituída de grama média sob solo arenoso. Este tipo de superfície apresenta segundo ASCE (1969 apud Tucci, 1993, p. 542), um coeficiente de escoamento médio igual a 0,13. Para as condições atuais, considerou-se o coeficiente de escoamento igual ao valor adotado no dimensionamento, ou seja, 0,95. A intensidade da chuva e a infiltração acumulada foram obtidas através dos dados do ensaio.

Como forma de ampliar a verificação da viabilidade da metodologia, foram analisados os custos referentes à construção de trincheiras e também o custo por metro cúbico mitigado. Para isto, adotou-se um lote urbano com características similares ao lote experimental, considerou-se que o comprimento e a largura da trincheira eram constantes e determinou-se o volume da trincheira em função de sua altura. A altura da trincheira foi determinada com base na Equação 4.20.

$$
\min _{h}\left\{\Delta V e(T)-\left[V_{\text {trin }}\left(h_{\text {trin }}\right) \cdot \varphi+\frac{I}{\text { coefseg }} \cdot A_{\text {molhada }}\left(h_{\text {trin }}\right)\right]\right\} \quad \text { Equação } 4.20
$$

sujeito a Equação 4.21 


$$
\left\{\Delta V e(T)-\left[V_{\text {trin }}\left(h_{\text {trin }}\right) \cdot \varphi+\frac{I}{\text { coefseg }} \cdot A_{\text {molhada }}\left(h_{\text {trin }}\right)\right]\right\} \geq 0
$$

Equação 4.21

em que $h_{\text {trin }}$ é a altura da trincheira variável em função dos parâmetros de entrada da metodologia de dimensionamento. 


\section{Capítulo 5}

"Um dos poucos resultados concretos obtidos nos primeiros vinte anos da pesquisa de inteligência artificial é o fato de que a inteligência requer conhecimento."

Elaine Rich

\section{5 - RESULTADOS E DISCUSSÕES}

Este capítulo trata das características geotécnicas do solo em que foi instalada a trincheira no item 5.1, apresenta os parâmetros de entrada do modelo de infiltração, os quais são a condutividade hidráulica saturada e a curva de retenção nos itens 5.2 e 5.3 e, por fim, aborda os resultados obtidos nos ensaios experimentais e a verificação da eficiência da metodologia proposta para dimensionamento de trincheiras de infiltração nos itens 5.4 e 5.5.

\section{1 - Análise granulométrica}

O ensaio de análise granulométrica, conforme procedimento descrito no item 4.2.2, definiu que o solo estudado é constituído de $26,4 \%$ de argila, 5,6\% de silte e, aproximadamente, $68 \%$ de areia. De acordo com essa distribuição granulométrica, o solo é classificado como uma areia média a fina argilosa. Em relação à classificação textural, utilizando o triângulo de classificação textural, o solo é classificado como Franco-argiloarenoso.

A classificação granulométrica obtida para o solo em estudo é, relativamente, idêntica ao solo trabalhado por Graciosa (2005), o qual apresenta 25\% de argila, 5\% de silte e 69,9\% de areia. Assim, o uso das informações do trabalho de Graciosa (2005) na análise de viabilidade de instalação da trincheira foi adequado visto a semelhança textural dos dois solos. 
Os resultados referentes à curva e à composição granulométrica, bem como os índices físicos do solo estão apresentados, respectivamente, na Figura 5.1 e na Tabela 5.1.

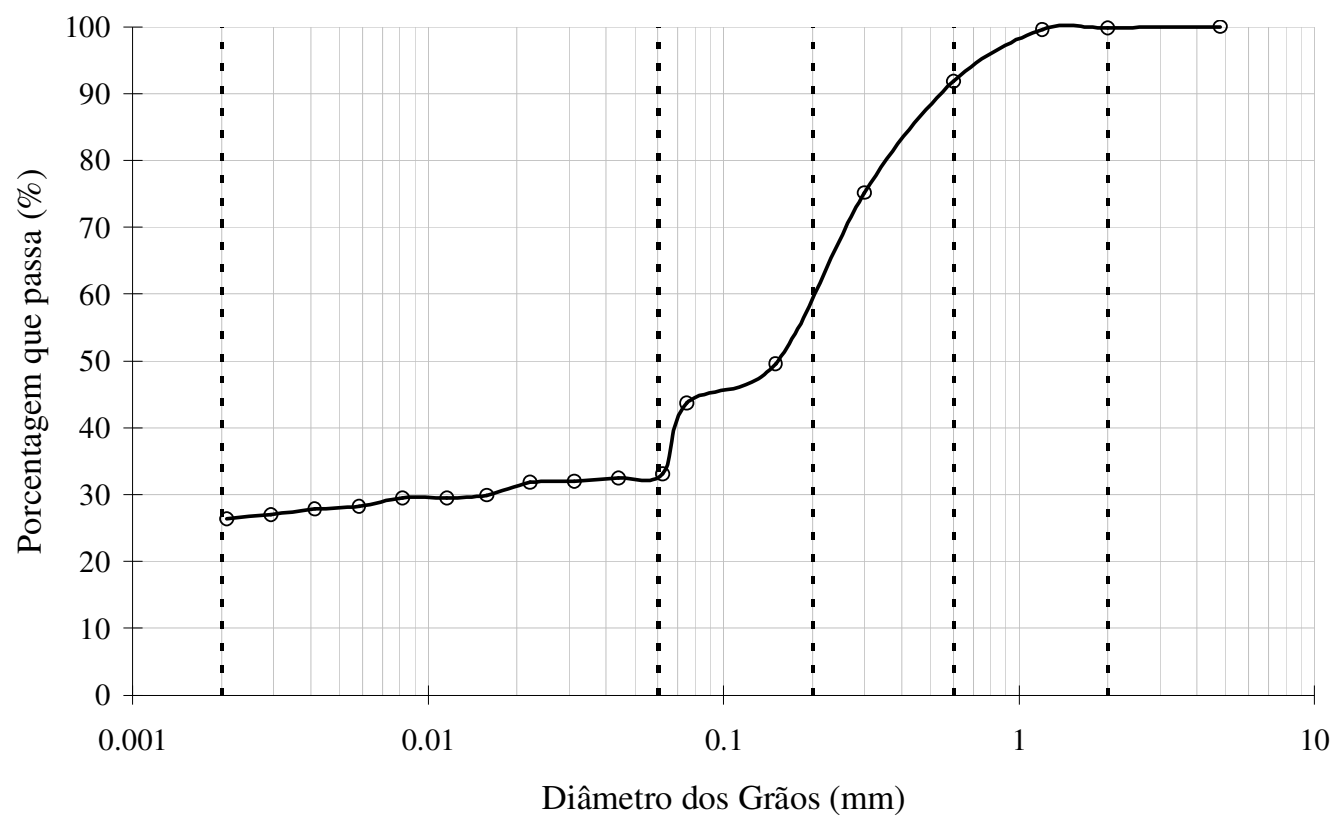

Figura 5.1 - Curva Granulométrica.

Tabela 5.1 - Composição granulométrica e índices físicos.

\begin{tabular}{|c|c|c|c|}
\hline \multirow{6}{*}{ 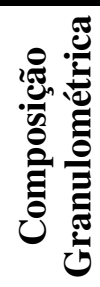 } & \multicolumn{2}{|c|}{ Pedregulho Fino } & $0,17 \%$ \\
\hline & \multirow{3}{*}{ Areia } & Grossa & $8,20 \%$ \\
\hline & & Média & $32,23 \%$ \\
\hline & & Fina & $27,40 \%$ \\
\hline & & & $5,63 \%$ \\
\hline & & & $26,37 \%$ \\
\hline \multirow{8}{*}{ 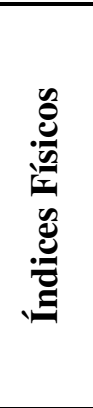 } & Massa & o solo $(\rho)$ & 1,527 g.cm $\mathrm{cm}^{-3}$ \\
\hline & Massa e & sólidos $\left(\rho_{s}\right)$ & $2,639 \mathrm{~g} \cdot \mathrm{cm}^{-3}$ \\
\hline & Massa es & olo seco $\left(\rho_{d}\right)$ & 1,347 g.cm $\mathrm{cm}^{-3}$ \\
\hline & & $\left.\eta_{s}\right)$ & $49 \%$ \\
\hline & & os $(e)$ & 0,96 \\
\hline & & ação & 0,40 \\
\hline & Umic & $\operatorname{ação~}\left(\theta_{s}\right)$ & $36,34 \%$ \\
\hline & & $\mathrm{al}\left(\theta_{i}\right)$ & $18,00 \%$ \\
\hline
\end{tabular}

O grau de saturação (relação do volume da água e do volume de vazios) demonstrado na Tabela 5.1, obtido dos 25 anéis retirados para realização do ensaio de curva de retenção, apresentou um valor inferior ao valor ideal (um). Desta forma, a umidade volumétrica de 
saturação não pode ser considerada igual à porosidade, uma vez que o volume de água não ocupou completamente o volume de vazios.

A umidade volumétrica de saturação é utilizada para determinar o primeiro ponto da curva de retenção feita com papel filtro.

\section{2 - Condutividade Hidráulica Saturada}

A Tabela 5.2 apresenta o resultado do ensaio de condutividade hidráulica saturada realizado com amostra cilíndrica retirada horizontalmente do bloco indeformado. O valor médio da condutividade hidráulica saturada corresponde a $9,06 \cdot 10^{-6} \mathrm{~m} \cdot \mathrm{s}^{-1}$. Com este valor e segundo a Tabela 2.2, o solo em estudo é caracterizado por apresentar uma boa capacidade de infiltração.

Tabela 5.2 - Ensaio de condutividade hidráulica saturada.

\begin{tabular}{|c|c|c|c|c|c|c|c|c|}
\hline 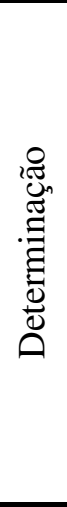 & $\stackrel{\Xi}{\tilde{\Xi}}$ & 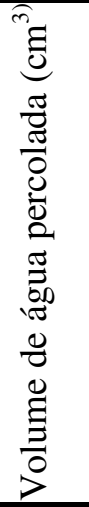 & 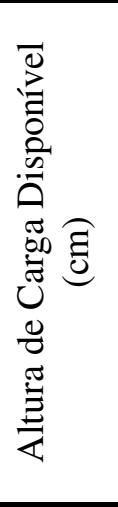 & 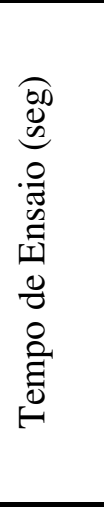 & 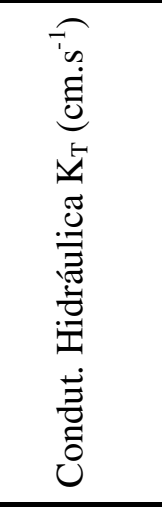 & 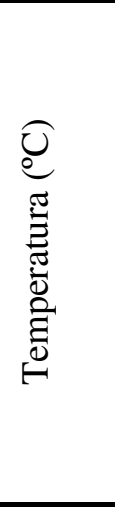 & 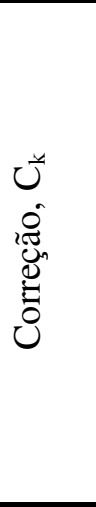 & 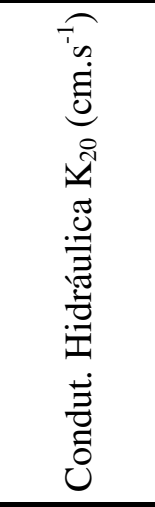 \\
\hline 1 & $13 /$ out & 7,3 & 42,3 & 120 & $9,55 \mathrm{E}-04$ & 24,3 & 0,91 & $8,66 \mathrm{E}-04$ \\
\hline 2 & 13/out & 6,8 & 42,3 & 120 & $8,90 \mathrm{E}-04$ & 24,3 & 0,91 & $8,07 \mathrm{E}-04$ \\
\hline 3 & $13 /$ out & 7,0 & 42,3 & 120 & $9,16 \mathrm{E}-04$ & 24,3 & 0,91 & $8,30 \mathrm{E}-04$ \\
\hline 4 & $13 /$ out & 8,5 & 52,4 & 110 & $9,80 \mathrm{E}-04$ & 24,3 & 0,91 & $8,88 \mathrm{E}-04$ \\
\hline 5 & $13 /$ out & 8,6 & 52,4 & 110 & $9,91 \mathrm{E}-04$ & 24,3 & 0,91 & 8,98E-04 \\
\hline 6 & $13 /$ out & 8,8 & 52,4 & 110 & $1,01 \mathrm{E}-03$ & 24,3 & 0,91 & $9,19 \mathrm{E}-04$ \\
\hline 7 & $13 /$ out & 8,6 & 57,4 & 100 & $9,95 \mathrm{E}-04$ & 24,3 & 0,91 & $9,02 \mathrm{E}-04$ \\
\hline 8 & $13 /$ out & 8,8 & 57,4 & 100 & $1,02 \mathrm{E}-03$ & 24,3 & 0,91 & $9,23 \mathrm{E}-04$ \\
\hline 9 & $13 /$ out & 8,7 & 57,4 & 100 & $1,01 \mathrm{E}-03$ & 24,3 & 0,91 & $9,13 \mathrm{E}-04$ \\
\hline 10 & $13 /$ out & 8,7 & 62,4 & 90 & $1,03 \mathrm{E}-03$ & 23,8 & 0,92 & $9,43 \mathrm{E}-04$ \\
\hline 11 & $13 /$ out & 8,7 & 62,4 & 90 & $1,03 \mathrm{E}-03$ & 23,8 & 0,92 & 9,43E-04 \\
\hline 12 & $13 /$ out & 8,7 & 62,4 & 90 & $1,03 \mathrm{E}-03$ & 24,2 & 0,91 & $9,35 \mathrm{E}-04$ \\
\hline 13 & $13 /$ out & 9,2 & 72,4 & 80 & $1,06 \mathrm{E}-03$ & 24,8 & 0,90 & $9,46 \mathrm{E}-04$ \\
\hline 14 & $13 /$ out & 9,2 & 72,4 & 80 & $1,06 \mathrm{E}-03$ & 24,8 & 0,90 & $9,46 \mathrm{E}-04$ \\
\hline 15 & $13 /$ out & 9,1 & 72,4 & 80 & 1,04E-03 & 24,8 & 0,90 & $9,35 \mathrm{E}-04$ \\
\hline \multicolumn{9}{|c|}{ Condutividade Hidráulica Saturada: $9,06 \cdot 10^{-6} \mathrm{~m} . \mathrm{s}^{-1}$} \\
\hline
\end{tabular}


De modo distinto a composição granulométrica, o valor da condutividade não foi similar ao valor obtido no trabalho de Graciosa (2005), o qual corresponde a $7.10^{-5} \mathrm{~m} . \mathrm{s}^{-1}$. Tal diferença pode ser justificada em função das amostras utilizadas nos respectivos ensaios serem retiradas em profundidade distintas. Segundo Klein e Libardi (2002), em virtude da compactação do solo, quanto maior for a profundidade menor será a condutividade hidráulica.

\section{3 - Curva de retenção}

Os ensaios de curva de retenção foram conduzidos conforme descrito no item 4.2.4. Em virtude de serem ensaios realizados por métodos distintos, os pontos experimentais das duas curvas de retenção foram diferentes (Tabela 5.3). É importante relembrar que foram obtidas duas curvas, sendo uma curva determinada pela técnica do papel filtro e a outra pela união dos pontos do funil de Haines e da câmara de Richards.

Tabela 5.3 - Pontos experimentais das curvas de retenção.

\begin{tabular}{cccc}
\hline \multicolumn{2}{c}{ Papel filtro } & \multicolumn{2}{c}{ Funil de Haines + Câmara de Richards } \\
\hline $\begin{array}{c}\boldsymbol{\theta} \\
\mathrm{m}^{3} \cdot \mathrm{m}^{-3}\end{array}$ & $\begin{array}{c}\text { Sucção } \\
\mathrm{mH}_{2} 0\end{array}$ & $\begin{array}{c}\boldsymbol{\theta} \\
\mathrm{m}^{3} \cdot \mathrm{m}^{-3}\end{array}$ & $\begin{array}{c}\text { Sucção } \\
\mathrm{mH}_{2} 0\end{array}$ \\
\hline 0,31 & 0,50 & 0,37 & 0,1 \\
0,29 & 0,51 & 0,36 & 0,2 \\
0,25 & 0,61 & 0,30 & 0,3 \\
0,22 & 0,67 & 0,26 & 0,4 \\
0,21 & 0,84 & 0,24 & 0,5 \\
0,18 & 3,16 & 0,21 & 1 \\
0,17 & 14,31 & 0,16 & 2 \\
0,12 & 539,16 & 0,15 & 3 \\
0,10 & 898,22 & 0,15 & 4 \\
0,07 & 1572,78 & 0,15 & 10 \\
0,04 & 1944,44 & 0,14 & 20 \\
0,02 & 3156,13 & 0,14 & 40 \\
& & 0,13 & 70 \\
\hline
\end{tabular}

Determinados os pontos experimentais, o modelo de van Genuchten e o modelo adaptado por Mendiondo (2001) foram ajustados a estes pontos.

$\mathrm{O}$ ajuste dos parâmetros $(\alpha, n)$ à curva de retenção com abordagem unimodal apresentou, para os dados dos dois ensaios, poucas configurações de valores ótimos. 
A configuração adotada como ótima no ajuste da curva de retenção com abordagem unimodal para os dados do ensaio com papel filtro (C. U. I) apresentou coeficiente de determinação igual a 0,893 e índice de confiança de 0,918. Já para os dados do ensaio com funil de Haines + câmara de Richards (C. U. II) apresentou coeficiente de determinação igual a 0,989 e o índice de confiança de 0,992 . De acordo com o critério estabelecido no item 4.2, o índice de confiança dos dois ajustes é considerado ótimo.

As curvas de retenção C. U. I e C. U. II estão ilustradas na Figura 5.2.

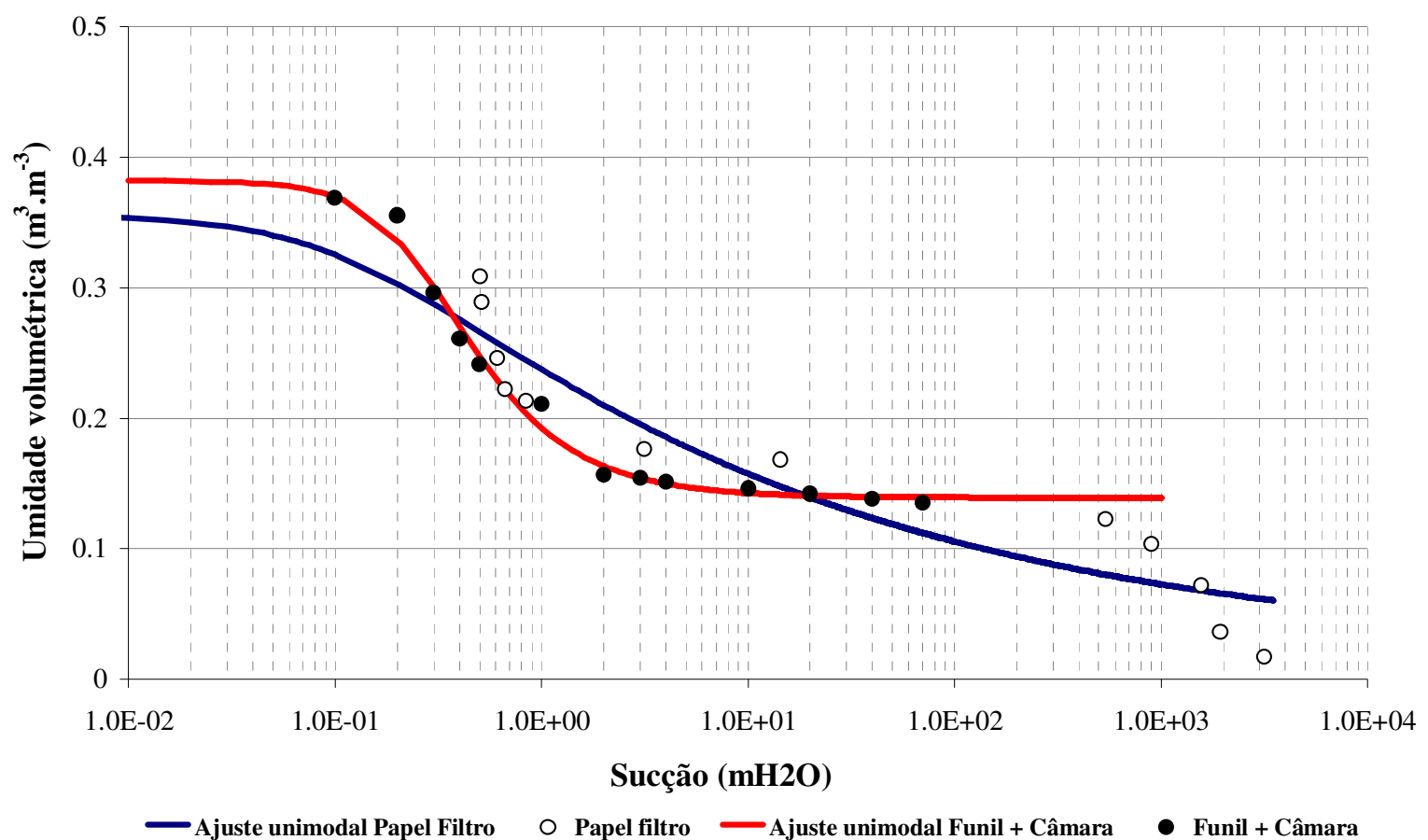

Figura 5.2 - Curvas de retenção determinada pela abordagem unimodal.

Segundo Mendiondo (2001) os parâmetros presentes na curva de retenção não refletem somente as características do solo quanto a sua capacidade de reter água e de transmiti-la, mas também a forma como a umidade pode se distribuir dentro do solo. Por isso, com base nos parâmetros ajustáveis das curvas de retenção (C. U. I e C. U. II) e através da relação gráfica entre $d \theta / d \psi$ e $\psi$, obteve-se as curvas de distribuição de frequência do tamanho de poros (Figura 5.3). 


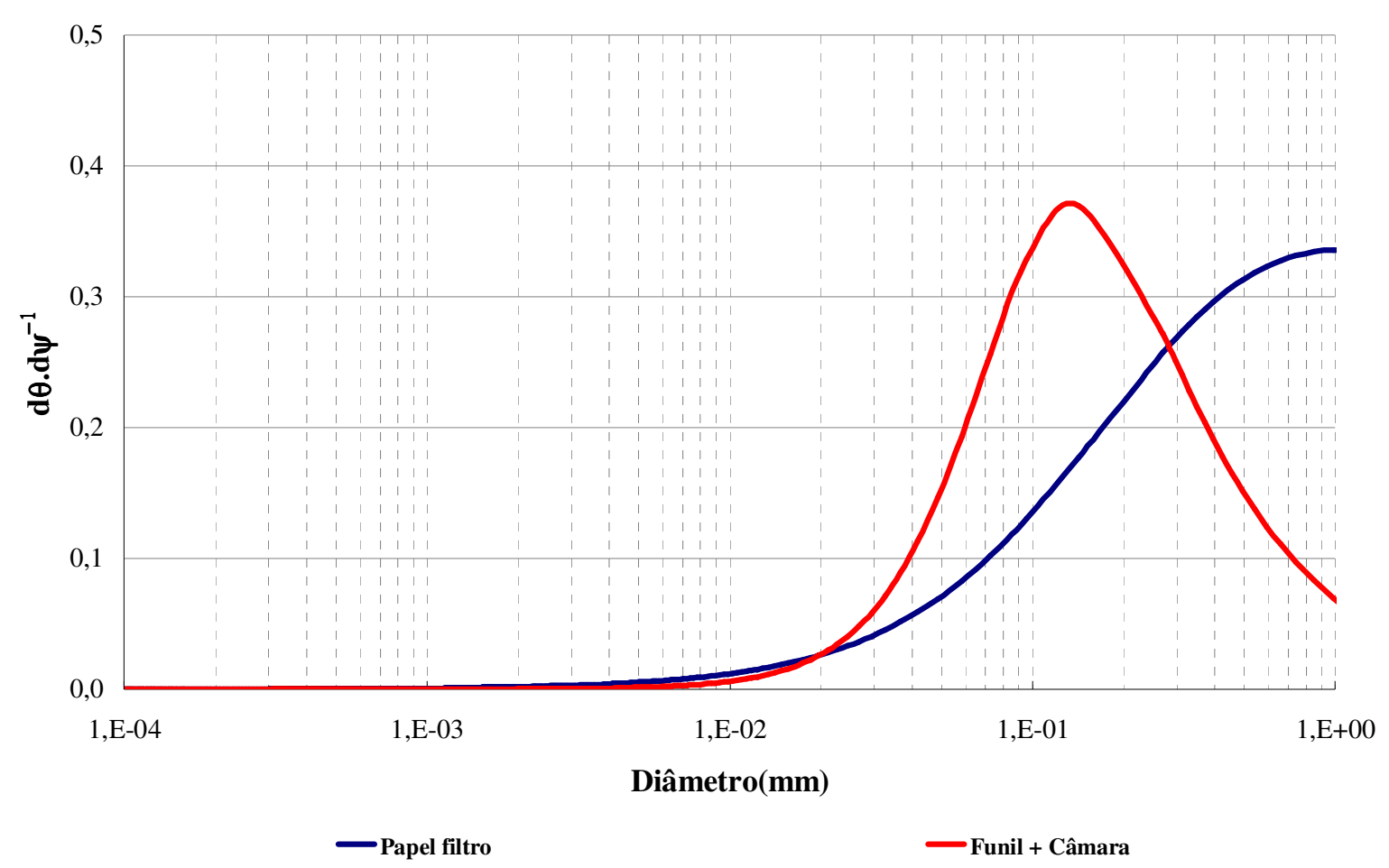

Figura 5.3 - Curvas de distribuição unimodal dos poros do solo.

Pode-se observar através da Figura 5.3 que o tamanho médio dos poros para os dados da C. U. I e da C. U. II são diferentes. Os parâmetros da C. U. I apresentam um diâmetro médio de 1,05 mm, já a C. U. II o diâmetro corresponde a 0,14 mm. Em virtude do valor de $\alpha$ ser muito alto na C. U. I, o valor do diâmetro seguiu o mesmo comportamento.

O ajuste da curva de retenção com abordagem bimodal apresentou, para os pontos experimentais dos dois ensaios, várias configurações, as quais se encontram demonstradas na Tabela 5.4. 
Tabela 5.4 - Parâmetros de ajuste para abordagem bimodal.

\begin{tabular}{|c|c|c|c|c|c|c|c|c|}
\hline & $\begin{array}{c}\boldsymbol{\theta}_{\mathrm{ps}} \\
\mathrm{m}^{3} \cdot \mathrm{m}^{-3}\end{array}$ & $\begin{array}{c}\boldsymbol{\alpha}_{1} \\
\mathrm{~m}^{-1}\end{array}$ & $\mathbf{n}$ & $\begin{array}{c}\boldsymbol{\alpha}_{\mathbf{2}} \\
\mathrm{m}^{-1}\end{array}$ & $\mathbf{R}^{2}$ & c & $\begin{array}{c}\mathbf{d}_{\text {microporo }} \\
\text { mm }\end{array}$ & $\begin{array}{c}\mathbf{d}_{\text {macroporo }} \\
\text { mm }\end{array}$ \\
\hline \multirow{5}{*}{ 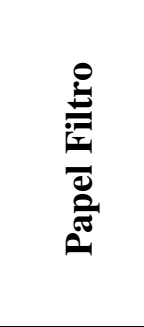 } & $1,62 \mathrm{E}-01$ & $3,33 \mathrm{E}-02$ & $1,48 \mathrm{E}+00$ & $6,07 \mathrm{E}+00$ & 0,887 & 0,911 & $2,12 \mathrm{E}-03$ & $3,87 \mathrm{E}-01$ \\
\hline & $1,80 \mathrm{E}-01$ & $3,09 \mathrm{E}-02$ & $1,45 \mathrm{E}+00$ & $7,82 \mathrm{E}+00$ & 0,882 & 0,908 & 2,07E-03 & $5,24 \mathrm{E}-01$ \\
\hline & $1,70 \mathrm{E}-01$ & $3,60 \mathrm{E}-02$ & $1,50 \mathrm{E}+00$ & $4,96 \mathrm{E}+00$ & 0,885 & 0,907 & 2,22E-03 & $3,06 \mathrm{E}-01$ \\
\hline & 1,60E-01 & $4,95 \mathrm{E}-02$ & $2,06 \mathrm{E}+00$ & $4,09 \mathrm{E}+00$ & 0,881 & 0,876 & $2,02 \mathrm{E}-03$ & $1,67 \mathrm{E}-01$ \\
\hline & 1,83E-01 & 5,02E-02 & $6,45 E+00$ & $1,84 \mathrm{E}+00$ & 0,909 & 0,910 & 1,53E-03 & 5,60E-02 \\
\hline \multirow{4}{*}{ 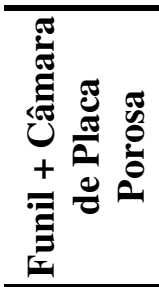 } & $1,35 \mathrm{E}-01$ & $1,45 \mathrm{E}-05$ & $1,94 \mathrm{E}+00$ & $2,91 \mathrm{E}+00$ & 0,992 & 0,994 & $6,23 \mathrm{E}-07$ & $1,25 \mathrm{E}-01$ \\
\hline & $1,36 \mathrm{E}-01$ & $4,54 \mathrm{E}-04$ & $2,14 \mathrm{E}+00$ & $3,46 \mathrm{E}+00$ & 0,994 & 0,995 & $1,81 \mathrm{E}-05$ & $1,38 \mathrm{E}-01$ \\
\hline & $2,10 \mathrm{E}-01$ & $6,90 \mathrm{E}-01$ & $3,63 \mathrm{E}+00$ & $3,70 \mathrm{E}+00$ & 0,996 & 0,997 & $2,24 \mathrm{E}-02$ & $1,20 \mathrm{E}-01$ \\
\hline & 2,20E-01 & $7,26 \mathrm{E}-01$ & $3,92 \mathrm{E}+00$ & $3,78 \mathrm{E}+00$ & $\mathbf{0 , 9 9 7}$ & $\mathbf{0 , 9 9 7}$ & 2,33E-02 & $1,21 \mathrm{E}-01$ \\
\hline
\end{tabular}

Algumas configurações do ajuste da curva de retenção com abordagem bimodal aos pontos experimentais do ensaio com papel filtro (C. B. I) apresentaram coeficiente de determinação e índice de confiança próximos a 1, porém com valores do diâmetro médio para os microporos menores que $2.10^{-4} \mathrm{~mm}$, ficando fora do intervalo proposto por Klein e Libardi (2002). Desta forma, a melhor configuração paramétrica $\left(\theta_{p s}, \alpha_{1}, \alpha_{2}, n_{b}\right)$ para a C. B. I foi igual a: $0,18,5,0.10^{-2}, 6,45$ e 1,84 . Para esta configuração o $R^{2}$ e o $c$ foram iguais a 0,909 e 0,910, respectivamente. Vale ressaltar que, em virtude da porosidade obtida em laboratório ter sido alta, o valor da umidade de saturação não foi utilizado no ajuste.

Para o ajuste da curva de retenção com abordagem bimodal aos pontos experimentais do ensaio com funil de Haines + câmara de Richards (C. B. II), as configurações não apresentaram muitas diferenças, a não ser no valor de $\theta_{p s}$. Assim, foi escolhida como configuração ótima aquela que apresentou o maior valor de $R^{2}$ e $c$, os quais ambos são iguais a 0,997. A configuração ótima apresentou os parâmetros da curva iguais a: $0,21,0,72,3,92$ e 3,78. A Figura 5.4 ilustra a C. B. I e a C. B. II. 


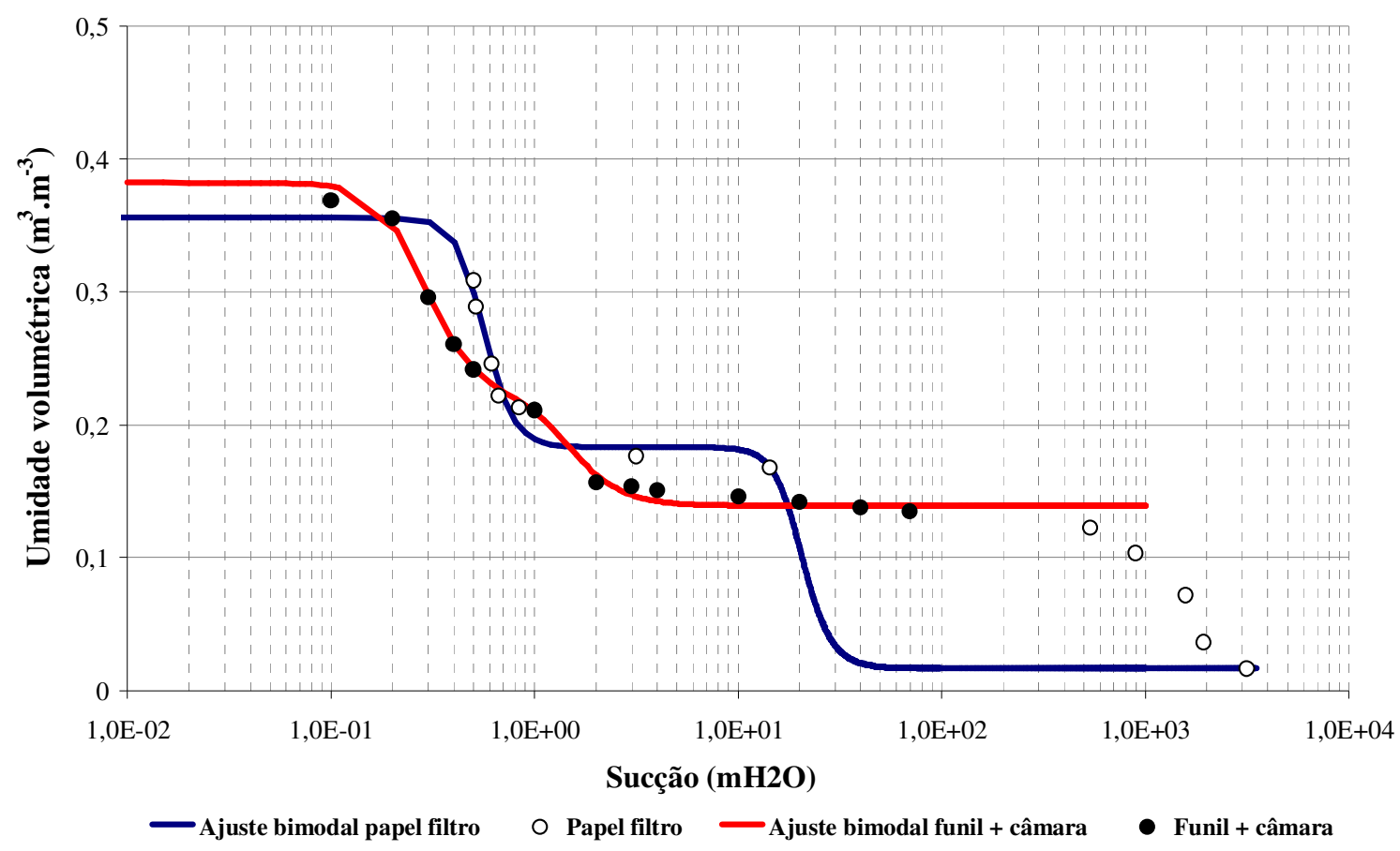

Figura 5.4 - Curvas de retenção determinada pela abordagem bimodal.

Assim como realizada para a abordagem unimodal, obteve-se a distribuição de frequência dos tamanhos dos poros para os parâmetros ajustáveis das C. B. I e C. B. II ( Figura 5.5). 


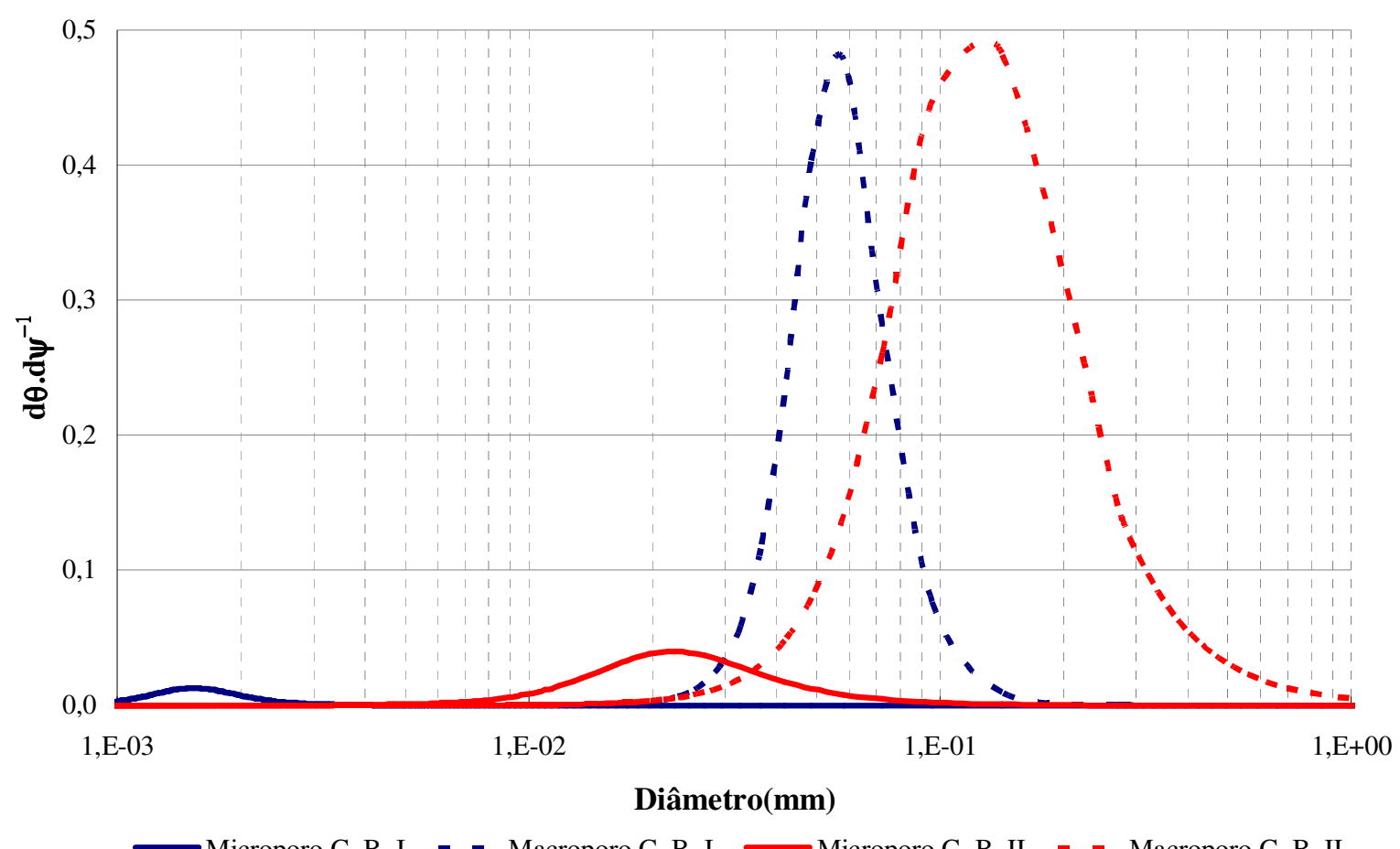

Figura 5.5 - Curvas de distribuição bimodal dos poros do solo.

Pode-se observar através da Figura 5.5 que, da mesma maneira que ocorreu para a distribuição unimodal, o tamanho médio dos microporos e dos macroporos foram diferentes para os dois métodos. A C. B. I apresentou o diâmetro médio dos micros e macroporos iguais a 0,0015 mm e 0,056 mm, respectivamente. Já a C. B. II apresentou para o diâmetro médio dos micros e macroporos os valores de $0,02 \mathrm{~mm}$ e $0,12 \mathrm{~mm}$, respectivamente.

Em relação ao intervalo do potencial matricial, os microporos da C. B. I e C. B. II compreendem o intervalo entre 10 e $35,7 \mathrm{mH}_{2} \mathrm{O}$ e 0,3 e $5,4 \mathrm{mH}_{2} \mathrm{O}$, respectivamente. Os macroporos da C. B. I e C. B. II estão, respectivamente, no intervalo entre 0,2 e 1,7 $\mathrm{mH}_{2} \mathrm{O}$ e 0,02 e $2 \mathrm{mH}_{2} \mathrm{O}$.

É importante lembrar que o diâmetro médio dos micros e dos macroporos é definido pelos coeficientes $\alpha_{1}$ e $\alpha_{2}$ e a largura e altura da distribuição são definidas pelo parâmetro $n_{b}$. Desta forma, como os coeficientes $\alpha_{1}$ e $\alpha_{2}$ e o parâmetro $n_{b}$ são diferentes nas duas curvas, a distribuição do tamanho dos poros também segue o mesmo comportamento. Buscando uma 
melhor visualização das diferenças encontradas na distribuição uni e bimodal de cada método apresenta-se a Figura 5.6.

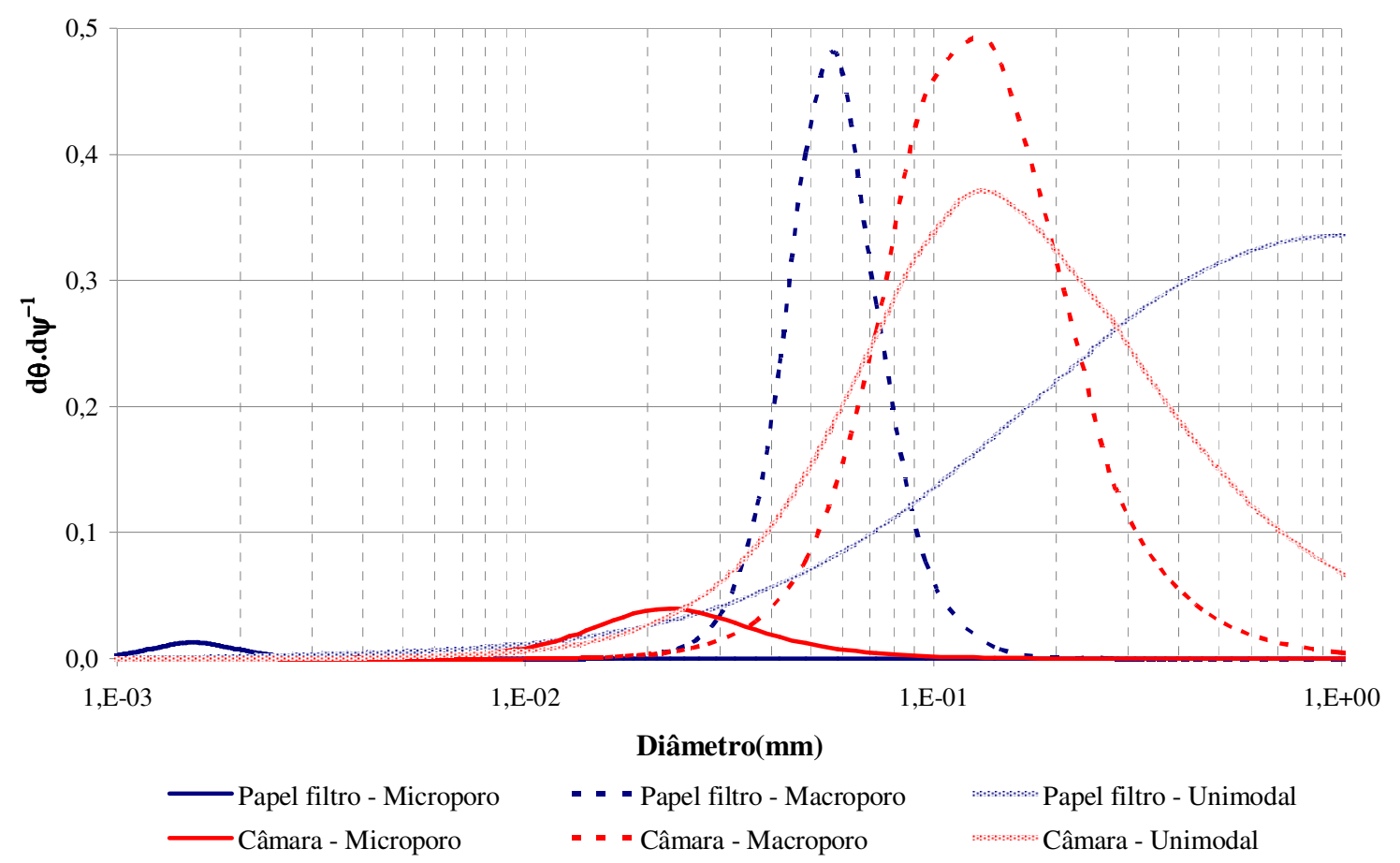

Figura 5.6 - Distribuição uni e bimodal obtida a partir da curva de retenção determinada através da técnica do papel filtro e da câmara de placa porosa.

$\mathrm{Na}$ distribuição dos dois métodos, o solo apresentou uma quantidade maior de macroporo. Tal fato é esperado por se tratar de um solo arenoso, o qual apresenta um número elevado de macroporos e alta permeabilidade.

A quantidade de macroporos calculadas através da distribuição bimodal pode ser confirmada através das imagens das seções transversais e longitudinais obtidas pela tomografia computadorizada (Figura 5.7). 


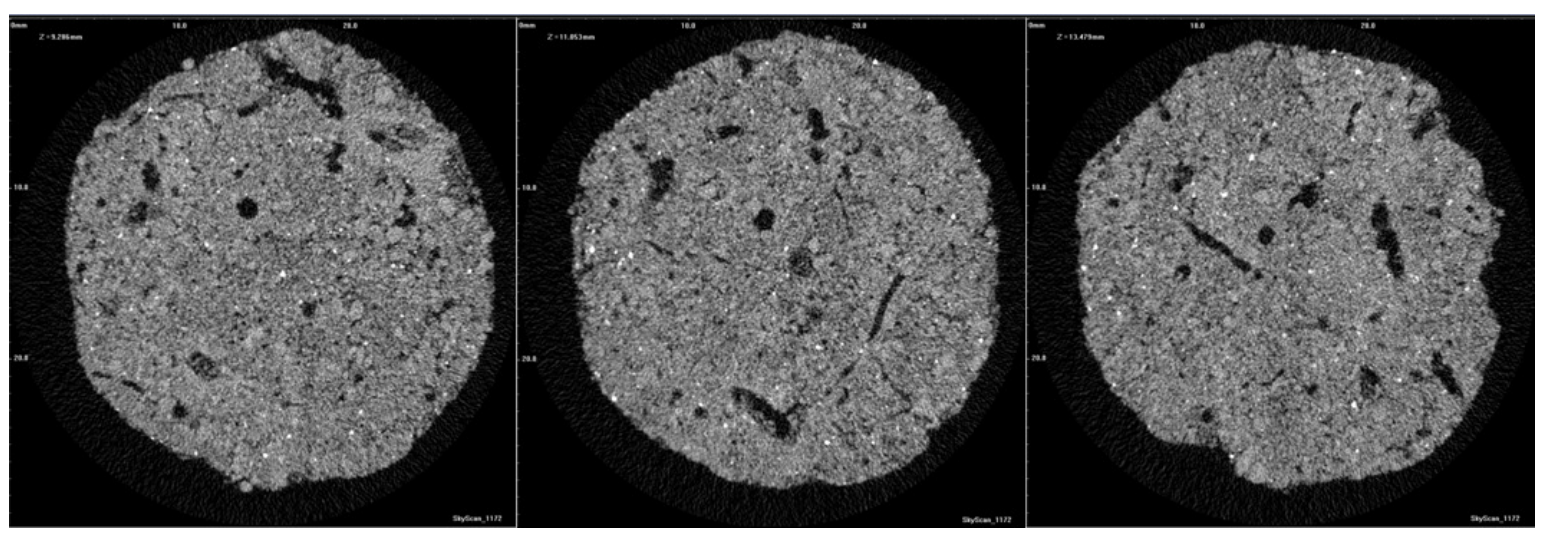

Figura 5.7 - Corte transversal de uma amostra do solo em estudo.

Com base nos parâmetros estatísticos $\left(\mathrm{R}^{2}\right.$ e $\left.c\right)$, a abordagem bimodal determinada pelos dois ensaios é estatisticamente melhor que a abordagem unimodal. Além disso, comparando as duas curvas com abordagem bimodal, verifica-se, através dos mesmos parâmetros estatísticos, dos valores de diâmetro médio de poros e do intervalo de sucção, que a curva bimodal determinada pelos dados do ensaio com funil de Haines e câmara de Richards (C. B. II) é melhor que a curva determinada pelos dados do ensaio com papel filtro (C. B. I).

Dessa maneira, a C. B. II foi a curva que apresentou melhores resultados, sendo, por isso, utilizada para determinar o potencial matricial, parâmetro de entrada do modelo de Green-Ampt. Entretanto, este também foi calculado pela C. U. II, uma vez que a avaliação estatística é simplificada.

\section{4 - Ensaios experimentais}

Anteriormente aos ensaios experimentais, realizou-se a calibração da equação do vertedor triangular. A calibração foi realizada em campo através da medição da altura de água no vertedor triangular e do tempo gasto para encher um recipiente com volume conhecido. Os resultados da calibração encontram-se demonstrados na Tabela 5.5. 
Tabela 5.5 - Calibração do vertedor triangular.

\begin{tabular}{|c|c|c|c|c|c|c|c|}
\hline$\underset{\mathrm{m}}{\text { Altura }}$ & $\begin{array}{l}\text { Qobservada } \\
\mathrm{m}^{3} \cdot \mathrm{s}^{-1}\end{array}$ & $\begin{array}{l}\mathbf{Q}_{\text {calculada }} \\
\mathrm{m}^{3} \cdot \mathrm{s}^{-1}\end{array}$ & Erro & $\underset{\mathrm{m}}{\text { Altura }}$ & $\begin{array}{c}\text { Qobservada } \\
\mathrm{m}^{3} \cdot \mathrm{s}^{-1}\end{array}$ & $\begin{array}{c}\text { Q }_{\text {calculada }} \\
\mathrm{m}^{3} \cdot \mathrm{s}^{-1}\end{array}$ & Erro \\
\hline 0,041 & 0,00048 & 0,00047 & $1,85 \%$ & 0,049 & 0,00070 & 0,00067 & $4,8 \%$ \\
\hline 0,041 & 0,00044 & 0,00047 & $-7,94 \%$ & 0,049 & 0,00072 & 0,00069 & $4,0 \%$ \\
\hline 0,044 & 0,00059 & 0,00055 & $6,88 \%$ & 0,050 & 0,00070 & 0,00071 & $-1,7 \%$ \\
\hline 0,044 & 0,00047 & 0,00055 & $-16,00 \%$ & 0,055 & 0,00093 & 0,00086 & $7,2 \%$ \\
\hline 0,044 & 0,00047 & 0,00055 & $-16,50 \%$ & 0,055 & 0,00093 & 0,00087 & $7,0 \%$ \\
\hline 0,044 & 0,00046 & 0,00055 & $-19,03 \%$ & 0,056 & 0,00094 & 0,00089 & $4,8 \%$ \\
\hline 0,044 & 0,00048 & 0,00056 & $-16,79 \%$ & 0,056 & 0,00096 & 0,00089 & $7,0 \%$ \\
\hline 0,046 & 0,00061 & 0,00059 & $2,86 \%$ & 0,058 & 0,00090 & 0,00094 & $-4,9 \%$ \\
\hline 0,046 & 0,00068 & 0,00061 & $10,71 \%$ & 0,065 & 0,00113 & 0,00119 & $-5,2 \%$ \\
\hline 0,047 & 0,00064 & 0,00062 & $3,68 \%$ & 0,075 & 0,00170 & 0,00160 & $5,7 \%$ \\
\hline 0,047 & 0,00069 & 0,00063 & $8,15 \%$ & 0,076 & 0,00154 & 0,00166 & $-7,9 \%$ \\
\hline 0,048 & 0,00071 & 0,00065 & $7,45 \%$ & 0,078 & 0,00161 & 0,00171 & $-6,6 \%$ \\
\hline
\end{tabular}

Determinado os dados de vazão e altura de água no vertedor, procedeu-se o ajuste de uma equação tipo potência aos dados. A equação ajustada (Equação 5.1) apresentou um coeficiente de determinação igual a 0,97. A curva de calibração está ilustrada na Figura 5.8.

$$
Q=0,2962 \cdot h^{2,0148}
$$

Equação 5.1

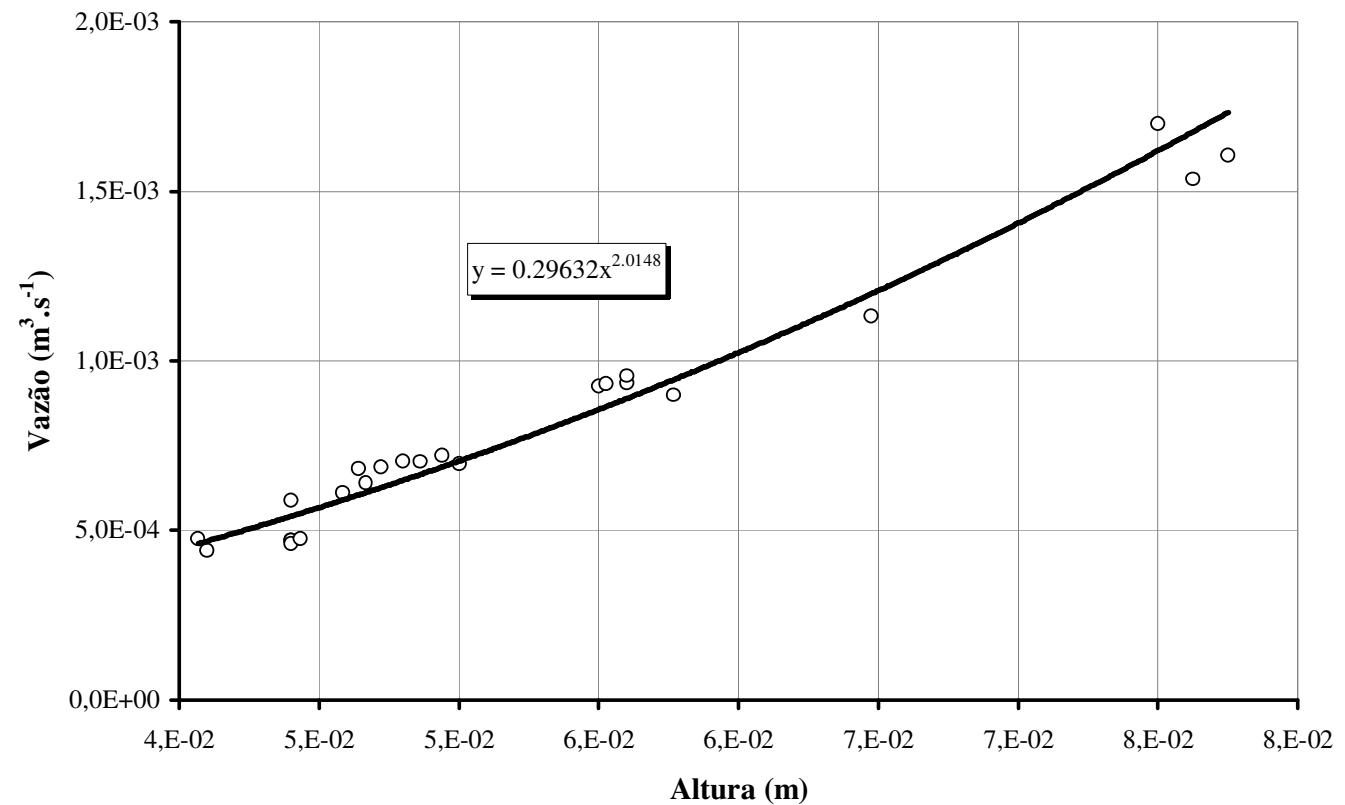

Figura 5.8 - Curva de calibração do vertedor triangular.

Após a calibração do vertedor triangular, deu-se início aos ensaios experimentais. Para não haver mudança no valor da umidade inicial, os experimentos foram realizados após 
decorrido um período sem chuvas. Ao todo foram realizados três experimentos, cada um deles apresentou características iniciais diferentes.

\subsection{1 - $1^{\circ}$ Experimento}

O primeiro experimento foi realizado no dia 07 de fevereiro de 2009 das $9 \mathrm{hrs} 34 \mathrm{~min}$ às 10hrs58min. Em virtude de ser o primeiro ensaio, era desconhecido o comportamento da trincheira em relação à infiltração. Por isso a vazão de entrada não foi mantida constante durante o experimento (aberturas diferenciadas da válvula de esfera pertencente ao sistema de tubulação responsável pela alimentação do reservatório à trincheira), sendo seu valor médio, obtido durante os 22 minutos em que ocorreu a fase de adução, igual a 1,13 $10^{-3} \mathrm{~m}^{3} \cdot \mathrm{s}^{-1}$ (Figura 5.9).

Transformando a vazão média em chuva, isto é, considerando que a vazão fosse proveniente de uma precipitação no lote experimental, esta teria intensidade de $81,8 \mathrm{~mm} \cdot \mathrm{h}^{-1}$ $\left(2,27 \cdot 10^{-5} \mathrm{~m} \cdot \mathrm{s}^{-1}\right)$ e período de retorno de 8,4 anos.

A fase de recessão durou 1 hora. Neste período, a variação da altura de água na trincheira ao longo do tempo foi menor do que na fase da adução, o que é esperado visto que em solos saturados a taxa de infiltração é menor. O comportamento da altura encontra-se ilustrado na Figura 5.9.

Cabe ressaltar que o comportamento da área infiltrante é igual ao da altura, sendo apenas diferente na ordem de grandeza, visto que a área é dada por $2 \times 2,4 \cdot h+2 \times 1 \cdot h$. Desta forma, a área média é dada pelo produto $6,8 \times h_{\text {média }}$, que para o Experimento I, foi igual a 2,24 $\mathrm{m}^{2}$

Como já foi dito, o Experimento I teve o intervalo de tempo igual a 1 minuto. Este intervalo foi apropriado, uma vez que não foi verificado na Figura 5.9 defasagem entre a entrada e a resposta de nível. 


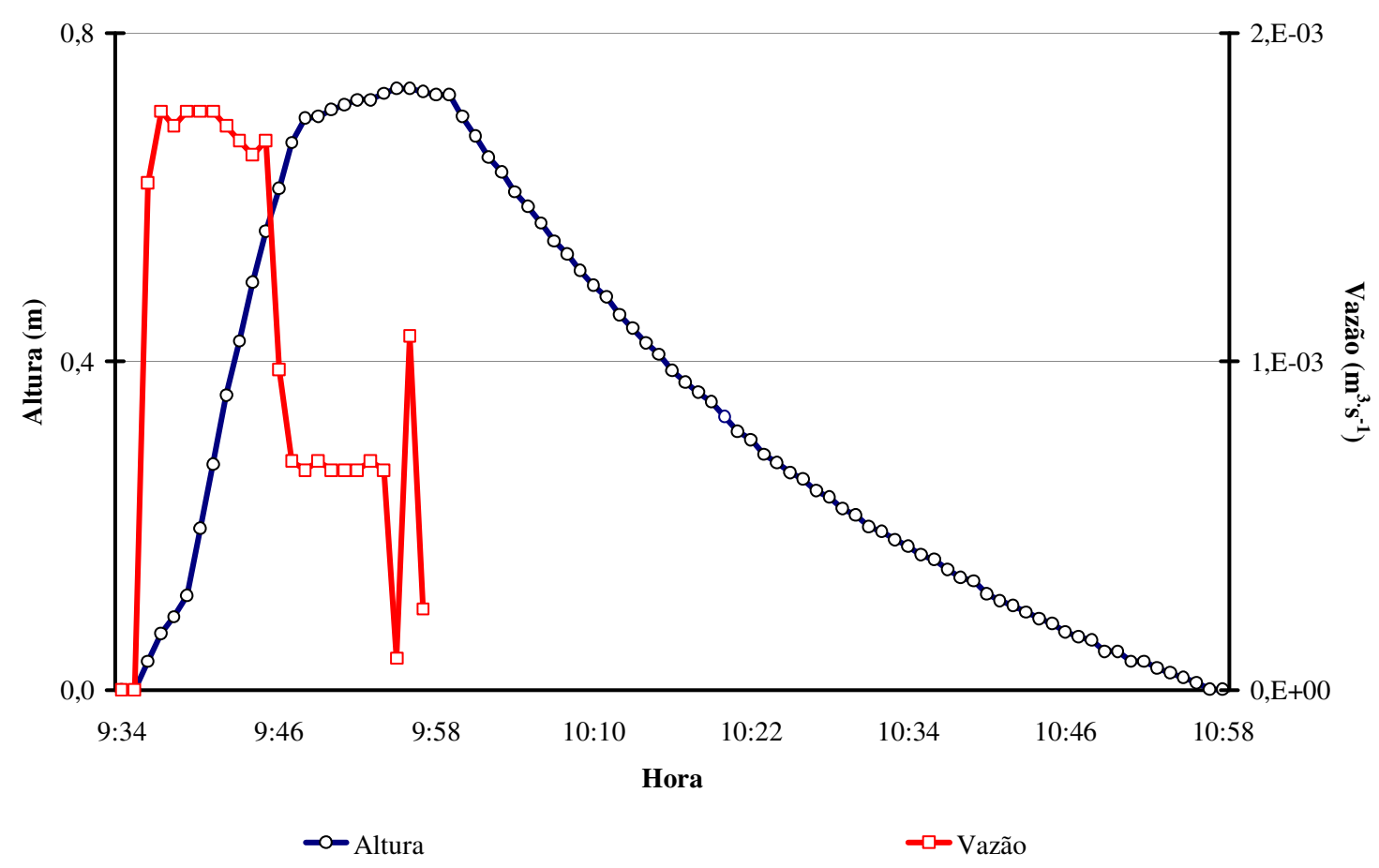

Figura 5.9 - Vazão de entrada e altura na trincheira durante a adução e recessão do Experimento I.

Processado os dados de vazão de entrada e de altura de água na trincheira, determinouse o volume infiltrado (Figura 5.10) através da Equação 4.11 e Equação 4.12.

Verifica-se na Figura 5.10 que após 10 minutos de iniciado a adução ocorreu na curva de volume de entrada uma mudança de declividade. Este comportamento é justificado em virtude da redução da vazão de entrada (ver Figura 5.9). Para este mesmo período, ocorreu um regime permanente em relação ao volume armazenado na trincheira.

O volume infiltrado apresentou ao longo da fase de adução mudanças na declividade da curva. Acredita-se que o motivo para tal mudança decorreu das variações da vazão de entrada, uma vez que o volume infiltrado é dado pela diferença entre o volume de entrada e o volume armazenado na trincheira. O total de volume aduzido e infiltrado foi igual a $1,5 \mathrm{~m}^{3}$. 


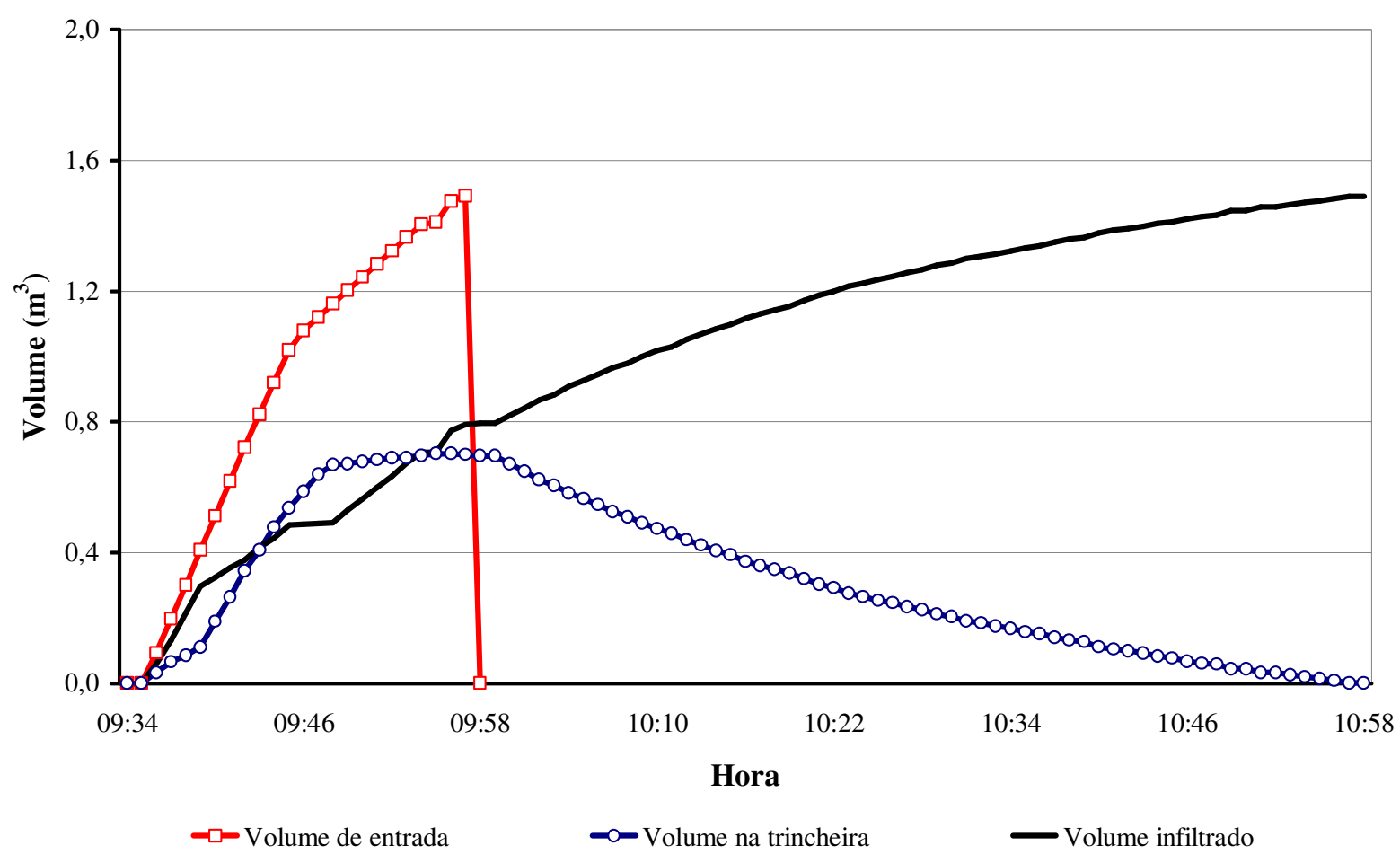

Figura 5.10 - Variação do volume durante a fase de adução e recessão do Experimento I.

Simultaneamente a medição da vazão de entrada e da altura, realizou-se a medição da umidade do solo. Entretanto, esta se iniciou minutos antes a fim de medir os valores iniciais (Figura 5.11).

Observa-se através da Figura 5.11 que as umidades do solo em todas as sondas eram constantes antes de iniciar o experimento. Além disso, verifica-se que a sonda 1 , localizada à $10 \mathrm{~cm}$ da borda superior da trincheira, não apresentou variação. Sendo isto justificado em virtude da altura de água na trincheira durante o experimento não ter atingindo-a (valor máximo igual a 0,74 cm, ver Figura 5.9). 


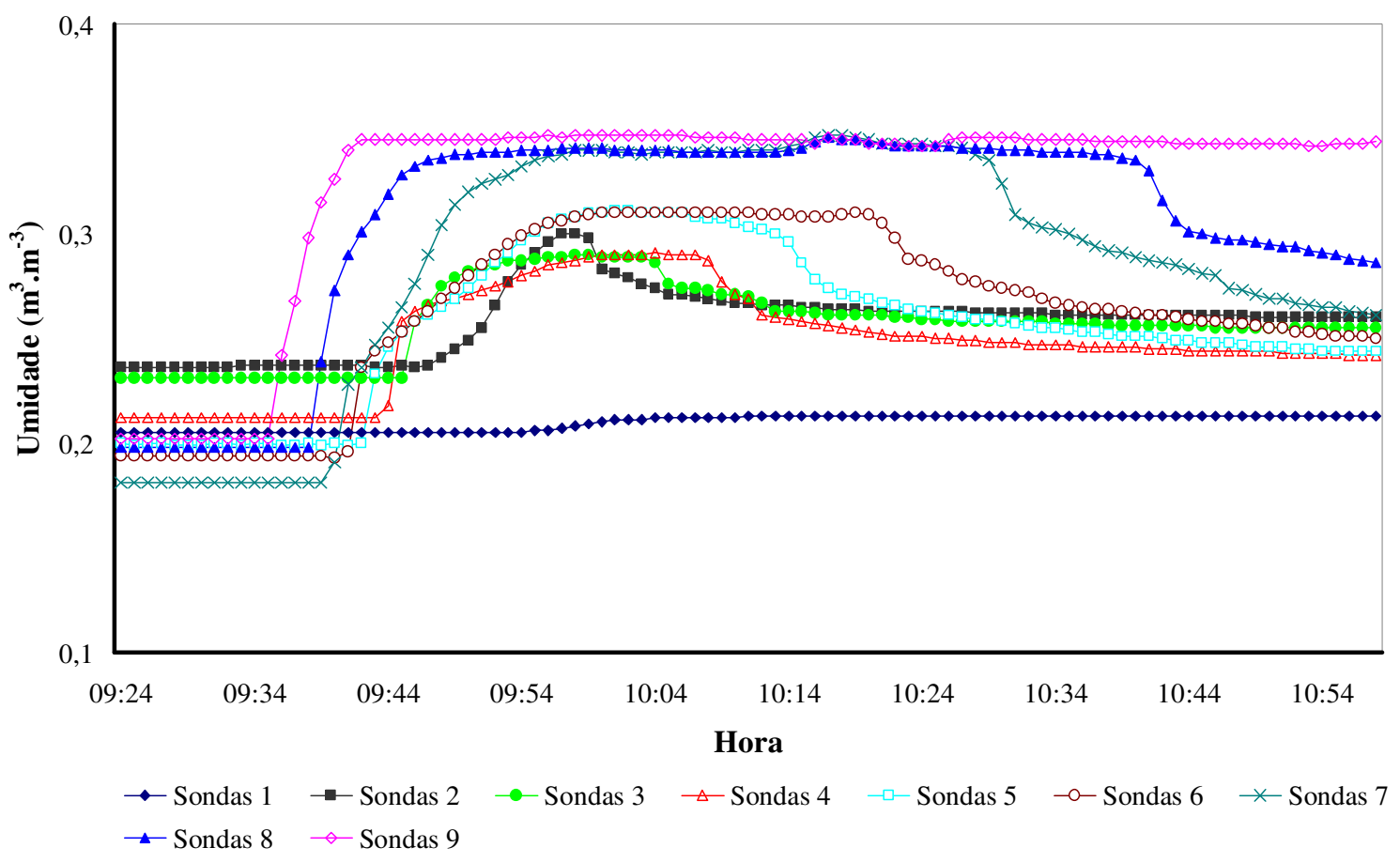

Figura 5.11 - Umidades do solo durante a adução e recessão do Experimento I.

É importante ressaltar que em virtude da consideração de fundo colmatado a sonda 9 não faz parte da modelagem. A sonda foi colocada para verificar como se processa a infiltração no fundo. Desta forma, verifica-se que após 6 minutos do início da adução, o fundo atingiu a condição de saturação e permaneceu assim até o final do experimento. Este comportamento expressa que, em virtude de ter atingido a saturação, a infiltração pela base da trincheira apresenta taxas pequenas quando comparadas com o restante da área infiltrante (lateral).

Com o valor de umidade medido, determinou-se o potencial matricial e sortividade (Tabela 5.6).

Tabela 5.6 - Umidade, potencial matricial e sortividade para abordagem unimodal e bimodal.

\begin{tabular}{|c|c|c|c|c|c|c|c|c|c|}
\hline & & nda 1 & onda 2 & Sonda 3 & onda 4 & Sonda 5 & Sonda 6 & Sonda 7 & Sonda 8 \\
\hline & $\theta_{\mathrm{s}}$ & 0,213 & 0,3 & 0,29 & 0,291 & 0,311 & 0,31 & 0,347 & 0,346 \\
\hline & $\theta_{\mathrm{i}}$ & 0,205 & 0,236 & 0,231 & 0,212 & 0,199 & 0,193 & 0,181 & 0,198 \\
\hline $\mathbf{U}$ & $\psi_{s}$ & 0,741 & 0,303 & 0,334 & 0,331 & 0,271 & 0,274 & 0,172 & 0,175 \\
\hline I & $\psi_{f}$ & 0,825 & 0,567 & 0,598 & 0,751 & 0,901 & 0,992 & 1,241 & 0,915 \\
\hline M & $\mathbf{S}$ & 1,E-03 & $5, \mathrm{E}-03$ & $5, \mathrm{E}-03$ & 8,E-03 & 1,E-02 & 1,E-02 & 2,E-02 & 1,E-02 \\
\hline
\end{tabular}


Tabela 5.6 - Umidade, potencial matricial e sortividade para abordagem unimodal e bimodal.

\begin{tabular}{rl|rrrrrrrr}
\hline $\mathbf{B}$ & $\boldsymbol{\Psi}_{\mathbf{s}}$ & 0,919 & 0,296 & 0,317 & 0,315 & 0,275 & 0,276 & 0,207 & 0,209 \\
$\mathbf{I}$ & $\boldsymbol{\psi}_{\mathbf{f}}$ & 1,071 & 0,550 & 0,605 & 0,939 & 1,180 & 1,288 & 1,517 & 1,198 \\
$\mathbf{M}$ & $\mathbf{S}$ & $1, \mathrm{E}-03$ & $5, \mathrm{E}-03$ & $6, \mathrm{E}-03$ & $9, \mathrm{E}-03$ & $1, \mathrm{E}-02$ & $1, \mathrm{E}-02$ & $2, \mathrm{E}-02$ & $2, \mathrm{E}-02$ \\
\hline
\end{tabular}

Determinado o volume infiltrado, a área infiltrante média e o valor médio da sortividade (Tabela 5.6), estimaram-se a infiltração acumulada observada e calculada (Figura 5.12). Vale ressaltar que a infiltração acumulada calculada foi obtida através do modelo de Green-Ampt de duas formas: uma utilizando a abordagem bimodal na determinação do potencial matricial e outra usando a abordagem unimodal.

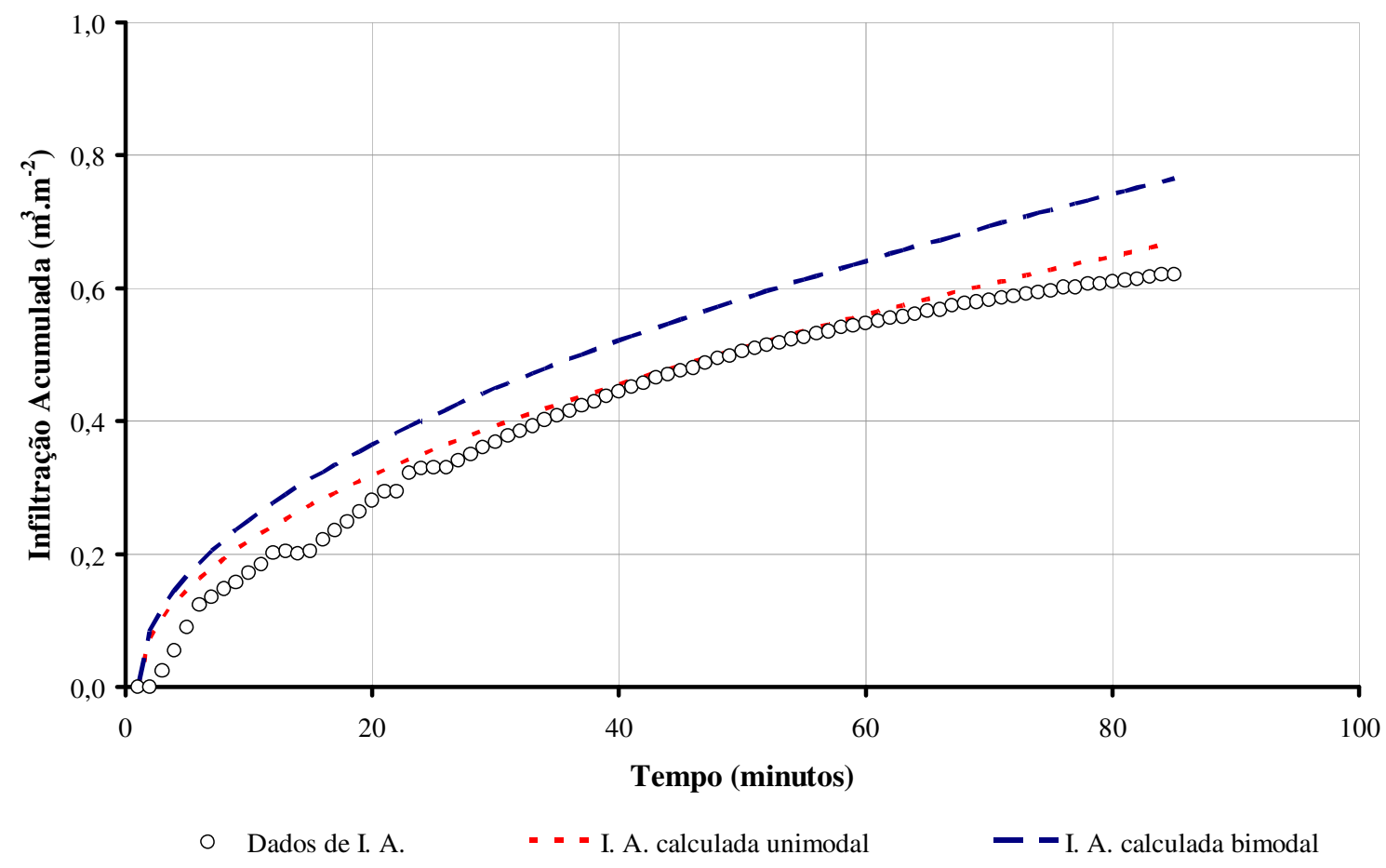

Figura 5.12 - Infiltração acumulada calculada e observada para o Experimento I.

A Figura 5.12 ilustra que os dados obtidos pelo modelo de Green-Ampt se correlacionam bem com os dados de infiltração determinados experimentalmente. Observa-se que a infiltração calculada com dados de potencial matricial estimados pela abordagem unimodal se demonstrou melhor do que os com abordagem bimodal. O coeficiente de Nash e Sutcliffe, para as duas abordagens, foram iguais a 0,963 e a 0,705 , respectivamente. 


\subsection{2 - $2^{\circ}$ Experimento}

O segundo experimento foi realizado no dia 14 de fevereiro de 2009 das $09 \mathrm{hrs} 48 \mathrm{~min}$ às $11 \mathrm{hrs} 28 \mathrm{~min}$. Diferente do primeiro experimento, a vazão de entrada teve um comportamento mais uniforme (Figura 5.13), sendo seu valor médio igual a $6.10^{-4} \mathrm{~m}^{3} . \mathrm{s}^{-1}$.

A fase de adução durou 36 minutos. Logo, transformando a vazão média em precipitação, esta teria intensidade de $46,8 \mathrm{~mm} \cdot \mathrm{h}^{-1}\left(1,3 \cdot 10^{-5} \mathrm{~m} \cdot \mathrm{s}^{-1}\right)$ e período de retorno de 2,4 anos.

A declividade da curva relativa à altura de água na trincheira no período de adução foi menos acentuada do que no Experimento I, uma vez que a vazão de entrada foi menor (Figura $5.13)$.

A fase de recessão permaneceu por $1 \mathrm{hrs} 03$ min, aproximadamente o mesmo período do primeiro experimento. $\mathrm{O}$ comportamento da altura, durante a recessão, foi relativamente igual ao Experimento I. O valor médio da altura foi $0,324 \mathrm{~m}$ e a área média infiltrante foi $2,2 \mathrm{~m}^{2}$.

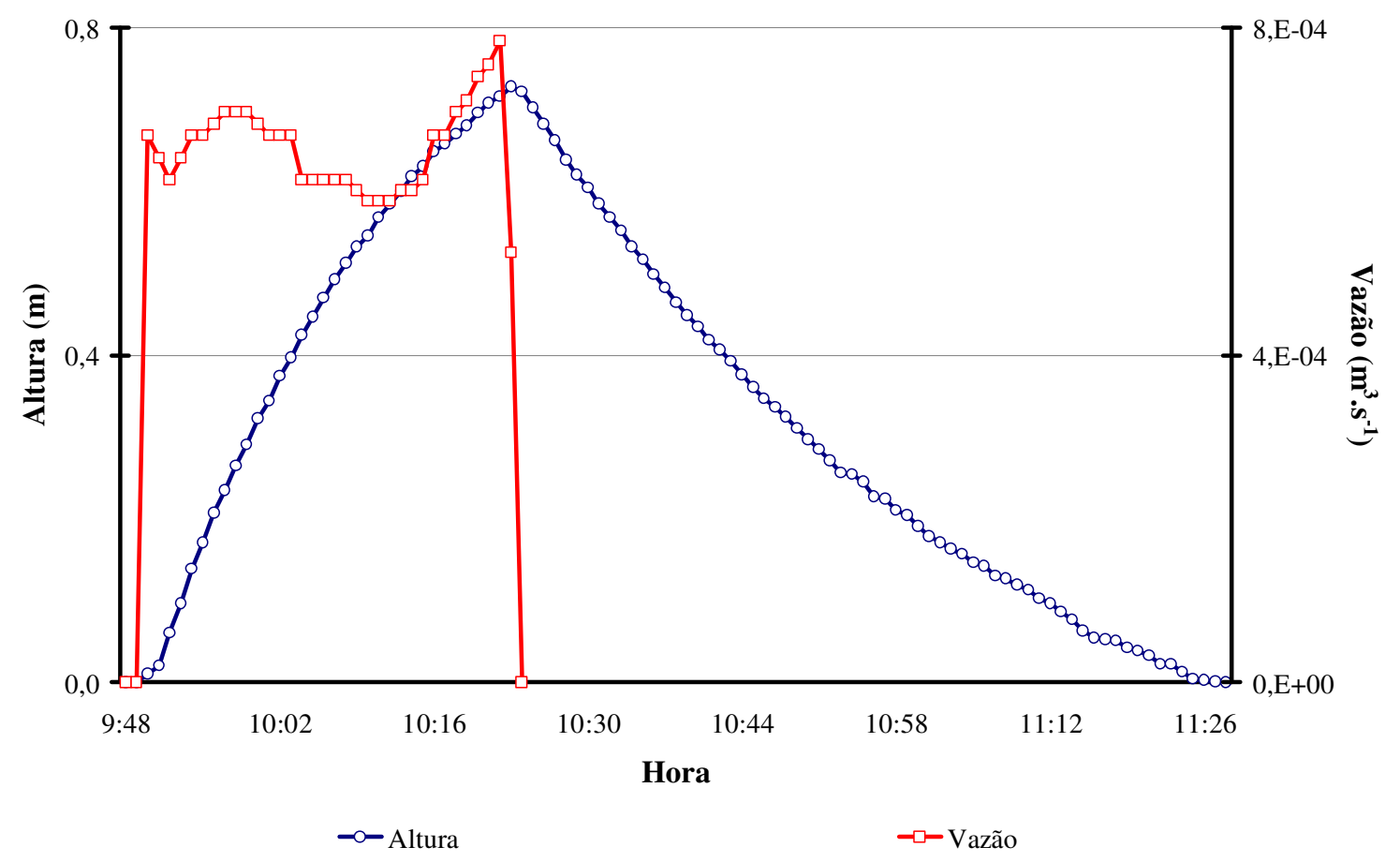

Figura 5.13 - Vazão de entrada e altura na trincheira durante a adução e recessão do Experimento II. 
Com os dados de vazão de entrada e nível na trincheira, estimaram-se os volumes aduzido, infiltrado e armazenado (Figura 5.14).

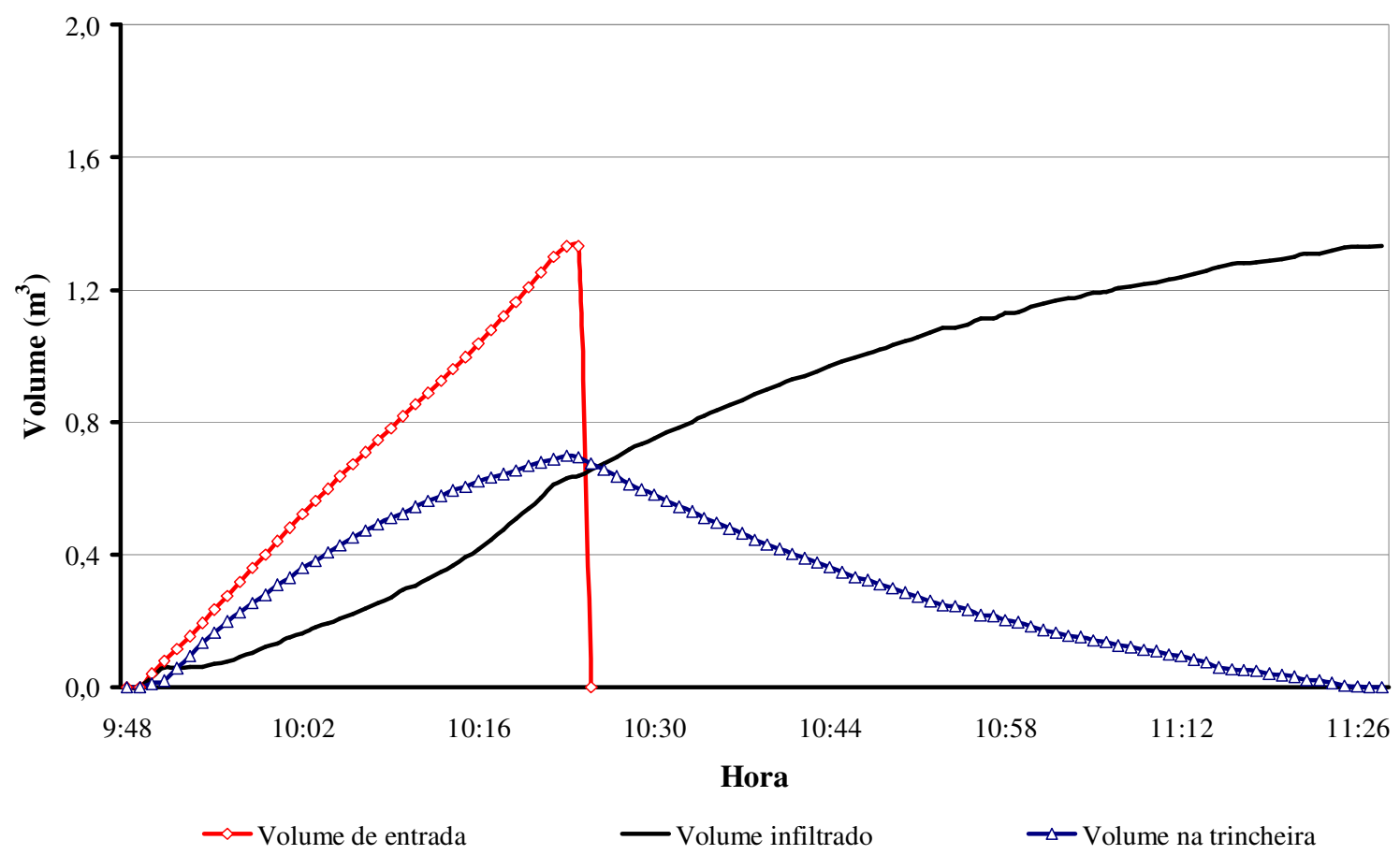

Figura 5.14 - Variação do volume durante a fase de adução e recessão do Experimento II.

Verifica-se na Figura 5.14 que as curvas definidas pelos volumes aduzido, armazenado e infiltrado apresentaram um comportamento linear, sendo, assim, diferente do Experimento I, que por apresentar uma vazão de entrada variável, apresentou mudanças na declividade da curva do volume aduzido e variações na curva do volume infiltrado.

Diferente do Experimento I, no Experimento II, onde a vazão foi mais controlada, não se observa regime permanente ao longo do volume armazenado. Além disso, no Experimento II, o volume infiltrado foi sempre menor que o volume armazenado na trincheira. $\mathrm{O}$ volume total aduzido e infiltrado do Experimento II correspondeu a $1,33 \mathrm{~m}^{3}$.

Concomitantemente à medição indireta dos volumes, realizou-se a medição da umidade do solo. O resultado desta medição apresenta-se na Figura 5.15. 


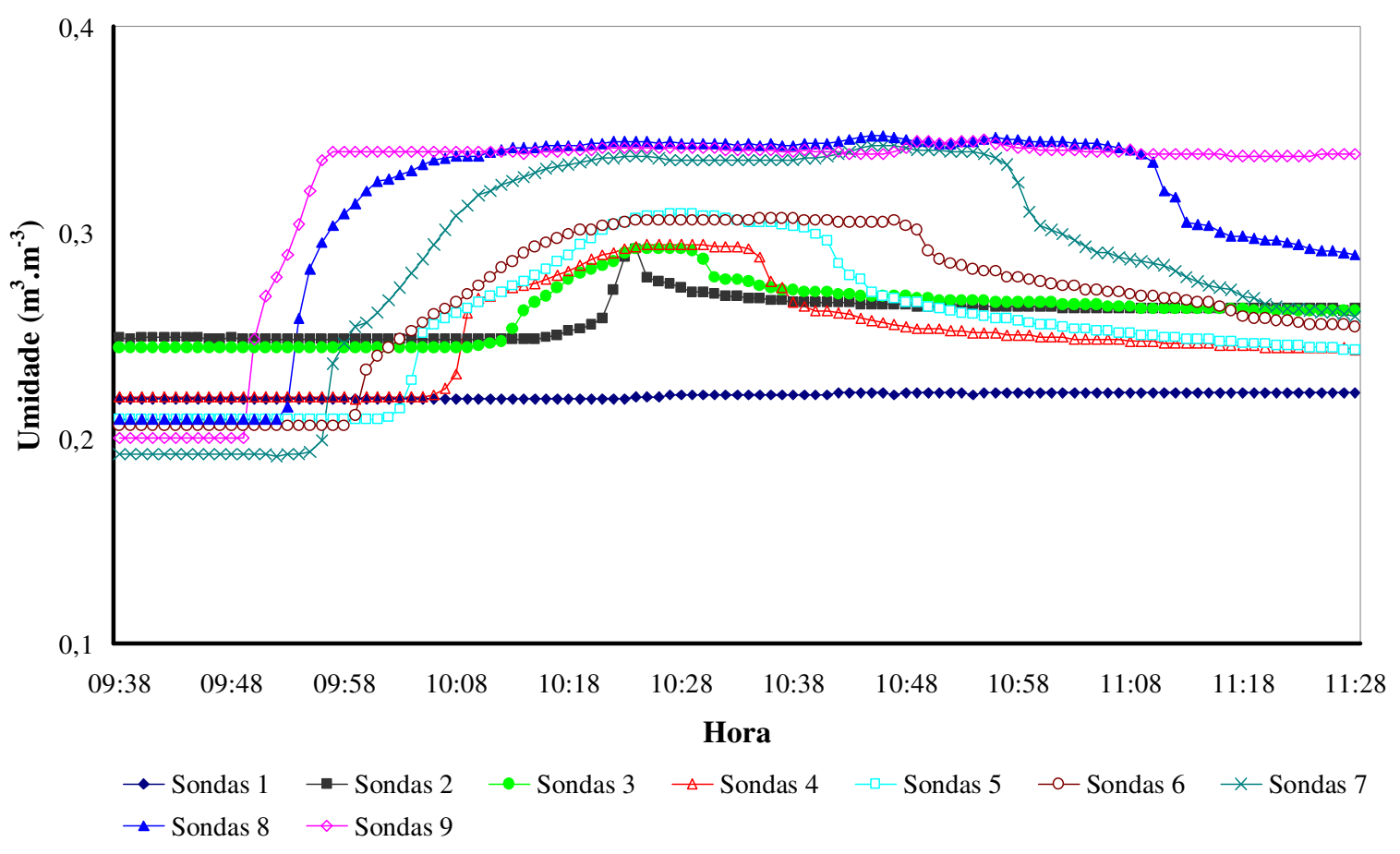

Figura 5.15 - Umidade do solo durante a adução e recessão do Experimento II.

De maneira igual ao ocorrido no Experimento I, a umidade do solo em cada sonda era constante antes da adução e a sonda 1 não apresentou variação da umidade do solo. Mais uma vez, a altura máxima adotada $(0,72 \mathrm{~m})$ foi menor que a altura onde foi instalada a sonda 1 .

Comparando a Figura 5.11 com a Figura 5.15, observa-se que o comportamento dos valores de umidade em cada sonda é idêntico, com exceção da sonda 2 que apresentou para o Experimento I uma concavidade mais aberta. O motivo pelo qual a sonda 2 comportou-se diferente é a existência do regime permanente no volume infiltrado durante o Experimento I.

Assim como ocorreu no Experimento I, no Experimento II a umidade do solo medida pela sonda 9 rapidamente ( 8 minutos) atingiu a saturação.

Estimados os valores de umidade, determinaram-se os parâmetros de entrada do modelo de Green-Ampt e, consequentemente, o valor de sortividade encontrado em cada sonda. Os valores resultantes deste processo encontram-se na Tabela 5.7. 
Tabela 5.7 - Umidade, potencial matricial e sortividade para abordagem unimodal e bimodal

\begin{tabular}{rrrrrrrrrr}
\hline & & Sonda 1 & Sonda 2 & Sonda 3 & Sonda 4 & Sonda 5 & Sonda 6 & Sonda 7 & Sonda 8 \\
\hline & $\boldsymbol{\theta}_{\mathbf{s}}$ & 0,222 & 0,292 & 0,292 & 0,294 & 0,309 & 0,307 & 0,342 & 0,347 \\
& $\boldsymbol{\theta}_{\mathbf{i}}$ & 0,219 & 0,248 & 0,244 & 0,219 & 0,209 & 0,206 & 0,191 & 0,209 \\
$\mathbf{U}$ & $\boldsymbol{\psi}_{\mathbf{s}}$ & 0,663 & 0,328 & 0,328 & 0,321 & 0,277 & 0,283 & 0,186 & 0,172 \\
$\mathbf{N}$ & $\boldsymbol{\psi}_{\mathbf{f}}$ & 0,687 & 0,500 & 0,521 & 0,687 & 0,781 & 0,814 & 1,026 & 0,781 \\
$\mathbf{I}$ & $\mathbf{M}$ & $4, \mathrm{E}-04$ & $4, \mathrm{E}-03$ & $4, \mathrm{E}-03$ & $7, \mathrm{E}-03$ & $1, \mathrm{E}-02$ & $1, \mathrm{E}-02$ & $2, \mathrm{E}-02$ & $1, \mathrm{E}-02$ \\
$\mathbf{M}$ & $\mathbf{S}$ & 0,745 & 0,313 & 0,313 & 0,309 & 0,278 & 0,282 & 0,217 & 0,207 \\
$\mathbf{B}$ & $\boldsymbol{\psi}_{\mathbf{s}}$ & 0,45 & & & & & & \\
$\mathbf{I}$ & $\boldsymbol{\psi}_{\mathbf{f}}$ & 0,801 & 0,4612 & 0,4858 & 0,801 & 0,996 & 1,0525 & 1,324 & 0,996 \\
$\mathbf{M}$ & $\mathbf{S}$ & $6, \mathrm{E}-04$ & $3, \mathrm{E}-03$ & $4, \mathrm{E}-03$ & $8, \mathrm{E}-03$ & $1, \mathrm{E}-02$ & $1, \mathrm{E}-02$ & $2, \mathrm{E}-02$ & $1, \mathrm{E}-02$ \\
\hline
\end{tabular}

Com base no valor médio da sortividade da Tabela 5.7 e nos dados resultantes da razão entre volume infiltrado e área média infiltrante, estimaram-se as três modalidades de infiltração acumulada (Figura 5.16).

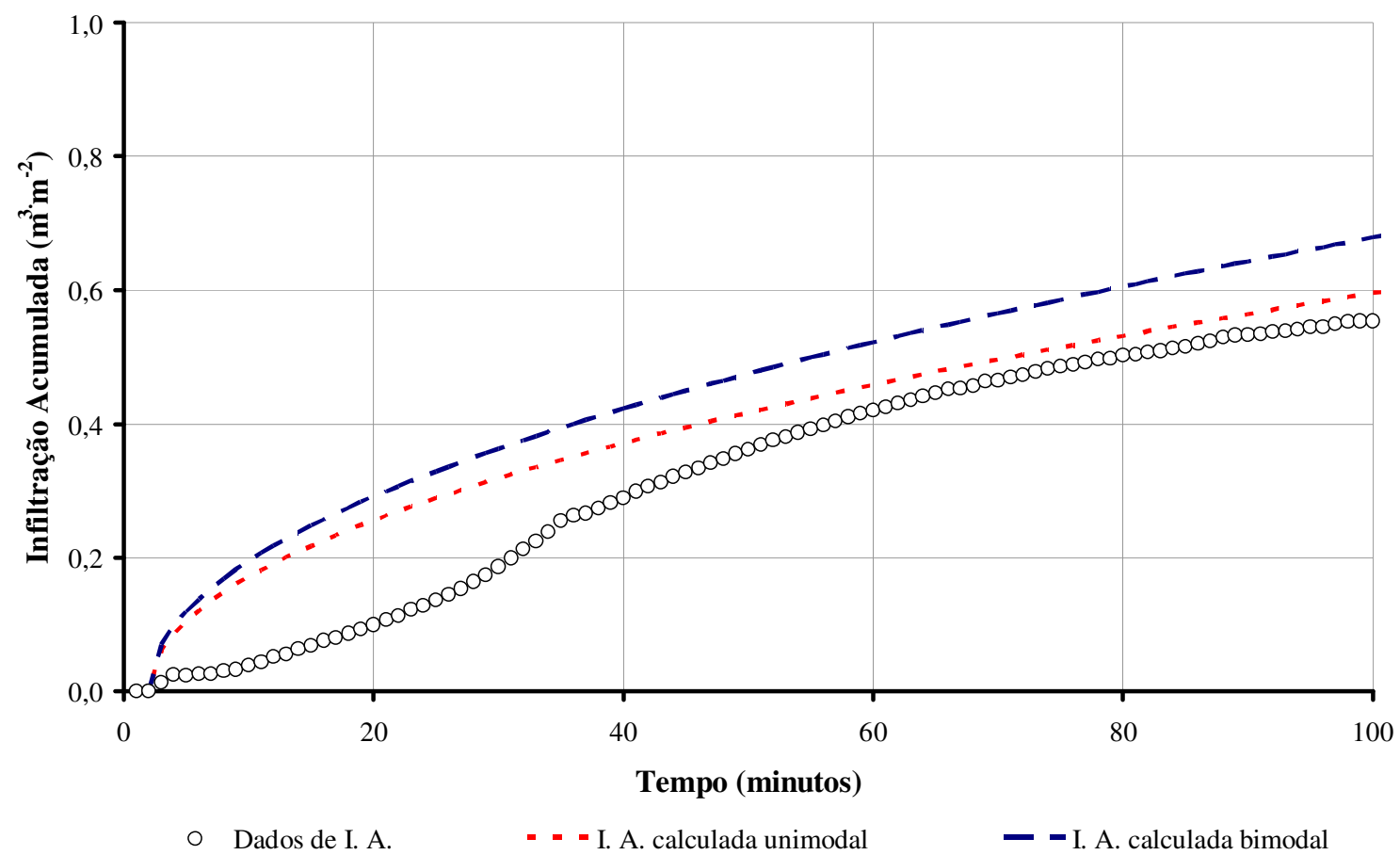

Figura 5.16 - Infiltração acumulada e observada para o Experimento II.

Assim como ocorreu no Experimento I, o modelo de Green-Ampt usando tanto a abordagem unimodal como a bimodal superestimou os valores de infiltração acumulada.

Para o Experimento II, as curvas de infiltração acumulada calculadas pelo modelo apresentaram menor correlação com os dados de infiltração medidos experimentalmente. Esta 
menor correlação também é expressa através do coeficiente de Nash e Sutcliffe, os quais foram iguais a 0,806 e 0,523 para a abordagem uni e bimodal, respectivamente.

\subsection{3 - $3^{\circ}$ Experimento}

O terceiro experimento foi realizado no dia 24 de fevereiro de 2009 das $14 \mathrm{hrs} 34 \mathrm{~min}$ às 15hrs44min. Buscando avaliar os dados experimentais para um tempo menor, utilizou-se o intervalo de tempo de 10 segundos. A escolha deste intervalo gerou maiores problemas na sincronização temporal dos equipamentos.

A fase de adução permaneceu por 14 minutos com uma vazão média de $2,4 \cdot 10^{-3} \mathrm{~m}^{3} \cdot \mathrm{s}^{-1}$. Considerando que a vazão média fosse proveniente de uma precipitação, esta teria intensidade e período de retorno iguais a $178,0 \mathrm{~mm} \cdot \mathrm{h}^{-1}\left(4,95 \cdot 10^{-5} \mathrm{~m} \cdot \mathrm{s}^{-1}\right)$ e 80,7 anos, respectivamente.

A fase de recessão durou 58 minutos. Durante este período mais o tempo em que ocorreu adução (Figura 5.17), o nível médio de água na trincheira foi de 0,31 m. Logo, a área infiltrante foi de $2,11 \mathrm{~m}^{2}$.

Mesmo a adução tendo durações diferentes para cada experimento, o tempo em que se processou a recessão foi praticamente igual em todos. Tal fato é esperado uma vez que o solo ao término da adução apresentou para os três experimentos características hidráulicas similares. Portanto, a redistribuição de água no solo apresentaria o mesmo desempenho. 


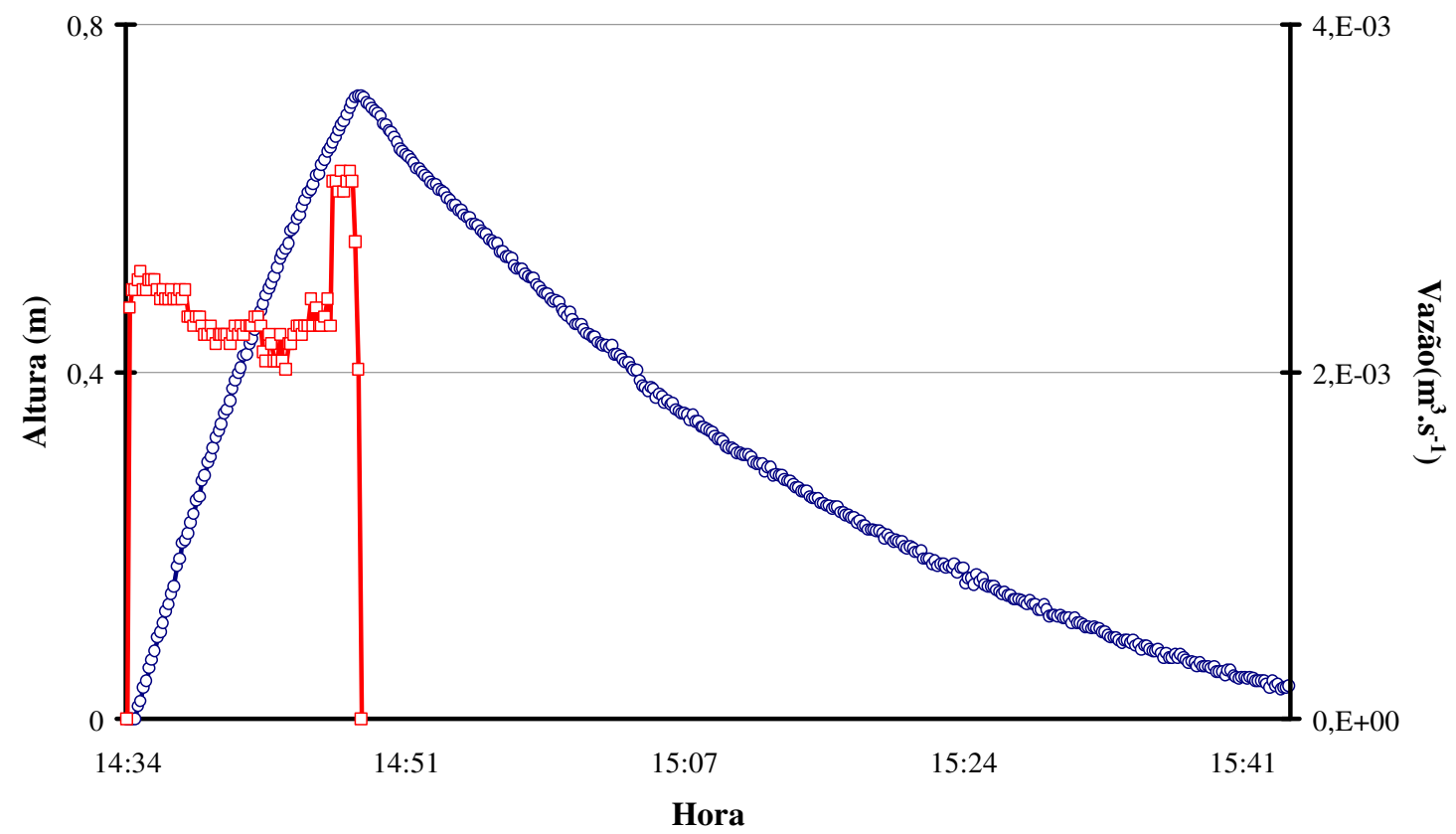

Figura 5.17 - Vazão de entrada e altura na trincheira durante a adução e recessão do Experimento III.

Estimados os dados presentes na Figura 5.17, determinaram-se os volumes aduzido, infiltrado e armazenado (Figura 5.18).

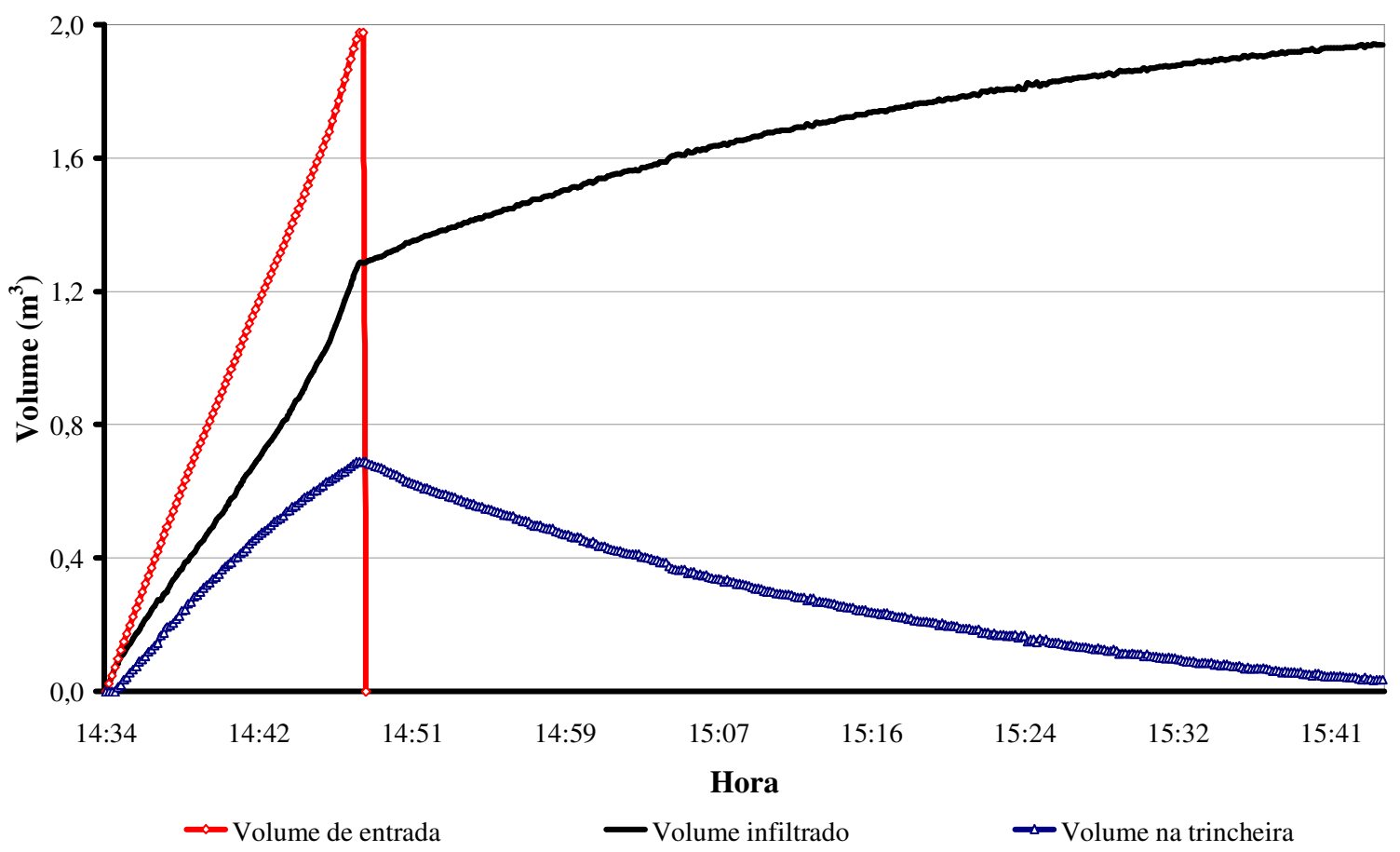

Figura 5.18 - Variaçaõ do volume durante a fase de adução e recessão do Experimento III. 
Em virtude do intervalo de tempo entre medições sucessivas ser relativamente curto, verifica-se para este experimento uma defasagem de 30 segundos entre a entrada e a resposta de nível. Este problema pode ser visualizado nos dados iniciais presentes na Figura 5.18.

Da mesma maneira que ocorreu no Experimento II, as curvas relativas aos volumes apresentaram comportamento linear durante a adução e a recessão. O volume total aduzido e infiltrado foi igual a $1,97 \mathrm{~m}^{3}$.

Verifica-se através da Figura 5.18 que o comportamento do volume infiltrado é bastante diferente do ocorrido para os outros dois experimentos. Acredita-se que o responsável por este comportamento seja o intervalo de tempo adotado, uma vez que quanto menor o intervalo temporal, maior é o número de dados e maiores são as chances de haver imprecisão nos dados medidos. Portanto, o comportamento obtido no Experimento III foi decorrente de uma superestimativa da vazão de entrada, uma vez que o valor do volume de entrada foi muito maior do que nos outros experimentos.

Vale observar através da Figura 5.10, da Figura 5.14 e da Figura 5.18, que para vazões baixas o volume infiltrado fica menor que o volume armazenado, já para vazões altas o comportamento é inverso. Tal fato se deve que para volumes de entrada maiores, maior será a variação de nível na trincheira e, consequentemente, mais rapidamente a área infiltrante total é utilizada.

Ao mesmo tempo em que foram medidos os volumes ilustrados na Figura 5.18, foram determinados os valores de umidade do solo. Estes estão ilustrados na Figura 5.19. 


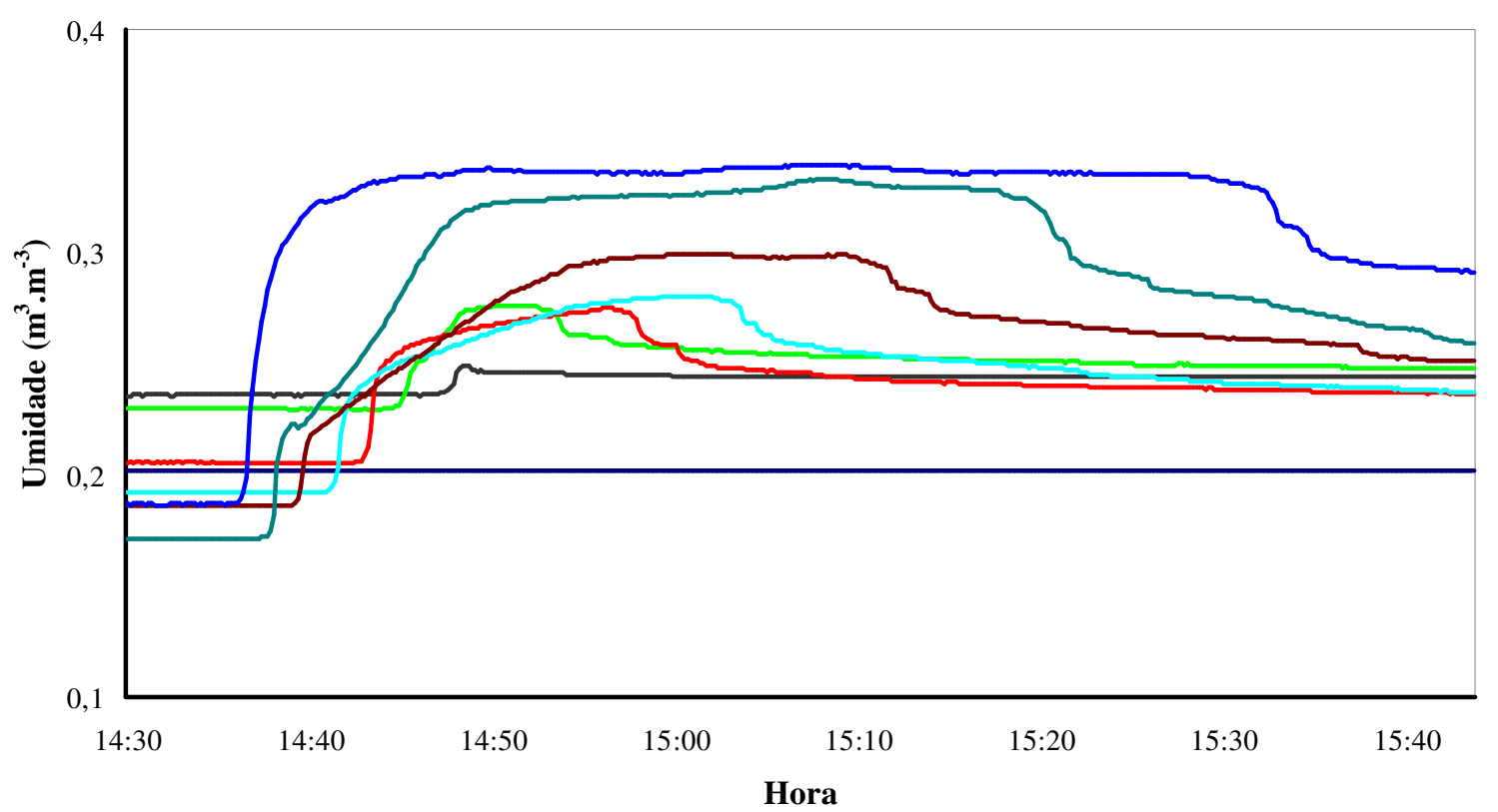

— Sondas $1-$ Sondas $2-$ Sondas $3-$ Sondas $4-$ Sondas $5-$ Sondas $6-$ Sondas 7 - Sondas 8

Figura 5.19 - Umidade do solo durante a adução e recessão do Experimento III.

Diferentemente dos outros experimentos, no Experimento III não foi utilizada a sonda 9, pois o processo de infiltração no fundo já é conhecido.

Com base nos valores de umidade do solo, foram determinados os parâmetros de entrada do modelo. Estes valores estão demonstrados na Tabela 5.8.

Tabela 5.8 - Umidade, potencial matricial e sortividade para abordagem unimodal e bimodal.

\begin{tabular}{|c|c|c|c|c|c|c|c|c|c|}
\hline & & Sonda 1 & Sonda 2 & Sonda 3 & Sonda 4 & Sonda 5 & Sonda 6 & Sonda 7 & Sonda 8 \\
\hline \multirow{4}{*}{$\begin{array}{l}\mathbf{U} \\
\mathbf{N} \\
\mathbf{I}\end{array}$} & $\theta_{\mathrm{s}}$ & 0,202 & 0,249 & 0,276 & 0,275 & 0,28 & 0,299 & 0,333 & 0,339 \\
\hline & $\theta_{\mathrm{i}}$ & 0,202 & 0,235 & 0,229 & 0,205 & 0,192 & 0,186 & 0,171 & 0,186 \\
\hline & $\psi_{\mathrm{s}}$ & 0,862 & 0,495 & 0,382 & 0,385 & 0,367 & 0,306 & 0,211 & 0,194 \\
\hline & $\psi_{f}$ & 0,862 & 0,573 & 0,612 & 0,825 & 1,009 & 1,124 & 1,575 & 1,124 \\
\hline M & $\mathbf{S}$ & - & 1,E-03 & 4,E-03 & 7,E-03 & 1,E-02 & 1,E-02 & 2,E-02 & 2,E-02 \\
\hline \multirow{3}{*}{$\begin{array}{c}\mathbf{B} \\
\mathbf{I} \\
\mathbf{M}\end{array}$} & $\psi_{\mathrm{s}}$ & 1,126 & 0,456 & 0,352 & 0,355 & 0,342 & 0,298 & 0,234 & 0,222 \\
\hline & $\psi_{f}$ & 1,126 & 0,560 & 0,631 & 1,071 & 1,306 & 1,418 & 1,745 & 1,418 \\
\hline & $\mathbf{S}$ & - & 2,E-03 & 5,E-03 & 1,E-02 & 1,E-02 & 2,E-02 & 2,E-02 & 2,E-02 \\
\hline
\end{tabular}

A umidade medida pela sonda 1, localizada a $10 \mathrm{~cm}$ da borda superior da trincheira, não apresentou variação ao decorrer do experimento. Logo, a variação da umidade é zero e o 
gradiente $(\partial \psi / \partial \theta)$ é indeterminado. Desta forma, no valor médio da sortividade não foi computada a sonda 1 .

Analisando os valores de umidade inicial e de saturação da Tabela 5.6, da Tabela 5.7 e da Tabela 5.8, verifica-se que o Experimento III iniciou com menores valores de umidade quando comparado com os outros experimentos. Além disso, observa-se que os valores de umidade inicial foram maiores para o Experimento II. No que se refere à umidade de saturação, o Experimento I apresentou valores máximos para as sondas colocadas mais próximas do fundo e o Experimento II para as sondas colocadas mais próximas da superfície.

Com base nos valores da Tabela 5.8 e nos dados resultantes da razão entre volume infiltrado e área média infiltrante, estimaram-se as três modalidades de infiltração acumulada (Figura 5.20).

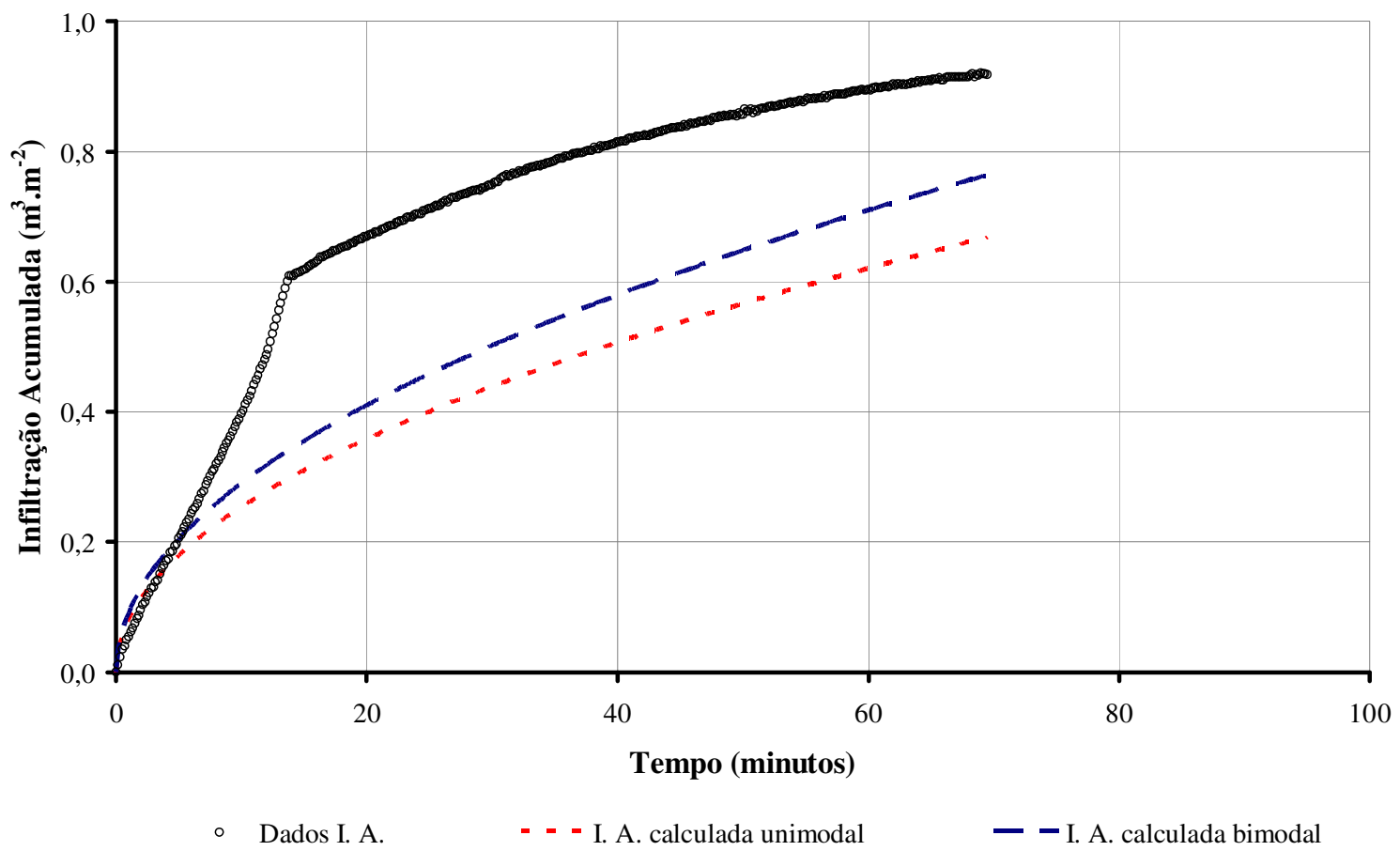

Figura 5.20 - Infiltração acumulada e observada para o Experimento III.

Como podem ser constatadas através da Figura 5.20, as infiltrações acumuladas calculadas pelo modelo de Green-Ampt subestimaram a infiltração. Isto, como já foi dito, foi ocasionado em virtude do volume infiltrado ter sido superestimado por problemas na medição 
da vazão de entrada. Os valores do coeficiente de Nash e Sutcliffe para a infiltração calculada unimodal e bimodal foram iguais a $-0,35$ e 0,22 , respectivamente.

É importante ressaltar que para os três experimentos, os quais apresentaram condições experimentais distintas, os valores determinados pela abordagem bimodal foram maiores que a unimodal. Além disso, para o experimento III o valor da abordagem bimodal foi o que mais se aproximou dos valores observados.

\section{5 - Metodologia de dimensionamento}

A metodologia proposta foi avaliada segundo os dados obtidos nos três experimentos realizados. Desta forma, para os dados de chuvas e sortividade determinados em cada experimento, dimensionou-se a trincheira de infiltração. Para o dimensionamento, considerouse constantes o comprimento e a largura. A altura da trincheira foi determinada de duas formas: $h_{m i t}$ que corresponde a altura da trincheira para absorver só o volume escoado que excede ao volume de pré-ocupação; e $h_{\text {tot }}$ que representa a altura da trincheira para absorver todo o volume escoado no lote.

É importante ressaltar que adotando $h_{\text {mit }}$, deve-se construir a estrutura de saída para rede de drenagem. Esta estrutura pode ser feita através de um dreno suplementar instalado sub-superficialmente no interior da trincheira e ligado à rede de drenagem.

Outro ponto importante é que a infiltração acumulada utilizada no dimensionamento foi calculada ao término da adução pelo modelo de Green-Ampt com abordagem unimodal. A escolha da unimodalidade ao invés da bimodalidade deve-se ao melhor comportamento na maior parte dos experimentos.

Tabela 5.9 - Dados experimentais para avaliação da metodologia de dimensionamento.

\begin{tabular}{lcccccccc}
\hline & $\begin{array}{c}\boldsymbol{t} \\
\text { minutos }\end{array}$ & $\begin{array}{c}\boldsymbol{i}_{\text {chuva }} \\
\mathrm{mm} \cdot \mathrm{h}^{-1}\end{array}$ & $\begin{array}{c}\boldsymbol{T} \\
\mathrm{anos}\end{array}$ & $\begin{array}{c}\text { Vazão } \\
\mathrm{m}^{3} \cdot \mathrm{s}^{-1}\end{array}$ & $\begin{array}{c}\boldsymbol{I}_{\boldsymbol{c}} \\
\mathrm{m}^{3} \cdot \mathrm{m}^{-2}\end{array}$ & $\begin{array}{c}\boldsymbol{h}_{\text {exp }} \\
\mathrm{m}\end{array}$ & $\begin{array}{c}\boldsymbol{h}_{\text {mit }} \\
\mathrm{m}\end{array}$ & $\begin{array}{c}\boldsymbol{h}_{\text {total }} \\
\mathrm{m}\end{array}$ \\
\hline Exp. I & 23 & 81,8 & 8,4 & $1,1 \mathrm{E}-03$ & 0,35 & 0,73 & 0,95 & 1,17 \\
Exp. II & 36 & 46,7 & 2,4 & $6,2 \mathrm{E}-04$ & 0,36 & 0,72 & 0,79 & 0,99 \\
Exp. III & 14 & 178,0 & 80,7 & $2,4 \mathrm{E}-03$ & 0,30 & 0,72 & 1,48 & 1,78 \\
\hline
\end{tabular}


Com base nos valores expostos na Tabela 5.9, verifica-se que para todos os dados experimentais a altura dimensionada $\left(h_{m i t}\right)$ é capaz de absorver eficientemente o volume escoado, apresentando folga para absorver outro evento precipitante que aconteça logo após o término do primeiro. Além disso, percebe-se que só para o Experimento III a estrutura foi superdimensionada. Tal fato ocorreu em virtude do modelo de Green-Ampt subestimar os valores de infiltração observados no Experimento III.

Outro ponto que pode ser observado na Tabela 5.9 é que em virtude dos valores de $h_{\text {total }}$ serem maiores que os valores $h_{\text {mit }}$, a adoção de trincheiras com controle parcial pode ser mais econômica que a utilização de trincheiras com controle total do escoamento. Soma-se a isso a possibilidade de redução da capacidade de infiltração em função da colmatação, o que acarretaria ao longo do tempo o aumento, durante a adução, da altura atingida, podendo ocasionar o extravasamento da trincheira. Tal situação não aconteceria na trincheira com controle parcial, visto que tudo que exceder a capacidade será encaminhada para o sistema de drenagem.

Como forma de avaliar economicamente a construção de trincheira de infiltração, realizou-se o orçamento, para um lote com as mesmas características geográficas do lote experimental, de todo custo com análise do solo, captação, direcionamento em armazenamento da água pluvial. A Figura 5.21 e a Figura 5.22 ilustram as características do lote adotado. 


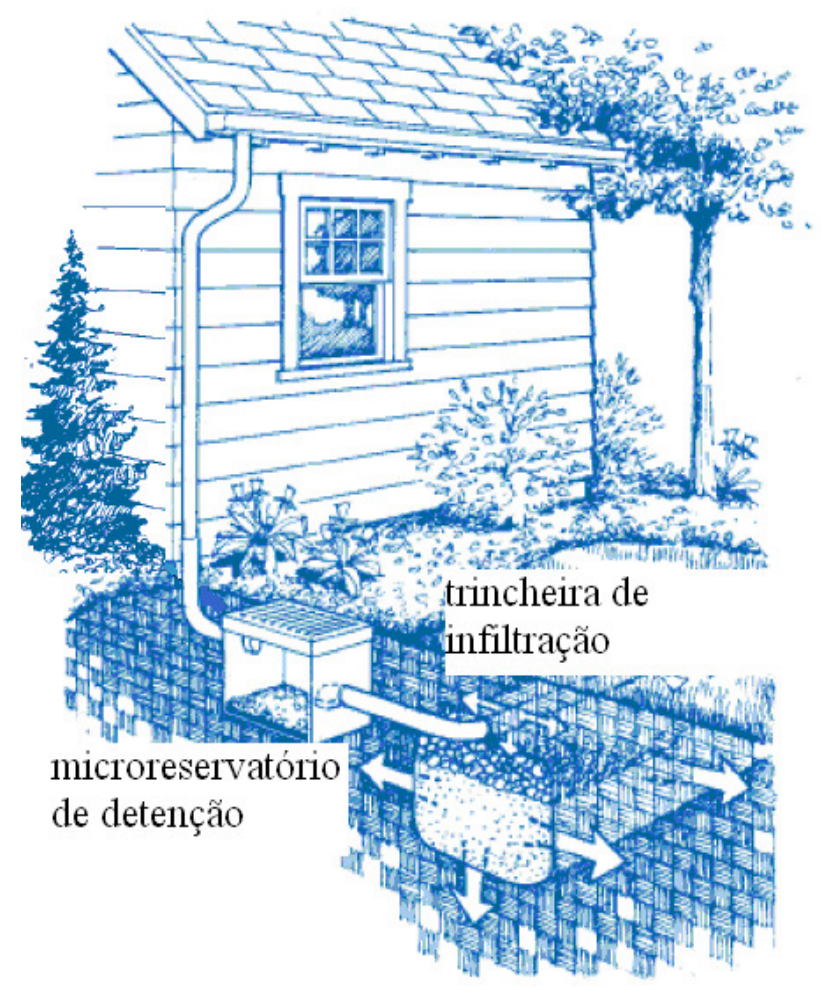

Figura 5.21 -Exempo ilustrativo da trincheira de infiltração adotada para dimensionamento.

Fonte: ESCP (2002 apud Ohnuma Junior, 2009).

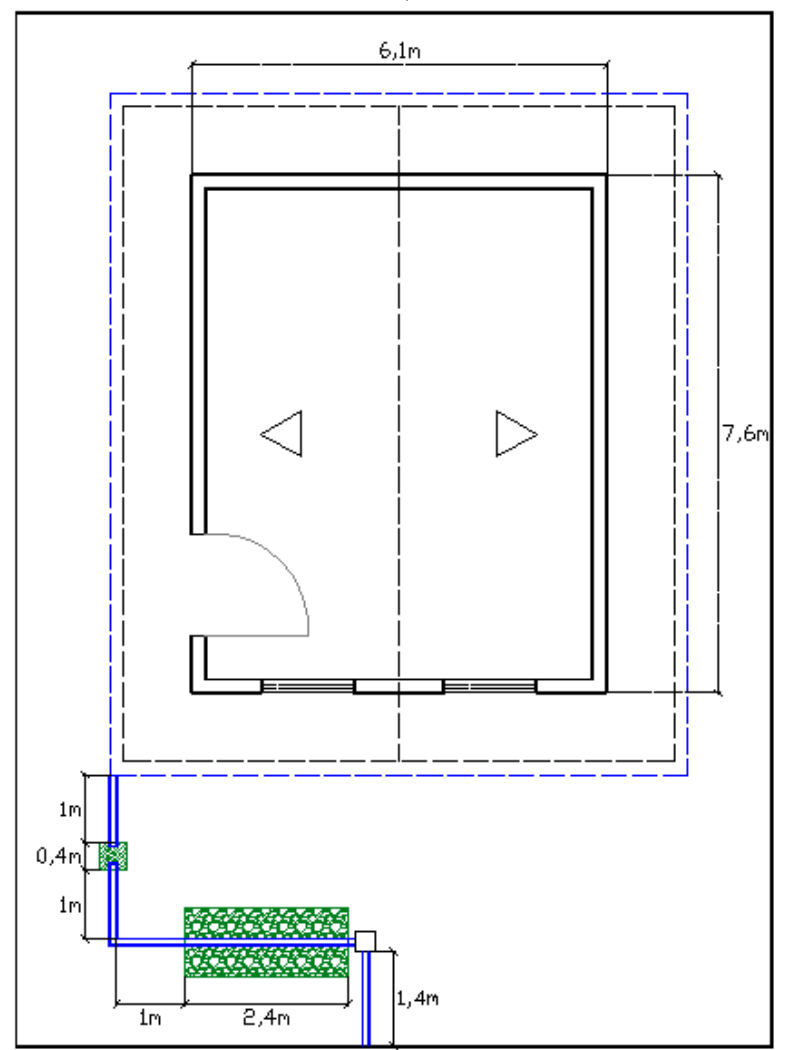

Figura 5.22 - Planta baixa da trincheira adotada para dimensionamento. 
O orçamento (Tabela 5.10) foi estipulado com base na cotação dada por fornecedores da cidade de São Carlos em março de 2009.

Tabela 5.10 - Orçamento para construção da trincheira.

\begin{tabular}{|c|c|c|c|c|c|}
\hline Item & Descrição & Quant. & Unid. & Unit. & Total \\
\hline \multicolumn{6}{|c|}{1 Serviços preliminares } \\
\hline \multicolumn{6}{|c|}{ 1.1 Análise do solo } \\
\hline 1.1 .1 & Condutividade hidráulica & 1 & amostra & $\mathrm{R} \$ 250,00$ & $\mathrm{R} \$ 250,00$ \\
\hline 1.1.2 & Curva de retenção & 10 & ponto & $\mathrm{R} \$ 20,00$ & $\mathrm{R} \$ 200,00$ \\
\hline 1.2 & Escavação manual & 2,4 & $\mathrm{~m}^{3}$ & $\mathrm{R} \$ 15,00$ & $\mathrm{R} \$ 36,00$ \\
\hline 1.3 & Escavação Mecânica & 1 & $\mathrm{~h}$ & $\mathrm{R} \$ 100,00$ & $\mathrm{R} \$ 100,00$ \\
\hline \multicolumn{6}{|c|}{2 Materiais } \\
\hline 2.1 & Geotêxtil & 11,6 & $\mathrm{~m}^{2}$ & $\mathrm{R} \$ 2,50$ & $\mathrm{R} \$ 29,00$ \\
\hline 2.2 & \multicolumn{5}{|l|}{ Material de preenchimento } \\
\hline 2.2 .1 & Brita & 2,16 & $\mathrm{~m}^{3}$ & $\mathrm{R} \$ 42,00$ & $\mathrm{R} \$ 90,72$ \\
\hline 2.2.2 & Brita branca & 2 & saco & $\mathrm{R} \$ 40,00$ & $\mathrm{R} \$ 80,00$ \\
\hline 2.3 & \multicolumn{5}{|l|}{ Tubos e conexões (PVC) } \\
\hline 2.3.1 & Tubulação de 3" & 9,2 & $\mathrm{~m}$ & $\mathrm{R} \$ 6,26$ & $\mathrm{R} \$ 57,59$ \\
\hline 2.3.2 & Cotovelo $3^{\prime \prime}$ & 5 & - & $\mathrm{R} \$ 3,19$ & $\mathrm{R} \$ 15,95$ \\
\hline 2.3 .3 & Calha Platibanda & 27,4 & $\mathrm{~m}$ & $\mathrm{R} \$ 15,60$ & $\mathrm{R} \$ 427,44$ \\
\hline \multirow{2}{*}{\multicolumn{2}{|c|}{3 Mão-de-obra }} & 1 & dia & $\mathrm{R} \$ 60,00$ & $\mathrm{R} \$ 60,00$ \\
\hline & & & & TOTAL & $\mathrm{R} \$ 1.346,70$ \\
\hline
\end{tabular}

O custo com a estrutura de saída para rede de drenagem foi computado apenas sobre $o$ valor da tubulação. Não foi calculado o custo com o micro-reservatório de detenção. Este pode funcionar como um reservatório de auto-limpeza, com entrada pela parte superior e uma saída apenas um pouco mais baixa que a entrada.

Como o comprimento e a largura foram considerados constantes, o custo da trincheira é função de sua altura. Assim, avaliaram-se para valores distintos de porosidade, período de retorno e coeficiente de escoamento os custos com a construção da trincheira por metro cúbico mitigado (Tabela 5.11).

Tabela 5.11 - Custos por metro cúbico mitigado $\left(\mathrm{R} \$ . \mathrm{m}^{-3}\right)$ para valores distintos de porosidade, período de retorno e coeficiente de escoamento.

\begin{tabular}{rccccccc}
\hline & \multicolumn{3}{c}{$\boldsymbol{T}\left(\boldsymbol{C}_{\boldsymbol{a}}=\mathbf{0 , 1 3} \boldsymbol{e} \boldsymbol{C}_{\boldsymbol{d}}=\mathbf{0 , 9 5}\right)$} & & \multicolumn{3}{c}{$\boldsymbol{C}_{\boldsymbol{a}}(\boldsymbol{T}=\mathbf{5}$ anos $)$} \\
\cline { 2 - 4 } \cline { 6 - 8 } $\boldsymbol{\eta}_{\boldsymbol{b}}$ & $\mathbf{2}$ & $\mathbf{5}$ & $\mathbf{1 0}$ & & $\mathbf{0 , 0 8}$ & $\mathbf{0 , 1 3}$ & $\mathbf{0 , 1 8}$ \\
$\mathbf{0 , 3}$ & 1.315 & 1.086 & 944 & & 1.033 & 1.086 & 1.148 \\
$\mathbf{0 , 4}$ & 1.289 & 1.068 & 925 & & 1.006 & 1.060 & 1.122 \\
$\mathbf{0 , 5}$ & 1.271 & 1.042 & 900 & & 989 & 1.042 & 1.104 \\
\hline
\end{tabular}


Observa-se através da Tabela 5.11, que quanto maior for a porosidade do material de preenchimento e o período de retorno adotado e menor for o coeficiente de escoamento mais econômica será a trincheira de infiltração. Estes valores são justificados em função dos custos com análise do solo e direcionamento da água pluvial serem os mais significativos na construção da trincheira. Logo, a altura é um fator relativamente invariante sobre o custo. Desta forma, quanto maior for o volume mitigado mais viável economicamente será a trincheira.

É importante lembrar que um fator que também deve ser considerado no custo da trincheira é a sua manutenção, a qual se não existir pode reduzir muito a vida útil do dispositivo. A utilização de estruturas a montante para retenção de partículas grossas aumenta a vida útil da trincheira e pode também ser bastante efetiva na redução da colmatação no solo. 


\section{Capítulo 6}

"Para nossa inteligência ser eminente,
teremos que associar a idéia com pesquisa e
conclusão."

Ivan Teorilang

\section{6 - CONCLUSÃO E RECOMENDAÇÕES}

O presente trabalho foi conduzido de modo a atender aos objetivos propostos no Capítulo 1. A partir dos resultados alcançados nos experimentos de campo, de laboratório e na modelagem numérica, pode-se formular algumas conclusões, bem como apresentar propostas para trabalhos futuros.

\section{1 - Ensaios de caracterização geotécnica e hidráulica do solo}

A análise granulométrica do solo e a determinação dos índices físicos foram determinados a fim de analisar as propriedades hidráulicas medidas em laboratório com base nas propriedades de solos que tenham a mesma classificação textural. Desta forma, pôde-se observar que todos os parâmetros hidráulicos correspondem a valores esperados para solos arenosos. Além disso, a composição textural do solo é relativamente idêntica ao solo trabalhado por Graciosa (2005), atestando a utilização das informações deste solo para análise da viabilidade da instalação da trincheira.

As curvas de retenção medidas pelos dois métodos laboratoriais apresentaram comportamentos distintos tanto em relação aos dados de umidade de saturação e residual como na distribuição do tamanho médio dos poros. Assim, pode-se concluir, através das divergências encontradas, que a curva de retenção determinada pela câmara de Richards é a 
que representa de forma mais real o conteúdo de água no solo e a relação entre umidade e potencial matricial.

O método de papel filtro por ser uma técnica simples e barata requer extremo cuidado no que se refere à determinação da relação entre umidade e potencial. Por isso, a menor precisão já é esperada em função dos vários fatores intervinenientes na determinação da relação entre umidade e potencial.

Sobre a abordagem uni e bimodal, observou-se que nos dois métodos a curva de retenção com abordagem bimodal apresentou valores mais altos dos coeficiente utilizados na avaliação das metodologias. Tais valores justificam-se em função da maior parametrização utilizada na abordagem bimodal. No entanto, a mesma abordagem não foi mais precisa na determinação da infiltração acumulada pelo modelo de Green-Ampt. Portanto, apesar dos modelos matemáticos com distribuição unimodal serem menos precisos na determinação da relação entre potencial e umidade do que os que utilizam abordagem bimodal, a mesma conlclusão não pode ser feita, para este solo, na determinação da infiltração.

Neste trabalho, por limitações físicas e de tempo, não foi possível considerar nos parâmetros hidráulicos a anisotropia local. Por isso, recomenda-se que em trabalhos futuros a condutividade hidráulica saturada e curva de retenção sejam determinadas em vários pontos ao longo da altura da trincheira. Desta forma, o modelo de Green-Ampt será aplicado em cada camada com maior precisão, uma vez que as características hidráulicas são mais realísticas.

\section{2 - Instalação e monitoramento de trincheira de infiltração}

A trincheira de infiltração por ter sido instalada atendendo todos os critérios e todas as recomendações estabelecidos nos trabalhos anteriores realizados com trincheira de infiltração, não apresentou nenhum problema após a instalação e durante a execução dos ensaios experimentais. 
Verificou-se, através dos experimentos, que a trincheira de infiltração se mostrou eficiente no controle do escoamento superficial. Todos os experimentos apresentaram intensidades de chuvas maiores aos que foram utilizadas no dimensionamento e, mesmo assim, a trincheira conseguiu absorver de forma eficiente o volume escoado.

A metodologia utilizada no monitoramento se mostrou adequada visto que conseguiu avaliar tanto o comportamento quantitativo como também a metodologia de dimensionamento proposta. No entanto, recomenda-se que em trabalhos futuros seja avaliada a infiltração considerando as três dimensões. Como pôde-se observar através da sonda 9 o fundo, mesmo tendo taxas pequenas de infiltração, é uma parcela representativa da área total responsável pela infiltração. A simplificação unidimensional, apesar de não ter comprometido o monitoramento, resume muito o processo de infiltração.

Sobre os equipamentos utilizados no monitoramento, pode-se concluir que as sondas de TDR e a sonda Diver forneceram valores precisos de umidade e nível de água na trincheira, respectivamente. Contudo, o manômetro utilizado para medição da lâmina de água no vertedor triangular apresentou uma precisão relativamente baixa às necessidades do experimento.

Em virtude do pouco tempo de monitoramento, não foi possível avaliar o processo de colmatação na trincheira. Portanto, a continuidade no monitoramento pode ser útil na avaliação da colmatação e, consequentemente, na vida útil de estruturas de infiltração.

\section{3 - Modelo de Green-Ampt}

O modelo de Green-Ampt, apesar de todas as simplificações adotadas na modelagem do processo de infiltração horizontal, apresentou resultados satisfatórios comparados aos dados observados nos ensaios experimentais, com valores do coeficiente de Nash e Sutcliffe altos. Tal conclusão não incluiu os resultados obtidos com o Experimento III, uma vez que para este experimento os valores não apresentaram boa correlação com os dados observados. 
A baixa correlação pode ser justificada pelo intervalo de tempo adotado, já que com este intervalo as imprecisões dos equipamentos ficaram mais evidentes.

O coeficiente de Nash e Sutcliffe por ser uma equação que calcula a diferença numérica (erro) entre valores observados e calculados é utilizado em alguns trabalhos (GARCIA, 2005; KALIN et al., 2003; e MOUSSA, 2008); como função-objetivo na calibração dos parâmetros do modelo, que neste trabalho corresponde aos parâmetros de entrada do modelo de Green-Ampt. Portanto, recomenda-se que em trabalhos futuros sejam calibrados, com base no coeficiente supracitado, a condutividade hidráulica saturada e os parâmetros que compõem a curva de retenção.

\section{4 - Metodologia de dimensionamento}

A metodologia de dimensionamento foi proposta com o objetivo de tornar mais simples a obtenção dos parâmetros relacionados com a infiltração, uma vez que na prática da engenharia civil quanto mais simples for a metodologia, mais chances ela terá de ser aplicada e difundida perante os órgãos gestores na drenagem urbana. Por isso optou-se pelo modelo de Green-Ampt, visto que a sortividade e a infiltração acumulada podem ser obtidas através de parâmetros com relativa facilidade de determinação em ensaios laboratoriais.

A metodologia foi testada para os dados obtidos nos ensaios experimentais e mostrouse eficiente no dimensionamento de trincheiras de infiltração, apresentando capacidade volumétrica para absorver eventos posteriores ao evento para a qual foi dimensionada.

Vale ressaltar que o coeficiente de segurança utilizado no dimensionamento pode ser questionado, uma vez que a consideração de fundo colmatado já representa um tipo segurança. Além disso, o extravasamento de trincheiras de infiltração, apesar de ser evitado, não causará grandes problemas à estrutura e nem mesmo ao lote em que ela encontra-se instalada. Portanto, recomenda-se que em trabalhos futuros seja avaliada a real necessidade deste coeficiente. 
Maiores estudos com esta metodologia de dimensionamento devem ser realizados a fim de verificar a sua eficiência em solos com características hidráulicas distintas ao solo estudado. 


\section{REFERÊNCIAS BIBLIOGRÁFICAS}

AGRA, S. G. (2001). Estudo experimental de microrreservatórios para controle do escoamento superficial. Dissertação (Mestrado em Engenharia de Recursos Hídricos e Saneamento Ambiental) - Instituto de Pesquisas Hidráulicas, Universidade Federal do Rio Grande do Sul, Porto Alegre, 121 p.

ALONSO, T. de P. (2005). Condutividade Hidráulica de solos compactados em ensaios com permeâmetro de parede flexível. Dissertação (Mestrado em Geotecnia) - Escola de Engenharia de São Carlos, Universidade de São Paulo, São Carlos, 137 p.

ANDRADE, J. P. M. (2006). Previsão hidrometeorológica visando sistemas de alerta antecipado de cheias em bacias urbanas. Dissertação (Mestrado em Engenharia Hidráulica e Saneamento) - Escola de Engenharia de São Carlos, Universidade de São Paulo, São Carlos, 99 p.

ANDREOLLI, I. (2003). Previsão em tempo real no rio Uruguai com base na previsão meteorológica. Dissertação (Mestrado em Engenharia de Recursos Hídricos e Saneamento Ambiental) - Instituto de Pesquisas Hidráulicas, Universidade Federal do Rio Grande do Sul, Porto Alegre, 182 p.

ARAÚJO, P. R.; TUCCI, C. E. M.; e GOLDENFUM, J. A. (2000). Avaliação da eficiência dos pavimentos permeáveis na redução do escoamento superficial. Revista Brasileira de Recursos Hídricos, Porto Alegre, n. 3, v. 5, p. 21-29.

BAPTISTA, M. B.; e NASCIMENTO, N. O. (1996). Sustainable Development and Urban Stormwater Management in the Context of Tropical Developing Countries. Congresso Interamericano de Ingeniería Sanitária y Ambiental. México: AIDIS, p. 523 - 529.

BAPTISTA, M. B.; NASCIMENTO, N. O.; e BARRAUD, S. (2005). Técnicas Compensatórias em Drenagem Urbana, Porto Alegre: ABRH, 266 p. 
BARBASSA, A. P. (1991). Simulação do efeito de urbanização sobre a drenagem pluvial na cidade de São Carlos - SP. Tese (doutorado em Engenharia Hidráulica e Saneamento) - Escola de Engenharia de São Carlos, Universidade de São Paulo, São Carlos, 327 p.

BRANDAO, V. S.; PRUSKI, F. F.; e SILVA, D. D. da (2003). Infiltração da água no solo. Viçosa: Editora UFV, 98 p.

BRAUNE, M. J.; e WOOD, A. (1999). Best Management Practices Applied to Urban Runoff Quantity and Quality Control. Water Science Technology, v. 39, n. 12, p. 117121.

CAMARgo, A. P.; e SENTElhaS, P. C. (1997). Avaliação do desempenho de diferentes métodos de estimativa da evapotranspiração potencial no Estado de São Paulo. Revista Brasileira Agrometeorologia, v. 5, p. 89-97.

CARVALHO, L. A. de (2006). Distribuição espacial dos parâmetros da equação da condutividade hidráulica em função da umidade do solo. Tese (Doutorado em Agronomia) - Escola Superior de Agricultura Luiz de Queiroz, Universidade de São Paulo, Piracicaba, 180 p.

CETESB. (1979). Drenagem urbana: manual de projeto. São Paulo, 467 p.

CICHOTA, R.; e LIER, Q. de J. V. (2004). Análise da variabilidade espacial de pontos amostrais da curva de retenção da água no solo. Revista Brasileira de Ciência do Solo, v. 28 , p. 585-596.

CICHOTA, R. (2003). Avaliação no campo de um TDR segmentado para determinação da umidade no solo. Dissertação (Mestrado em Agronomia) - Escola Superior de Agricultura Luiz de Queiroz, Universidade de São Paulo, Piracicaba, 120 p.

COELHO, E. F.; VELlaME, L. de M.; COELHO FILHO, M. A.; e LEDO, C. A. da S. (2006). Desempenho de modelos de calibração de guias de onda acopladas a TDR e a multiplexadores em três tipos de solos. Revista Brasileira de Ciência do Solo, v. 30, p. $23-30$. 
COOMBES, P. J.; ARGUE, J. R.; e KUCZERA, G. (1999). Figtree Place: a case study in water sensitive urban development (WSUD). Urban Water, v. 1, p. 335-343.

COSTA, W. A.; OliveirA, C. A. S.; e KATO, E. (2008). Modelos de Ajuste e Métodos para Determinação da Curva Característica de um Latossolo-Vemelho Amarelo. Revista Brasileira de Ciência do Solo, v. 32, p. 515-523.

DARCY, H. (1856). Les fontaines publiques de La Ville de Dijon. Victor Dalmont, Paris, $593 \mathrm{p}$.

DAMODHARA, R. M.; RAGHUWANSHI, S. N.; SINGH, R.; SCHMITZ, G. H.; e LENNARTZ, F. (2008). Evaluation of time domain reflectometry (TDR) for estimating furrow infiltration. Irrig. Sci. v. 26, p.161-168.

DOURADO NETO, D.; NIELSEN, D. R.; HOPMANS, J. W.; REICHARDT, K.; e BACCHI, O. O. S. (2000). Software to model soil water retention curves (SWRC, version 2.00). Scientia Agricola, Piracicaba, SP, v. 57, n. 1, p. 191-192.

DUCHENE, M.; MCBEAN, E.; e THOMSON, N. (1994). Modeling of infiltration from trenches for storm-water control. Journal of Water Resources Planning and Management, v. 120, n. 3, p. 276-293.

DURNER, W. (1994). Hydraulic conductivity estimation for soils with heterogeneous pore structure. Water Resour. Res., v. 30, p. 211-223.

FREDLUND, D. G.; e XING, A. (1994). Equation for the soil-water characteristic curve. Canadian Geotechnical Journal, v. 31, p. 521-532.

GARCIA, J. I. B. (2005). Monitoramento hidrológico e modelagem da drenagem urbana da bacia hidrográfica do Arroio Cancela. Dissertação (Mestrado em Engenharia de Recursos Hídricos e Saneamento Ambiental) - Programa de Pós Graduação em Engenharia Civil, Universidade Federal de Santa Maria, 169 p. 
GOERL, R. F.; KOBIYAMA, M. (2005). Considerações sobre as inundações no Brasil. In: Anais do XVI Simpósio Brasileiro de Recursos Hídricos, João Pessoa - PB.

GOLDENFUM, J. A. (2008). Notas de aulas da disciplina de Gerenciamento da Drenagem urbana. Disponível em:< http://galileu.iph.ufrgs.br/joel/iph014/IPH_01_014Apresentacao.pdf>. Acesso em: 10 de junho de 2008.

GRACIOSA, M. C. P. (2005). Trincheiras de infiltração como tecnologia alternativa em drenagem urbana: modelagem experimental e numérica. Dissertação (Mestrado em Engenharia Hidráulica e Saneamento) - Escola de Engenharia de São Carlos, Universidade de São Paulo, São Carlos, 231 p.

GRACIOSA, M. C. P.; MENDIONDO, E. M.; e CHAUDHRY, F. H. (2008). Metodologia para o Dimensionamento de Trincheiras de Infiltração para o Controle do Escoamento Superficial na Origem. Revista Brasileira de Recursos Hídricos, Porto Alegre, v. 13, n. 2, p. 207-214.

GRANTZ, D. A.; PERRY, M. H.; e MEINZER, F. C. (1990). Using time-domain reflectometry to measure soil water in hawaiian sugarcane. Agronomy Journal, v. 82, p. 144-146.

GREEN, W. H.; e AMPT, G. A. (1911). The flow of air and water through soils. Journal of Agricultural Science, Cambridge, v. 4, n. 1, p. 1-24.

GVIRTZMAN, H.; SHALEV, E.; DAHAN, O.; e HATZOR, Y. H. (2008). Large-scale infiltration experiments into unsaturated stratified loess sediments: Monitoring and modeling. Journal of Hydrology. v. 349, p. 214-229.

HORTON, R. E. (1940). An Approach Toward a Physical Interpretation of Infiltration Capacity. Soil Science Society of America Proceedings, v. 5, p. 399 - 417.

HUTSON, J. L.; e CASS, A. (1987). A retentivity function for use in soil-water simulation models. J. Soil Sci., v. 38, p. 105-113. 
IBGE (2008). Instituto Brasileiro de Geografia e Estatística. Disponível em: <http://www.ibge.gov.br/home/estatistica/populacao/censohistorico/1940_1996.shtm> . Acesso em: Junho de 2008.

HORTON, R. E., (1940). An Approach Toward a Physical Interpretation of Infiltration Capacity. Soil Science Society of America Proceedings, v. 5, p. 399-417.

KALIN, L.; GOVINDARAJU, R. S.; e HANTUSH, M. M. (2003). Effect of geomorphologic resolution on modeling of runoff hydrograph and sedimntograph over small watersheds. Journal of Hydrology, v. 276, p. 89-111.

KLEIN, V. A.; e LIBARDI, P. L. (2002). Condutividade hidráulica de um Latossolo Roxo, não saturado, sob diferentes sistemas de uso e manejo. Ciência Rural, Santa Maria, v. 32, n. 6, p. 945-953.

KOSTIAKOV, A. N. (1932). On the dynamics of the coefficient of water percolation in soils and the necessity for studying it from a dynamic point of view of purposes of ameliorations. Trans. 6th Comm. Int. Soil Sci. Soc., Russian Part A, p. 17-21.

KRONAVETER, L.; SHAMIR, U.; e EKESSELER, A. (2001). Water sensitive urban planning: modeling on-site infiltration. Journal of Water Resources Planning and Management. v. 127, n. 2, p. 78 - 88.

KUO, C. Y.; ZHU, J. L. e DOLLARD, L. A. (1989). A study of infiltration trenches. Virginia Wate Resources Research Center, Bulletin 163, 87 p.

LANDPHAIR, H. C.; MCFALLS, J. A.; e THOMPSON, D (2000). Design Methods, Selection, and Cost-Effectiveness of Stormwater Quality Structures. Texas Department of Transportation In Cooperation with the U.S. Department of Transportation Federal Highway Administration.

LENCASTRE, A. (1961). Manuel d'hydraulique générale, Paris : Eyrolles, 411 p. 
LEONG, E. C.; e RAHARDJO, H. (1997). Review of soil-water chacacteristic curve equations. Journal of Geotechnical and Geoenvironmental Engineering, ASCE, v. 123, n. 12 , p. 1106-1117.

LIBARDI, P. L. (2005). Dinâmica da Água no Solo. São Paulo: Editora da Universidade de São Paulo, 200 p.

LIMA, J. C de (2003). Avaliação dos riscos e danos de inundação e do impacto da adoção de medidas não-estruturais em Itajubá/MG. Belo Horizonte. Dissertação (Mestrado em Saneamento, Meio Ambiente e Recursos Hídricos) - Escola de Engenharia, Universidade Federal de Minas Gerais, 160 p.

MALLANTS, D.; TSENG, P.; TORIDE, N.; TIMMERMAN, A.; e FEYEN, J. (1997). Evaluation of multimodal hydraulic functions in characterizing a heterogeneous field soil. Journal of Hydrology, v. 195, p. 172-199.

MAHESHWARI, B. L. (1997). Interrelations among physical and hidraulic parameters of non-cracking soils. J. Agric. Engng Res. v. 68, p. 297-309.

MANIERI, J. M.; VAZ, C. M. P.; e MARIA, I. C. de (2007). Sonda espiral de TDR para a medida da umidade no perfil do solo. Revista Brasileira de Ciência do Solo. v. 31, p. 191-198.

MEDEIROS, J. D. F.; CASTRO, N.; GOLDENFUM, J. A.; e CLARKE, R. T. (2007). Clibração de Sondas do TDR em um Latossolo. Revista Brasileira de Recursos Hídricos, v. 12, n. 2, p. 19-25.

MENDIONDO, E. M. (2001). Contribuições da análise de incertezas para a recuperação ambiental de bacias através da abordagem interdisciplinar de Geobiohidrologia. Tese (Doutorado em Engenharia de Recursos Hídricos e Saneamento Ambiental) - Instituto de Pesquisas Hidráulicas, Universidade Federal de Rio Grande do Sul, Porto Alegre, $327 \mathrm{p}$. 
MIKKELSEN, P. S.; e JACOBSEN, P. (1993). Stormwater infiltration design based on rainfall statistics and soil hydraulics. Proc. ASCE International Symposium on Engineering Hydrology, San Francisco, California, p. 653-658.

MIKKELSEN, P. S.; JACOBSEN, P.; e FUJITA, S. (1996). Infiltration practice for control of urban stormwater. Journal of Hydraulic Research, v. 34, n. 6, p. 827-840.

MINASNY, B.; e MCBRATNEY, A. B. (2000). Estimation of sorptivity from discpermeameter measurements. Geoderma, v. 95, p. 305-324

MOUSSA, R. (2008). Effect of channel network topology, basin segmentation and rainfall spatial distribution on the geomorphologic instantaneous unit hydrograph transfer function. Hydrological Processes, v. 22, p. 395-419.

NAIME, J. M. (2001). Um novo método para estudos dinâmicos, in situ, da infiltração da água na região não saturada do solo. Tese (Doutorado em Ciências da Engenharia Ambiental) - Escola de Engenharia de São Carlos, Universidade de São Paulo, São Carlos, $231 \mathrm{p}$

NASCIMENTO, N. O.; BAPTISTA, M. B.; e SOUZA, V. C. B. de (1997). Sistema Hidrourb para o pré-dimensionamento de soluções alternativas de drenagem urbana parte1: Conceitos. In: Simpósio Nacional de Recursos Hídricos, 12. Vitória. Anais do XII Simpósio Brasileiro de Recursos Hídricos. São Paulo: Associação Brasileira de Recursos Hídricos, v. 3. p. 669-676.

NOGUEIRA, J. B. (2001). Mecânica dos Solos - Ensaios de Laboratório. São Carlos: EESCUSP, $212 \mathrm{p}$.

OLIVEIRA, M. B. de (2005). Análise do desempenho de equações de infiltração e de métodos de determinação da capacidade de campo para solos em uma bacia hidrográfica de São José de Ubá - RJ. Tese (Mestrado em Engenharia Civil) - COPPE. Universidade Federal do Rio de Janeiro. Rio de Janeiro, 230 p. 
OTHMER, H. B.; DIEKKRUGER, B.; e KUTILEK, M. (1991). Bimodal porosity and unsaturated hydraulic conductivity. Soil Sci. v. 152, p. 139-150.

PREVEDELLO, C. L. (1996). Física do solo com problemas resolvidos. Curitiba: Sociedade Autônoma de Estudos Avançados em Física do Solo, 446p.

PEREIRA, S.; OLIVEIRA FILHO, D.; MANTOVANI, E. C.; e MARTINS, J. H. (2006). Reflectometria no domínio do tempo na determinação do conteúdo de água no solo. R. Brás. Eng. Agr. Ambiental, v. 10, n. 2, p. 306-314.

PONIZOVSKYA, A. A.; CHUDINOVA, S. M.; e PACHEPSKY, Y. A. (1999). Performance of TDR calibration models as affected by soil texture. Journal of Hydrology, v. 218, p. 35-43

PORTO, R. L. L.. (1995). Escoamento superficial direto. In: Drenagem Urbana. BARROS, M. T. DE; PORTO, R. L. L.; E TUCCI, C. E. M. (orgs.). Porto Alegre: ABRH/Editora da UFRGS, p.107- 165.

REEVE, M. J.; SMITH, P. D.; e THOMASSON, A. J. (1973). The effect of density on water retention properties of field soils. Journal of Soil Science, Oxford, v. 24, p. 355367.

REICHARDT, K. (1985). Processos de transformação no sistema solo-planta-atmnosfera, Campinas, Fundação Cargill.

REICHARDT, K. (1986). Dinâmica da matéria e da energia em ecossistemas. Piracicaba: ESALQ, 505p.

REICHARDT, K. (1990). A Agua em Sistemas Agrícolas. Sao Paulo: Manole, 188 p.

ROESNER, L. A.; BLEDSOE, B. P.; e BRASHEAR, R. W. (2001). Are best management - practices criteria really environmentally friendly. In: Journal Water Resources Planning and Management, v. 127, n. 3, p. 150-154. 
SCHMUGGE, T. J.; JACKSON, T. J.; e MCKIM, H. L. (1980). Survey of methods for soil moisture determination. Water Resources Research, v. 16, n. 6, p. 961-979.

SILVA, A. M. (2005). Banco de dados de Curvas de Retenção de Água de Solos Brasileiros. Dissertação (Mestrado em Geotecnia) - Escola de Engenharia de São Carlos, Universidade de São Paulo, São Carlos, 136p.

SILVA, G. B. L. (2006). Avaliação Experimental Sobre a Eficiência de Superfícies Permeáveis com Vistas ao Controle do Escoamento Superficial em Áreas Urbanas. Tese (Doutorado em Tecnologia Ambiental e Recursos Hídricos) - Departamento de Engenharia Civil e Ambiental, Universidade de Brasília, Brasília, 180p.

SILVA, J. P. (2007). Estudos Preliminares para implantação de Trincheiras de Infiltração. Dissertação (Mestrado em Engenharia Civil), Departamento de Engenharia Civil e Ambiental, Universidade de Brasília, Brasília, 155p.

SILVEIRA, A. L. L. (1999). Impactos Hidrológicos da Urbanização em Porto Alegre. In: XIII Simpósio Brasileiro de Recursos Hídricos, Belo Horizonte, Brasil.

SOUZA, C. F.; FOLEGATTI, M. V.; MATSURA, E. E.; e OR, D. (2006). Calibração da reflectometria no domínio do tempo (TDR) para a estimativa da concentração da solução do solo. Engenharia Agrícola, Jaboticabal, v. 26, p. 282-291.

SOUZA, C. F.; e MATSURA, E. E. (2002). Avaliação de sondas de TDR multi-haste segmentadas para estimativa da umidade do solo. Revista Brasileira de Engenharia Agrícola e Ambiental, Campina Grande, v. 6, n. 1, p. 63-68.

SOUZA, C. F.; MATSURA, E. E.; e OR, D. (2006). Calibração do equipamento da TDR para um Latossolo Vermelho Distroférrico. Engenharia Rural, v. 17, p. 29-33.

SOUZA, V. C. B. de (2002). Estudo experimental de trincheiras de infiltração no controle do escoamento superficial. Tese (Doutorado em Engenharia de Recursos Hídricos e Saneamento Ambiental) - Instituto de Pesquisas Hidráulicas, Universidade Federal do Rio Grande do Sul, 151 p. 
SUTIKTO, T.; e CHIKAMORI, K. (1993). Evaluation of Philip's infiltration equation for cultivated upland terraces in Indonesia. Journal of Hydrology, v. 143, p. 279-295.

TABUAdA, M. A.; REgO, Z. J. C.; VACHAUd, G.; e PEREIRA, L. S. (1995). Twoimensional infiltration under furrow irrigation: modelling, its validation and applications. Agricultural Water Management, v. 27, n. 8-9, p. 105-123.

TOMMASELLI, J. T. G. (1997). Influência de algumas características do solo sobre a calibração de um aparelho de TDR (time-domain reflectometry). Tese (Doutorado em Energia Nuclear na Agricultura) - Centro de Energia na Agricultura, Universidade de São Paulo, Piracicaba, 109 p.

TOPP, G. C.; DAVIS, J. L.; e ANNAN, A. P. (1980). Electromagnetic determination of soil water content: measurements in coaxial transmission lines. Water resources Research, v.16, n. 3, p. 574-582.

TUCCI, C. E. M. (1993). Escoamento Superficial In: TUCCI, C. E. M. Hidrologia: Ciência e Aplicação, Editora da Universidade/UFRGS, p.527-572.

TUCCI, C. E. M. (2002). Gerenciamento da drenagem urbana. Revista Brasileira de Recursos Hídricos, Porto Alegre, v. 7, n. 1, p. 5-27.

URBONAS, B.; e STAHRE, P. (1993). Stormwater: best management practices and detention for water quality, drainage and CSO management. Englewood Cliffs: Prentice Hall. 447p.

VAN GENUTCHEN, M. T. (1980). A closed-form equation for predicting the hydraulic conductivity of untaturated soils. Soil Science Society of America, v. 44, p. 892-898.

VILAR, O. M. (2002). Resistência ao Cisalhamento (Apostila). Escola de Engenharia de São Carlos. 
VILLWOCK, R.; TAVARES, M. H. F.; e BOAS, M. A. V. (2004). Calibração de um equipamento TDR em condições de campo. Irriga. v. 9, n. 1, p. 82-88.

ZURMUHL, T.; e DURNER, W. (1998). Determination of Parameters for Bimodal Hydraulic Functions by Inverse Modeling. Soil Sci. Soc. Am. J. v. 62, p. 874-880.

WARNAARS, E.; LARSEN, A. V.; JACOBSEN, P.; e MIKKELSEN, P. S. (1999). Hydrologic behaviour of stormwater infiltration in a central urban area during $23 / 4$ years of operation. Water Science and Technology Technology, v. 39, n. 2, p. 217-224. 


\section{APÊNDICE A - ENSAIOS LABORATORIAIS}

Tabela A.1 - Dados físicos para determinação da massa específica dos sólidos.

\begin{tabular}{|c|c|c|c|c|c|c|c|}
\hline \multirow[b]{2}{*}{ Cápsula } & \multirow[b]{2}{*}{ P186 } & \multirow[b]{2}{*}{217} & \multirow[b]{2}{*}{249} & \multicolumn{2}{|c|}{ ANTES DO ENSAIO } & \multicolumn{2}{|c|}{ APÓS ENSAIO } \\
\hline & & & & $\mathbf{M}=$ & $57,5 \mathrm{~g}$ & Pyrex : & 19 \\
\hline $\mathbf{M}+\mathbf{M}_{\mathbf{C}}$ & $21,76 \mathrm{~g}$ & $22,9 \mathrm{~g}$ & $26,82 \mathrm{~g}$ & $\mathbf{w}=$ & $14,54 \%$ & $\mathbf{M}_{S}+\mathbf{T}_{\mathrm{C}}=$ & $922,32 \mathrm{~g}$ \\
\hline $\mathbf{M}_{\mathrm{S}}+\mathbf{M}_{\mathrm{C}}$ & $20,44 \quad \mathrm{~g}$ & $21,64 \mathrm{~g}$ & $25,09 \mathrm{~g}$ & $M_{S}(0)=$ & $50,20 \mathrm{~g}$ & $\mathbf{T}_{\mathrm{C}}=$ & $871,93 \mathrm{~g}$ \\
\hline $\mathbf{M}_{\mathbf{C}}$ & $11,37 \mathrm{~g}$ & $12,97 \mathrm{~g}$ & $13,19 \mathrm{~g}$ & $M_{S}(0)-M_{S}=$ & $-0,19 \mathrm{~g}$ & $\mathbf{M}_{\mathbf{S}}=$ & $50,39 \mathrm{~g}$ \\
\hline $\mathbf{M}_{\mathbf{S}}$ & $9,07 \quad \mathrm{~g}$ & $8,67 \mathrm{~g}$ & $11,9 \mathrm{~g}$ & \multirow{3}{*}{\multicolumn{4}{|c|}{$\rho_{\mathrm{w}}(20)=0,9982 \mathrm{~g} \cdot \mathrm{cm}^{-3}$}} \\
\hline $\mathbf{M}_{\mathbf{W}}$ & $1,32 \mathrm{~g}$ & $1,26 \mathrm{~g}$ & $1,73 \mathrm{~g}$ & & & & \\
\hline $\mathbf{w}$ & $14,55 \%$ & $14,53 \%$ & $14,54 \%$ & & & & \\
\hline
\end{tabular}

Tabela A.2 - Dados do ensaio de massa específica dos sólidos.

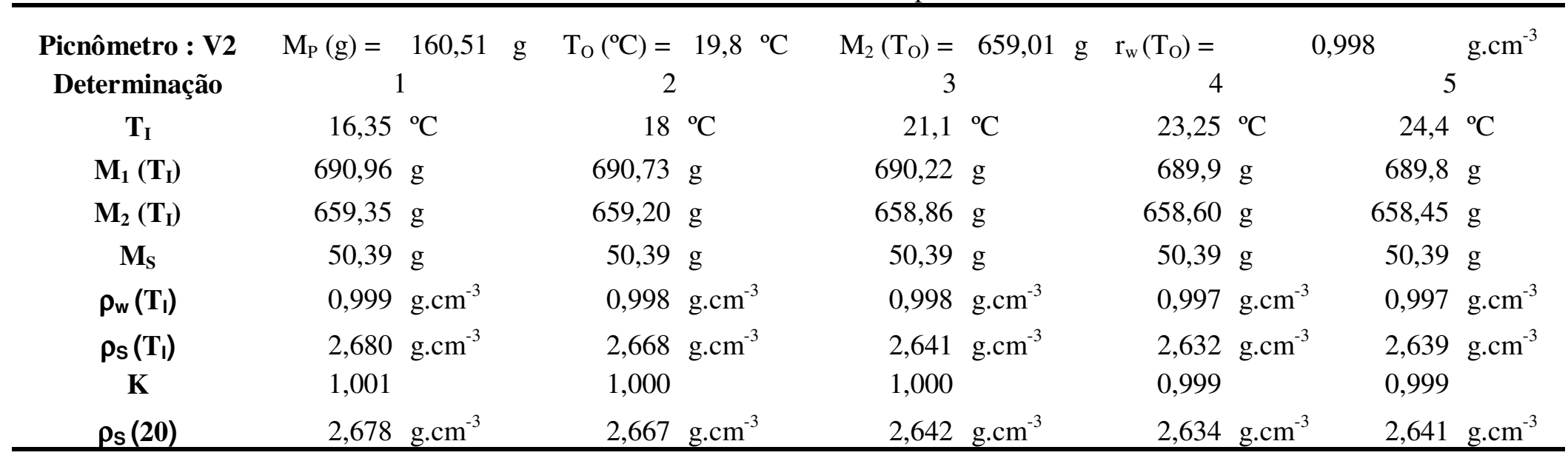


Tabela A.3- Ensaio de peneiramento para determinação da composição granulométrica.

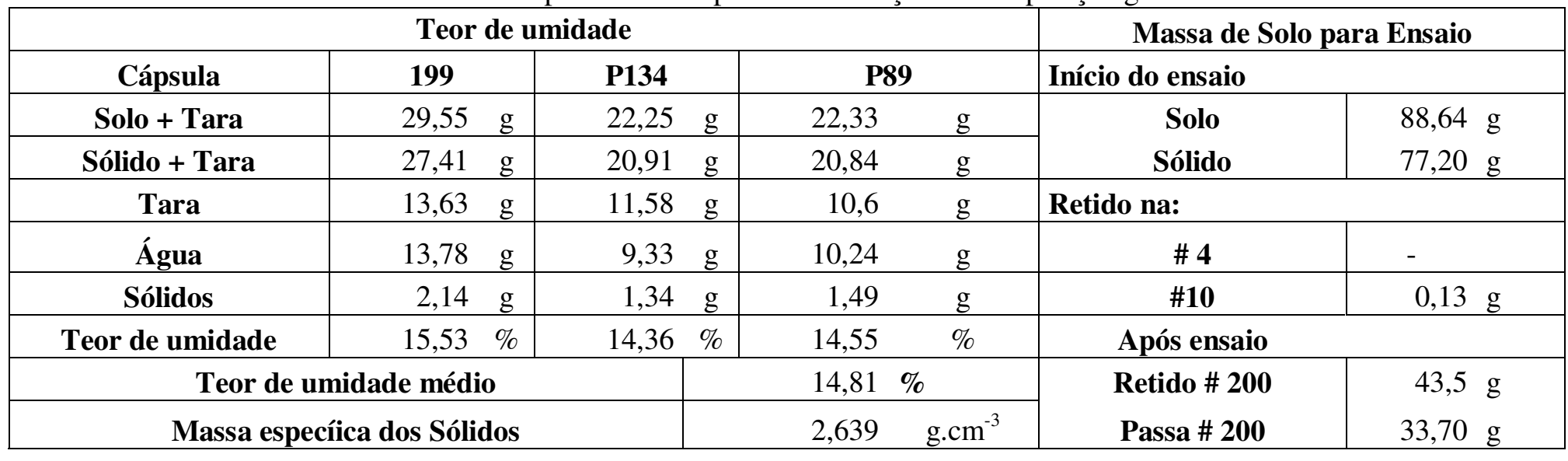

Peneiramento

\begin{tabular}{|c|c|c|c|c|c|c|}
\hline \# & Massa & $\mathrm{P}_{\mathrm{r}}\left(\#-{ }_{-}\right)$ & $\sum \mathrm{P}_{\mathrm{r}}\left(\#-{ }_{-}\right)$ & $\mathrm{P}_{\mathrm{p}}\left(\# \_\right)$ & \multicolumn{2}{|c|}{ Densímetro: 151 H (ASTM) } \\
\hline 10 & 0,13 & 0,17 & 0,17 & 99,83 & \multicolumn{2}{|c|}{ Correção desvio menisco: $+0,5$} \\
\hline 16 & 0,2 & 0,26 & 0,43 & 99,57 & & \\
\hline 30 & 5,98 & 7,75 & 8,17 & 91,83 & \multirow{2}{*}{\multicolumn{2}{|c|}{$\begin{array}{l}\text { Defloculante: } \\
\text { Hexametafosfato de sódio }\end{array}$}} \\
\hline 50 & 12,87 & 16,67 & 24,84 & 75,16 & & \\
\hline 200 & 4,59 & 5,95 & 56,34 & 43,66 & & \\
\hline Prato & 4,40 & 5,70 & 62,04 & - & & \\
\hline
\end{tabular}


Tabela A.4 - Ensaio de sedimentação para composição granulométrica.

\begin{tabular}{ccrrrrrrrrr}
\hline Data & Hora & Tempo & $\mathbf{r}(\mathbf{H})$ & $\mathbf{T}\left({ }^{-} \mathbf{C}\right)$ & $\boldsymbol{\mu} \mathbf{1 0 ^ { - 4 }} \mathbf{P a} . \mathbf{s}$ & $\mathbf{z}(\mathbf{c m})$ & $\mathbf{r}_{\mathbf{w}}$ & $\mathbf{D}_{\mathbf{i}}$ & $\mathbf{r}(\mathbf{H})-\mathbf{r}_{\mathbf{w}}$ & $\mathbf{P}\left(<\mathbf{D}_{\mathbf{i}}\right)$ \\
\hline $23 / 4 / 2008$ & $08: 27$ & 0,5 & 20,5 & 22 & 9,61 & 10,77 & $-4,66$ & 0,062 & 15,8 & 33,0 \\
$23 / 4 / 2008$ & $08: 28$ & 1 & 20,2 & 22 & 9,61 & 10,85 & $-4,66$ & 0,044 & 15,5 & 32,4 \\
$23 / 4 / 2008$ & $08: 29$ & 2 & 20,0 & 22 & 9,61 & 10,91 & $-4,66$ & 0,031 & 15,3 & 32,0 \\
$23 / 4 / 2008$ & $08: 31$ & 4 & 19,9 & 22 & 9,61 & 10,93 & $-4,66$ & 0,022 & 15,2 & 31,8 \\
$23 / 4 / 2008$ & $08: 35$ & 8 & 19,0 & 22 & 9,61 & 11,17 & $-4,66$ & 0,016 & 14,3 & 29,9 \\
$23 / 4 / 2008$ & $08: 42$ & 15 & 18,8 & 22 & 9,61 & 11,23 & $-4,66$ & 0,012 & 14,1 & 29,5 \\
$23 / 4 / 2008$ & $08: 57$ & 30 & 18,8 & 22 & 9,61 & 11,23 & $-4,66$ & 0,008 & 14,1 & 29,5 \\
$23 / 4 / 2008$ & $09: 27$ & 60 & 18,2 & 22 & 9,61 & 11,39 & $-4,66$ & 0,006 & 13,5 & 28,3 \\
$23 / 4 / 2008$ & $10: 27$ & 120 & 18,0 & 22 & 9,61 & 11,44 & $-4,66$ & 0,004 & 13,3 & 27,8 \\
$23 / 4 / 2008$ & $12: 27$ & 240 & 17,6 & 22 & 9,61 & 11,55 & $-4,66$ & 0,003 & 12,9 & 27,0 \\
$23 / 4 / 2008$ & $16: 27$ & 480 & 17,3 & 22 & 9,61 & 11,63 & $-4,66$ & 0,002 & 12,6 & 26,4 \\
\hline
\end{tabular}


Tabela A.5 - Índices físicos obtidos no ensaio com papel filtro.

\begin{tabular}{|c|c|c|c|c|c|c|c|c|c|c|c|c|c|c|}
\hline $\begin{array}{c}\text { Anel } \\
\mathrm{N}^{\mathrm{o}} \\
\end{array}$ & $\begin{array}{c}\mathrm{M} \\
\text { (anel) } \\
\mathrm{g} \\
\end{array}$ & $\begin{array}{c}\text { f (anel) } \\
\mathrm{cm} \\
\end{array}$ & $\begin{array}{c}\mathbf{H} \text { (anel) } \\
\mathrm{cm} \\
\end{array}$ & $\begin{array}{c}\mathbf{V} \text { (anel) } \\
\mathrm{cm}^{3} \\
\end{array}$ & $\begin{array}{l}\mathbf{w} \\
\% \\
\end{array}$ & $\begin{array}{c}\text { M (anel + } \\
\text { solo) } \\
\text { g } \\
\end{array}$ & $\begin{array}{c}\text { M (solo) } \\
\mathrm{g} \\
\end{array}$ & $\begin{array}{c}\mathrm{M} \\
\text { (sólidos) } \\
\mathrm{g} \\
\end{array}$ & $\begin{array}{c}\rho \\
\text { g.cm }{ }^{-3} \\
\end{array}$ & $\begin{array}{c}\rho_{\mathrm{d}} \\
\text { g.cm } \mathrm{cm}^{-3}\end{array}$ & $\begin{array}{c}\rho_{\mathrm{s}} \\
\text { g.cm }\end{array}$ & $\begin{array}{l}\text { e } \\
- \\
\end{array}$ & $\begin{array}{l}\mathbf{n} \\
\% \\
\end{array}$ & $\begin{array}{l}\mathrm{Sr} \\
\% \\
\end{array}$ \\
\hline $\mathrm{V}_{1}$ & 7,35 & 5,31 & 1,04 & 23,13 & 13,36 & 40,98 & 33,63 & 29,67 & 1,45 & 1,28 & 2,64 & 1,06 & 51,40 & 33,35 \\
\hline $\mathrm{V}_{2}$ & 7,81 & 5,32 & 1,09 & 24,11 & 13,36 & 44,26 & 36,45 & 32,15 & 1,51 & 1,33 & 2,64 & 0,98 & 49,47 & 36,02 \\
\hline $\mathrm{V}_{3}$ & 7,68 & 5,34 & 1,07 & 23,98 & 13,36 & 44,29 & 36,61 & 32,29 & 1,53 & 1,35 & 2,64 & 0,96 & 48,97 & 36,75 \\
\hline $\mathrm{V}_{4}$ & 7,00 & 5,32 & 1,01 & 22,44 & 13,36 & 42,70 & 35,70 & 31,49 & 1,59 & 1,40 & 2,64 & 0,88 & 46,83 & 40,04 \\
\hline $\mathrm{V}_{5}$ & 7,06 & 5,31 & 1,01 & 22,35 & 13,36 & 42,62 & 35,56 & 31,37 & 1,59 & 1,40 & 2,64 & 0,88 & 46,82 & 40,06 \\
\hline $\mathrm{V}_{6}$ & 8,02 & 5,31 & 1,05 & 23,26 & 13,36 & 43,61 & 35,59 & 31,39 & 1,53 & 1,35 & 2,64 & 0,96 & 48,86 & 36,92 \\
\hline $\mathrm{V}_{7}$ & 7,22 & 5,31 & 1,01 & 22,33 & 13,36 & 40,01 & 32,79 & 28,92 & 1,47 & 1,30 & 2,64 & 1,04 & 50,92 & 33,99 \\
\hline $\mathrm{V}_{8}$ & 8,24 & 5,31 & 1,06 & 23,36 & 13,36 & 44,03 & 35,79 & 31,57 & 1,53 & 1,35 & 2,64 & 0,95 & 48,79 & 37,01 \\
\hline $\mathrm{V}_{9}$ & 7,38 & 5,30 & 1,02 & 22,47 & 13,36 & 42,18 & 34,80 & 30,70 & 1,55 & 1,37 & 2,64 & 0,93 & 48,22 & 37,87 \\
\hline $\mathrm{V}_{10}$ & 8,06 & 5,29 & 1,06 & 23,25 & 13,36 & 44,93 & 36,87 & 32,52 & 1,59 & 1,40 & 2,64 & 0,89 & 47,00 & 39,77 \\
\hline $\mathrm{V}_{11}$ & 7,79 & 5,30 & 1,04 & 22,85 & 13,36 & 44,30 & 36,51 & 32,21 & 1,60 & 1,41 & 2,64 & 0,87 & 46,59 & 40,43 \\
\hline $\mathrm{V}_{12}$ & 8,40 & 5,28 & 1,02 & 22,42 & 13,36 & 43,61 & 35,21 & 31,06 & 1,57 & 1,39 & 2,64 & 0,90 & 47,51 & 38,97 \\
\hline $\mathrm{V}_{13}$ & 7,19 & 5,33 & 1,04 & 23,13 & 13,36 & 40,72 & 33,53 & 29,58 & 1,45 & 1,28 & 2,64 & 1,06 & 51,54 & 33,16 \\
\hline $\mathrm{V}_{14}$ & 7,79 & 5,31 & 1,04 & 23,01 & 13,36 & 41,81 & 34,02 & 30,01 & 1,48 & 1,30 & 2,64 & 1,02 & 50,57 & 34,47 \\
\hline $\mathrm{V}_{15}$ & 6,98 & 5,31 & 1,04 & 23,12 & 13,36 & 40,96 & 33,98 & 29,97 & 1,47 & 1,30 & 2,64 & 1,04 & 50,87 & 34,06 \\
\hline
\end{tabular}


Tabela A.6 - Parâmetros de secagem obtidos no ensaio com papel filtro.

\begin{tabular}{|c|c|c|c|c|c|c|c|c|}
\hline $\begin{array}{c}\text { Anel } \\
\mathrm{n}^{\circ}\end{array}$ & $\begin{array}{c}\mathbf{M}_{\text {sat }} \text { (solo+anel) } \\
\mathrm{g}\end{array}$ & $\begin{array}{c}\text { M (anel) } \\
\mathrm{g}\end{array}$ & $\begin{array}{c}\mathbf{M}_{\mathbf{1}} \text { (solo) } \\
\mathrm{g}\end{array}$ & $\begin{array}{c}\text { w (Satur) } \\
\% \\
\end{array}$ & $\begin{array}{c}\mathbf{M}_{\mathrm{S}} \text { (sólidos) } \\
\mathrm{g}\end{array}$ & $\begin{array}{c}\text { w (Final) } \\
\% \\
\end{array}$ & $\begin{array}{c}\mathbf{M}_{2} \text { (solo) } \\
\mathrm{g}\end{array}$ & $\begin{array}{c}\mathbf{M}_{\mathrm{F}} \text { (solo+anel) } \\
\mathrm{g}\end{array}$ \\
\hline $\mathrm{V}_{1}$ & 44,86 & 7,35 & 37,51 & 36,34 & 27,51 & 36,30 & 37,49 & 44,84 \\
\hline $\mathrm{V}_{2}$ & 47,69 & 7,81 & 39,88 & 36,34 & 29,25 & 35,80 & 39,72 & 47,53 \\
\hline $\mathrm{V}_{3}$ & 47,51 & 7,68 & 39,83 & 36,34 & 29,22 & 35,30 & 39,53 & 47,21 \\
\hline $\mathrm{V}_{4}$ & 45,91 & 7,00 & 38,91 & 36,34 & 28,54 & 34,80 & 38,47 & 45,47 \\
\hline $\mathrm{V}_{5}$ & 45,69 & 7,06 & 38,63 & 36,34 & 28,33 & 34,30 & 38,05 & 45,11 \\
\hline $\mathrm{V}_{6}$ & 46,73 & 8,02 & 38,71 & 36,34 & 28,39 & 32,70 & 37,68 & 45,70 \\
\hline $\mathrm{V}_{7}$ & 43,46 & 7,22 & 36,24 & 36,34 & 26,58 & 31,30 & 34,90 & 42,12 \\
\hline $\mathrm{V}_{8}$ & 47,34 & 8,24 & 39,10 & 36,34 & 28,68 & 29,20 & 37,05 & 45,29 \\
\hline $\mathrm{V}_{9}$ & 45,17 & 7,38 & 37,79 & 36,34 & 27,72 & 27,30 & 35,29 & 42,67 \\
\hline $\mathrm{V}_{10}$ & 47,90 & 8,06 & 39,84 & 36,34 & 29,22 & 24,21 & 36,29 & 44,35 \\
\hline $\mathrm{V}_{11}$ & 47,34 & 7,79 & 39,55 & 36,34 & 29,01 & 21,30 & 35,19 & 42,98 \\
\hline $\mathrm{V}_{12}$ & 47,03 & 8,40 & 38,63 & 36,34 & 28,33 & 17,30 & 33,23 & 41,63 \\
\hline $\mathrm{V}_{13}$ & 44,00 & 7,19 & 36,81 & 36,34 & 27,00 & 13,30 & 30,59 & 37,78 \\
\hline $\mathrm{V}_{14}$ & 44,78 & 7,79 & 36,99 & 36,34 & 27,13 & 10,00 & 29,85 & 37,64 \\
\hline $\mathrm{V}_{15}$ & 44,02 & 6,98 & 37,04 & 36,34 & 27,17 & 8,00 & 29,34 & 36,32 \\
\hline
\end{tabular}


Tabela A.7 - Teor da umidade da amostra obtido no ensaio com papel filtro.

\begin{tabular}{ccccccc}
\hline Cápsula & Mu+Mc & Ms+Mc & Mc & Mw & Ms & w (\%) \\
\hline $\mathrm{V}_{1}$ & 29,84 & 26,85 & 13,80 & 2,99 & 13,05 & 22,91 \\
$\mathrm{~V}_{16}$ & 28,80 & 26,02 & 13,06 & 2,78 & 12,96 & 21,45 \\
$\mathrm{~V}_{3}$ & 30,52 & 27,86 & 13,30 & 2,66 & 14,56 & 18,27 \\
$\mathrm{~V}_{4}$ & 30,28 & 27,66 & 13,37 & 2,62 & 14,29 & 18,33 \\
$\mathrm{~V}_{5}$ & 28,58 & 26,40 & 13,18 & 2,18 & 13,22 & 16,49 \\
$\mathrm{~V}_{6}$ & 30,63 & 28,28 & 13,42 & 2,35 & 14,86 & 15,81 \\
$\mathrm{~V}_{7}$ & 30,74 & 28,02 & 13,06 & 2,72 & 14,96 & 18,18 \\
$\mathrm{~V}_{8}$ & 30,04 & 28,13 & 13,55 & 1,91 & 14,58 & 13,10 \\
$\mathrm{~V}_{9}$ & 29,57 & 27,74 & 13,07 & 1,83 & 14,67 & 12,47 \\
$\mathrm{~V}_{10}$ & 28,95 & 27,63 & 13,11 & 1,32 & 14,52 & 9,09 \\
$\mathrm{~V}_{11}$ & 30,03 & 28,90 & 14,21 & 1,13 & 14,69 & 7,69 \\
$\mathrm{~V}_{12}$ & 29,73 & 28,87 & 12,77 & 0,86 & 16,10 & 5,34 \\
$\mathrm{~V}_{13}$ & 27,32 & 26,95 & 13,27 & 0,37 & 13,68 & 2,70 \\
$\mathrm{~V}_{14}$ & 28,86 & 28,69 & 13,28 & 0,17 & 15,41 & 1,10 \\
$\mathrm{~V}_{15}$ & 29,19 & 29,00 & 13,63 & 0,19 & 15,37 & 1,24 \\
\hline
\end{tabular}


Tabela A.8 - Sucção matricial obtido no ensaio com papel filtro.

\begin{tabular}{|c|c|c|c|c|c|c|c|c|}
\hline \multirow{2}{*}{$\begin{array}{c}\text { Anel } \\
\#\end{array}$} & \multicolumn{3}{|c|}{$P_{\text {úmido }}(\mathbf{g})$} & \multicolumn{3}{|c|}{$\mathbf{P}_{\text {seco }}$} & \multirow{2}{*}{$\begin{array}{c}\text { w (papel) } \\
\%\end{array}$} & \multirow{2}{*}{$\begin{array}{c}\text { Sucção } \\
\mathbf{k P a}\end{array}$} \\
\hline & Topo & Base & Média & Topo & Base & Média & & \\
\hline $\mathrm{V}_{1}$ & 0,452 & 0,473 & 0,463 & 0,188 & 0,192 & 0,190 & 143,474 & 5,0 \\
\hline $\mathrm{V}_{16}$ & 0,460 & 0,458 & 0,459 & 0,188 & 0,191 & 0,190 & 142,164 & 5,2 \\
\hline $\mathrm{V}_{3}$ & 0,437 & 0,412 & 0,424 & 0,186 & 0,179 & 0,183 & 132,393 & 6,1 \\
\hline $\mathrm{V}_{5}$ & 0,419 & 0,406 & 0,413 & 0,183 & 0,179 & 0,181 & 128,122 & 6,7 \\
\hline $\mathrm{V}_{6}$ & 0,387 & 0,385 & 0,386 & 0,179 & 0,177 & 0,178 & 116,671 & 8,4 \\
\hline $\mathrm{V}_{8}$ & 0,310 & 0,300 & 0,305 & 0,187 & 0,176 & 0,181 & 68,360 & 31,6 \\
\hline $\mathrm{V}_{9}$ & 0,255 & 0,260 & 0,257 & 0,179 & 0,180 & 0,180 & 43,155 & 143,1 \\
\hline $\mathrm{V}_{10}$ & 0,219 & 0,211 & 0,215 & 0,186 & 0,179 & 0,182 & 17,818 & 5391,6 \\
\hline $\mathrm{V}_{11}$ & 0,215 & 0,202 & 0,208 & 0,188 & 0,176 & 0,182 & 14,254 & 8982,2 \\
\hline $\mathrm{V}_{12}$ & 0,205 & 0,200 & 0,203 & 0,186 & 0,181 & 0,184 & 10,343 & 15727,8 \\
\hline $\mathrm{V}_{13}$ & 0,193 & 0,192 & 0,192 & 0,177 & 0,176 & 0,177 & 8,862 & 19444,4 \\
\hline $\mathrm{V}_{14}$ & 0,192 & 0,189 & 0,190 & 0,181 & 0,179 & 0,180 & 5,630 & 30891,9 \\
\hline $\mathrm{V}_{15}$ & 0,188 & 0,199 & 0,193 & 0,179 & 0,188 & 0,183 & 5,480 & 31561,3 \\
\hline
\end{tabular}


Tabela A.9 - Índices físicos obtidos no ensaio de curva de retenção.

\begin{tabular}{|c|c|c|c|c|c|c|c|c|c|c|c|c|}
\hline Anel & M (anel) & $\phi$ (anel) & H (anel) & V (anel) & $\begin{array}{c}\text { M } \\
(\text { anel + solo })\end{array}$ & M (solo) & $\mathbf{w}$ & $\rho$ & $\rho d$ & $\rho_{s}$ & $\mathbf{e}$ & $\mathbf{n}$ \\
\hline $\mathrm{N}^{\mathrm{o}}$ & $\mathrm{g}$ & $\mathrm{cm}$ & $\mathrm{cm}$ & $\mathrm{cm}^{3}$ & $\mathrm{~g}$ & $\mathrm{~g}$ & $\%$ & g.cm ${ }^{-3}$ & g. $\mathrm{cm}^{-3}$ & g.cm ${ }^{-3}$ & - & $\%$ \\
\hline $\mathbf{C}_{1}$ & 5,74 & 5,29 & 1,02 & 22,50 & 40,460 & 34,720 & 13,36 & 1,54 & 1,36 & 2,64 & 0,94 & 48,41 \\
\hline $\mathbf{C}_{2}$ & 5,74 & 5,30 & 1,02 & 22,46 & 39,480 & 33,740 & 13,36 & 1,50 & 1,32 & 2,64 & 0,99 & 49,79 \\
\hline $\mathbf{C}_{3}$ & 5,76 & 5,33 & 1,01 & 22,57 & 39,160 & 33,400 & 13,36 & 1,48 & 1,31 & 2,64 & 1,02 & 50,54 \\
\hline $\mathbf{C}_{4}$ & 9,28 & 4,36 & 1,61 & 23,96 & 45,086 & 35,806 & 12,62 & 1,49 & 1,33 & 2,64 & 0,99 & 49,73 \\
\hline $\mathrm{C}_{5}$ & 9,21 & 4,36 & 1,54 & 22,96 & 44,549 & 35,339 & 12,62 & 1,54 & 1,37 & 2,64 & 0,93 & 48,20 \\
\hline $\mathrm{C}_{6}$ & 8,79 & 4,41 & 1,65 & 25,18 & 44,020 & 35,230 & 12,62 & 1,40 & 1,24 & 2,64 & 1,12 & 52,93 \\
\hline
\end{tabular}

Tabela A.10 - Dados para a composição da curva de retenção.

\begin{tabular}{|c|c|c|c|c|c|c|c|c|c|c|c|c|}
\hline & \multirow[b]{2}{*}{ Saturado } & \multicolumn{3}{|c|}{ Funil de placa porosa } & \multicolumn{8}{|c|}{ Câmara com placa porosa } \\
\hline & & $1 \mathrm{KPa}$ & $5 \mathrm{KPa}$ & $10 \mathrm{KPa}$ & $10 \mathrm{KPa}$ & $20 \mathrm{KPa}$ & $30 \mathrm{KPa}$ & $40 \mathrm{KPa}$ & $100 \mathrm{KPa}$ & $200 \mathrm{KPa}$ & $400 \mathrm{KPa}$ & $700 \mathrm{KPa}$ \\
\hline \multirow{3}{*}{ 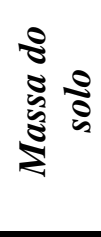 } & 43,8631 & - & - & - & 39,9842 & 39,8906 & 39,818 & 39,7563 & 39,68 & 39,57 & 39,4758 & 39,41 \\
\hline & 43,0094 & - & - & - & 38,8473 & 38,7634 & 38,7115 & 38,6424 & 38,51 & 38,43 & 38,3449 & 38,275 \\
\hline & 42,745 & - & - & - & 38,3869 & 38,3172 & 38,2633 & 38,2018 & 38,03 & 37,95 & 37,8794 & 37,8206 \\
\hline \multirow{3}{*}{ 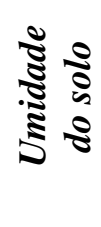 } & $24,43 \%$ & & & & $11,77 \%$ & $11,47 \%$ & $11,23 \%$ & $11,03 \%$ & $10,78 \%$ & $10,42 \%$ & $10,11 \%$ & $9,90 \%$ \\
\hline & $26,23 \%$ & $27,81 \%$ & $17,67 \%$ & $16,98 \%$ & $12,14 \%$ & $11,85 \%$ & $11,68 \%$ & $11,44 \%$ & $10,99 \%$ & $10,72 \%$ & $10,44 \%$ & $10,20 \%$ \\
\hline & $27,87 \%$ & & & & $12,81 \%$ & $12,57 \%$ & $12,39 \%$ & $12,17 \%$ & $11,58 \%$ & $11,30 \%$ & $11,06 \%$ & $10,86 \%$ \\
\hline
\end{tabular}


